\title{
A CHINESE CRITICAL PRAGMATISM
}

By

Cecilia Ying Sze Yung, B.A.S.

\begin{abstract}
A thesis submitted to the Faculty of Graduate and Postdoctoral Affairs in partial fulfillment of the requirements for the degree of

Master of Architecture
\end{abstract}

in

M.ARCH (Professional)

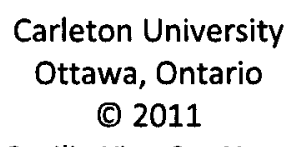

Cecilia Ying Sze Yung 
Library and Archives

Canada

Published Heritage Branch

395 Wellington Street Ottawa ON K1A ON4

Canada
Bibliothèque et

Archives Canada

Direction du

Patrimoine de l'édition

395 , rue Wellington

Ottawa ON K1A ON4

Canada
Your file Votre référence

ISBN: 978-0-494-83188-5

Our file Notre référence

ISBN: 978-0-494-83188-5
NOTICE:

The author has granted a nonexclusive license allowing Library and Archives Canada to reproduce, publish, archive, preserve, conserve, communicate to the public by telecommunication or on the Internet, loan, distribute and sell theses worldwide, for commercial or noncommercial purposes, in microform, paper, electronic and/or any other formats.

The author retains copyright ownership and moral rights in this thesis. Neither the thesis nor substantial extracts from it may be printed or otherwise reproduced without the author's permission.
AVIS:

L'auteur a accordé une licence non exclusive permettant à la Bibliothèque et Archives Canada de reproduire, publier, archiver, sauvegarder, conserver, transmettre au public par télécommunication ou par l'Internet, prêter, distribuer et vendre des thèses partout dans le monde, à des fins commerciales ou autres, sur support microforme, papier, électronique et/ou autres formats.

L'auteur conserve la propriété du droit d'auteur et des droits moraux qui protège cette thèse. $\mathrm{Ni}$ la thèse ni des extraits substantiels de celle-ci ne doivent être imprimés ou autrement reproduits sans son autorisation.
In compliance with the Canadian Privacy Act some supporting forms may have been removed from this thesis.

While these forms may be included in the document page count, their removal does not represent any loss of content from the thesis.
Conformément à la loi canadienne sur la protection de la vie privée, quelques formulaires secondaires ont été enlevés de cette thèse.

Bien que ces formulaires aient inclus dans la pagination, il n'y aura aucun contenu manquant.

\section{Canadä}




\section{Abstract}

Over the past decade, there have been increasing interests to redefine the potential of architectural practice in relation to the process of global modernization. Intellectual debate, from the 2004 Harvard Design Magazine Stocktaking symposium, to George Baird's renowned article Criticality' and It's Discontents, and followed by Zhu JianFei's Criticality in between China and the West, seems to have polarized academic discussions into the theoretical discourse of criticality and an emerging position: the post-critical interventions.

Extracting from pragmatic experience in traditional Chinese architectural developments, would it be possible to articulate an alternative approach to contemporary architectural practice? This thesis sets out to explore criticality and its relevance to the globalizing modernity. Through a series of analytical investigations on traditional Chinese architectural concepts, we intend to resolve a substantial approach with which the architectural profession could attempt to provide solutions, rather than negations, in improving the status quo.

Focusing on a design strategy, the thesis would move on to a postcritical pragmatic project to respond to some of the arising challenges. We acknowledge that many of the socio-economical issues we face today stretch far beyond the capacity of architecture, or any single professional disciplines for that matter. Only when architects commit to an accommodative position, and when an open platform-on which architectural explorations could become accessible to external collaborative efforts at the individual level-is established, the potentials in the future of profession may be sustained.

If the ultimate question for architects is how to make the world a better place, we must consider how modernization from the previous centuries has left us with irreversible consequences. It is only ethical if architectural profession would, at the very least, attempt possible solutions by taking a pragmatic position critically and responding proactively to the problems we are facing in reality. In preparation of the answers for the inevitable challenges of tomorrow, both critical and pragmatic approaches seem to be essential in the post-critical developments of the architectural practice. 
This ongoing work in progress is dedicated to my grandmothers:

Ms. Liu KamPing for her inspirations and wisdoms,

Ms. Lau KamWai for her enduring faith in me,

and to all family and friends for their unwavering support. 


\section{Acknowledgements}

Thank you,

to all the architects and historians who have devoted their time and efforts

in documenting and reconstructing an intellectual framework of Chinese traditional architecture;

to my advisor Roger CONNAH for his guidance;

and also to Greg ANDONIAN and Tom DUBICANAC for their advises and lessons in architecture. 


\section{Notes}

All images and

all Chinese translations are provided by the author

unless otherwise specified.

Chinese terms are quoted using PinYin,

\section{the standardized Mandarin romanization system in use.}

To minimize miscommunications, other pronunciation systems used in quotes from other sources are converted to PinYin

as indicated in square brackets. 


\section{Contents}

序論 OUVERTURE

臸一, 分新 PART I. ANALIZE

Architecture \& Professional Reality

13

Architecture \& Social Reality

30

Architecture \& Total Reality

69

参二、策割 PART II. STRATEGIZE 


\section{become within the context of the contemporary globalizing}

conditions?

\section{EISENMAN \& A Geopolitical Reality}

Amongst the first who foresaw the predicaments of a globalizing reality and its affects on architecture, Peter Eisenman in his 1995 essay 'Critical Architecture in A Geopolitical World' identified the challenges the Western critical structure would soon encounter. He saw an end of the class struggle of Capitalism versus Communism,

\section{序论 Ouverture}

To question the nature of architecture today comes with a burden. It might have been a trivial or even irrelevant topic of discussion before the emergence of a global world. But today we live in a world where information technology has revolutionized the very nature of space in which traditional rules of politics and economics apply. Inevitably, the growing intimacy amongst different cultures that were once separated by physical distance has opened up an international forum which has recently began to question the established approach in architecture. Within the academic circles and professional practitioners, in the West, some of the more recognized individuals, such as George Baird, Michael Hays, Peter Eisenman, Michael Speaks, Rem Koolhaas have contributed to the heated debate. Though much has been argued, behind the trenches of these crossing fires a hidden concern remains substantial to all discussions: What could the nature of architecture

where developed worlds stand in contentions with the emerging worlds, believing the new condition of ideological politics would be based on geopolitics. In his words,

\begin{abstract}
Geopolitics involves two conditions: one, that despite the increasing mediation of the globe as a single entity, location has become an important political factor, and two, since western capital finds itself unable to continue to provide for the economic, social and political infrastructure that evolved in the nineteenth century, the emerging Pacific Rim and Muslim world countries, and their geopolitical positions, are no longer necessarily dependent on the western world for capital. ${ }^{[01]}$
\end{abstract}

Historically in the West since Kant's critical discourse was first architecturally manifested in Piranesi's drawing during the late eighteenth century, the idea of a critical architecture has always been seen as part of an ideological struggle of the emerging class against the established order-it critiques the status quo. We became familiar with Eisenman and his American counterpart Michael Hay's position, 
which has consistently focused intellectually on concepts of "resistance" and negation". [02]

Here Eisenman, resonating with Frankfurt school philosophy, argued that the enabling mechanism of the critical-the embodied transgression towards politics-has expired in Western developed worlds where an ideological class struggle no longer exists. Furthermore, when architecture has been voided of any ideological purpose, voided of symbolic functions, and no longer able to justify its necessity, the Capital would have no reasons to provide for a critical discourse.

Eisenman believed that while the West faced the problems of a shortage of capital in supporting the relevance of a critical structure for architecture, the emerging worlds, on the other hand, had no tradition in generating the enabling mechanism to support the idea of criticality. He is categorical when he claims that,

[t]his gap in society's sensibility as to what would even constitute a critical architecture and its purposes, leads to a fracturing of architecture away from its social, ideological and iconic purposes. ${ }^{[03]}$

It has been pointed out that certain power structures would be alarmed by the transgressive nature and the destabilizing idea of architecture as a critical discourse. Moreover, Eisenman observes that currently in such nations only a reverse of the critical architecture-an accommodating architecture-could be admitted in the face of geopolitical reality. The emerging East is undergoing a process of recolonisation; an architecture of capital accommodation which allows anything to be read by anybody-a 'Teflon' architecture ${ }^{[04]}$, so to speak.

In short, Eisenman continues to stress the importance of the critical as an ideological instrument in the context of the geopolitical. He believes that the self-referentiality of the critical tradition, the idea how one deals with being and the possibility of knowledge, is an important necessity for emerging nations in their developing geopolitics. He also suggests that the idea of a mediated architecture, and architecture's possibility to be media, should be examined if architecture is to remain relevant, and if critical discourse were to become an even more important concept in the West.

Though Eisenman shaped the topics of architecture, namely the history and developments of Western critical discourse, into some logical expectations of the arriving geopolitical reality, it is somewhat remarkable that he attempts to extend the applicability of the critical traditions beyond the Western context. But as Zhu JianFei, a professor from The University of Melbourne, points out in a recent article: Criticality in between China and the West, Eisenman's means of argument seems to be deficient in two aspects. First, he continuously insisted upon confining the critical to internal assumptions of a 
supposedly autonomous architectural discipline. ${ }^{[05]}$ He dismisses the very possibility of practice having the capability to critique and to contribute to a critical discourse. Secondly, though it might have been an unintentional approach, he has over generalized non-Western cultural contexts. To an audience who are familiar with these alternative cultures, this may come as a passive treatment of the complex geopolitics of Asia.

Asia is blank, flat and passive, just like the realm of practice which is also treated as a passive backdrop, on which the critical spirit is to issue its force of transgression. ${ }^{[06]}$

Lastly, we might add, Eisenman has also underestimated the potential of the media. Though he is aware of architecture's history as strong media, (i.e. Gothic Cathedral), and of the diminished influence of its iconic structure, it was impossible for him, at the time of this essay, to have anticipated the extensive affects of informational technology which we are all accustomed to today. Even if architecture maintains its presence as media through its affective relationship to the tactile experience of the body, the virtual media and its accelerating efficacy in engaging the mind, is now providing even greater satisfactory in seducing an audience who may not have the means or the intention to experience architecture.

Furthermore, on such virtual platform, the limits of geopolitical reality are minimal. Every individual who has access to the virtual social network is able to represent and broadcast his or herself not as a member of any collective organization, but as a unique embodiment of his or her critical conscious being, as constructed by his or her physical cultural experience. It would be a mistake to underestimate such power of self-representation and self-expression as an isolated desire in the virtual world. This complete freedom of expression would further project its temptation onto the physical world. If architecture as a physical manifestation (which must abide by it physical limits within the context of the geopolitical reality) must compete with the fast evolving social media and the immeasurable freedom it offers, it may simply not be enough to depend solely on its affective relationship to the physical experience of the body and its ability to '[restore] the relationship between the mind and the body.' [in]

Even when architecture is now adapted to sustain ideas and knowledge more effectively with the assistance of digital technology, it is far from being able to compete with the social media, or to become anything remotely similar. Following Eisenman's line of thought: in our current information age where spontaneous information is more prevalent over ideologies and knowledge, his notion of a 'mediated architecture'-one which maintains 'criticality' in a condition of being which speaks of the possibility 'in being' of information, ideas, knowledge-could only exist within the virtual realm where it loses its advantage of providing any physical experience. 
It is most unfortunate that the moment such architecture exits the virtual world and claims a physical presence, it forfeits its possibility to be a proficient media. And I would dare to elaborate that Eisenman's insistent focus on the architectural design process, his obsessions in abstract perfection of forms, over the actual resulting production, is nothing more than a timid retreat to this deeply conflicted condition. So until physical architecture could reform its inert, permanent properties, it is quite possible that architecture as an ideological instrument or iconic representation may not even be relevant in the foreseeable future. At the present, it is clear that Eisenman's prospects of criticality and its assumed potential may remain unfulfilled before these concerns have been resolved.

\section{KOOLHAAS \& A Post-Critical Reality}

Fifteen years have passed since Eisenman's publication, and it seems that today's geopolitical reality is searching for guidance beyond the critical discourse. It has become obvious that 'criticality' and the concept of critical architecture is under attack. In advanced circle of academic scholars and certainly many practicing professionals, we see many are interested in moving outside the limits of theory and ideologies by committing themselves to the 'post-critical'-an 'affectdriven, non-oppositional, non-resistant, non-dissenting, and therefore non-utopian form of architectural production.' ${ }^{[08]}$ Though this movement is often associated with many emotive terms, unfortunately they are at best abstractive expressions attempting to summarize real-time observations. It thus seems more appropriate to leave it at 'post-critical'.

It would be difficult to better elucidate this development than Michael Speaks' title of an article published in Architectural Record: After Theory-Debate in architectural schools rages about the value of theory and its effect on innovation in desian. And not long before this publication, George Baird offered a comprehensive outlook on two generations of related discussions in his article "Criticality" and Its Discontents. It is difficult to resist quoting (from Baird) an important comment made by Rem Koolhaas at one of the series of conferences organized by $A N Y$ magazine at the Canadian Centre for Architecture in 1994:

\section{"The problem with the prevailing discourse of architectural criticism...is [the] inability to recognize there is in the deepest motivations of architecture something that cannot be critical." [09]}

Contrary to Eisenman's passive efforts, Koolhaas is clearly more open and absorbs specific ideas from non-Western localities. Since 1995 Koolhaas has published a series of works ${ }^{[10]}$ investigating architecture's role as bystander to the unrestrained force of market economy and globalization in various Asian cities. By letting himself become intimate with the operational aspects of the practicing profession in challenging parts of contemporary Asia, where building 
practice is undergoing intensive transformations, Koolhaas recognizes a need to persistently question the adequacy of applying western critical theory in these emergent conditions. Contrary to other postcritics such as Sylvia Lavin and Stan Allen ${ }^{[11\}}$, his purpose is not to eradicate the critical traditional all together but to reform the critical spirit with new elements attained from a more projective approach to practice. Within an intense belief in the necessity of a professional architectural efficacy, "criticality" is valued so long as it does not constrain efficacy. Koolhaas's aim is to find a new critical position where pragmatic urgencies can be internalized. It is important that such approach is 'not to oppose two situations-the European and the Asian, the eastern and the western-but to establish parallels so that conclusions can be drawn. ${ }^{[12]}$

Thus far, Koolhaas seems to be the most influential practitioner amongst all post-critical advocates. In accord with his approach, Robert Somol and Sarah Whiting, in their much discussed article Notes around the Doppler Effect and other Moods of Modernism, have summarized, at least in abstraction, that the post-critics are more concerned with the instrumentality of 'force and effect' and are less constrained by formal Western traditions; and in contrast, the more traditional critics prioritize 'architectural disciplinarity' as 'autonomy and process' above anything else. ${ }^{[13]}$

At the risk of over generalizing a much-complicated development amongst these professional hordes, I am prompted to suggest that whether accepting or rejecting theory and the established ideology both sides are essentially attempting to engage with the same problems by asking different questions. The obvious concerns these architects are dealing with mostly, if not entirely, is beyond the scope of architecture. Technological dominance, globalization, rapid modernization, late-capitalism, market-corruption....the list goes on: these are all objective problems of a larger reality. While the critics have tried to confront these issues by asking the question: WHAT IS ARCHITECTURE?' in self-indulgent isolation, the more recent postcritics are undertaking the current situations by actively involving themselves with other discipline and questioning: 'WHAT CAN ARCHITECTURE DO?'

Those who endeavor to find meaning, to define some truth in architecture, inevitably strive for some degree of autonomy. Engaged with the Althusserian concept of 'semiautonomy', as denoted by Michael Hays, many have attempted to maintain or construct socialconsensual meaning and a practical architecture for such meaningproduction. [14] Michael Speaks has made observations of such approach in Eisenman's works:

'Eisenman's writings...contend that there is no ultimate truth, but only incomplete, critical engagements with historically determined versions of truth. For Eisenman, critical, or "dislocative," architecture, as he once called it, critiques these normative versions of architectural truth in a 
seemingly endless search for a real but ultimately unattainable essence of architecture. And this essence, for Eisenman, can only be expressed in the abstract perfection of forms shielded from the market-driven demands of program, use and commercial viability. ${ }^{i[15]}$

These internalized efforts have pushed architecture into becoming a hybrid between designed form and representation; but somehow in the process of doing so, these higher intentions arrive at some utopian alternatives and have detached architectural discourse from connecting with reality. Architecture at the end of the critical discourse has become concept-oriented in its extreme resolutions and accomplished little more than pure ideological representation-a media that is only capable of one-way broadcast.

However surely it is not a mistake to pursue meaning in architecture per se. Whether it is intended or not, architecture as physical manifestation will always mean. But to prioritize its symbolic functions over other pragmatic obligations is simply an unsustainable aspiration given the contemporary external conditions. Though he is optimistically anxious in believing that criticality could be once again relevant by transforming architecture into media, Eisenman himself has been aware of the facts of reality. He questioned himself with some very pertinent questions:

'Clearly the issue today is, whether there is any need for architecture to examine the possibility of being, when in fact it has a difficult time merely sustaining being itself. In other words, when 250,000 housing units need to be built in eighteen months, does one need to examine the question of the possibility of meaning? is there the time, energy or support system for such an examination? ${ }^{\text {(115] }}$

These are precisely the enquiries Koolhaas has committed himself to in his ongoing developments of the new professional stance. As mentioned previously, Koolhaas is not eager to put ideology, and along with it the critical discourse, into the ground; at least not while an articulating body of post-critical theory is still under incubation within the newest architectural test labs. Speaks is affirmative that inside these small offices and workshops where new forms of architectural practice are being forged-ShoP, FACE, FOA, UN Studio, to name just a few-a growing appreciation for a spontaneous methodology in thinking-as-doing through design prototyping is fostering an interactive, nonlinear means of innovation. ${ }^{[17]}$

This new generation of architectural practice sees architecture not as a representation but as an operation that connects with external reality. This is a new exploration into the instrumental potentials of architecture as an interactive, and perhaps a living mechanism. Such context-oriented approach, architecture as agency, is open to engage with external disciplines, which would become ultimately beneficial to the profession in general by broadening the network to include a wider audience. 
Thus far, Koolhaas with his practice OMA*AMO is on the frontier of the global post-critic operation. And it is important to attend to the very interesting suggestion Zhu has made in his article:

...[I]t is in Asia today that practice and pragmatism are reaching their extreme intensity. My argument is that it is this intense practice and pragmatism that are providing some of the impetus to the west for a transformation through mediating figures such as Rem Koolhaas...this move to post-criticality in the west must have been engendered, partly at the least, by the storms of urbanization and modernization in Asia. ${ }^{[18]}$

If Koolhaas is leading the post-critical expedition with the advantage he gains from his extensive practice in Asia, Zhu believes this would imply that by manoeuvering through an 'inter-regional, cross-cultural space' of geo-global reality, Koolhaas has successfully nudged into a 'third position' that is external to both the East (China specifically because of his close working relationship with Chinese locations) and the West in general. And it is this particular position that enables him to be critical and 'transgressive' to certain traditions in both. Zhu has detected a certain parallelism between Chinese intensive practices and the 'projective', 'pragmatic' and 'diagrammatic' attributes many focus on in formulating the post-critical discourse. In short, he postulates that China, with its expanding politico-economic capacity on the global level, could have the capability to convey a unique momentum that is 'effectively post-critical'.

Zhu continues his paper with a general outlook on Chinese modern development since the 1980 s before he moves onto to specific works and individual positions of a number of contemporary practicing professionals in China. He draws a conclusion where he summarizes the Chinese practice into two general positions: an abstract regionalism, and a socially concerned urbanism. Indigenous to the Chinese practice, there is also a peculiar 'filtering process':

\begin{abstract}
...the separation between 'theory' and 'practice' in the west is not suitable to China. There is a subtle move here: although the idea of critical autonomy is absorbed, there is no need for excessive or absolute autonomy that negates practice or pragmatic considerations. ${ }^{[19]}$
\end{abstract}

Zhu seems to have put his trust in a number of 'mobile global agents'-individuals such as Rem Koolhaas and a number of wellestablished Chinese professor-architects, namely Chang Yung Ho and Ma QingYun-to carry out the future enhancement of the profession by exchanging ideas, fostering integration, and synthesizing theory with practice.

Though we may have some reservations towards some of Zhu's rather hasty inferences and relatively vague elucidations, the basis of his speculations carry merit. This paper is clearly significant and has 
aroused much extensive international response; first over the architectural web, followed by a most intriguing article published by Tongji University, "Dialoque: Debate on "Criticality in between China and the West"-a compilation of responses from a number of the above-mentioned architects and critics from both overseas and local. Indeed, these dialectical debates have offered much insight into the ongoing process of professional transformation in reaction to global modernization,

The most relevant of Zhu's implications is the proposition that through perpetual studies of inter-regional, cross-cultural practices - which interrelate with the geo-global reality - non-Western-modernizing cultures, such as contemporary China, could offer much impetus in the development of a post-critical position. Again, it is imperative to stress that, picking up from Koolhaas' experience and insight, taking a postcritical stance is not a rejection of criticality. Rather, it can be perceived as a progression beyond the critical-one which is open and embraces criticality instead of being restricted by it. Though Zhu, in his mild implications, misleadingly reduces a situation where contemporary architects are somehow caught between a stand off between critics and post-critics, he is correct in recognizing the potential contribution the Chinese culture may bring to the table. But contrary to his resolution in contemporary Chinese local practices and Western practices in China, it is likely that China's yet to be refined potential remained embedded in past architectural traditions.
Though this thesis sets out to clarify the pragmatic nature of Chinese traditional architectural developments, it is not merely an exercise to renew some long expired cultural traditions, or to contrive some ideology to assign cultural significance. The intention is to selectively learn from China's architectural traditions and acumulated experiences in the hope of exploring and developing a feasible postcritical approach in the challenges of the contemporary modernization progress. In seeking to establish a versatile strategy that responds to the contemporary conditions of globalism and globalization, a collaborated design methodology will be tested in developing an integrated prototype that reestablishes connections with nature's reality, with our socio-economic reality, and ultimately, with each individual occupant who shares the utmost intimacy with the living spaces.

For those who are limited in the comprehension of Chinese culture, implicit frustration may stand as one of the least unsettling obstacle in contextualizing and conceptualizing Chinese architectural traditions. In retrospect, Chinese culture and many of its traditions differ from the West fundamentally in a distinct perception of relativity. In general, Western culture, in particular classical Greek, legitimizes each person's association with society and with at higher existence through his or her individuality. Chinese culture however justifies a relational framework within which the individual connects with the society as a 
whole, and with that higher existence mostly through subsidiary means. Perhaps this would be more comprehensible when it is put in a socio-political context:

The true significance of [the Western-modern] legislative structure resides in a "united consensual constitution", meaning the establishment of a collective compliance in a "social contract", which is an agreement, formulated through a series of ample discussions, democratic negotiations, and mutual compromises, amongst the entire body of citizens, who by definition are equally sanctioned with the freedom of will and an independent character (or amongst the representatives selected by their own accord). ${ }^{[1,3+1]}$ Such concept never exists in the

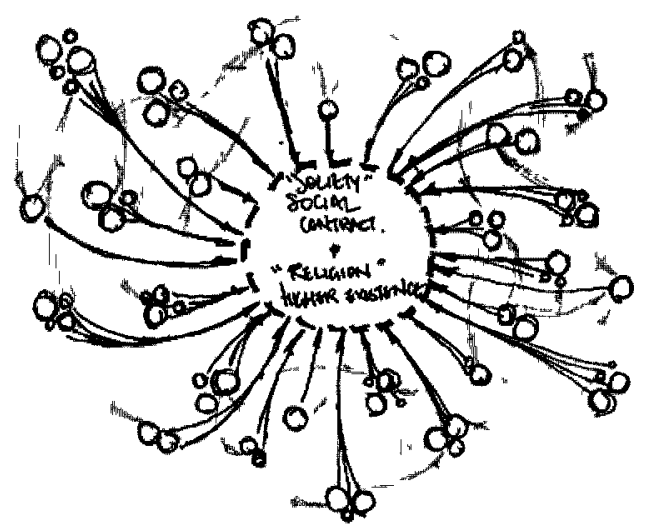

[Wwt 31$]$ Western Social Structure

traditional Chinese society. Whether when it was during the States Era, or when it was during the Imperial Era; there were no concept of citizen, and there were no concept of independent character and the freedom of will. Amongst individuals, each being is connected to another through subsidiary means. A son would accede to his father; a wife would yield to her husband; a subordinate would obey his supervisor; and every individual would submit to the emperor. [iMG 02] [20]

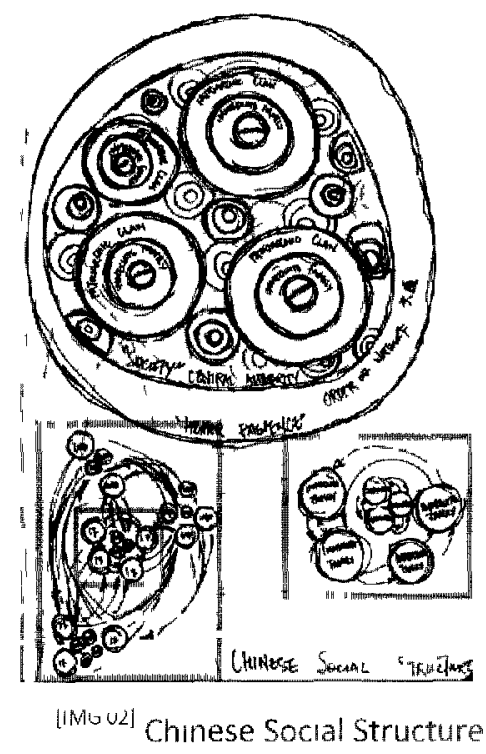

The clear distinction in social structure and cultural context has influenced the development of architectural developments in many ways. Perhaps an indulgence on collective requisites above considerations of individual merits has encouraged a relatively pragmatic approach in architecture. In its 7000 years of indigenous evolution, the Chinese architectural discourse has somehow cultivated a common formal language that prioritizes material and structural efficacy. In addition, its adaptive spatial principles have completed 
various dimensions of the diverse Chinese cultural context, and have been instrumental in manifesting a set of centralized political ideologies. Above all, the Chinese architectural traditions have accommodated margins, however little they may be, for metaphysical connections with the order of nature, and room for individual liberation. In general, the traditional Chinese architectural discourse prioritizes the pragmatic. Symbolic gestures and individual aspirations were embraced so long as they do not conflict with efficacy or suggest motives for disrupting the politico-cultural framework.

\section{AFTER ALL}

Architect is arguably the most conflicted professional. Within practice in the physical reality, architects are really just engaging with the 'how'-how to adjust the spatial and structural components to better fit the needs of the concept or the content. Not to mention that parts of this duty are is often fragmented and shared with other professionals such as engineers and urban planners.

The questions of why-why is there the intention to build, why is there the purpose of the concept-are only affordable to those individuals or to the power institutions which have authority over distribution of the required resources. To state the unspeakable truth: the service of the architect is only required when resource is plentiful and when people of means seek to build beyond necessity. The much vulnerable architects have lived in illusions of freedom in creation, believing in themselves and that the control over architectural agenda is at their disposal; when in reality, agendas that couldn't accommodate the wills of the means and limits of the reality have rarely made it far beyond paper.

And so in many ways to justify the necessity of the profession, architects have torn themselves between the questions of 'what'what is architecture; and what can architecture do. These contentions of a critical self and a pragmatic self have perhaps obscured the most important question: What would become of the nature of architecture within the context of the contemporary globalizing conditions? In acknowledging the reciprocal relationship between architectural will and the availability of resources, one must realize that the perception of professional autonomy is a baggage from the past architects must surrender in hopes of sustaining a future. When the exterior system with its illusions of permanence has suffered great deterioration during a course of continuous denial and negligence, it prompts the question: is there time to speculate a better future or a more pleasant utopia when the very possibility of having a future is silently fading away?

If there were ever an urgency to find rationalization of post-critical pragmatic intentions; it would be that it is a response, direct or indirect, to a world of depleting resource of our contemporary conditions. Though the threats of an apocalyptic dystopia is frequently dismissed as irrelevant menaces favored by cynical alarmists who 
seeks purpose in regular dosage of fear and public panic, more and more the new generation witness the effects of shortages of food and supplies, energy crisis, wasteful resources and ecological contaminations all in the names of satisfying a compromised monetary consumption cycle and a system that is reluctant to reinvent itself. These universal issues that the immediate generations rejected to acknowledge would eventually become a problem that the future generations could not avoid. If a destabilizing future is remotely possible, perhaps it would be timely to start asking ourselves questions in preparation: where does architecture stand in a world where resources are scarce and building beyond necessity may simply be unaffordable?

It seems that, unleashed from century old systems of ideology and if granted support from the capital, architects are free to indulge frivolously amongst the infinite possibility of plural positions, of multiplicity and of inter-disciplinary; but desperately, it is ever more imperative to persist criticality in such post-critical discourse. This freedom of innovation and its advantages must be utilized; and though not by manifesting as resistance or negation, criticality must prevail. The blunt reality is that architects of the current professional practices have no leverage against the capital in challenging the established orders of the vicious market ecology. Not to mention that the pedagogical comrades have long surrendered to the market force and have retreated to the safety of their ivory towers. Architects are in the exigency to start playing the game if there were any chance in winning the race. The agony of pursuing solutions to accommodate both the critical self and the pragmatic self would perhaps engender a new form of architecture that has the potential to better commit itself in transforming our future reality. 


\section{Reference \& Notes:}

${ }^{[01]}$ EINSENMAN add full title \& publisher etc....(1995) P 78

${ }^{[02]}$ BAIRD (2004) P 17

${ }^{[02]}$ EINSENMAN (1995) P 78

${ }^{[04]}$ IBID. P 81

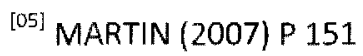

${ }^{[06]}$ ZHU (2005) P 481

[07] EINSENMAN (1995) P 81

${ }^{[03]}$ MARTIN (2007) P 150

${ }^{[09]}$ BAIRD (2004) P 16

${ }^{[10]}$ S, M, L, XL (1995), Mutations (2001), Great Leap Forward (2001), Content (2004)

${ }^{[11]}$ BAIRD (2004) P 18

${ }^{[12]}$ SPEAKS (2005) P 74

${ }^{[13]}$ KOOLHAAS (2001) P 309

${ }^{[14]}$ HAYS (1995) P 43

[15] SPEAKS (2005) P 73

${ }^{[\mathrm{REF}]}$ ZHU T. (2007) P 200-202

${ }^{[16]}$ MARTIN (2007) P 151-152

${ }^{[17]}$ SPEAKS (2005) P 75

${ }^{[18]}$ ZHU (2005) P 484

${ }^{[19]}$ IBID. P 496

\section{List of Illustrations:}

[imG ${ }^{011}$ Western Social structure: Sketch

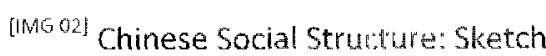


the reality of the building process did not occur until the Italian Renaissance. ${ }^{[02]}$ It is during this period that the architect as a professional specialist began to emerge beyond the act of construct. The fifteenth century Italians dismissed the conventional medieval master-builders and looked back at the Classical architect. Leone Battista Alberti echoed Vitruvius in the preface of De re Aedificatoria,

\section{分析 · ANALYZE}

\section{ANALYZE. 1 - Architecture \& Professional Reality}

... [IIt is dangerous to equate the wish or the process or the job description with the act because, in truth, there are no artists, no architects, and no men of letters. There is only art, architecture, literature, and a lot of hapless, confused people trying to make objects or text that will someday be recognized as art or architecture or literature by the citizens who make those decisions well after the fact. It is not architecture because an architect made it... Architecture is the consequence of a building having been made and subsequently valorized. It is not a privilege of the title, and the whole idea of accepting the mantle in advance of the act mitigates ambition and cheapens our endeavors. ${ }^{[01]}$

Perhaps architecture was never altogether distinct from building. Although one would deliver services on both conception and production, these are nonetheless separate progress of construction developments. The actual separation of the architect-conceiver from

\begin{abstract}
An architect is not a carpenter or joiner...the manual worker being no more than an instrument to the architect, who by sure and wonderful skill and method is able to complete his work. ... To be able to do this, he must have a thorough insight into the noblest and most curious sciences. ${ }^{[03]}$
\end{abstract}

Architecture, along with Painting and Sculpting, was one of the three fine arts that rose to an intellectual status during the Renaissance. As a renewed Liberal Art with ideals mostly savaged from the remaining relic of Classical Antiquity, architects picked up architecture at where it was left off prior to the arrival of Dark Ages. One aspect that is quite different from Antiquity is a change of the agenda. Architecture no longer stood to celebrate a glorious empire; rather, it is dedicated to the manifestation of individualism.

This may very well have been the most significant point of departure between architects and builders. At this early stage of Classical mannerism, anybody embarking on the career of an architect were 
demanded first to be scholarly at Classical detail and proportions. This new perspective in architecture set off a departure from the practical side of building. This separation in labor became problematic. As Vitruvius back in Roman Era tried to explain the necessity of theoretical knowledge and praxis as the bases of the profession,

...a mere practitioner cannot give sufficient reasons for the forms he adopts, while a theoretician 'grasps a shadow instead of substance $e^{\text {[04] }}$

The new conception of architecture began to take shape. As Renaissance architects continued to discover and establish their places in the rapidly changing societies, they have arrived at a point where it is necessary to distinguish themselves against those who were should not be viewed as architects, but nonetheless building professionals involved in the processes. Philibert DeLorme (1510-1570), a great architect of the French Renaissance, was the first to attempt in giving a clear definition of the working relations between architect, patron, and workman, who are more or less builders in the traditional sense. The true architect, he argued, is

...a man who combined the practical experience of the master mason with the knowledge of the amateur, a man...schooled not only in books but in long experience. What gave the architect as a professional man his definition was a set of relationships-both professional and social-with those he came in contact with: the patron, the workmen, and the administrator and officials of the building program. ${ }^{[05]}$
According to their appropriate positions and duties, as

DeLorme defined, patrons

...should employ architects instead of turning to "some master mason or master carpenter as is the custom or to some painter, some notary or some other person who is supposed to be qualified but more often than not has no better judgment than the patron himself." ${ }^{[06]}$

The workman, and others who designed buildings but should not be considered a professional were contrasted against architects.

...Most of [the] would-be architects were really trained for manual work and had no knowledge of the principles of architecture. The others had stopped at book learning and, satisfied with their geometrical demonstrations, they could not apply their theory to the work. What they did was nothing but "a shadow of a real building"... [07]

\section{General - Domains of architecture}

Despite architectural profession, in practice and in education, has further institutionalized since the Renaissance, but some reality of the architectural profession remain unchanged. To extend the investigations into professional desires and limits, it would be important to first identify the difference between two domains that permeated the entire discourse of Western architectural developments: institutional architecture and commercial architecture. Dave Hickey in his article On Not Being Governed has pointed out that 
the "order of commercial architecture" is absolutely distinct from the "order of institutional architecture". ${ }^{[08]}$ Attributing to these separate domains, commercial architecture and institutional architecture, desires and limits within architectural professional reality manifests in different ways. Too often the pedagogue and critic are only concerned with the eccentric "high architecture" and deride discussing commercial domains of the profession, thereby eviscerating the overall discourse of architecture.

\section{Institutional Architecture}

Institutional architecture is about a pursuit towards the beyond. In Towards a New Architecture, Le Corbusier outlines the following:

Architecture has another meaning and other ends to pursue than showing construction and responding to needs (and by "needs", [Le Corbusier] mean[s] utility, comfort and practical arrangement). ARCHITECTURE is the art above all others which achieves a state of platonic grandeur, mathematical order, speculation, the perception of the harmony which lies in emotional relationships. This is the AIM of architecture. ${ }^{[09]}$

Hickey referenced a metaphor made by Morris Lapidus in his definition of institutional architecture. He described this category of architecture as one of the only two primal kinds of building and used the analogy of the corral. The corral is in a fence around a space, of which structures would prioritize the walls and insist on the vertical relationship between the sky and the earth, between God and Nature.
Institutional architecture is about walls and control, about keeping out time and change, aliens and foreigners. ${ }^{[10]}$

Often monumental in Institutional Architecture in the traditional societies often includes palace, temples, and towers; in modern days, such prodigious ambitions are portrayed in government headquarters, museums, corporate skyscrapers, and more. Entwined with elitism, aesthetic connotations and cultural experience of the institutional environment often take precedence over economic cogitation and everything else. Cultivated in such conditions, Institutional Architecture must fulfill beyond utilitarian objectives. Such architecture is a landmark of the society and it is desired to denote senses of aesthetics, authority, wealth, or immortality through the use of various symbolic gestures. With motives to achieve greater design ambition and tendencies of detaching from market realism, institutional architecture usually requires relatively more excessive investments in physical resource and human innovation. The limits of cost and time seldom determine the quality and scope of its construction.

\section{Commercial Building}

Stephen Kieran made a rather interesting case of distinguishing architecture as art and/or commodity in his book Refabricating Architecture. He explains that commercial building is a commodity. It is an artifact of use to be bought and sold in accordance with prevailing principles of economic exchange. Kieran is precise to the point that 
architecture as commodity 'merely provide[s] shelter with a minimum of means ${ }^{[11]}$. Reducing from architecture as art, the traditions of craft are no longer present as architecture commoditize within the modern establishments of building orders. Kieran believes that the modern transformation from handcraft to machine-craft fostered an exclusion of architect from participating in the means and methods of making, and thus diverged architecture into the choice between art or commodity

He elaborated on the comparison between the Parthenon from the Greek Antiquity and Le Corbusier's grain towers in his argument that architecture could be simultaneously art and commodity. Almost solely utilitarian, architecture could be a commodity of value serving a specific function and purpose. But here he is incorrect in assuming that Parthenon has achieved a status of both art and commodity, breaking the typical dichotomy in architecture. In fact, the Parthenon is far from being a commodity. The scarcity of relics remained from Classical Antiquity made it easy to immediately assume that such artifacts are common productions of the ancient building industries. Contrary to these presumptions, there are reasons to believe that the majority of ancient commoners lived and worked in buildings that are substantial different than the institutional architecture that we are familiar with.
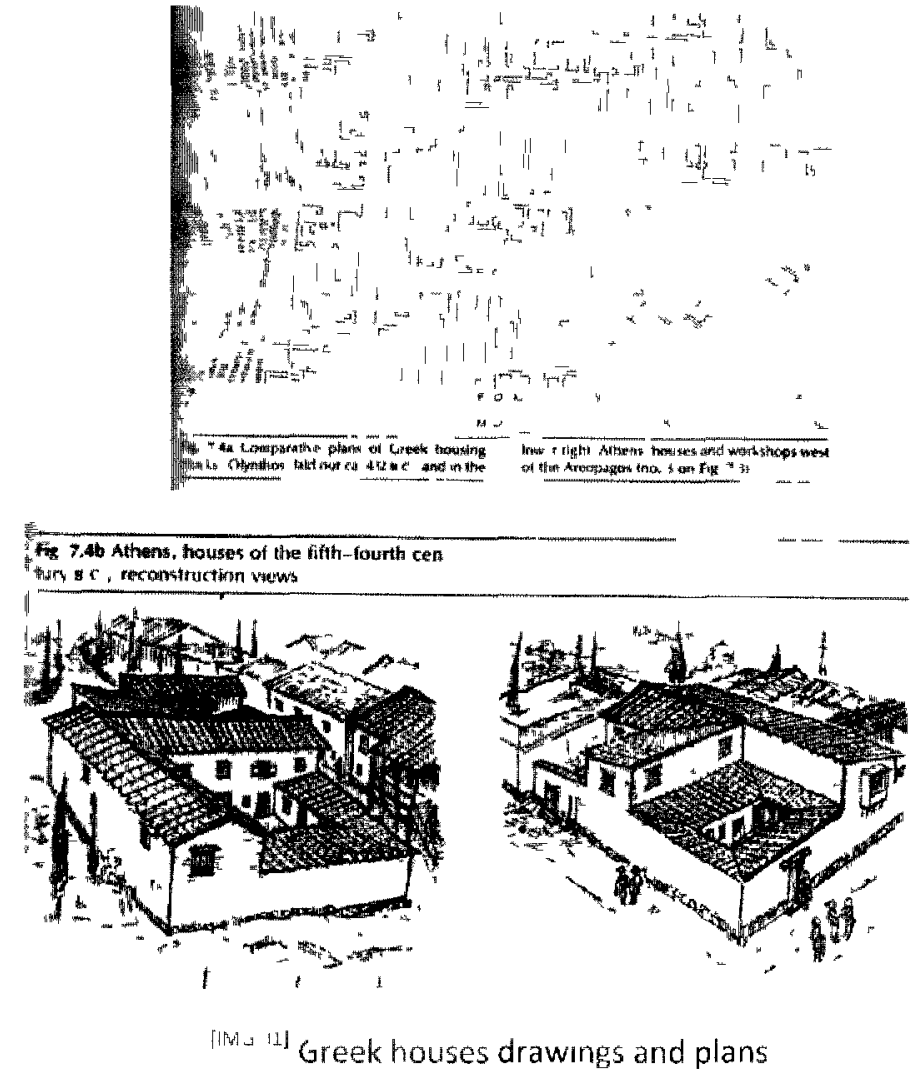

In examining reconstruction drawings of indigenous houses and plans of housing blocks in Classical Greek cities such as Olynthos (ca. $432 \mathrm{BC}$ ) and Mietus $(479 \mathrm{BC})^{\text {|IMG 01] }}$, one could find plans of residential building blocks that are more relevant to the common culture. In them we could see that commercial building from the Antiquity is very different than institutional architecture, temples and civic buildings alike, in terms of material, tectonics, and spatial configurations. Perhaps we could locate the earliest physical evidence of these buildings in Roman 
cities, namely Rome, Pompeii, and Ostia. ${ }^{[1 M G 02]}$ Here is what we know of commoners' dwellings generally in these ancient urban centers:

Within the powerful walls of Roman cities there were private dwellings as well as public buildings. These accommodations reflected the rank and wealth of their inhabitants, and since the range of Roman society was so varied, from the lowest to the highest, so were the dwellings...At the lowest level of the scale were makeshift quarters above shops or squalid hovels such as those in Ostia on the Via della Foce. Less degrading, but still cramped lower-class quarters were generally available in the multistoried tenement houses, of which there are many remains in Ostia. These so-called insulae tended to be built to questionable heights by greedy landlords, sometimes to as much as 100 feet of inadequate construction...Like modern Parisians, the ancient Romans practiced vertical social gradation in their buildings: less desirable, cramped apartments on the upper floors and attic led to members of the lower class, while the lower stories were made into more ample middle-class units, with good ventilation, balconies, and sometimes even running water. ${ }^{[12]}$

There are certain facts of commercial building that we must come to terms with to engage in a holistic discussion of architectural discourse. We must acknowledge that, historically speaking, there are some degrees of pedagogical deficit in the studies of such architecture. Perhaps it is motivated by a collective subconscious determined by cultural characteristics of Western societies, of which art and aesthetics are almost exclusively affiliated with elitism. Nevertheless, such lack of discernment should not encourage rash inferences. It would be a mistake to observe commoditized architecture as merely a

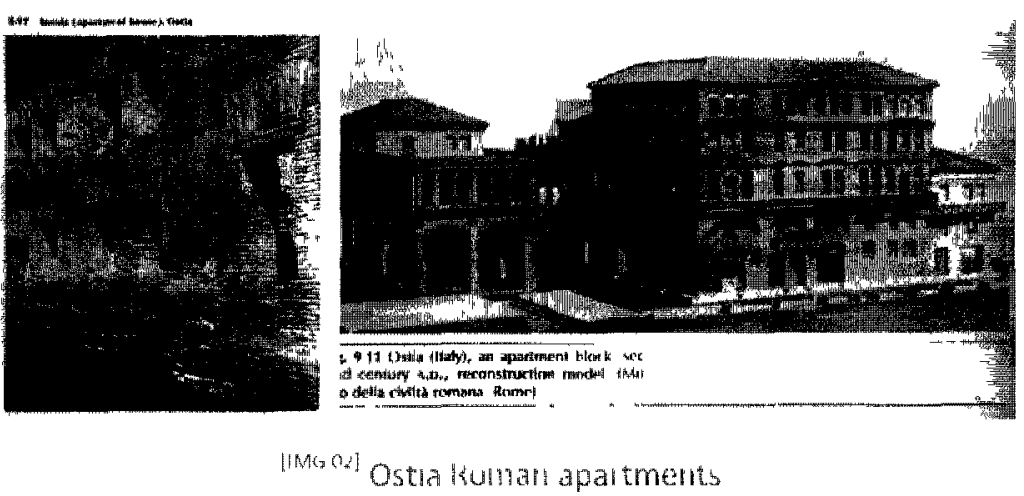

modern phenomenon. The exigencies in understanding its nature and behavior in contemporary societies should not be overshadowed by its obscure presence in academic inquisition.

Too often rendered obsolete by a self-involved profession, commercial building and its historical development deserve much postponed academic attention. In many occasions, commercial building is socially and culturally, sometimes even aesthetically, challenged; largely because, it in its nature is a commodity, which possess a single-minded focus on purpose and economy. Commodities are typically object of possession; and perhaps in more sophisticated societies, objects of investment. Its physical presence is generally contrived with much considerations of conventional production mentalities and often limited by the cost and time restrictions in construction. Commercial architecture is built with desires to minimum expenditure of resource in achieving maximum gain, and to consummate optimum fitness in 
accordance with the economy of means. Its attention to efficacy leaves little room for aesthetic contemplation; with exceptions in cases where aesthetic prospects are not in conflict with cost efficiency, or when these expensive luxuries intangibly enhance its economic value.

\section{Professional Relativity}

In pre-modern societies, an architect's duty was to be attentive to his patron's desires. Architecture as cultural and aesthetic manifestation was usually a concoction of shared interests and desires between the refined architect and his enlightened patron. Builder, with an operative approach, was committed to the essential needs of the average man. Building as typical solution, which focused on maximizing efficacies of material resource and manual labor, was offered to the populace by the 'mere practitioner'. [10ut dis As mentioned previously, because of the academic disinterest in this rather common scope of practice, it is difficult to determine exactly how traditional builder responded to and interacted the needs and wants of the common man.

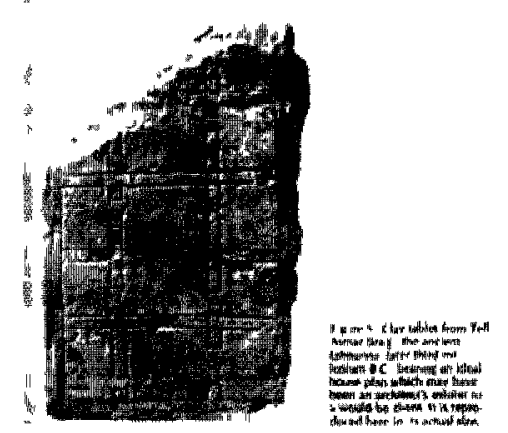

[IMG 03] KOSTOF (2000) P19
In modern industrialized societies, building professional are institutionalized and professionalized with a divergence between the architect, whose obligation is in conception, and the contractor, the evolved builder who is in control of production. Professionally speaking, this is a clear separation; but in the contemporary consumer society, their relations to one another usually involve intricate complexity. In reality, even though the architect could be taken out of the builder; it is nearly impossible to pull the builder out of the architect, except in virtual projects where rules of reality do not apply.

When dealing with institutional architecture, the architect's engagement has not changed much from its traditional role. The patron recruits service from an architect of whom he or she shares design ambitions with. Within the process of conception, aesthetic desires of the project compete with and at times overwhelm economical concerns of its material reality. The architect usually attempts to innovate by enforcing his or her personal aspirations and/or reciprocating with theoretical approaches that are culturally established. Overall, such project in general operates similar to the traditional construction relations, which is a direct result of design and making.

Commercial architecture, traditionally correlated to builders, operates with an altered mechanism in respond to a larger context of the $20^{\text {th }}$ century. The current consumer society runs 
and feeds on an expanded middle class, the exigencies to provide architectural solution to their collective needs have spawned urbanism and its relative architectural discourse. Devoid of precedent, modernists turned to mass-produced industrial models for inspiration and determined that the common men of modern society are entitled to architecture of a new ideal with a concurrent order. This suggests a new order of building production where economic and social agendas were merged with construction and architecture; the directness of institutional projects seeks to translate to the economies of industrial production.

Patron, which brings in the capital, is by and large entitled to direct building project as he/she pleases. After all in most occasions, the building process is a material production that is not bound by aesthetic principles but by laws of economic. More and more it comes to a realization that, by the end of the $20^{\text {th }}$ century, a new hybrid of patron-builder was starting to dominate a large share of the professional industry. Today, corporate developers continue to oblige other professionals in the parade of manufacturing less than satisfactory architecture commercially fitted to meet the needs of consumption. The end product assembled from this mode of operation often leaves much to be desired.
Architecture is seldom autonomous; in contrary, architecture in its present condition is mostly instrumental. Kostof has made this point clear,

...the architect is substantially governed by the historical conditions of practice. Inspiration and genius, long considered almost supernatural requirements for architectural production, are displaced by social forces like economics and politics." ${ }^{[13]}$

\section{Professional Challenge}

According to Stan Allen in the 2004 Stocktaking Conference, at least in North America, the contemporary profession is oscillating between two equally unacceptable extremities: either subject to market realism and play by the practical rules as implemented by corporate organizations, or retreat to the outdated pedagogical strategies of avant-gardes and be marginalized on narrowing paths of resistance and continual experimentation. This bifurcation between profitseeking and aesthetic experience characteristic of modern culture has meant that buildings have typically been conceptualized either as assets and equipment, with little concern for noneconomic factors, or as architectural monuments to be appreciated only by an informed and elite audience. ${ }^{[14]}$

This professional confliction is, unfortunately, deemed unappealing for discussion amongst quite a large proportion of the pedagogical establishments. But it is of utmost importance to reconcile discrepancy between the institutional and the commercial, and 
between the pedagogical and practical. The challenge ahead then, is not in disputing and criticizing theoretical fundamentals of the building industry; but rather, it is in committing to realize complex projects with physical and economical limits while maintaining high level of design ambition and desire. Such ambition could not be achieved by questioning in isolation the essentials of architecture with the baggage of preconceptions. By comparing Western architectural discourse to alternative manners and ideas from other culture's past, this discussion could open up to more possibilities; and hopefully, deliver a potential solution.

\section{Chinese Approach to Architecture}

As an asset, architecture is the autonomous enlightenment of desires and aspirations, and as equipment, building is an instrumental reflex responding to limits and consumption. Either as assets or equipments, buildings of the West are perceived as formalist objects of delight or utility. The profession is always concerned (or, confused?) with the questions: What IS Architecture? What MEANING should it convey? Unfortunately, such desire of intellectual elevation makes architecture hardly accessible; the dialogue is by invitation only. Concentrating on these subjective issues, architecture habitually obliges itself to an alienated category. Too often we forget that there are other approaches to architecture. The traditional Chinese approach is one that focuses on objectivity and instrumental aspects of the built environment. It is worth exploring the relationship between this indigenous system and its professional reality.

Architectural professionalism is an imported concept of the $19^{\text {th }}$ century; therefore to interpret Chinese traditional architecture from a western professional perspective would be quite difficult. The Chinese indigenous architectural developments, its instrumental aspects in particular, are so extensively enveloped within the larger cultural context that the needs for a specific curriculum and an established professionalism hardly came into attention. The traditional building industry is mostly comprised of a diversity of craftsmen, GōngJiàng【工匠】, in planning and in construction.

LI YŭnHé 【允驺】discuss this condition in his book Cathay's Idea 【华夏意】 by paraphrasing Sir Banister Fletcher in A History of Architecture on the Comparative Method, "Amongst all the Arts from the Western architecture, the Chinese only share a similar recognition of painting as an intellectual prominence; sculpture, architecture, and other forms of craft are considered as mere works of dexterity. Art in general is the commitment to poetics (of emotional interactions), rather than to materiality. The Chinese are allured by sensational beauty of nature, but are not susceptible to emotion projections of the built objects; buildings are perceived as mere practical necessities of everyday life." [REF] Traditionally occupied within such cultural parameters, even though the crafts of construction are generally valued, academically, it had not quite transformed into an intellectual 
discipline. This is an issue of recognition cultivated by the indigenous academic mentality.

Zhāng QīnNán【張㳄䡛】， however, considers this condition deplorable. In Chinese Ancient Architects【中国古代理筑师】，he suggests that this is a consequence of the traditional societies' accustomed negligence in science and technology. The Chinese academies are much concerned with comprehensive discourse in humanities; but are generally indifferent to specific analysis in the science of nature and technology. [REF] This is not to say that the traditional Chinese architects are obsolete, their contributions, their desires and objectives, are just different at the fundamental cultural level. Unfortunately, the general disinterest in Chinese practice left us little to fulfill a thorough interpretation from a professional angle, but it is possible to piece together details associated with architecture and practitioners from a variety of historical scripts, paintings and literature. Though they are not written specifically for the purpose of documenting architectural developments, they have been one of the most important sources of research in modern approaches to understand traditional architecture.

Zhãng is convinced that Chinese traditional architects could be divided into three distinctive groups. First, there is the official imperial architect who works within the political frameworks and provides service to government institutes. This official, or GuānFāng【官方】， category are mostly represented by ministers and his administrators of the construction division within the government organization. The Office of Construction, usually by the name of JiāngZuò 【將作】, was a branch under the Board of Works [NOTE] within the traditional government infrastructure.

In the Record of Examination of Craftsman, the master craftsman, JiàngShi【匠硓】, is one of the specific craftsman specialized in wood productions. He is obligated to collaborate with BăiGōng【百工】, other official specialized craftsmen who are owned by the state during Early Imperial Eras (circa $2^{\text {nd }}$ century BCE - mid $6^{\text {th }}$ century BC). By early $7^{\text {th }}$ century, these craftsmen are relieved from the official system and established civilian status as contract-based service providers. The master craftsmen would perform duties which includes surveying in planning the state capital; managing and executing its construction which includes palace, ritual buildings, ancestral temples and roads; and lastly, directing military and civil projects at the national level, such as building city walls, drilling wells, engineering hydraulic projects, storage and other utilitarian structure. ${ }^{[15]}$

The master craftsmen continued to work with different titles during Imperial China within the Office of Construction, but their scope of work remained relatively the same. The position of director is usually appointed to an experienced official, who enters the governmental system through the States Examinations with extensive education of the classical curriculum. It is certainly possible, however rarely, that a talented and experienced master craftsman from within the Office, or 
a distinctively reputable commoner craftsman from private practice, to be appointed or promoted into prominent positions within the Office. Generally speaking, the role of these official architects was primary to supervise construction and less often to design large-scale building projects.

Another type of "architect" is rather unique to the Chinese culture. They are usually not builders per se, but they are absolutely indispensable in traditional Chinese architectural developments. Literati, or WénRén【女人, are traditional academics who are well educated in Classical schools of thought, poems, literatures, and often devote interests in various arts ${ }^{\text {[NOTEl }}$, namely painting and calligraphy. They often capture the beauty of architecture in writing and in painting; more importantly, they contribute directly into architectural designs in many occasions. To elaborate on their extensive achievements, Zhāng writes,

The intangible influence Chinese Literati project on architecture is frequently far and wide. It is the "software" of Chinese architecture. Their influence could be divided into three major types: one of which is through the many housing-garden complexes these Literati build for themselves. Establishing physical examples...these complexes made prominent distinctions with the focus on the beauty of an idiosyncratic metaphysical realm and the focus on the reconciliation with nature. While these intentions make a vivid contrast to the grandeur of imperial palaces and noble houses, their pursuit to beauty within the realm certainly are quite influential to imperial and civilian architectural developments. The second type of Literati influence is through the interface of poems... [, literatures alike], and paintings. These subjective descriptions of architecture through individual perspectives are similar to what we would refer as "architectural critique" in modern days. These elegant literature, poems and paintings had produced a silent impact within the larger society, and had cultivated concepts of aesthetic appreciation and temperamental interests of architecture within the common minds. The last type is direct discussions on essential values [, mostly economical (i.e. luxurious vs. modest), ] of architecture. Such candid deliberations are relatively rare through the course of Chinese history. A more usual approach is commonly manifested as hidden suggestions within the descriptions of the architecture itself and its aesthetics. ${ }^{[16]}$

The last type of architect is the master craftsman ${ }^{[17]}$ who practices amongst the commoner society, or MínJiān【民䛜】, who often provides service to commercial and residential clients. These civilian constructors would also provide service to government institutes, usually at a lower level, when commissioned by administrations. The master craftsman is familiar in working with wood, but his skills and experience sets him apart from a carpenter. Liǔ ZōngYuán【榴宗元】 (773 - $819 \mathrm{CE}$ ), a renowned Literati from the Tang Era [唐代 . TóngDài ], has taken an interest

in observing a master craftsman and his crew on an official commission. In his literature, The Tales of The Master Craftsman I 梓人罚, ZZRénZhuón $]^{[18]}$, he praised on the collaboration between 
YángQián【楬洒】 and the other carpenters, and reference this sophisticated organization in architectural production as a metaphor for managing government administration. In the story, the first three paragraphs focus on his observations of the building crew:

...A master craftsman knocked on [ Péi's ${ }^{[19]}$ ] door and asked to rent one of his vacant houses. Though he did not have any money to pay Péi, he offered his service in exchange. He carried with him some measuring

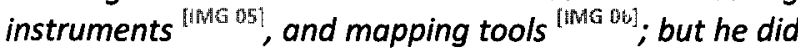
not have any tool for cutting and refining wood. When he was asked of his talents. He said, "I am good at measuring materials. I observe structural forms of houses, I understand the adequate width, shape and length of the wood; and I could direct a group of workmen to build. Without me, they would not be able to build a single house. Therefore, when I am commissioned by the officials, I should be paid three times more than the others; when I am commissioned by private clients, I should be paid more than half of the total labor wage."

A few days after he moved in, I visited him at his house. His bed was broken but he could not take care of it. He said, "I would hire a craftsman to fix it." I laughed at him and told him he was a person of no skills, merely one who is possessed of greed for salary and money.

Later when the Capital's Governor, [ 京妆 $\#$. Jingzhơorin ], renovated houses of the official complex [ 徱同 . Yámen I, I passed by the site. [There] compiled many building materials; and a group of men, some held axes ${ }^{[\mathrm{IInG}}$ 07] and some held saws "IMtG eil! gathered around responding [to Yáng]. [Yáng], holding a ruler in his left hand and a staff in his right, stood in the middle lamongst the workmen]. He measured the loads on the structural frame and observed the wood's capacity; then he waved his staff, and commanded, "axe!" A man holding the axe ran to the right. [Yáng] turned and pointed [at the wood]; he ordered. "saw!" A man holding the saw ran to the left. Soon, the rest of men with axes started to cleave, and the rest of men with blades started to chisel. The men all looked to his facial expressions and followed his words, none of them dared to be selfdetermined. There were men that were not competent, he became furious and dismissed them, none others dared to complain. [Yáng] drew [a structural drawing of] the building on the wall. The diagram [only] fills a foot [in length] but it demonstrates every detail of the structural form. [Yáng] measured the diagram and finished constructing the grand structure, and there was no mistake. When the building is finished, he wrote on the upper ridge, "Built by that man on that day of that month of that year". Of course that man was himself in his name. The other men he put to work were not listed. I looked around and I was overwhelmed. Then I knew the greatness of his efficacious skills. ${ }^{[20]}$

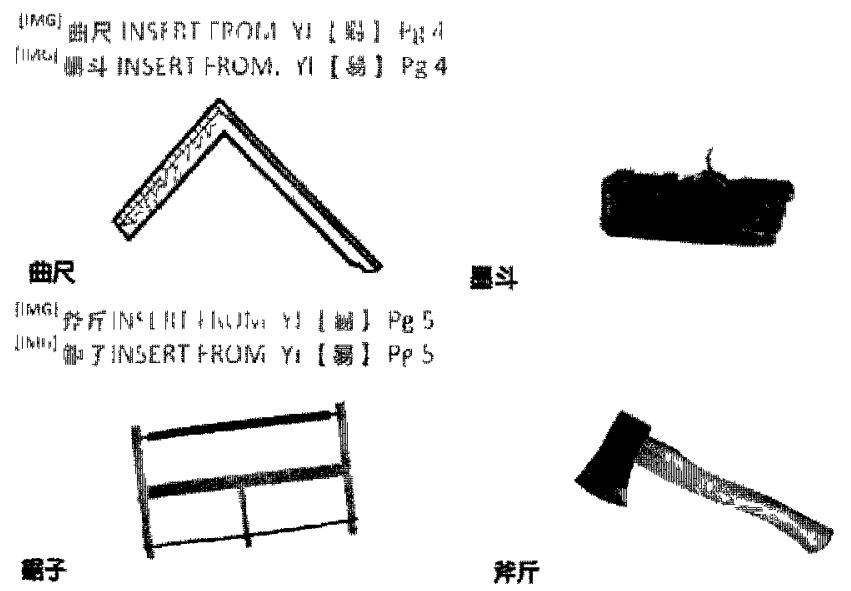




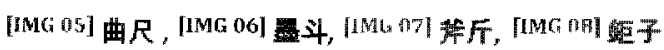

Liǔ further acclaimed that Yáng must have given up crafting with his tactile talents in order to apply his mind and intelligence towards the essential structure. Liǔ believed that there is a difference between those who labor with their hearts and those who labor with their bodies; and it is natural for the former to direct and put the latter to work. While people with normal skills and talents contribute with physical work, the bright minded individuals would contribute by strategizing and planning. This is the apparent difference between the master craftsmen and other workmen, carpenters alike. In general, the master craftsman is likely to work at the capacity of a structural engineer while assuming the role as project director in macro managing the construction process.

Yáng and craftsmen alike, however, cannot be considered as the architectural designer in the modern sense. Chinese building methodology and its cultural traditions are unique in the way that the structural planning has been standardized and modularized. The spatial compositions are incorporated in a series of independent structures, rather than grouped inside one monolithic framework. Generally, most traditional architecture has no desire to challenge height and gravity; instead it seeks flexibility, adaptability, and organic growth on the horizontal plane. This make the planning process relatively simple and therefore accessible to every individual without the requirement of a professional education. Hence, where as the master craftsman would lead and manage his crew to ensure the structural integrity of the individual buildings and details are followed as directed; the client, private or official, who provides funding for the construction is most likely to be the master planner or designer of the overall scheme.

Other than the officials, the Literati, and the master craftsman; there is one more group of architect that must be mentioned. Perhaps the rural commoners, especially farmers, are the most intimate individuals to architecture. Despite their lack of professional training in the specifics of building techniques; their ingenuity and contributions to Chinese traditional architecture should not be undermined. CHIU KwongChiu【

\section{Architecture 【不只中圆木建察】writes,}

No one understands the earth better than the farmers; with the soil they grow to produce the five crops and foods; they grow to produce cottons, hemps, garments and looms; they grow to produce rafts, carriages, instruments, and utensils; to one's surprise, they also grow to produce houses and homes. ${ }^{[21]}$

A farmer's building ambitions could allow for more patience and time. The building process begins with the planting of trees; it takes at least five years to grow a rafter, and a normal beam or column takes ten years. With the more preferable species, it may even take twenty years for the tree to grow into a usable building material. As the 
farmer waits for the trees to mature, he gathers best fitting rocks to lay his foundation. This is a seemingly long process of building, but this is a continual process where fathers would plant and prepare the material and pass on their building experience to their next generations. From harvesting and transporting the wood and earth, to firing bricks and the making of tiles, the accumulated building knowledge and experience circulate through indigenous rhymes and songs. A compilation of these folk rhymes and scattered construction scripts formed the basis of LüBān's Manual [ 理維 . LüBänlīng ] during the early Ming Era [ 明代. MingDàr ] (ca. $14^{\text {th }}$ century).

With such folk wisdom, every scenic village that covers the Chinese mountains and rivers are built with collaborations between its dwellers; and almost very traditional farmer is an avocational architect. When the time is right, every member from the entire family contributes towards a common goal and the tasks are divided in phrases according to each individual's ability. In early Spring, structural frames would be raised; and at the end of Fall when farming activates are paused, the roof would be placed to enclose the home beneath. During the building process, it is common to invite fellow villagers and families to help complete the project. ${ }^{\left[1 v^{2}\right.}{ }^{04]}$ It is evident that such building activities are inseparable from the peasant's way of living and the larger common culture.

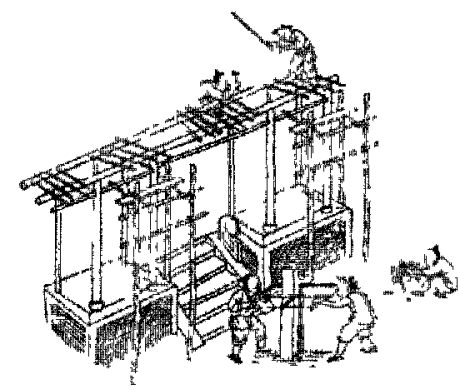

$\lfloor\mathrm{MG} 09\rfloor$

Aside from the above listed types of Chinese architect, there are other associates worth mentioning, one in particular is a unique character of the Chinese traditional building industry. The associate professional neither design nor build, but contributes as a consultant during both conception and production. Advice given by a feng shui specialist [ 成水師 , Fenghshuishi ] is essential before every planning process begins. Whether it' $d$ be city planning, new building construction, or an existing house renovation; the client or the master craftsman consults with the specialist first to locate the best possible site orientation and working area in advance. Zhāng LiángGāo【张良莘】 writes in his book Seven Comments on Traditional Chinese Architecture [匠学七说】 the prices intentions of these feng shui specialists: 
The craft of feng shui demands considerations for the proximate environment: respect nature when project is located in a natural terrain; and/or respect the existing context when project is located in a built neighborhood. The craft of feng shui does not allow new architecture to “confront and offend" [ 冲犯 . ChòngFan ] an existing condition; or in a positive proposition, it is a demand to accord with the surroundings. The craft of feng shui endows architecture with "character", but the appearance of such "character" originates from its surrounding conditions; therefore it could naturally be returned to the environment, and be assimilated into its proximity. The important responsibilities of the feng shui specialist are in caring for the immediate neighbors and considering the works of local's past, in achieving a high level of harmony. ${ }^{[22]}$

\section{Domain of Architecture}

It is safe to suggest that in the past most Western architectural developments have yielded to profess the distinct differences between the domains of architecture. The repudiation of such deficit of attention in developing applicable solutions in the commercial domains of the profession have assisted little in easing the expanding demands of the past century. Ultimately, the modern father's desperate attempt to borrow from the process of industrial production have led to dead ends of their movements.

In contrast, China's historical approach has provided an alternative outlook of architecture has allowed an extensive distribution of architectural insights geographically and socially. Of course there are similar needs to implemented particular design attributes within the distinguished institutional and commercial domains. In fact, manifesting refinements of the official, or Guānfāng【官方】, characteristics amongst the many secular, or Mínsiän [居间】， traditions are quite essential to many aspects of Chinese culture.

It should be noted that the establishment of Chinese architectural orders differs from that of the Western developments. In comparison with the separate approaches to institutional and commercial architecture in the West (i.e. example of Parthenon as compared to the various insulae in Ostia), Chinese refrained from establishing architectural dispositions through distinctive typological variation. Whether it would be the royal palace, administrative complex, or government endorsed religious buildings, most official institutions correspond to a general discipline of building tectonics and construction methodologies; and such cultivation of architectural manifestation extends throughout regular practice amongst the general public. In short, both institutional and commercial domains of the Chinese professional practice adopt the same sets of structural and spatial configurations in design and in production.

In China the arrangement of space has always been governed by laws. Architecture has always been an art guided and controlled by the state, aim not only at organizing the environment but also at providing a frame for the social system. The size of a building, its internal arrangement and its architectural decoration 
were already determined by the owner's social position as early as the Zhou Dynasty $\left(11^{\text {th }}\right.$ to $3^{\text {rd }}$ century BC). ${ }^{[23]}$

Even though architectural dispositions were regulated, at times rigorously, in accordance with the occupant's social standing, there are reasons to believe that such circumscribed measures in construction methodologies were established beyond fulfilling the needs to fortify certain control mechanism of the feudal bureaucratic systems. Extensive details of the Chinese structural logics would be further interpreted in the following chapter; but in the mean time, let us acknowledge the fact that the traditional Chinese is the only culture that has fully achieved architectural standardization on a pervasive amplitude. ${ }^{[24]}$ Such construction solutions are not only pragmatic in nature; time and cost efficient in their production; and more importantly, they favor a high level of flexibility in implementation. By many accounts, traditional Chinese architectural development sustains many practical principles that constituted the foundations of modern architecture in our society today.

\section{Professional Relativity}

The Chinese traditional process of development in design and construction facilitates an original dynamic between the architect, the builder, and the patron. In most occasions, a master craftsman would serve as the builder, and the patron would render the role of an architect. As mentioned earlier, such conjunction is the explicit consummation of China's highly established construction solutions, which are profoundly standardized and immaculately modulated.
The unit of a building is the same as the cross-section of its bracket-arms. The actual size of a unit varies, but as soon as the category of a building and the number of spans across its front was known, the [master craftsmanj knew the actual size of the building's unit and could then proceed with construction. ${ }^{[25]}$

Details of this modulated standard system would be discussed in detail in Chapter 3; here it is important to note that since every building component is directly proportional to the basic unit, the patron as architect would have little difficulty calculating the approximate expense of building materials. This relatively comprehensive building system also allows the patron-architect to conceive an overall spatial design of a building complex almost effortlessly. The highly adaptable natures of Chinese traditional architecture provide much resilience when changing conditions demand structural renovation and/or spatial modification. Most crucial of all, such widely adopted structural logic opens up a flexible architectural traditional that is accessible to all. Builders and patrons alike both have access to the basic knowledge of a comprehensible system that was standardized for economical efficiency, and at the same, was sufficiently flexible to meet ad hoc customizations for each individual occupant. 


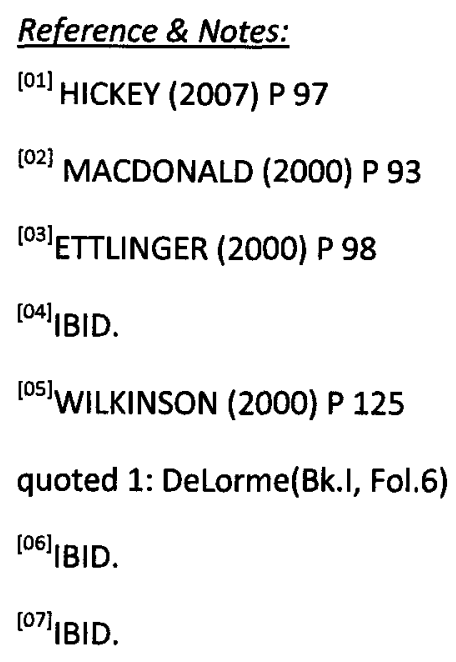

The Ministry of Winter [ 冬官 . DōngGuōn ], which governs all industrial production and construction (hence the name Ministry of Labors). However, the original specifics of this section were lost in Western Han Era [ 西㴖 . XiHàn]. It is replaced with The Record on The Examination of Labors, KăoGōngJi [ 考工記 , KăoGōngfi], a generally accepted collaborated treatise originated from the State of Qí [ I sometime through Eastern Zhou Dynasty [ 東周 . DongZhöu ] (770$221 \mathrm{BCE})$.

${ }^{[15]}$ The Rites of Zhou [ 周福 ，Zhöulir] 。The Minıstry of Winter /

The Record on The Examınation of Labors [ 冬官考工記 . DōngGuōn KĕoGongji ] • JlàngRén [⿷匚斤 $\lambda$ ]

${ }^{[16]}$ Q. Zhāng 【張钦棈】 P 85

${ }^{[17]}$ The master craftsman has many different names in the commoner culture. Some of the frequently used titles are:

JiàngShī [匠陾】，JiàngRén [匠人】，GōngJiàng【工匠】，ZǐRén【样人】， and etc. $[\ldots]$

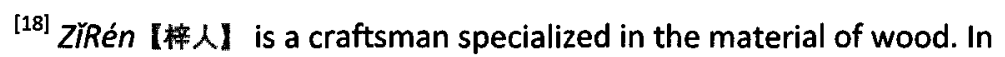
Ancient China, Zlíén specifically means craftsmen who make frames to hang musical instruments, drinking utensils, and target boards for archery. Later in Imperial China, ZǐRén generally refers to carpenters or architectural craftsmen.

${ }^{[19]}$ Péi is referring to Péi FēngShū 【封赫】，who is married to Liǔ ZōngYuán's【柳宗元】 sister.

${ }^{[20]} \mathrm{A}$ foot is about $30 \mathrm{~cm}$.

《说文》。按，十发为程，而当一分，十分为寸。

《说文》。尺，十寸也。 
${ }^{[R E F]}$ Tang [ 唐 . Tóng]。Liǔ ZōngYuán【机宗元】。The Tales of The

Master Craftsman [ 粹人傳 . ZiRénZhuán ]

Modern translation:

Q. Zhäng【張钦榑】P 130

http://news.xinhuanet.com/edu/2010-08/25/c_12482916.htm

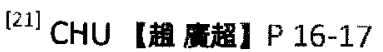

${ }^{122]}$ L. Zhāng【馒是】 P 210-211

${ }^{[23]}$ PIRAZZOLI P11

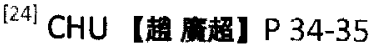

${ }^{[25]}$ STEINHARDT P50

\section{List of Illustrations:}

[IMG (1)] Kostof (1995) Pg 141

[iwt 021 Trachtenberg (2002) P152; \& Kostof (1995) Pg 200

[NAGI KOS ROF (2000) P19

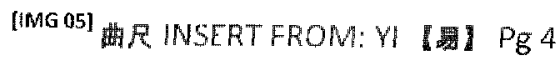

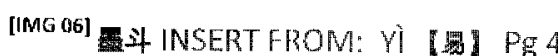

[IMG 07] 斤INSERT FROM:Yì 【晶】Pg 5

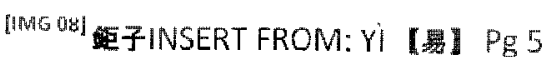

[IMG 09] SOURCE: CHUU【㙕】Pg 17 


\section{分析·ANALYZE}

\section{ANALYZE. 2 - Architecture \& Social Reality}

To better understand the nature of architecture in Chinese traditions, it is necessary to study its developments along with the Chinese social evolution. It is important to be reminded that architecture is perceived very differently in Chinese culture than it is in Western cultures. Though its traditions of crafts is remarkably close in becoming an intellectual discipline; architecture is not an art that is generally valued academically, and it is mostly perceived as a practical necessities of everyday life. To put it in simpler terms, Chinese traditional architecture has never quite made it far beyond the subconscious state; it exists, in the larger part as an instrument within the larger whole of Chinese traditional culture.

The awareness of the distinctions between institutional architecture and commercial architecture should be revisited in the exploration of architectural developments in relations to social realities. As discussed previously, most Chinese cultural manifestation during the Imperial Era and their developments are divided into the official types, or Guānfäng【官方】; and the secular types, or MínJiān【民币】. While the Guānfāng【官方】architecture is very much associable with pragmatic characteristics of their Western counterparts, institutional architecture; the Minsiān【民间】 architecture share similar purpose with that of commercial architecture. But in contrast to Western examples where tectonic distinctions are apparent between the institutional types, as manifested in temples and other public monuments, and commercial types, as indicated in examples of indigenous houses and insulae; the Chinese counterparts share similar attributes in spatial and structural principles, especially within the urban contexts. Physical resemblance aside, the socio-political reasons for the rigorous classification of GuānFāng【官方】 architecture and Mínsiān【民同】 architecture of the Imperial Chinese traditions were one of the few central concepts that has directed architectural developments in traditional Chinese culture.

This may very well be a reminiscence of a more ancient past, but a more important task here would be to understand how these continuous and self-evolved architectural developments adjust to structural changes in Chinese societies from the very beginning. What we recognize as Chinese traditional architecture today is in fact a matured system that gradually took shape over millennia of innovation and synthesis. There are reasons to believe that the 
essence of Chinese architectural traditions could be found in isolating the conceptual elements that endured radical social transformations and maintained in the course of architectural evolution. In attempting to understand the nature of these unique architectural concepts in relations to the Chinese social realities, perhaps it would be adequate to return to the beginning of the Chinese civilization.

Prehistoric China is profoundly different than what we understand as Chinese today. At the dawn of civilization in the subcontinent of central Asia, human societies existed as mere scattered tribal clans thriving for survival. Though evidence suggests that primitive activities and cave occupations, those of homo erectus dating as far back as some 1.7 million years ago, were present in different regions across the vast regions of which we geologically recognize today as China; architecture as we know was born in the Neolithic period ${ }^{[01]}$. It would a difficult, if not impossible, task to envision a precise lineage of the primitive huts, but perhaps a general outlook could be generated with some assistance from the trusted words of the Chinese ancients.

One of the earliest mentioning of architecture origins was recorded in The Ceremonial Usages: Their Origins, Developments, and Intention

【部通 . Lih!, a chapter of The Classic of Rites【請記 . Lis 】, as part of the conversation between Confucian 【孔子】 and his students during $5^{\text {th }}$ century BCE:

Formerly the ancient kings had no houses. In winter they lived in caves which they had excavated, and in summer in nests which they had framed...The later sages then arose, and men (learned) to take advantage of the benefits of fire. They [molded] the metals and fashioned clay, so as to rear towers with structures on them, and houses with windows and doors...They were thus able to nourish the living, and to make offerings to the dead; to serve the spirits of the departed and God. In all these things we follow the example of that early time. ${ }^{[02]}$

Mozi 【e 1 】 from the late $5^{\text {th }}$ to early $4^{\text {th }}$ century BCE writes in the script Indulgence in Excess【解過 、CGuo】 :

"Before the art of building houses and palaces was known, primitive people lingered by the mounds and lived in caves. It was damp and injurious to health. Thereupon the sage-kings built houses and palaces. The guiding principles for these buildings were these: The house shall be built high enough to avoid the damp and moisture; the walls thick enough to keep out the wind and cold; the roof strong enough to stand snow, frost, rain, and dew..."

While Confucian【れ子】 and Mozi 【學子】 both recorded the origin of building activities in an abstractive past, the famous legalist Hanfeizi 【韩非子】 from the $3^{\text {rd }}$ century BCE was more conscious in terms of his historical time settings. In his political argument, WuCan 【五桖】， Hanfeizi【輤非子】 identified three periods of his contemporary pasts: the distant past, the intermediate past, and the recent past. 
During the times of our distant past, the people number few and the beasts number much. The people could not compete with the wild creatures. There is a sage man who crafts, gathered wood in forming nests in order to avoid all hostile creatures. The rest of the people were pleased, made him the king of all, and called him YóuCháoShì有㫦氏】[, meaning "the one who has nest].

...During the times of our intermediate past, the world was suffering from the great flood until Gün [EI and his son Yŭ [需】 consolidated the drainage solutions...

...During the times of our recent past; Tāng Ii I

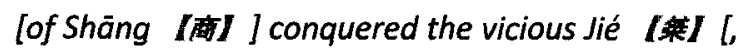

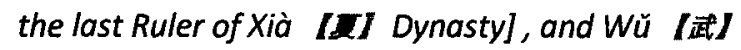
[of Zhōu (野I Dynasty ] brought down the ruthless Zhòu (at) [, the last sovereign of Shāng [RI Dynasty]. ${ }^{[04]}$

These historical figures provide reference in translating the events of Hanfeizi's 【非子】 contemporary pasts into our relative understanding of historical time settings. Though the times of YŏuCháoShì 【有临氏】could not be accounted for; his time definitely precedes YanDi 【类帝】 and HuangDi 【黄帝】, the mystical tribal leaders of the "Five Emperors" 【五帝】 period and the forefathers to the HuaXia civilization which was paternal to the Han 【潢】 ethnicity. Like many other Chinese folk epic before the establishment of Xià

【I】, YơuCháoShì有巢氏】 and the people he has impressed most probably belonged to one of the many late Neolithic chiefdoms that pervaded the vast regions of prehistoric China some time before or during the gradual transitions from matriarchal society to patriarchal tribes.

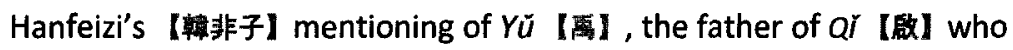
established Xià 【II the first dynasty of ancient China, puts the beginning of the intermediate past near the end of the third millennium BCE. The intermediate past is somewhat concurrent with chiefdom societies-or in Chinese archeological terms, tribal alliance

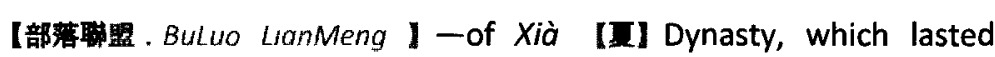
close to 500 years from late $21^{\text {st }}$ century BCE to late $16^{\text {th }}$ century BCE.

In his defeat of Jié 【缺】 -the last ruler of Xià 【X】 Dynasty-a chiefdom leader from the east by the name of Tāng【晹】 seized the throne and established the tribal states alliance I部落国家㬝昷、BuLuo Guolia LranMeng】 of Shäng【㢈】 some time during late $16^{\text {th }}$ century BCE. And by overthrowing Zhòu【㭙】, who was the last to reign the Shāng【商】 regime, King Wŭ 【武】 became the first alliance king 【共主.GongZhul of Zhōu【周】 Dynasty-a states alliance【国察盟. Guojla LanMeng I -in the year 1046 BCE. Therefore it would be safe to assume that the recent past roughly refers to some 600 years from $16^{\text {th }}$ century BCE to $1046 \mathrm{BCE}$. 


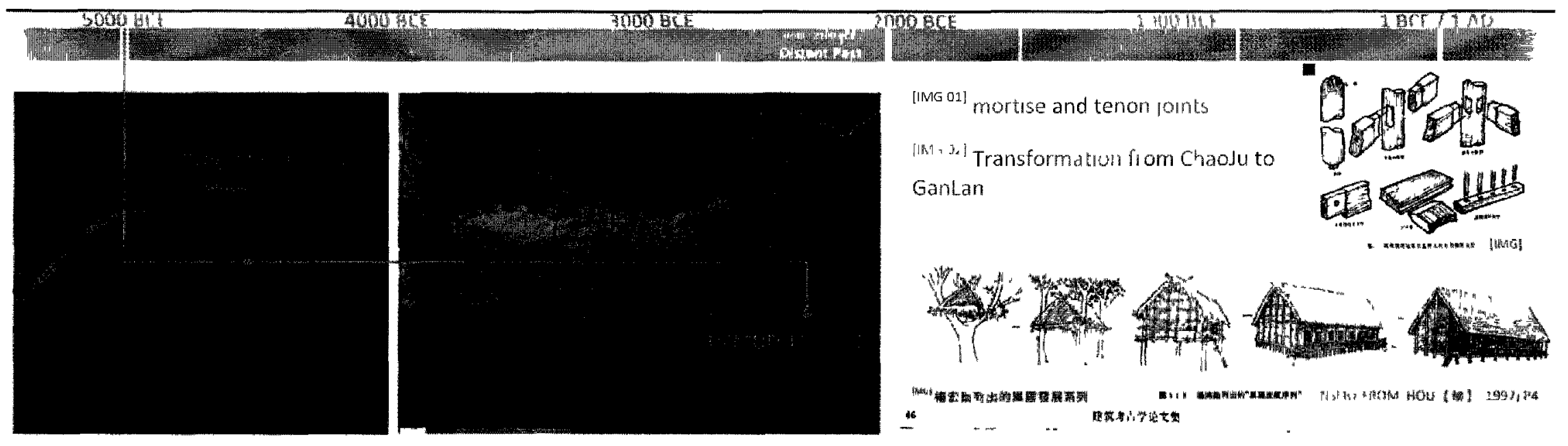

Hanfeizi【非子】 in this literature argues that because social conditions and conventions undergo constant changes through the course of history; if a state wishes to survive, the ruler must readjust his political strategies accordingly. Each of his definitions of the contemporary pasts clearly outlined consequential events where critical changes occurred and triggered fundamental social reconstruction. The systematic changes of each social restructure have left their imprints on the shaping of architectural ideals during the initial formation of ancient Chinese culture.

YŏuCháoShì 【有䒩民】 of the distant past may arguably be the first inventor of one of the primitive huts, ChaoJu 【巢居】, literally meaning "nest dwelling". Perhaps the best evidence of YǒuCháoShì 【有巢氏】 and his influence could be found at Hemudu【河姆度】 site which was located in the lower reaches of the Yangtze River, on a piece of wetland south of the modern city Shanghai across the water of Hangzhou Bay. Within its fourth cultural layer, the oldest remains were found to be dating back to approximately 5000 BCE. The abundant architectural relics discovered in this layer marked the true emergence of wood-beamed stilt houses. Parts remained suggest that these stilt houses were built in long rectangular shapes, measured at about 23 meters by 7 meters, and were mostly supported by wooden structural joints and timber poles. The most extraordinary of all discoveries amongst the debris left by the Hemudu

their common application of the world's oldest examples of mortise and tenon ${ }^{1: W 6} 011$-a joinery that employs notches and inserts. ${ }^{[05]}$ Chinese scholars generally accepts that these stilt structure, or in Chinese terms GanLan【干欄】， matures from ChaoJu【巢居】 and as widely adopted as housing strategies not only in the Yangtze River 
regions but also across the vast regions of Southern Asia then occupied by the Ancient Yue 【超] clans. ${ }^{[I M G 02]}$

The renowned architectural archeologist Yang HongXun【㢦捣助】 in

his authoritative report-Essays on Archaeology of Architecture in

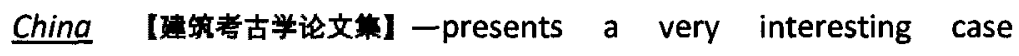

concerning these structural remains of Hemudu stilt houses. From the excavated site, Yang determined that these stilt houses were first destroyed in fire. The residence had no choice but to abandon the structure; but not before they savaged and reclaimed most of the wooden structural components, leaving only grounded timber poles which were once columns of the foundations, main beams of the floor, and scattered floor boards. It is most astonishing that with what simple stone tools the Hemudu residents possess, they were able to create these delicate joints and made it a habit to reuse and recycle the wooden structural members. Any structural component of a destroyed stilt house would be directly reused, serving its original purpose in a new construction if it were not physically affected by the destruction ${ }^{\left[1 W^{0} 03\right]}$. But if required, the Hemudu residents were flexible in altering the member to fit for other uses: sometimes a beam would be made into a column and vice versa, or a column into a foundation pole. When the large structural members were destroyed beyond repair or alteration, it would be recycled and divided into smaller structural components such as a floorboard and continues its service. [06]

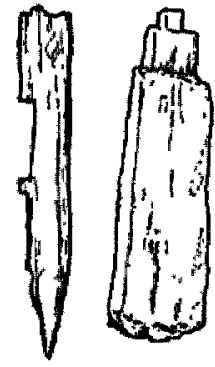

糟

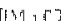

HeMuDu structural components. fabrication of a fentse

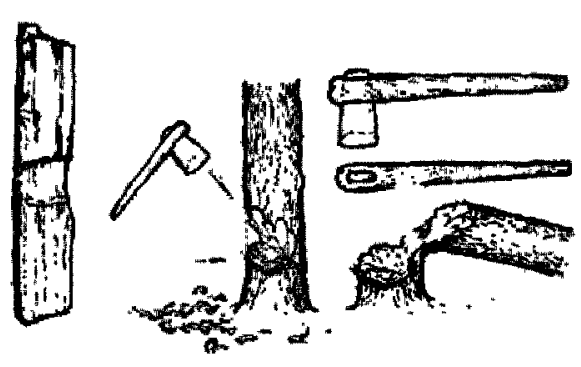

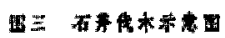

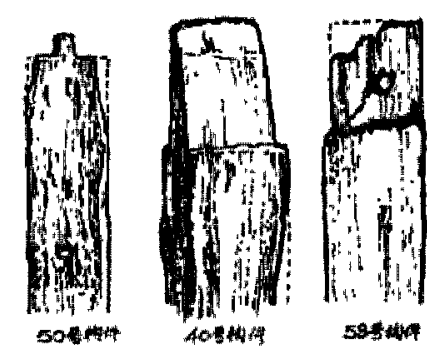

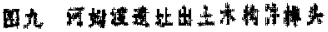

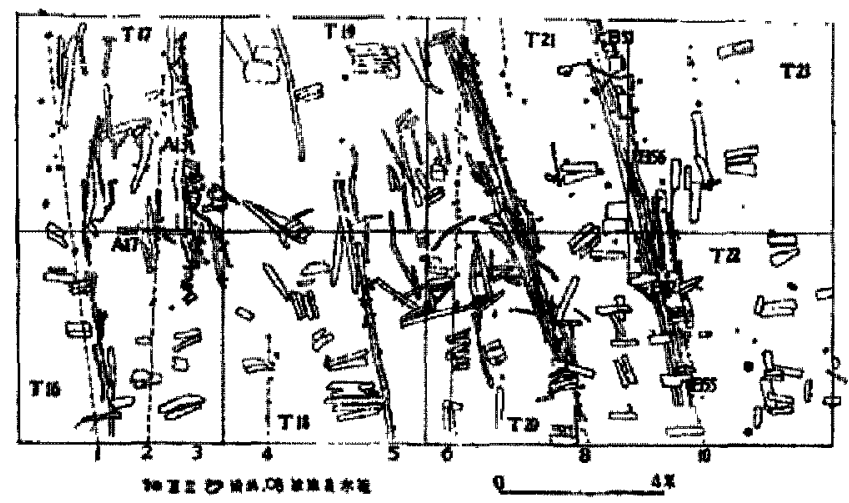

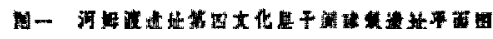

[Mn'ring Sile Plan: HeMuDu architecturd 
Though remnants of the Hemudu stilt houses during the height of Neolithic Era revealed much on their ground-breaking structural components in construction activities, and their appreciation of conservation in building resources; because of their ephemeral qualities, we know little of their spatial organizations and the relative social context.

What we know from the scattered information remained from the excavations within the same temporal setting is that tribal communities in China during this time are engaged in a very early form of society-a matriarchic clan communal society【母系氏族公社】. Up north at the edges of the vast Loess Plateau【黃土高原】， other forms of matriarchic clan communities found a very different way of inhabiting within nature-another important type of primitive hutscave dwellings, or in Chinese terms Xuésū 【c居】 .

It must be emphasized that architectural developments of this region are of particularly significant in the shaping of the overall architectural traditions. We know that two of the "Three Ancient Dynasties" I三代 . SanDaI \-Xia and Zhou-originate from this area along the middle reaches of the Yellor River Valley ${ }^{[1 \mathrm{MG} \text { 04] }}$. And in fact, as Yang has specified:

Terrains along the Yellow River Basin hosts the primary founding grounds of the Chinese culturethese are the earliest regions where hierarchical society was first developed in Ancient China. "The
Three Ancient Dynasty”【三代. SanDai 】 tribal slaveholding regimes were formulated and developed in these regions; legends of Prehistoric Eras as recorded in pre-Qin【先秦, XtanQin 】 classics generallv take staae in these domains. ${ }^{[07]}$

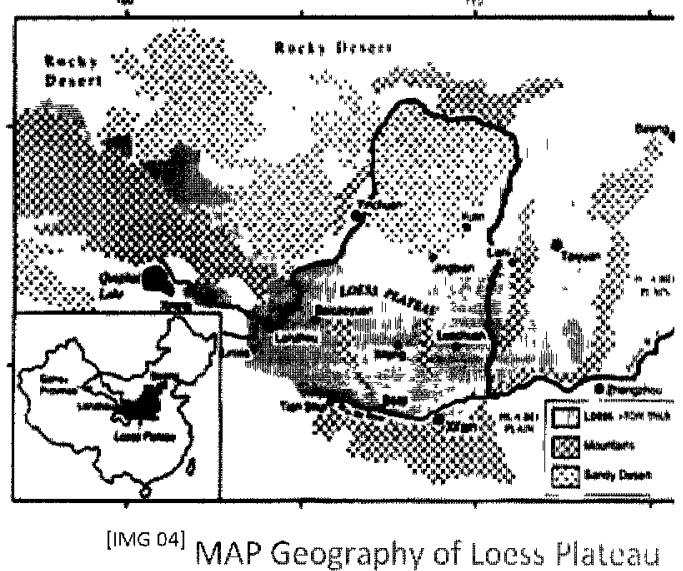

The cave dwellings on the Loess Plateau are different in essence when contrast with those from European Neolithic cultures. Perhaps the difficulties of artificially reconfiguring natural habitats, such as the Lascaux caves, has impressed upon the European ancestors in the late third millennium $\mathrm{BCE}$; and motivated them to develop masonry

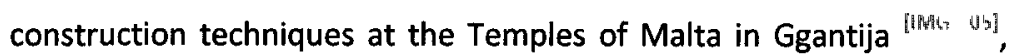
ones that reenact the Paleolithic cave dwelling experience. Though its interior space mimics the natural compositions of a cave, these temples are completely compositions of manmade form-built of local stone in forms of double shelled massive walls filled with earth and rubble. Kostof calls these temples the first true building type-an architectural form that is thought out and reproducible; ones that 
were invented for a specific purpose and achieves a general validity, both visual and ritual, through its repeated use ${ }^{[08]}$.

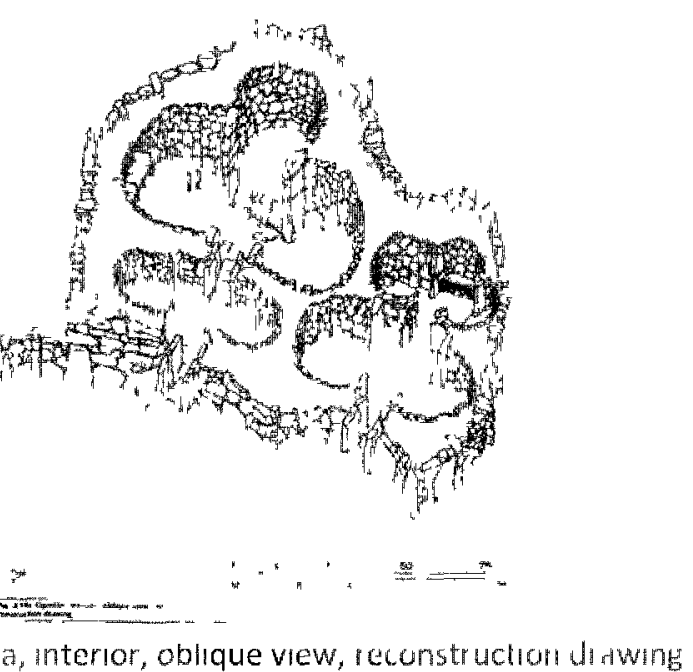

In comparison, we know many primitive tribes who were blessed with the unique geological properties of the Loess Plateau are the original inventors of the indigenous cave dwellings that are particular in the northern regions of Neolithic China. On the edges of the world's largest Loess Plateau within the steep valleys of the Yellow River, these primitive tribes utilized the richly fertile loess soil in their agrarian developments. Not only could the land be easily cultivated with simple Neolithic tools, the silty sediments-compiled in the millennium of its formation-could be almost effortlessly carved out and the soil itself is able to stand in vertical columns in dry conditions, thus sustaining interior forms of subtractive spaces. Though such loess structure is vulnerable in moist conditions and it could be easily collapsed when wet, such deficiency is rendered irrelevant given the relatively dry climates of the Plateau.

Along these fringes as the plateau levels down towards the river valley, many tribal communities took advantage of these geographical locations, explore the distinctive characteristics of what the land has to offer, and further advanced cave dwelling into its matured form: YaoDong【窑洞】 - a self supportive barrel space that is excavated into a vertical side of the loess hills. With three sides surrounded by solid

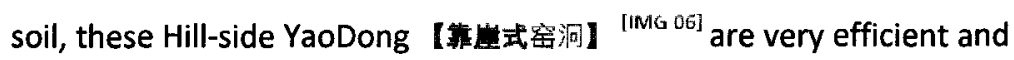
extremely economical to build, not to mention that they are naturally well insulated. Their interiors require little heating during winter, and they maintain a cool temperature during summer seasons. Where the loess ground is relatively leveled, the primitive tribes quickly adapted the constructions principle of these loess caves into a new level of artificial configuration. In creating a Submerged Courtyard YaoDong【井院式窑洞】， first they would dig open an underground, then each separate YaoDong would be formed along the internal sides of its walls. When completed, the land on top of such complex could be put into agrarian and community use. 

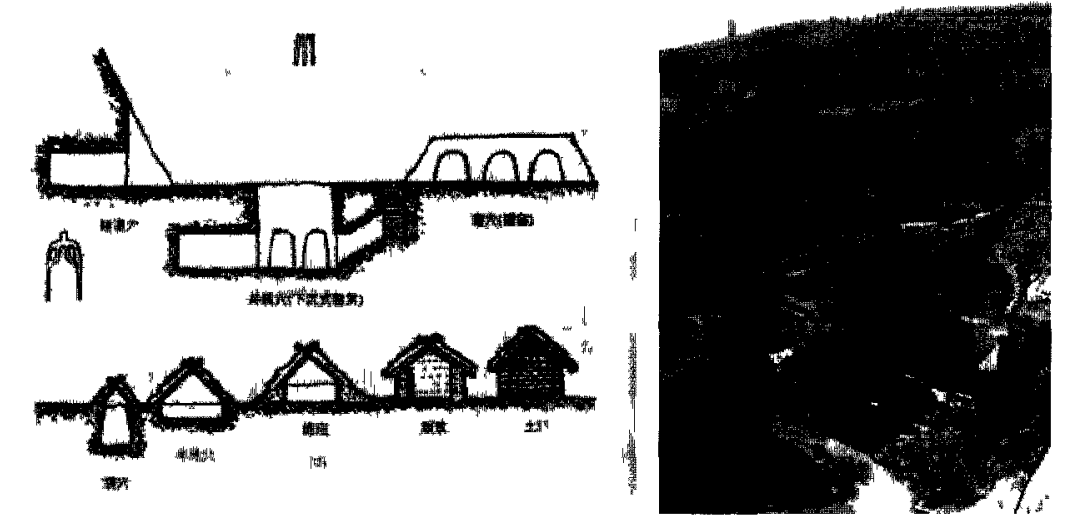

lliwk ${ }^{16}$ Transformation from Xuelu to YaoDong, Hill-side YauDong, Submerged Courtyard YaoDong Physical example Hill-side YaoDong

Repeatedly in his book Seven Comments on Traditional Chinese

Architecture, Zhang L.【張良臬】 stresses that these matured building typologies that evolved from primitive cave dwellings are the predecessors of traditional courtyard complex that are built on ground level. He further argues that,

...[b]ecause YaoDong is a particular architectural type that extracts space from solids-a "subtractive architecture", so to speak; such typology stands as an indication that Chinese architectural traditions have fully developed spatial conscious since prehistoric times, thereby consolidating a solid foundation of spatial aesthetics. Spatial aesthetics in Chinese architectural traditions is at least as important as its formal aesthetics. In the West, spatial conception generally yields to formal manifestation-even though courtyard designs are widely adopted from Egypt through Arabia and later to Spain and Italy, the spatial consciousness within their architecture is clearly a subsidiary consideration. ${ }^{[09]}$

Perhaps Zhang has over generalized in comparing prehistoric spatial aesthetıcs and its role in architectural development potn in the west and in the Chinese traditions, but it is worthy of extended speculations later in this analysis. Though the efficient and economic qualities of YaoDong typologies merit predominantly in China's loess regions; but as the primitive tribes expands and migrates away from the ridges of the Loess Plateau and ventured onto the alluvial plains, new geological challenges expedited further evolutions of cave dwellings.

Located immediately east of the historical city XiAn, the largest known Late Neolithic village site BanPo【半坡】 is about a millennium younger than the Hemudu settlements. On the river banks of ChangHe

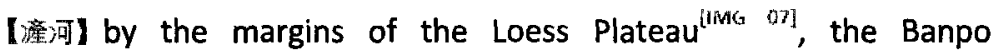
resident-descendents of the ancient DiQiang [氏羔] aboriginalscontinued the evolution of cave dwellings that are progressively independent from the advantages and limits of the flattened loess soil. Like other tribal communities of the YangShao Culture【仰韶文化】 (5000 BCE - 3000 BCE) along the middle reaches of Yellow River, the sedentary Banpo society experienced a relatively rapid transition from cave dwelling to raised housings. 


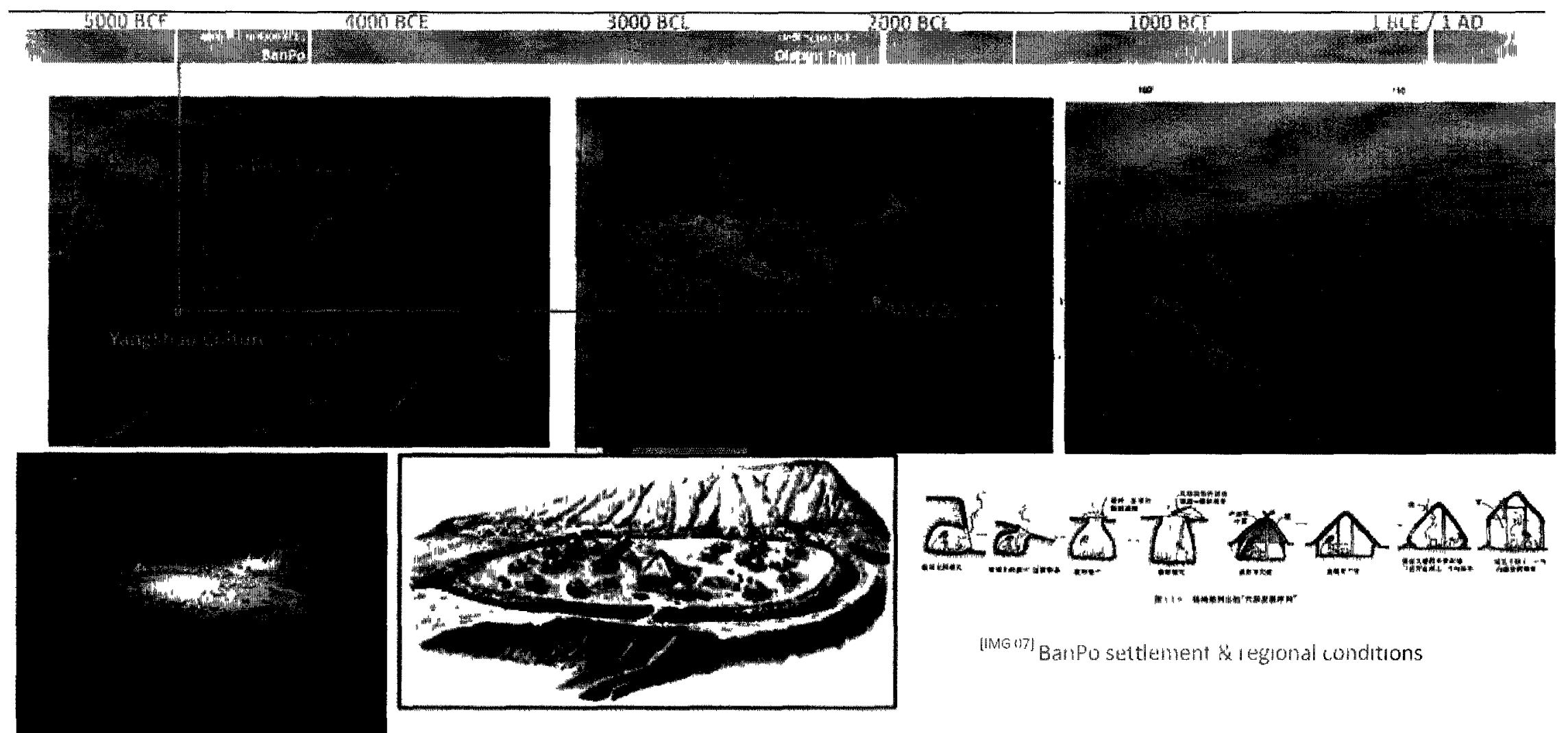

Yang has categorized its development into three phases. Dwelling found in the earliest stage were all semisubterranean dwellings【半穴居】. While the bottom part of a typical primitive hut during this phase is a subtractive space vertically dug about $80 \mathrm{~cm}$ from the ground level down; the top component consists of a canopy, usually a

mud-plastered roof structure or a branching framework covered with

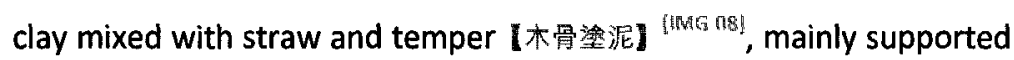
by one or more grounded vertical central posts. Structurally speaking, such semisubterranean dwellings laid the foundations of Earth and Timber Intergrated Structure【士木混合結櫣】 for later Chinese architectural standards. ${ }^{[10]}$ In fact, in later developments, rammed earth and wood framing had become such important techniques throughout Chinese history that the ancient called building 
construction the "work of earth and wood" 【土木】 - a term still in use in our present days.

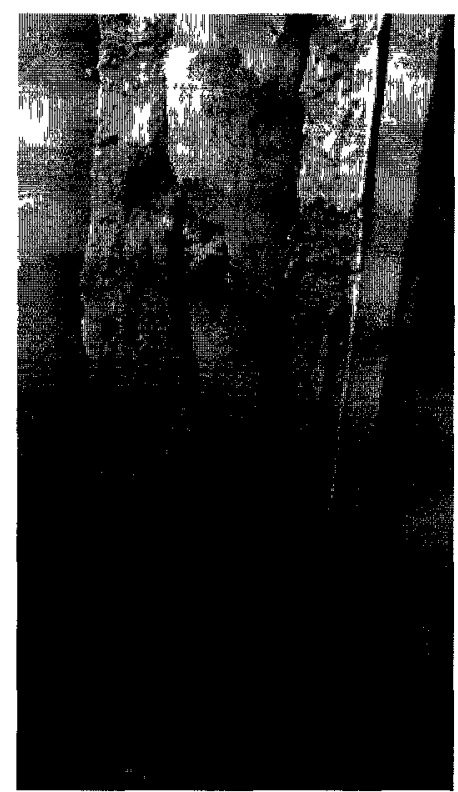

[IMG O8] LATER EXAMPLES OF CLAY PLASTERED WOODEN

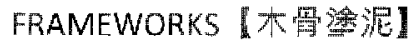

The fundamental characteristic manifested in the dwellings from the middle phase is the advanced constructions with wood as the structural material. It seems that the Banpo villagers have cultivated a more sophisticate understanding of wood framing, thereby allowing them to replace the loess walls of semisubterranean dwellings with artificial vertical structure. With much of its construction methods were borrowed from roof structure, the concept of weight bearing vertical element was established. Therefore, it would come as no surprise that the living surface during this phase is generally raised upwards to the ground level, and internal spaces are essentially enclosed by earth-plastered walls internally framed with wooden frameworks. Banpo residents have also further developed structural components such as rafters and horizontal tie beams in conjunction to the improved central poles. Structural connections of these different elements were different than the mortise and tenon joineries of the HeMuDu residents, but rather crude junctions of naturally forked timber reinforced with rustic braiding ${ }^{\text {[IMG } 09]}$. The most significant of all is in the division of vertical elements used as central posts and also in

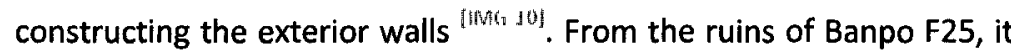
is apparent that the villagers have applied wooden posts of two different sizes: the load bearing posts measured up to $25 \mathrm{~cm}$ in diameter, and the filler branches ranged from 5 to $10 \mathrm{~cm}$ in diameter. In Banpo F24, it is evident that the load bearing posts were arranged into a grid formation.

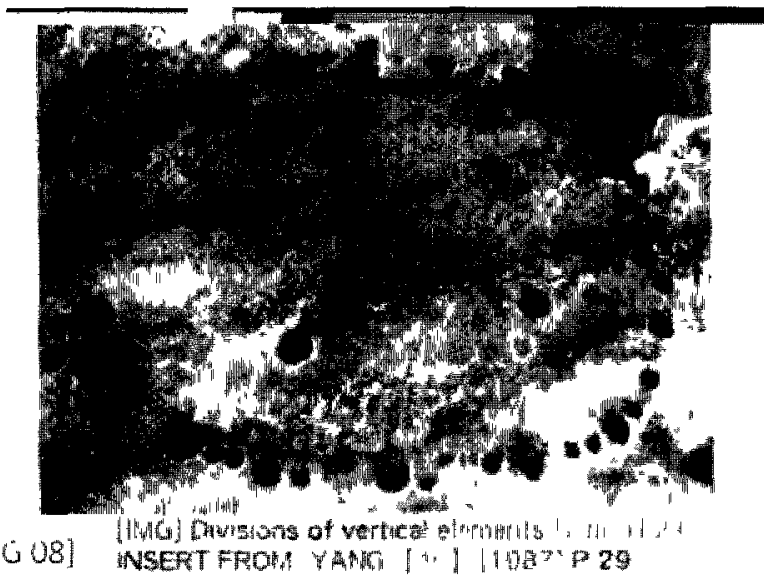



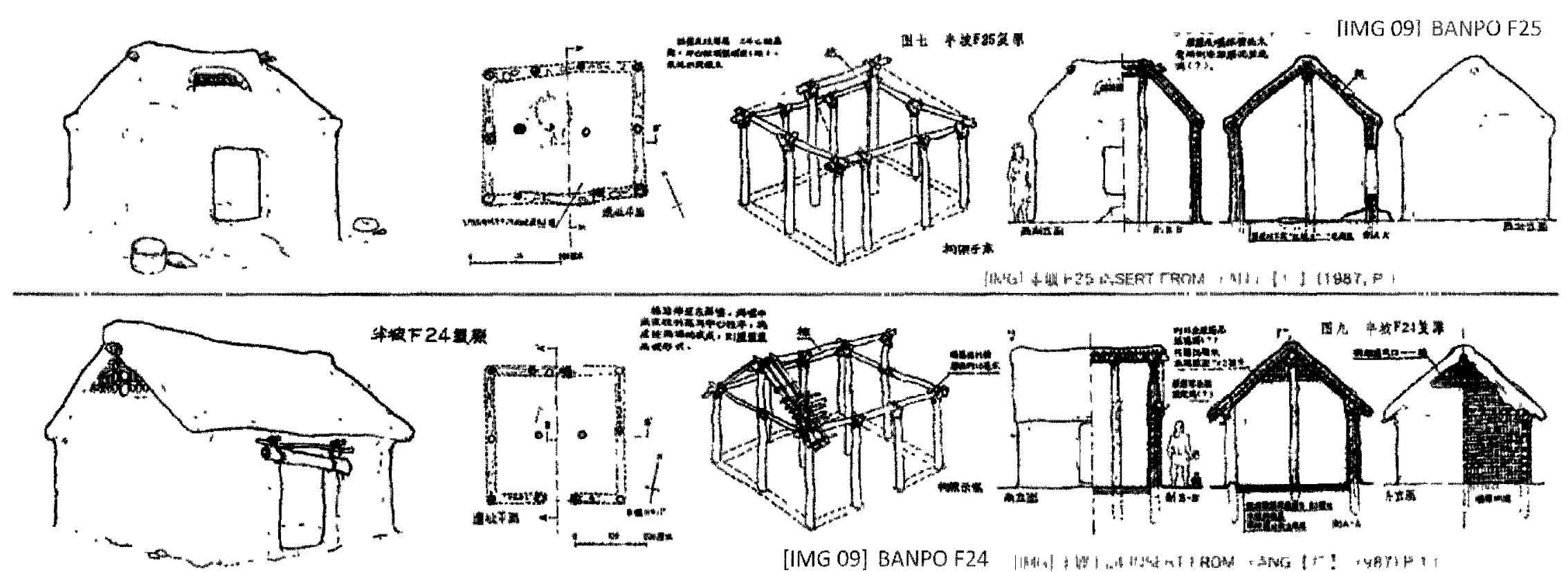

Yang argues that this is the first specimen of Jian 【間1，a spatial module unit that would later matured into a fundamental design principle of the traditional Chinese wood frame architecture.

This is a very important archetype. It indicates the formulation of China's disposition in utilizing the JianJia /為架J as the basic unit of the classical wood frame structure-one that stress the independence of load bearing elements-in the Chinese manner of speaking, "the house stands even when the walls

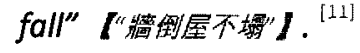

According to the Carbon14 determinations of structural remains from the early and middle phases, Yang was able to gather these developments took about three to four hundred years to complete ${ }^{[12]}$; however, this relatively rapid advancement pales in comparison to the 
As Yang has inulcated in nis plaris arlu sections of Banpo F1, the Banpo residents have developed a primordial concept that would be later developed into a fundamental spatial organizational principle of Chinese architecture-public hall at the front and private room(s) at the back【前堂後室】. Yang suspect that while the front hall served as a gather space for ritualistic purposes, the divided rooms at the back were reserved as dwellings for both the leaders, the most respected "grandmothers" in the village, and also as the residence for dependent members of the Banpo society-the old, the young, and the wounded. The purpose of such centralized living arrangements at the nucleus of the settlement was to maximize the efficiencies of communal care. It reflected the united endocentric social structure as characterized in clan communal societies【氏族公社】.Yang further explained that,

When the primitive communal societies collapsed and replaced by [stratified societies] established [upon] slavery systems; the most advanced structure amongst the estate left by the primitive society-the Big Houses-would most definitely be dominated by slave lords. Its content and context would be further transformed, and evolved into the first royal estates of the ruling class in [Chinese] history. As evident in The Record on The Examination of Labours 【考工記】, the palace of Xia Dynasty has inherited the previously discussed spatial organizational principles from the Big Houses, in which public halls were placed at the front and private rooms were located at the back 【前朝缕寝】. Moreover, preliminary evident were found at the ruins of early Shang palaces, which followed the traditions of the Xia regime. ${ }^{[13]}$

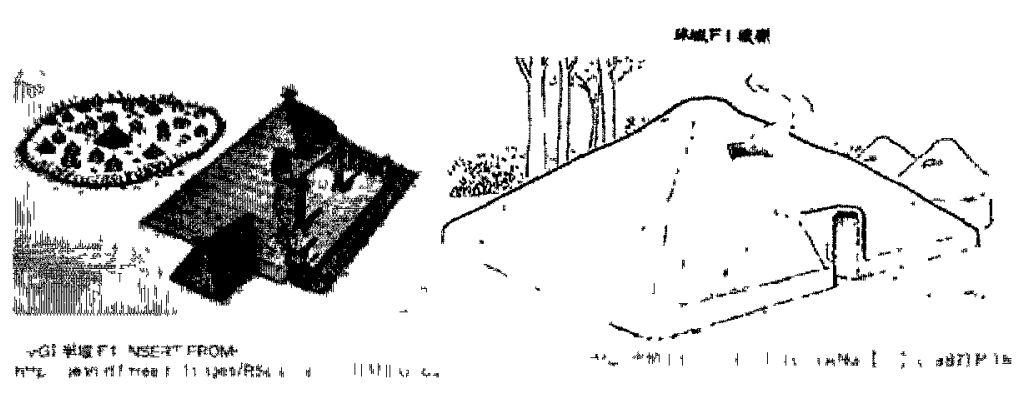

[IMG 10$]$ RHAPo F1. Big House

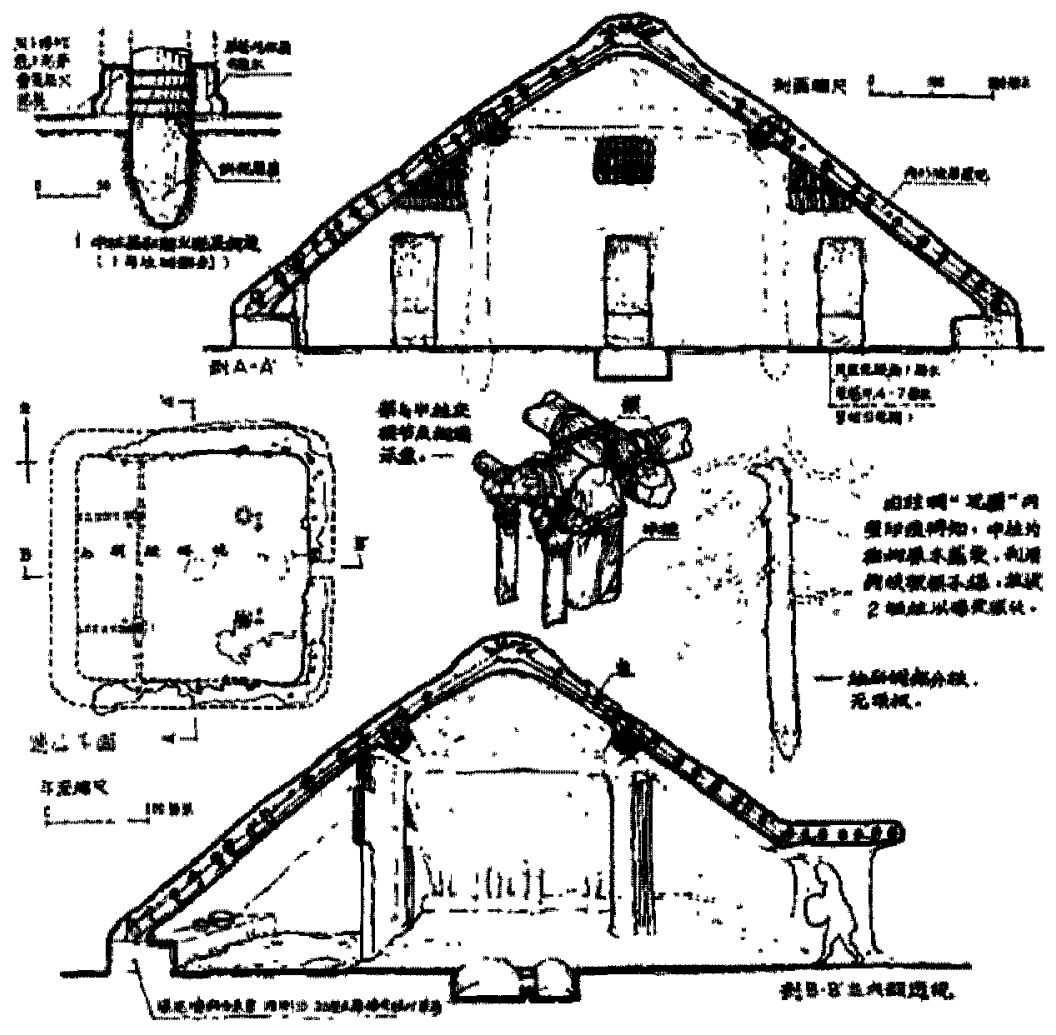


Like other Neolithic settlement, the Banpo village was surrounded by a main moat that was five to six meters deep and wide built for draınage and defensive purposes. Inside the settlement, smaller moats were dug to separate different districts accordıng to their specific purposes (i.e. residential, pottery workshops, etc) and to drain precipitations. The Big House surrounded with a large open plaza was enclosed at the center of the settlement with many small common huts within the perimeter of the moat. Yang suggests that the limited production abilities of YangShao societies could only afford to build habitats for human living purpose, therefore storage facilities remained undeveloped and took form as numerous simple vertical burrows that scattered across the site ${ }^{[\mathrm{MmG} 11]}$.

As matriarchic clan communal systems of YangShao culture gradually transforms into patriarchic clan communal societies of LongShan 【龍山】 culture, which emerged sometıme around the third millennium BCE, clan settlements similar to the Banpo village were further expanded into towns, and dwelling constructions continued to develop both subterranean and aboveground. Some historians have suggested a correlation between LongShan cultures with the Chinese mythical timeline of WuDi【五帝】 -the "Five Emperors" period. But with little evidence to precisely indicate sophisticated developments of social stratification, it is only safe to conclude that such societal transformations have not disrupted the continual developments of timber and earth architecture withın both the communal and the common realms of Neolithic settlements.

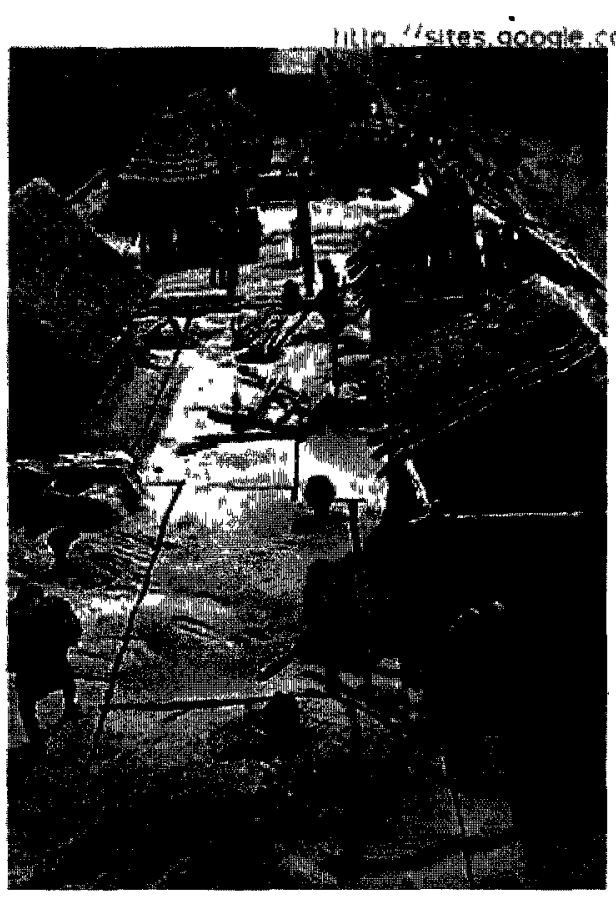

[MG 11] Rampo Vilage \& Building lectonics

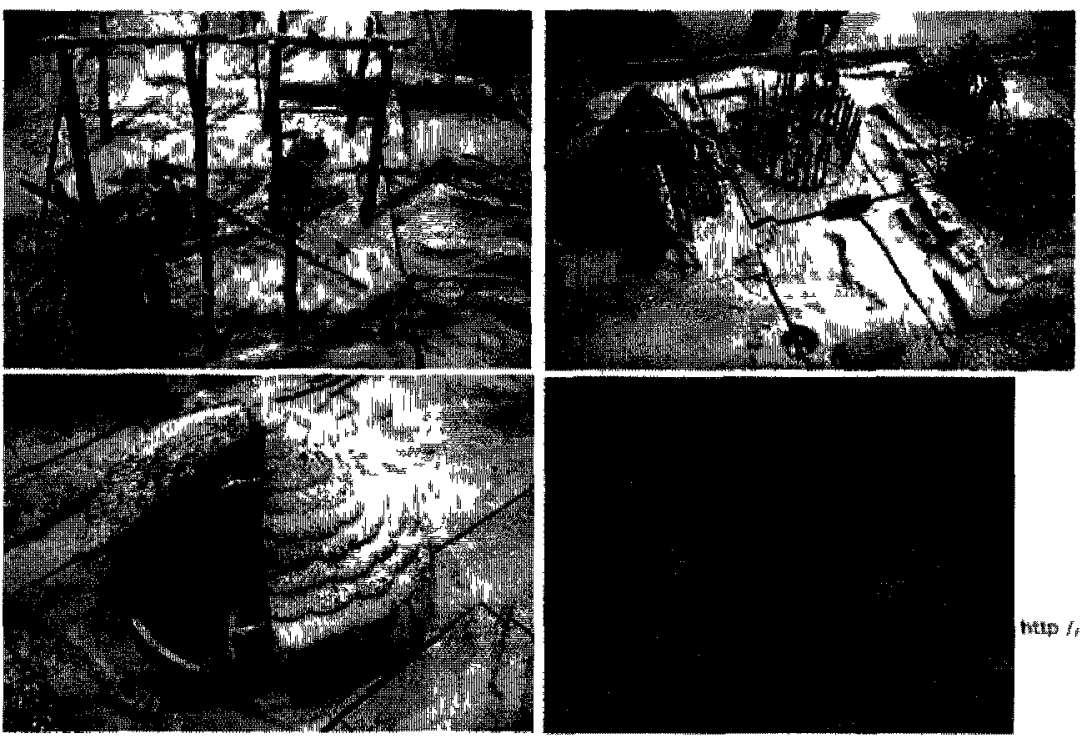




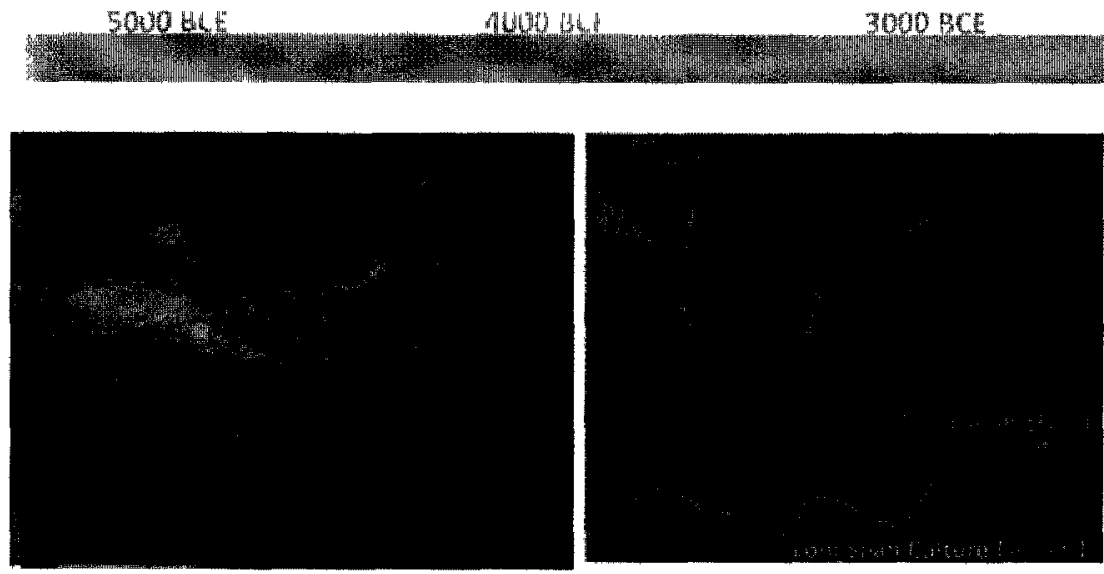

We do know for certain that, during this late period of HanFeizi's

【非子】distant past, individuals with specific contributions to the tribal collectives were rewarded with leadership status. The larger prehistoric tribal societies were occupied under a somewhat democratic system in which coalition leader was elected by all tribal leaders of the alliances before appointed by the previous leader, rather than successions by blood. Also relative to earlier stages, we find social dispositions of privatization when approaching the end of primitive societies; but fundamentally, the societies were still operating under primordial communal principles. ${ }^{[13}{ }^{11}$ Andrew Boyd, in his book Chinese Architecture and Town Planning, elaborated on such social conditions:

...the Neolithic tribal organization...[was] based on the clan commune as the social unit, a village or group where all were related, in which weapons were owned individually but land, houses and tools were owned in common, administered collectively but with an elected head...The tribe is thought to have been formed out of neighbouring clancommunes led by an elected tribal chief, and the tribal alliance to have been formed from neighbouring tribes, with a head elected from amongst the tribal chiefs. ${ }^{[14]}$

According to Confucian literati, this was the period of the Grand Union society 【大同社 I，in which the Grand Course 【大道】 was pursue by all. The details of such social conditions were described in

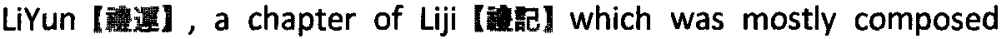
during the Warring States period:

... a public and common spirit ruled all under the sky; they chose men of talents, virtue, and ability; their words were sincere, and what they cultivated was harmony. Thus men did not love their parents only, nor treat as children only their own sons. A competent provision was secured for the aged till their death, employment for the able-bodied, and the means of growing up to the young. They showed kindness and compassion to widows, orphans, childless men, and those who were disabled by disease, so that they were all sufficiently maintained. Males had their proper work, and females had their homes. [They accumulated] articles [of value], disliking that they should be thrown away upon the ground, but not wishing to keep them for their own gratification. [They laboured] with their strength, disliking that it should not be exerted, but not exerting it [only] with a view to their own advantage. In this way [selfish] scheming were repressed and 
found no development. Robbers, filchers, and rebellious traitors did not show themselves, and hence the outer doors remained open, and were not shut. This was [the period of] what we call the Grand Union. ${ }^{[15]}$

The legendary battle, between the alliance of HuangDi【炎帝】and YanDi【稀】 from the Yellow River basin against the JiuLi tribal groups【九糸】 from the Southeast led by ChiYou【贵尤】for the control over the Central Plain regions 【中原 . ZhongYuan 】 ${ }^{[14-1]}$, marked the beginning of the eras of chiefdom societies, which Chinese archeologists often refer to as tribal alliances. With his victory, HuangDi【蒡】 was ultimately established as the first alliance leader and was generally accepted as the founder of the HuaXia [榡晋] civilization. Many eminent figures of this period, though they were customarily referred to as "emperors" in Chinese mythologies, were in fact by modern definition talented military leaders within the tribal alliance who have proofed themselves worthy of great responsibilities; and were nominated and appointed as the leader of the entire alliance by the majority of tribal leaders.

There are reasons to believe that increasing cultural exchanges between a variety of prehistoric ethnic groups-predominately, Eastern $\mathrm{Yi}$ 【東真】 tribal groups who learned much from the Ancient Yue 【盍I migrants from the south into the northern plains along the eastern coasts (e.g. the HeMuDu residents); and progenies of ancient DiQiang【低】 who spread towards the east from the West along the
Yellow River (e.g. the BanPo settlers)-contributed to the ethnic amalgamations of the HuaXia【萃】 culture. Very much similar to the influences of prehistoric Aegean civilizations extended on later developments of Greco-Roman Mediterranean culture in general; the synthesis of HuaXia civilization is immensely significant to the evolutions of Chinese traditional societies.

Xia

The primitive patriarchic tribal systems would soon collapse as HanFeiZi's【輤非子】 distant past drew to an end with the epic event of the Great Flood of Yellow River which took place at around 2100 BCE. During this time, the course of the river's lower reaches was completely altered and vast regions of the Central Plain were

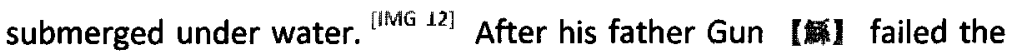
assignment of taming the flood by containment and sentenced to execution as punishment, Yu【西】 was appointed by the coalitional leader Shun to continue his father's work. According to legends, it took $\mathrm{Yu}$ thirteen years to complete an alternative approach to drain and diverge the flood into different rivers and seas. In order to do so, $\mathrm{Yu}$ exerted himself intensively to survey and examine the relative geographies of the affected areas. With only two appointed assistances from his tribe, much of the work carried out in different geographical locations required the collaborated efforts from a variety of local tribes of different ethnicity. Perhaps Yu's extensive works in reducing 


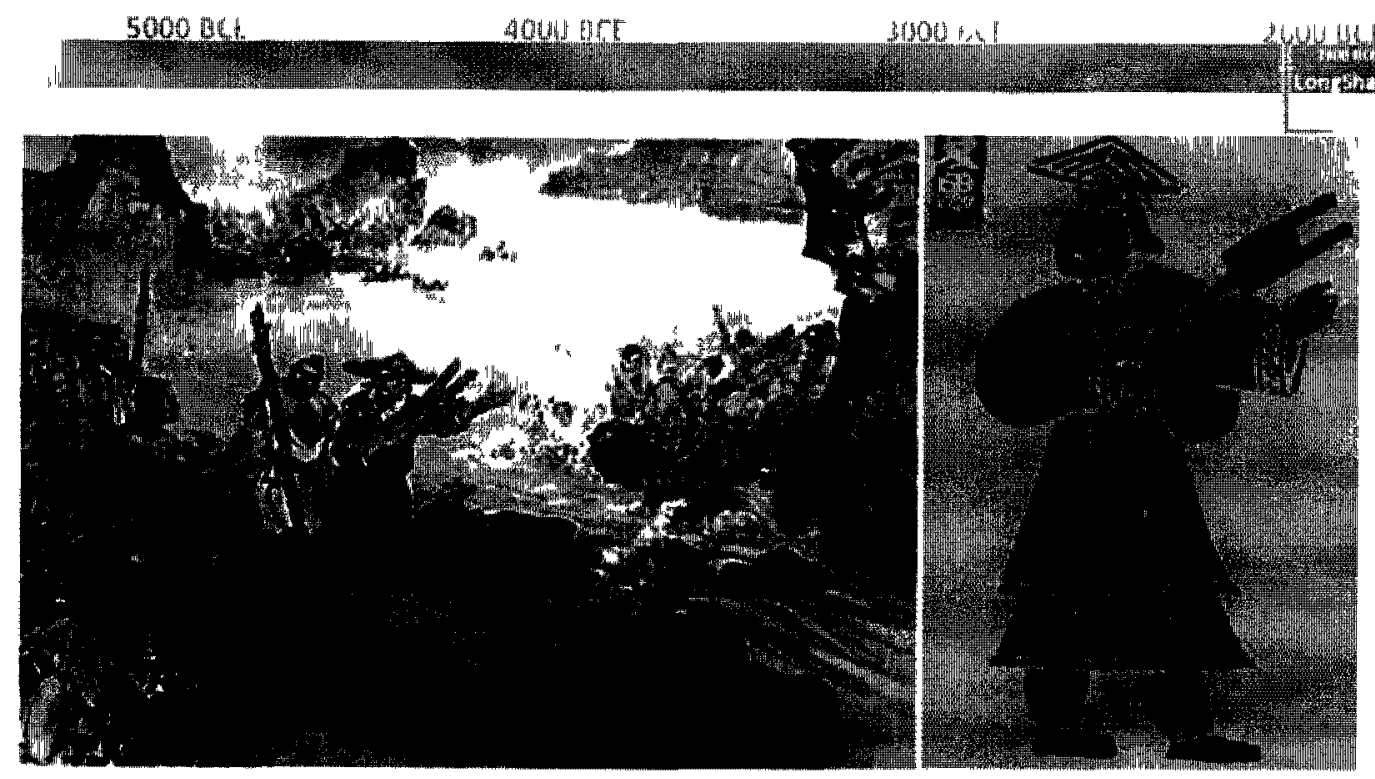

[IMG 12 ] Yu the Great and changed paths of the Yellow Ruel

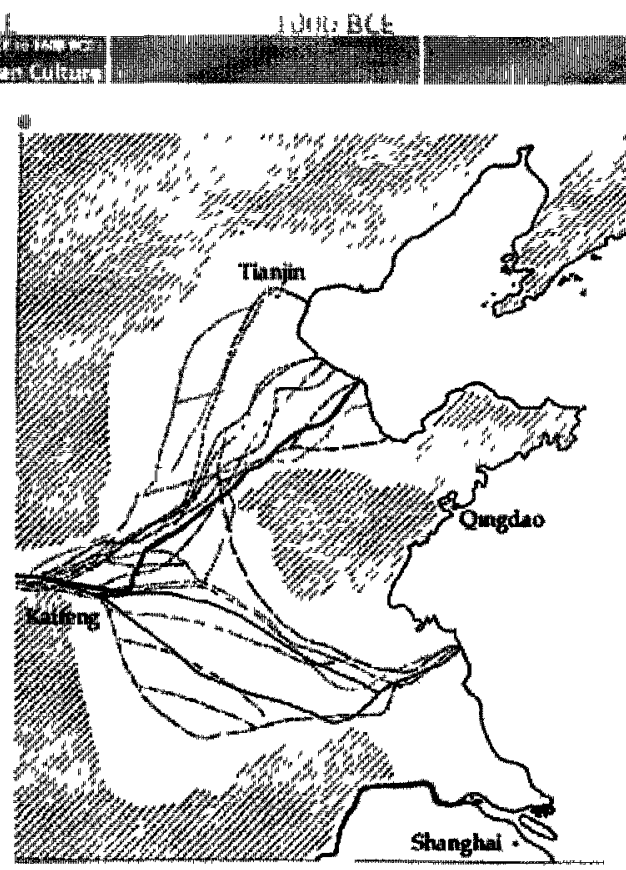

the flood has resulted in further intensification of tribal interactions between different regions.

Yu's accomplishments and dıligence have gaıned him much celebrated reputations amongst many tribal leaders. He later succeeded as coalitional leader after Shun has abdicated his position, and he was recognized as Yu the Great. Yu's ambitions have driven him to further extend the social systems of tribal alliances beyond the conventional, relatively isolated independent organizations. With his experience and

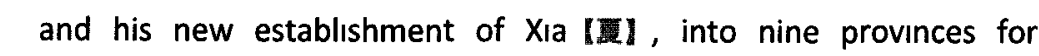
admınistrative purposes. ${ }^{\text {[IMG } 13}$

...[H]e ordered nine [d]ing tripods, or the Nine Tripod Cauldrons (thI to be cast in metal brought as tribute from each of the nine provinces, and decorated with representations of the remarkable things characteristic of each region... From dynasty to dynasty they were handed down as the palladia of empire, but at the end of the [Z]hou they were lost. knowledge of the larger geographical context of the Central Plain regions, Yu divided the territories, which subjected to his leadership 


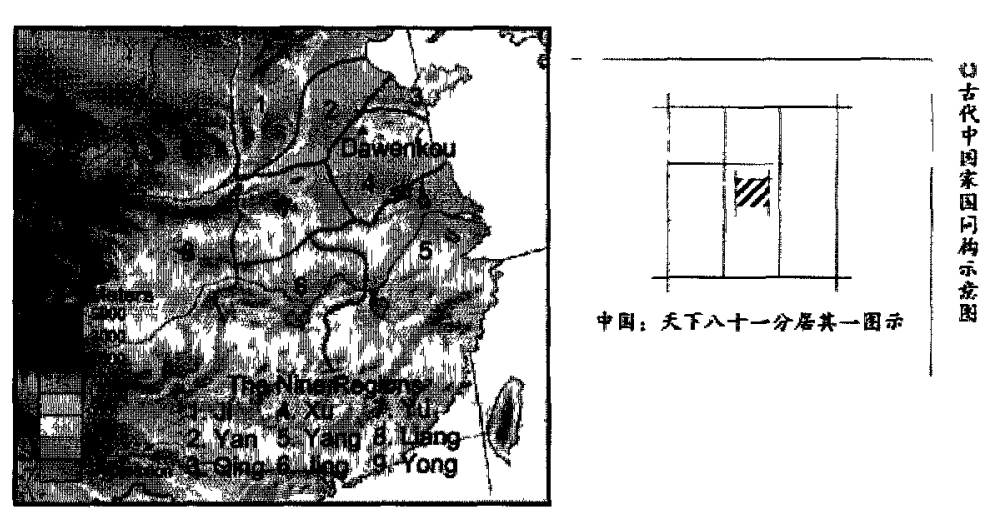

[IMG 13] XIA division of Nime Regions \& Yu's claim of the central position Bottom Ancient position of Son-ufuHeaven in relationship to the enture construct of the world.

The complete demise of communal attributes of the tribal societies was inevitable when $Q_{i}$ If d $^{\prime}$, Yu's son, rebelled against the conventions and argued that his father has extricated the world from great devastations; therefore, $\mathrm{Q} i$ believed the leader status of the tribal alliance should be rightfully claimed by his family rather than elected by all tribal leaders within the alliance. He was determined to privatize the world for himself and his decedents and he did not hesitate to resort to military forces to eliminate and enslave opposing threats; thus setting the precedence for a new hereditary system, and began the eras of slave societies on which the ancient Three Dynasties 【三代】 were established upon. Confucian literati belıeve that this was the beginning of a new order in which the Grand Course【大道】 was obstructed and fallen into obscurity. This new society in general have departed from the states of Grand Union【大同】 :

...the kingdom is a family inheritance. Every one loves [above all others] his own parents and cherishes [as] children [only] his own sons. People accumulate articles and exert their strength for their own advantage. Great men imagine it is the rule that their states should descend in their own families. Their object is to make the walls of their cities and suburbs strong and their ditches and moats secure. The rules of propriety and of what is right are regarded as the threads by which they seek to maintain in its correctness the relation between ruler and minister; in its generous regard that between father and son; in its harmony that between elder brother and younger; and in a community of sentiment that between husband and wife; and in accordance with them they frame buildings and measure; lay out the fields and hamlets Ifor the dwellings of the husbandmenl; adjudge the superiority to men of valor and knowledge; and regulate their achievements with a view to their own advantage. Thus it is that [selfish] schemes and enterprises are constantly taking their rise, and recourse is had to arms; and thus it was [also] that Yu 【禹】，Tang 【皘I，Wen 【奴】 and Wu 【武】，king Cheng 【文王】, and the duke of Zhou [/用公】 obtained their distinction. Of these six great men every one was very attentive to the rules of propriety, thus to secure the display of righteousness, the realization of sincerity, the exhibition of errors, the exemplification of benevolence, and the discussion of courtesy, showing the people all the normal virtues. Any rulers who did not follow this course were driven away by those who possessed power and position, and all regarded 
them as pests. This is the period of what we call Small Tranquility [/小]. ${ }^{[17]}$

This period of the intermediate past $(\sim 2070$ BCE to $\sim 1600$ BCE) concurrent to the founding phase of a new stratifying social order is critical to further comprehend cultural evolutions of HuaXia culture and to the later ancient Chinese culture of which it precedes. Such radical social transformation had immense impact in the shaping of Chinese architectural traditions. Unfortunately, reliable scientific evidences to shed lights on the architectural transitions from late Neolithic to Bronze Age are scarce. Though the emergence and the existence of Xia has been repeatedly mentioned in numerous cultural references throughout Chinese history, the earliest comprehensible linguistic system established later in Shang Dynasty-which was ruled by an eastern tribe who led the conquest to overthrow the Xia regime-offered no description of Xia's presence. But if we focus on records of these drastic social transitions from historical sources written in later periods, we could begin to understand many founding principles of Chinese traditional architecture.

Perhaps these late Neolithic epics of early Xia were only coincidental to the imminent introduction of bronze and its disruptive forces in shattering the equalitarian and cooperative structure of tribal society. Boyd justified that the individuals' initiatives taken in improving bronze technologies inevitably became incidental to aggressive intentions of advancing themselves at the expense of others, to seize communal property, to acquire dependents and political power; and thus began the "spectacular advance to civilization" ${ }^{[18]}$ with emerging conceptions of private property, competition, social classes, slavery, despotism and luxury. Whichever the pivotal factor was in the formation of China's first main historical period ${ }^{\mid \mathrm{AU} U \mathrm{TE}}$-slave societies were the first of two main forms of socio-economical systems-we are certain that modes of living during early phases of the ancient HuaXia civilization were continued from conventions inherited from the diverse primitive cultures from previous periods.

\section{Geographic Integration}

While the social organizations of the HuaXia civilization during the three ancient dynasties-Xia, Shang, and Zhou-gradually transitioned from tribal alliances to states alliances, it is important to note that ruling families of the different dynasties were actually three originally distinguishable cultural groups developed in different areas. Zhang L. specified that it is crucial to understand the distinctive architectural approaches of these cultural groups and their contributions to the comprehensive architectural developments of the HuaXia civilization. While the majorities of Xia and Zhou subjects were descendant of ancient DiQiang cave settlers from the west ${ }^{[19]}$; the famous Han

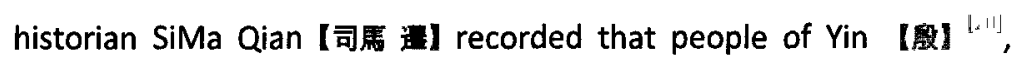
who were rulers of Shang, originated from the Southeast. It is highly possible that the Shang culture was more intimate with the BaiYue lineages $^{[21]}$ and the people who were most accustomed to stilt dwellings. While such speculations were grounded on many 
established cultural references, with few extant artifacts and scientific support available from excavations, we could only conclude that the plurality of the simultaneous origins of prehistoric Chinese civilization across the vast regions of ancient China-in the Yellow River valleys, Yangtze River basin, and the Liao River regions-have all contributed to the genesis of Chinese architectural frameworks. We find the most influential architectural provenances of the Central Plain regions 【中原.ZhongYuan】 have directly contributed to architectural developments of the ancient HuaXia civilization.

\section{Social Restructure}

\section{Professor Wang QiJun 【王其均】 of QingHua University}

【清程大】 explained in his book 30 Topics on Chinese Vernacular Dwellings:

Following the establishment of private ownership, the class system emerged. Such led to stratifications within the human social context-there was a ruling class of slave lords, and a slave class who submitted to their dominations, and also a general class of the common people. In response to the strata of individual ranks, it was apparent that houses for the purpose of living were also divided hierarchically. Slave lords, especially governing aristocrats at the top of the social pyramid, were privileged to dwell in palaces and royal courts; while common civilians would only afford to reside in houses of simpler constructions. We should say, such was the beginning of the term MinJu [民居J-which has since been used to describe vernacular dwellings of the commoners-as opposed to Guānfāng 【官方】 and royal architecture. ${ }^{[22]}$

This period, which lasted until the end of Bronze Age in China, was critical in shaping many customs and institutions found throughout the rest of Chinese history. Because of its importance; as difficult as it is with limitations of the few available sources, it is necessary to attempt investigating in the origins of Chinese architectural contexts during the beginning stages in the maturation of the HuaXia civilization.

Restricted to socio-economical conditions during the early Bronze age, architectural development in the Central Plain regions is relatively slow. Generally, dwellings for commoners and slaves remained relatively rudimentary at a level quite similar to the subterranean caves and surfaced huts built by the BanPo settlers. These longestablished modes of dwellings persevered well into the Xia and Shang Eras of the early Bronze Age, such were determined by the socioeconomical conditions of the ancient slave societies. Confined to conventions inherited from primeval societies and given the relatively elementary methods of production, ceremonial and palatial edifices of royal rulers were also unable to depart far from the primitive constructions of “straw thatched roofs and earth terrace”【氷茨土谱】. [23]

In his book Aesthetics of Chinese Architecture, Professor Hou YouBin 【候 幼须】 draws examples from the ruins of palatial complex 


\section{discovered at the ErLiTou 【二里賏】 archeological site near the modern}

city of LuoYang【洛禺】 from $1800 \mathrm{BCE}$ to $1500 \mathrm{BCE}$; and articulated that these earliest progress of architecture during the beginning of HuaXia civilization clearly continued on the predisposed path of Earth and Timber Integrated Structure【土木混合結構】 in its primal articulations of straw thatched roofs and earth floors [萐茨土陼] ， ${ }^{124]}$ These sophisticated groups of palatial complexes within the exceedingly large town center of the early Bronze Age shared similar attributes:

...here were courtyards built above rammed earth platforms, and on top of which, pounded earth foundations of the palatial hall. Here were mud-walls built with internal wood frames and rammed earth walls. Here were orderly arrangements in the arrays of load bearing wood posts. Here we could identify the three-part compositions of classical structural formation in Chinese architecture: the roof, the vertical body, and the platform. Here we could find the classical courtyard configurations enclosed with internal galleries, and the apparent classical spatial principles of threshold and main hall relationshipthe MenTang formal composition (門堂满成形態】 in the articulations of main entrances and palatial halls. ${ }^{[25]}$

Compared to the subterranean cave dwellings and the surfaced huts, which Hou referred to as the first and second generations of Earth and Timber Integrated Structure【土木混合結構】 respectively, the third generation as demonstrated in ErLiTou's palatial compounds is primarily distinguished by the integration of timber structure with the employment of rammed earth techniques ${ }^{[26]}$. Rammed earth, also known as,

...[p]ounded earth [, or terre pisé], is the ubiquitous market of ancient architecture for modern archaeologists. The technique usually required excavating a trench or foundation with a level base, then refilling that cavity with thin layers of loose soil placed inside rough wooden forms. The raw soil was compacted into hard layers approximately 5-15 centimeters in thickness by laborers using pounders. [IMGG 14] The procedure was repeated until a total thickness of a much as much as several meters was attained, a laborious and time-consuming technique. The top surfaces of pounded-earth platforms, when cleared today by archaeologists, still bear the pock marks produced by this process. Large walls or foundations might require that enormous volumes of earth be dug, moved and pounded. ${ }^{[27]}$

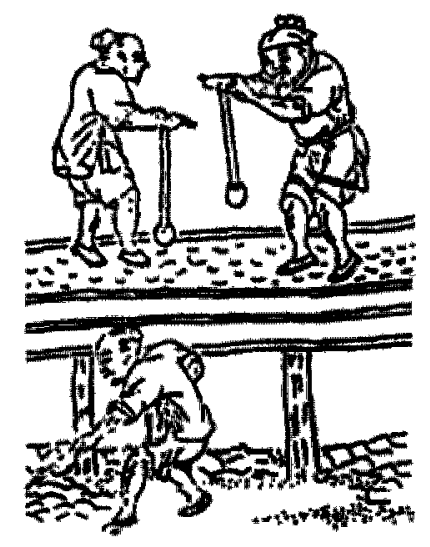

[MG Ital pounding Earth Techniqute 
Given the level of building technologies throughout the Bronze age, the invention and continuous implementation of rammed-earth constructions require extensive labor forces, which would only be affordable given the social parameters of slave societies Evolved from its original purpose as a military defensive mechanism, the strengths of rammed earth constructions were quickly utilized in institutional projects serving the needs of authorities. It enhances the nascent timber frame structures by providing height and grandeur as its foundation. The rammed-earth platforms also compensate the weakness of wood as a building material by elevating the structure from flood and protection against moisture capillarity.

Inherited building traditions and construction experience from the yellow-loess region, and further supported by the rammed-earth platforms, the Chinese fully utilized the natural advantages of timberframe structures. The traditional benefits of timber structure are mostly associated with its efficiency. It is a sustainable natural resource that is easily attainable from local regions; therefore the need for transportation is greatly reduced. Timber is fit for semi-dry climates of the immediate yellow-loess environments. Most important of all, the material is convenient to work on and the craftsmanship is not labor intensive. Simple tools used in primitive agriculture could be conveniently adapted in building constructions. In short, based on resourcefulness, on environmental conditions, and on technical aspects; the ancient Chinese's persistence on cultivating timber construction advancements was a rational and realistic disposition. ${ }^{[28]}$

In terms of structural assemblage, Yang gathered from the reminisce of the column grid from complex foundation 1 found inside ErLiTou's palatial city I官城 . GongCheng I and determined that forked timber posts were employed to support beams and rafters. Tying beams might have been used in between these posts. It could be possible that some simple mortise and tenon joineries were applied, but ErLiTou resident would still depend on braiding reinforcements for more complicated connections. ${ }^{[29]}$

Lastly from a design perspective, the weaknesses of early timber structure lie in its inability to accomplish monumental scales as an architectural composition of massive structure. By overcoming such limits with the integration of rammed-earth techniques, Li believes that the primary rationales in developing a mainstream discourse of timber structure is justified as the most rational and the most perfect architectural mode of construction. ${ }^{[30]}$ In every prospect, timberearth integrated construction-one which synthesizes the efficiencies of timber structures and the substantial advantages of rammed-earth techniques-was in fact the most logical and pragmatic approach to architecture given the socio-economical conditions of the slave societies of Bronze Age China.

Beyond basics of construction methodologies, spatial components of Chinese traditional architecture were also defined during the early Bronze Age. Ever since the establishments of primitive societies, prehistoric settlements such as the Banpo village have displayed a strong converging disposition with its focus in the open courtyard, which underlies most planning principles. As we have seen in the 
example of the Banpo village, within a typical Stone Age settlement, the area is divided into areas of specific purpose,

Residential area was composed with groups of single dwellings, which were arranged in specific orders. At the center in each small group of residential dwellings, the entrance of every individual dwelling opened towards a "Big House"-the central building which facilitates communal activities for all members of the patriarchic clan. ${ }^{[31] \text { [HWG 15] }}$

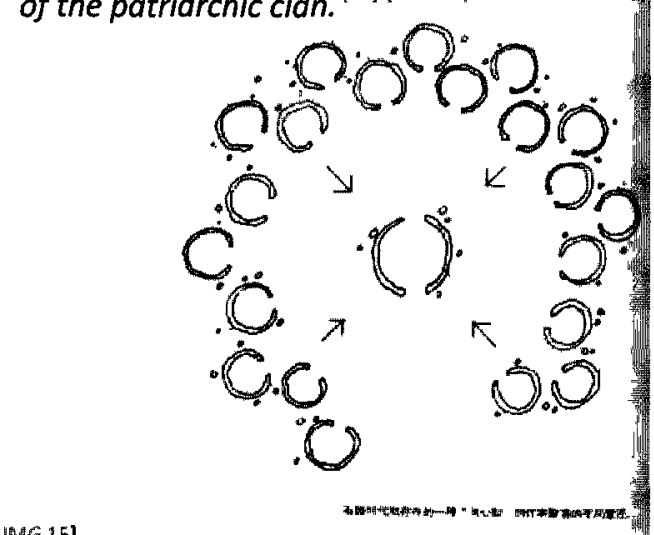

[IMG 1.5] Neolithic settlement concentuic spatidildispostion

Transitioning into the more sophisticated slave societies of early Bronze Age, the slave lords' privatization of communal properties were not limited to the Big House, but also its surrounding open plazas. Within the city layout discovered at the ErLiTou excavation, there are clear indications of a refined spatial planning strategy of this urban settlement. In which the open communal plazas surrounding the now privatized Big Houses were walled and claimed by the ruling authorities. The continual developments of the Big House, now established in form of courted complex, would steered architectural advancements until the late eras of the salve societies.

While drainage were resolved by underground water channels, internal moats were replace by rammed-earth walls to distinguish and protect governing royalties' privatized properties and assets from

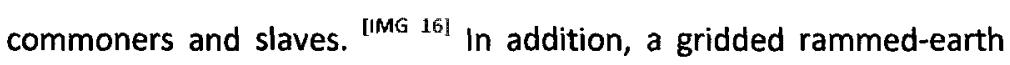
road system ${ }^{[I M G \mid}{ }^{17]}$ were structured right next to the palatial city walls to define its central position within the larger city and to service carriages (likely affordable only to the privileged members of the society) [MAG ${ }^{18]} .^{[32]}$ Immediate to its south and extending to the riverside is a rammed-earth walled district of turquorse and copper

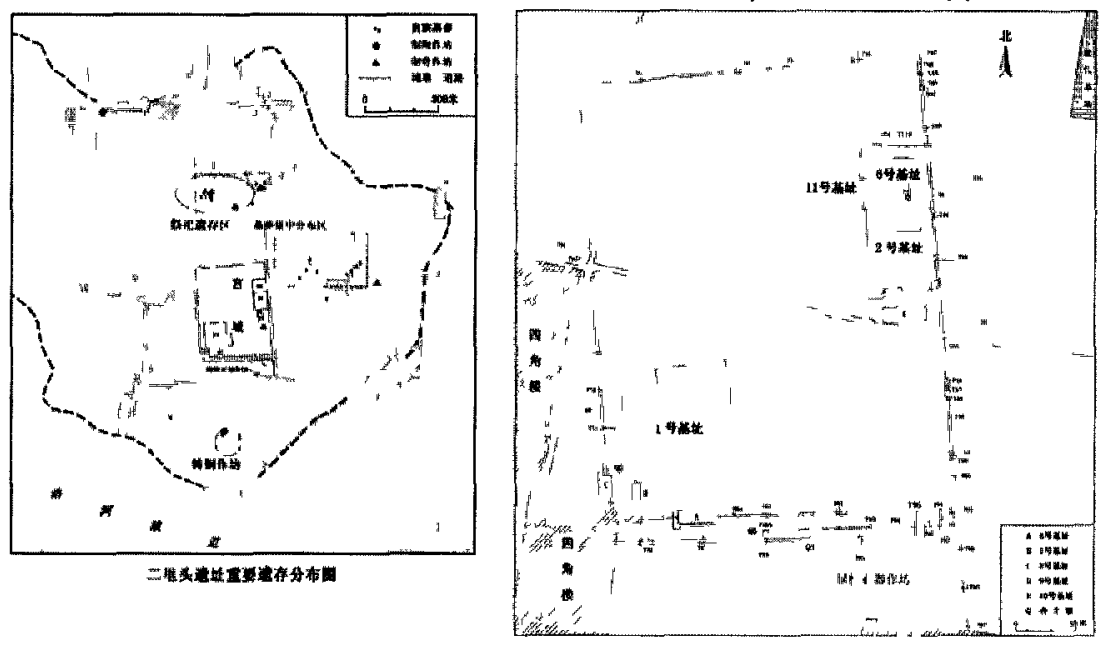

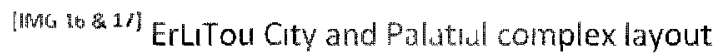




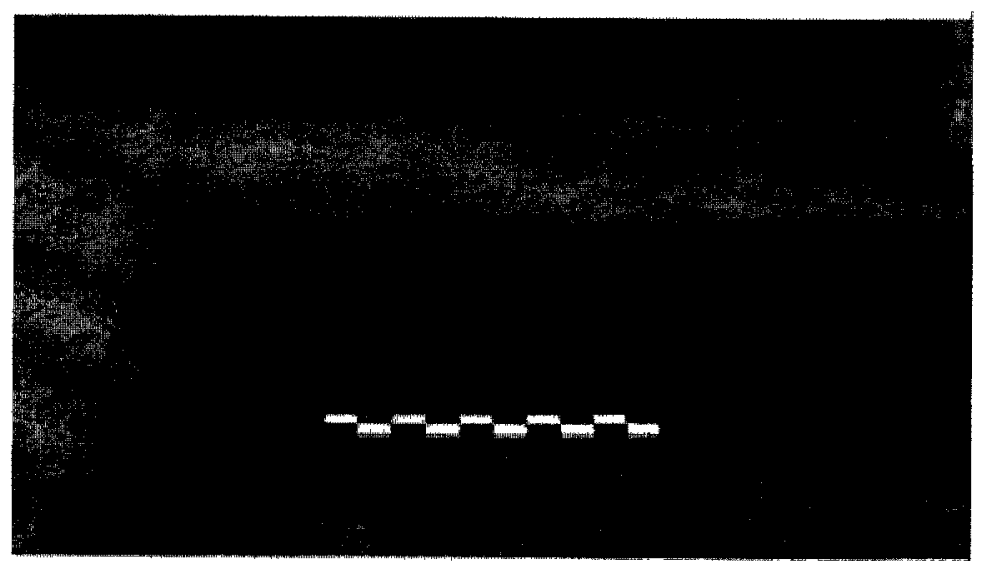

[iMg 18] Pounded Eurth matri road

In contrast to prehistoric cities of the LongShan culture, the defensive strengths of rammed-earth structures were utilized not only to shield against external threats, but also to secure authorities from their subjects within the new orders of a stratifying society. The word "city" in modern Chinese is ChengShi【城市. ChengSh I; but in ancient script, Cheng【城. Cheng】 and Shi【市 . ShI are separate entities [IMG 19].
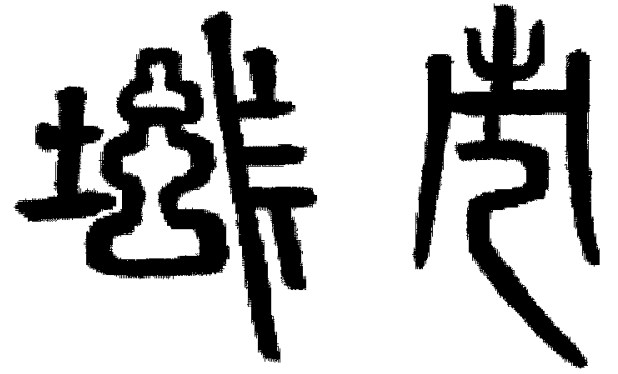

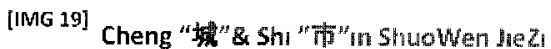

As depicted in Chinese Architectural Art History edited by Xiao Mo, cheng's pictograms indicates $\mathrm{Ge}$, an ancient weapon, on the right; earth, or land, on the left; with a cauldron, which symbolizes power of

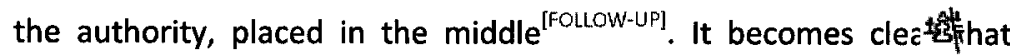
Cheng, , is an establishment with military power to protect the land and the regime. Shi,

, on the other hand, is composed of a counter in the middle, with a banderole waving above and the hook of a scale hanging below. ${ }^{[3]}$

As the HuaXia civilization matured as a stratified slave society, the establishments of royal court complexes and planning of the palatial city as "cheng" have became the priority in architectural and urban developments throughout the rest of the Bronze Age.

\section{Shang}

The oracle bone script-the earliest recognizable Chinese writing system-was discovered as prophetic articles recorded by the people of Shang regime.

The inscriptions on the oracle bones tell much about the beliefs, social organization and activities of the Shang-or Vin, as the [Z]hou people called them. Shang society was probably feudal, thought this cannot be said as positively o the Shang as of the [Z]hou. Successful generals, sons and even wives of the Shang rulers were enfeoffed, while small neighbouring 'states' paid regular tribute. Prominent amount the officials was the chen-jen who, as a scribe, composed and probably wrote the inscriptions on the oracle bones, and, as a diviner, 
interpreted the cracks which appeared in them when a hot metal rod was applied to one of the holes bored into the back. ${ }^{[34]}$

In comparison to the modest Xia subjects who generally practiced ancestral and natural worship, the Shang society was more sophisticatedly established on religious divination. It was believed that knowledge and directions could be attained by communicating with deified ancestors and spirits of the nature. To serve such purpose, the Shang elites have enhanced prehistoric precursors of ideographic symbols towards the development of the first comprehensible logographic linguistic system. Because of its pictographic nature, Li believes that these earliest words themselves could in fact be the first reliable records of Chinese architectural conditions:

\begin{abstract}
...[T]he origin of the Chinese language are "pictographs", which means they are intrinsically "diagrams"-firstly as pictorial representations of a specific object or event, then they become "word forms" by reducing the "diagrams" into it's very abstractive essence. Because dwellings are specific objects, when language was invented, the words themselves would record the conditions of "architecture", including its external shapes and internal contents. ${ }^{[35]}$
\end{abstract}

L. Zhang further elaborates on Li's argument and suggested that perhaps the Shang people were proud heirs of a more advanced level of timber construction technology: ${ }^{[36]}$

[The word "shang" In oracle bone script, $\mathbf{K}$, ] is the shape of a gateway in timber construction...It is likely that was the name of this door (or gateway) which guards Shang's capital city...it was a deliberate and logical decision to use the city's gate formally as a representation of their state, and as the symbol of their regime, and as the word of its name.

According to ShuoWenJiezi, an authoritative dictionary which original edition dates back to the $1^{\text {st }}$ century, the word "shang" was the name of the Shang sovereign's metropolis and the word itself is also defined as "knowing the inside from the outside" [37]. Though Zhang's suggestions do yield some merits in his deduction; it may be too early to suppose that the Shang people should be credited for contributing a higher sophistication in timber construction into the shaping of HuaXia architecture.
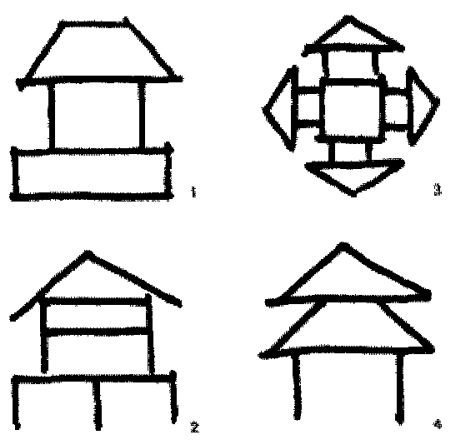

[1Nith 20$]$

In comparison, Li's modest approach into the oracle bone scripts offers a more comprehensive understanding of the conditons of architectural developments during the Shang Eras. With the example 
of the words "shi" -a room- $\$$ \& - ी , and "gong" - a palacethese old Chinese writing forms were in fact simplified diagrams of architectural plan, elevation, and section. He concludes that,

\begin{abstract}
This group of the oldest "architectural diagram" clarifies many questions regarding ancient Chinese architecture. Firstly, during the Yin-Shang eras when the oracle bone script was used, the use of foundation platforms and hipped roofs were already a standard architectural typology. Secondly, architecture at the time were constructed with timber frames. Thirdly, it was already a common methodology to plan groups of architecture surrounding a central space. In general, the basics of Chinese architectural formalities have been established in this era; and all subsequent advancements continued developing upon these founding principles. Therefore, we could also arrive at this conclusion: the fundamental principles of Chinese architectural design were predominantly constituted 3500 to 4000 year ago. It's development was-exactly as how S. Liang has depicted-" "a perpetual movement lasting four millennia".
\end{abstract}

Many other examples listed by Zhang and Li are quite illustrative sketches of architectural conditions, which the Shang culture built on their inheritance from the Xia societies. Though it is unclear of specifically how timber building technology evolved during this era, whether it is an internal amalgamation with the introduction of the Shang traditions or if it is influenced by external knowledge imported through cultural exchanges with the many other tribes foreign to the HuaXia civilization, there are much archeological evidence to support wide proliferations of continual advancements in timber constructions. The most prominent testimony is the mid-Shang town of PanLongCheng discovered near the modern city WuHan located in the middle reach of Yangtze River. Professor Hou and Dr. Yang both have indicated the extraordinary resemblance between the noble complexes at PanLongCheng ${ }^{[1 M G} 2 \mathbb{1}$ and the palatial complex at the earlier discussed ErLiTou site from the Yellow River regions. [39] Steinhardt depicted the architectural progression of this Shang establishment with a comparison to its Xia predecessor in detail:

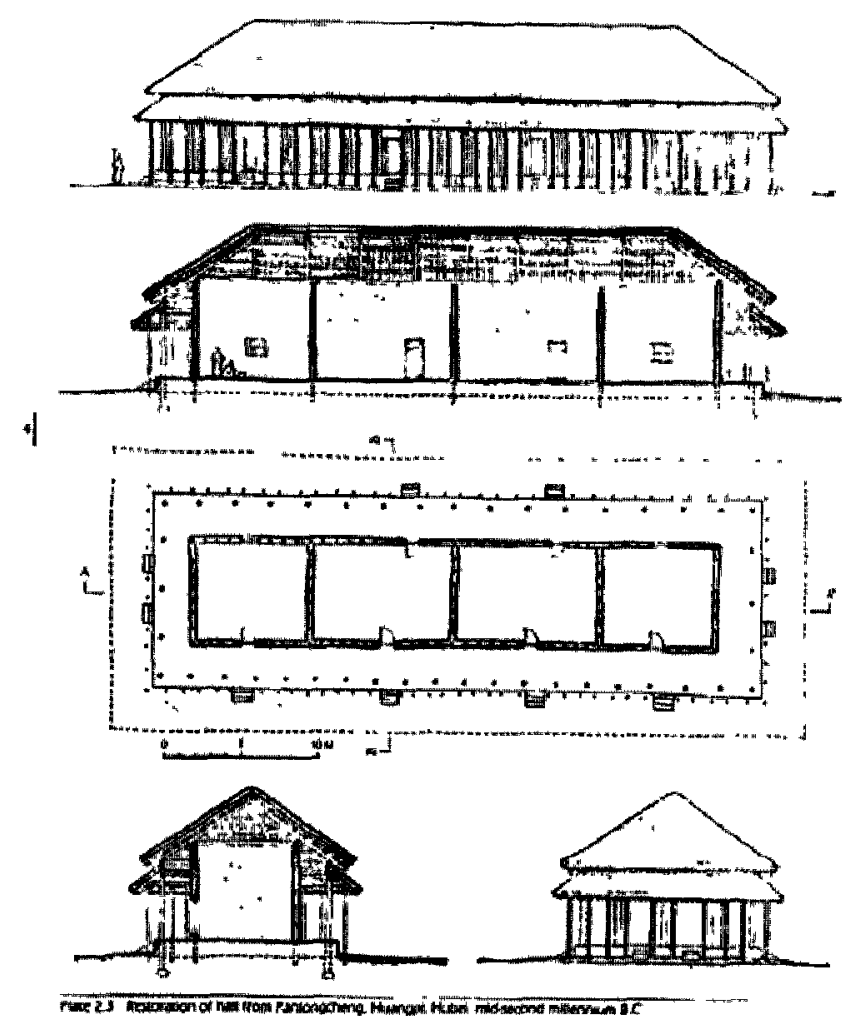

[IMG 21] 
The same design was found at the PanLongCheng Shang site north of WuHan in HuBei province, where as at ErLiTou the chamber walls were built of earth pounded hard around closely spaced, small diameter posts. The interior spaces of such chambers could reach 7-9 meters across by 5-6 meters deep, areas of 35-54 square meters. The modes size of these chambers and their construction do not differ much from earlier, Neolithic dwellings, yet several important steps had been taken. The chambers were elevated on pounded-earth foundations, rather than built at ground level or as semi-subterranean houses. Aligned side by side, the several chambers could support a large roof with a ridge pole parallel to the façade, an attribute that enhanced the majesty and physical presence of the hall. The overhang of roof eaves, or secondary eaves on all four sides, sheltered the foundation surface, creating a shallow gallery. These several traits were to distinguish main halls ever after.

As a cultivated slave society, Shang complexes of the ruling class continued to dominate the course of early architectural developments. The distinctive contrast between the architectural breakthroughs of privileged establishments and the suspended progression of slaves and peasants alike are typical products of stratified society. Such conditions remained consistent until the complete dissimilation of the proto-feudalist slave society.

\section{Zhou}

Much similar to the way King Tang of Shang gathered a collective legion with the support from many tribes from within the alliance to rebel against Xia the alliance leader; under the mandates of Heaven, King Wu of Zhou assembled an army combined with the united forces of many states and tribes to attack Zhou ${ }^{[41]}$, the last King of the declined Shang regime. The gradual transition from tribal groups into feudalist states was finally consummated after King Wu conquered the Shang court and instated them as state leaders. A five rank hereditary system was created to officially address these newly appointed leaders. ${ }^{[41]}$ He also awarded all tribal and state leaders, who joined his epic march of armies, with respect to their original entitlements with the additions of land from the defeated Shang. King Wu himself regarded himself as son-of-Heaven and reigned as the leader of this new established feudalist system as the Coalition King of all-beneathHeaven who governs the entire states alliance. Unlike the superstitious Shang leader who believed that under divine order of their ancestral deities, they were legitimized to rule in replacement of the sinful $\mathrm{Xia}^{[42]}$; after his victory, King Wu began to question about dependencies on the Heaven's will. In his conversation ${ }^{[41]}$ with his loyal brother Dan the Duke of Zhou, he analyzed Shang's examples and he came to a conclusion that faithfulness and offerings would not guarantee an enduring approval from the Heaven. In order to ensure continuous blessings from the above and to perpetuate the stability of Zhou regime, King Wu prioritized the establishment of a state capital that is in accordance with the cosmological orders; and thereby prompting the people's submission to the Zhou court. His ultimate goal is to broadcast the morals of Zhou clearly to all others from the 
four corners of all-beneath-Heaven. Although King $\mathrm{Wu}$ began the preliminary concepts, specific planning and implementation of the Zhou capital was not carried out for years until his son King Wen matured to his ascended throne and ordered his uncle Dan the Duke of Zhou to continue his father's work at Feng $\left[\left.\mathbf{I}\right|^{[43]}\right.$. Much like their legendary ancestor DanFu, the King Tai of Zhou, who led the resettlement of his people; King Wen and Duke Dan were meticulous planners of the new city. After many divinations and repeated surveys, the capital was finally built and the Nine Tripod Cauldron was placed. Similar to how $\mathrm{Yu}$ divided his territories and remained at $\mathrm{t}$ a central position, Zhou's capital at Feng was located at the center of allbeneath-Heaven and therefore all state leaders from the four cardinal directions would travel the same distance when they pay tribute to Zhou. Unfortunately, the capital at Feng was destroyed in later years of Western Zhou, but it is likely its schematics would be very similar to the idealized capital city plan as recorded during the late Zhou eras in

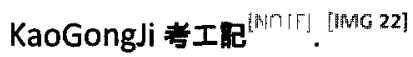

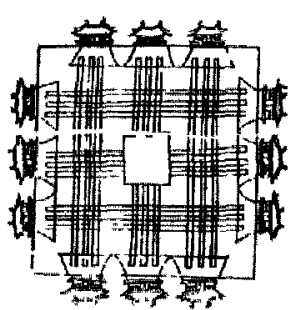

[IMG 22] Zhou Capital Layout

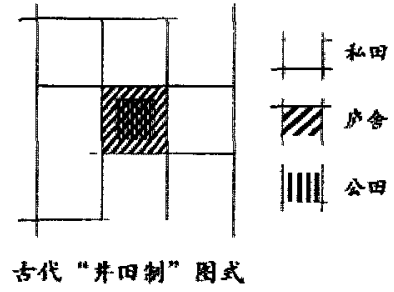

[IMG 23] Ancient JingTian
System
During his stay at Feng, with the ambition to clarify, summarize, and modify on national regulations, social order, the people's ways of living, and the standard of behaviors established since the Xia and Shang regimes, Dan took lead in composing ZhouGuan【 周官 \，which is the original name for Zhouli I 周青 1-a manual on official administrations and regulations through the implementations of specific rites and music. ${ }^{[\mathrm{WTE}]}$ Reinforcing the established Zhou regime, this classical ideal of harmony in the society could only be achieved when rite and music is perfected:

What do [the words] $L i$ and Y[ue] mean? Li 'rites' means Ii 'to tread'; to go [the way] which may be trodden. Y[ue] 'music' means to 'joy', "the Noble Man rejoices when he has attained the [right] Way, the small man rejoices when he has reached what he desired".

Why does the King perfect his rites and music? To manifest his joy and anger in a regulated and cultivated way.

...Therefore music is that wherewith to incite [man] to turn back from evil, rites are that wherewith to curb licentiousness and check prodigality. ${ }^{[44]}$

Like many other rites addressed in ZhouLi, the planning principles of the ideal Zhou capital has become the Locus Classicus ${ }^{[45]}$ in formal urban planning (e.g. the planning of ChangAn, Beijing, and etc.), but it has also become the canonical doctrine for the methodical developments of institutional architectural design: 
The master craftsman constructs the state capital. He makes a square nine li on each side; each side has three gates. Within the capital are nine north-south and nine east-west streets. The north-south streets are nine carriage tracks in width. ${ }^{[46]}$

It is apparent that the idealistic city layout relied on the same principle of subdivision as the old well-field, or JingTian I \#田 】, system [IMG 23] ${ }^{[24]}$ of land settlement and cultivation. ${ }^{[47]}$ Adopted into the classic design of urban layouts, the methodological application of the wellfield system was transcended to a symbolic gesture of how the Zhou society distinguished themselves in relationship to the Heaven above and to the Earth below. Cosmologically, the ruler of all-beneathHeaven would reside at the central nucleus of the city; and in a larger scale, the capital city as a microcosm of the universal orders would be appropriately located at the very center of the Earth. Since prehistoric times, the Heaven was perceived as the perfect circle; and the Earth a finished square【天回地方】. Therefore both cheng【城】，the inner palatial city walls; and guo【郭】, the larger city walls has taken the ideal shape of an intact square as the replica of the Earth. The Zhou planners further followed the examples of how $\mathrm{Yu}$ divided his world into nine provinces,

... [i]t is therefore reasonable to think of the city that was subdivided into nine units, with the royal palace in the centers, as a microcosm embedded in a concentric system, from the Chinese empire up to the scale of the whole world, on the pivot of which resided the Son of Heaven [ I $₹ \ngtr /$ ]...One of the most notable and important features in the mode of the canonical disposition of these principal urban structures, and indeed, in the whole set of city planning principles prescribed in the Zhou[Li], ideal as they were, is the proper, symbolic positioning of every physical element of the city by reference to cardinal orientation...It formed an order that was seen as durable because it was not arbitrary but based on an understanding of Nature, the eternal standard. ${ }^{[48]}$

Here we must address that, on top of other prevalent considerations, early Chinese architectural traditions and ancient city planning were developed directly under the influence of two unique aspects of the ancient HuaXia culture: LiZhi 【敖 \, the regulation of rites; and XuanXue 【玄臱】, the Chinese philosophies on metaphysics. ${ }^{[49]}$ Though these two ideologies and their related topics have long expired in modern practice, it is nonetheless important to understand their significant role in the continual progressions of Chinese architecture.

As a device to serve feudalist political purposes, the relationship between rites and architecture were especially important in order to construct and maintain a formal order within the ancient society. In other words, architectural codifications as a formal rite were part of the political regulations by which constituted the fundamentals of classical Zhou's establishment. 
By the Zhou dynasty, the architecture of the aristocracy and rulers was very much a system of silent visual symbols, so that if the textual specifications were followed land tomb excavation shows that this was not always the case), the rank of the highest-ranking resident was apparent from the exterior of a town or building complex. ${ }^{[50]}$

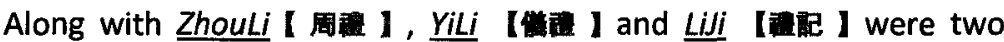
important scripts on ritual and rites imparted and administered since the Zhou eras. Academics of the imperial Han era organized these classics and called it The Three Rituals 【三II; and from which they

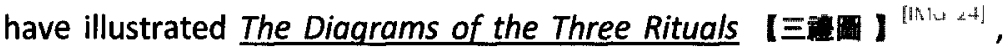
perhaps the earliest record of Chinese architectural theory, based on their interpretations on Zhou's most formal composite ritual complex-MingTang 【明堂 】 ${ }^{\left[{ }^{1} 1\right]}$, the Bright Hall, and BiYong【辟鹳】，

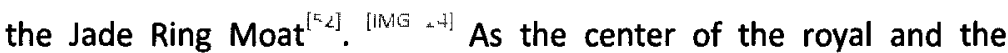
imperial power, the original concept of this composite ritual complex could be traced back to the deified father of all HuaXia descendents and from Chinese mythologies one of the Three Emperors I 三塭 I who ruled at the very beginning of the civilization-FuXi 【伏 \, who tradition claims authored The Book of Changes【聂經】. Serving a number of ritual purposes-astronomical observations, educational insitution, sacrificial ceremonies, calendaric regulations, official announcements, diplomatic receptions, and etc-the composite ritual complex was a multifunctional establishment and the highest form of integral space ranked at the top of the ancient social structure.
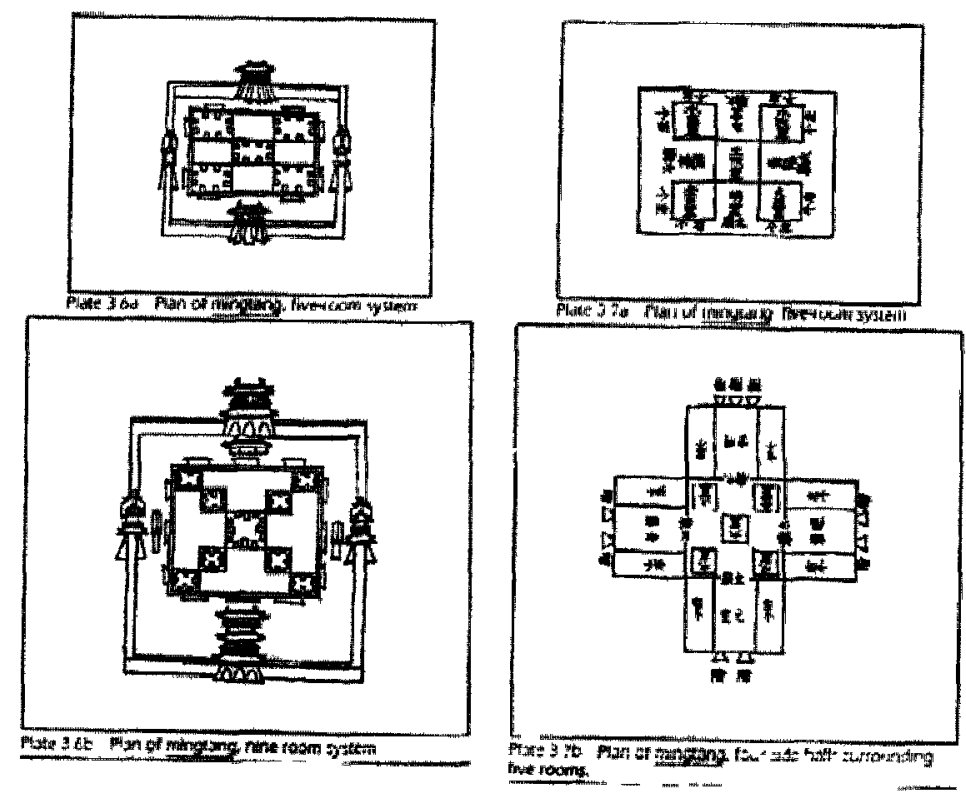

[IMG 24]

Refined in The Diagrams of the Three Rituals, it is clear that schematic concepts such as the precise definition of the squared periphery, an explicit reference to the four cardinal orientations, and an absolute axial symmetry were all manifestations of ritualistic regulations of Classical Zhou. While LiZhi was a system of ritual regulation to install a social framework in which every member of the society could orderly position his or herself in; XuanXue was the metaphysical ideology-the unique Chinese cosmopoiesis-in which the ancients could relate themselves to the nature's order and to maintain a role in their 
comprehension of the universe. Since the beginning of prehistoric culture, the Chinese ancestors have been cultivated as devoting worshippers of the nature and of the cosmos. Over the centuries, they have established an inimitable comprehension of the world:

Perception of [the] environment is not restricted to the world of their experience, but in an all inclusive structuring of the cosmos. Being an agriculturally based society, this cosmic order is responsive to the inherent rhythms of nature. All of the known elements and phenomena are organized by the perceived order of the rising and setting sun as well as the renewed cycle exhibited in the yearly change of seasons. ${ }^{[53]}$

As it is later developed into XuanXue, the Chinese metaphysics explained their observations of the nature and their visions of the universe with abstractive concepts such as Ying and Yang, the five elements, and their interactions with each other. Though the origin of XuanXue philosophies may be as old as the civilization itself; with the excavated Taili diagram at the Ruins of Yin ${ }^{\left[M^{25} \text {, }\right.}$, we know for certain that the fundamental concepts of The Book of Changes【勿繆】一the ontology of Yin 【愫】 and Yang 【H】 - has been consolidated by the Shang era. During the classical Zhou, superstitious reminisces from the prehistoric past were slowly replaced by a holistic metaphysical philosophy. With the metaphysical concepts of nature remained as the perfect reference of the Chinese ideals, rite and rituals which dictates individual behaviors as well as all aspects of social interactions were rendered in conformity to the nature's paradigm:
Music takes its image from Heaven, rites model themselves on Earth. All men contain in themselves the essence of Heaven and Earth, and harbor the instinct for the Five Constant [Virtues]. [54]

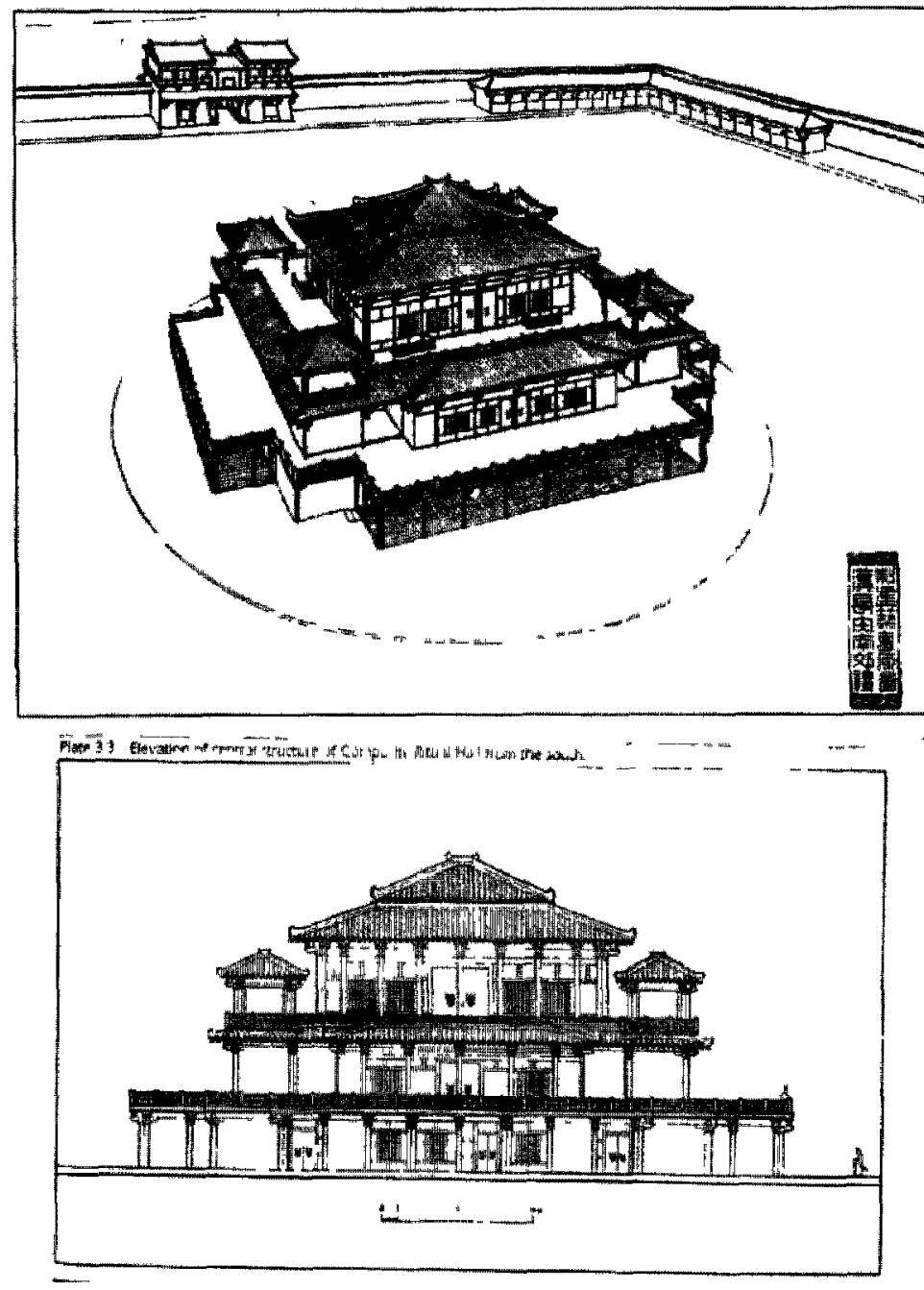

[IMG 25$]$ 
By late Zhou, the ritual contents were fully integrated with the metaphysical contexts within the institutional framework as the foundation of ancient Chinese architectural theory. ${ }^{[55]}$ As such, the formal layout of MingTang was also dedicated to accord with symbolic representations of the ancient metaphysical context:

All four of these illustrations give names for the four directional halls and the corner chambers located between each pair of halls. The halls are named after their respective symbols: the feathery red phoenix of summer on the south, the scaly green dragon of spring on the east, the shelled tortoise of winter on the north, and the furry white tiger of autumn on the west. The four animals... The corner halls symbolize four of the five elements-wood, fire, metal, and water-with the fifth element, earth, occupying the central square...The essence of the symbolism of the ritual hall lies in the two perfect shapes that comprise the hall-the circle, denoting heaven and the square representing the order imposed by man on his universe, the earth. The [king or the] emperor provides the link between the two through his enactment of rites at the ritual hall. ${ }^{[56]}$

As it would be briefly discussed again in the next chapter, the classical ritual contents and the metaphysical contexts would continue to have a complex and extensive relationship with Chinese architectural developments. However, in order to reinforce the Chinese ideal of regulated harmony in the society, the classical rite and ritual contents would later become the predominant dogma of the Chinese imperial institutions when Emperor Wu of Han Dynasty elevated the Confucian philosophies to its canonical status during $2^{\text {nd }}$ century BCE. Considered the utmost important principle employed by the imperial regimes, ritual regulations as related to architectural contents have therefore been transformed into the undefiable and immutable principles governing all official establishments. As explained by Kostof, architecture as the apparatus for social distinctions has become a convention within architectural practice through out Chinese traditions:

\begin{abstract}
Rectilinearity and axiality-these were the operative principles of Chinese design. And with them went the horizontal aesthetic, the conscious preference for a uniform range of heights that shifted the environmental burden of social distinctions to the placement of buildings in the general scheme of the city, the level of the terraces on which they invariably stood, the area they covered, and the degree of their ornamentation. All of these were officially prescribed. Han sources set down the specific code, based on status, hat controlled where a house was allowed to be in its fang or neighborhood, how big it was to be, and how involved its design. The system of rigorous discriminations carried over to the frame of the single building or compound. ${ }^{[57]}$
\end{abstract}

\section{Prototype of courtyard complex}

The composite ritual complex was truly the epiphany of the ancient HuaXia architectural legacy, which may have began with BanPo's Big House. As mentioned earlier, the process of privatization of the early HuaXia developments have resulted in a unique architectural tradition 
in which spaces within the urban setting is always defined with walled peripheries. A precise definition of the exterior boundary has become one of the most accustomed characteristics of Chinese complex enclosures. In short, the concept of open or public space hardly exists. In this regard, Kostof has made an interesting observation contrasting the West from the East:

...Roman emperors built to be remembered. And most of what they built had the public good or leisure activities in mind.

The notion of architecture as public service, or the instrument of the state, or a transmitter of culture was alien to the ruling dynasties of China. Concern for the people might be evinced through gifts to the poor, amnesties, or the remission of some taxes. One did no undertake to supply them with baths, theaters, or forums. Unlike the strong urban legacy of the Roman Empire, there had never been a tradition of independent cities in China attentive to public amenitites and civic display. Behind imperial power here was the peasant masses. In the cities the central task of government was social control.

...No religious architecture competed for attention; no priesthood diverted centralized power. ${ }^{[58]}$

Within the Chinese cities of walls, open spaces were privatized and scattered within each enclose complex. These internal open spacesthe voids-are just as important as the solid structures in Chinese architecture. It is clear that the formality of any complex was defined by how the solids were articulated in relationship to the voids within. In the highest forms of institutional architecture such as the composite ritual complex and later imperial palatial halls for political assemblies, emphasize on the establishment was manifested by positioning the solid structures along a central axis; while the surrounding voids assert the center of attention with minimal distractions. However, in complex further removed from political and ritual significance we began to see a different interaction between spaces and voids.

Perhaps the best example of this void-space correlation could be found in a noble compound discovered at FengChu village located in the modern day province of Shanxi. Though its programmatic intentions remained unclear, dating back as early as Western Zhou in late second millennium BCE, this particular artifact has provided an unequivocal architectural outlook on one of the earliest formal complex and its structural and spatial organizations.

Upon entering the Fengchu complex, one first encountered a screen wall, an early example of a feature that was to become common in Chinese palatial architecture. Behind this screen was a gate with a passage through its center, then the principal hall, and finally an enclosing covered arcade from which two small rooms projected at the front. There were three courtyards-a large one between the front gate and the principal hall and smaller ones east and west behind the principal hall. Excavation near the main hall suggests that it was supported with pillars and had mud-brick walls and pottery drainage pipes. Not only does the layout of the FengChu site seem to follow textual descriptions of the "three courts" system mentioned above, digging beneath rooms of the western side corridor uncovered inscribed 
tortoise shells and oracle bones, suggesting that it was once a ceremonial complex of a king or possibly a feudal lord. ${ }^{[5]}$

This double-enclosure, ErJin 【二進】, courtyard layout have demonstrated the prioritize of courtyards, or voids, as the pivotal centers of the surrounding structures on all four cardinal directions. The Four Directional System 【四向制】 ${ }^{\left[1 M\left[x^{26]}\right.\right.}$ as depicted in ancient script dictating building structures surrounding a centralized courtyard from east, west, south, and north, was formed during the Shang and Xia-or even earlier-Eras. In fact, the purpose of the rigid placement of building structure on the four cardinal directions was to construct an enclosed void-a concentric courtyard. ${ }^{[6]]}$ The ancient Chinese were extremely conscious with different characteristics of the distinctive spaces-the voids and the solids; and when utilize in complements with each other, they fulfill different needs as required in different aspects of human activates in the traditional Chinese lifestyle:

Because of the simple planning layout of individual architecture within the Chinese tradition, [buildings] have to rely on the courtyard as the central core to achieve a complete mechanism. The weight of the courtyard must be equivalent with the importance of the structural buildings; otherwise the dispersed buildings could not be organized as a complete organic whole. Moreover, in terms of design conception, individual architectural structure could be perceived as subsidiaries to the courtyard; only when they are considered as such, architectural groups [within any complex] could be layered in a hierarchical composition and organized in groups. Courtyards were flexible in size and shape; and through this freedom of composition it is possible to project the relationships between the internal and the external, and also the superior and the subordinate. Because [configurations of] individual buildings have adopted principles of standardization $^{[\mathrm{NOTE}]}$, there is an extent to the variations of their compositions. However, since courtyards were allowed freedom in infinite variations of shapes, sizes, and programmatic characters; the limitations of standardization were resolved when the "infinite" courtyards direct the arrangements of the "restrained" buildings [in the overall planning schemes]. ${ }^{[61]}$

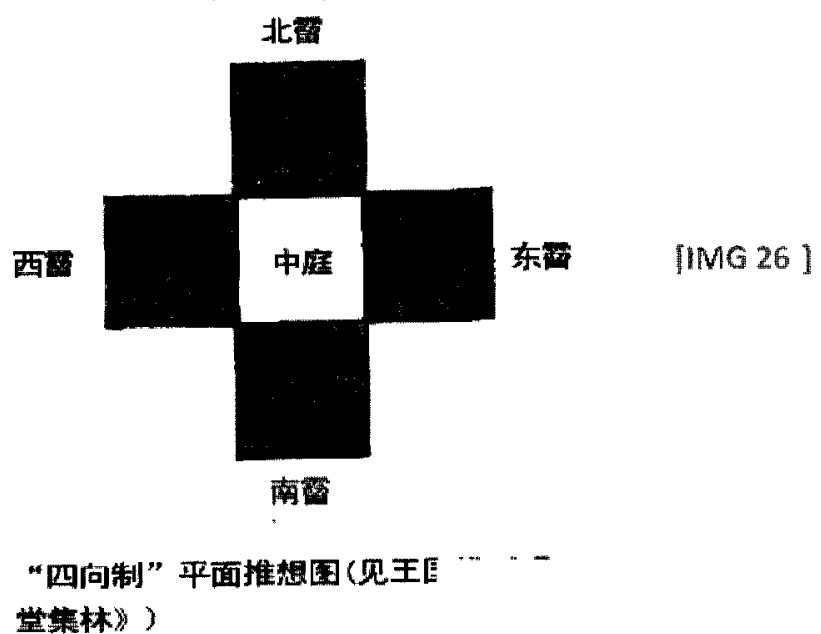

In short, rather than being a subtractive space in excess of the solid enclosures, the Chinese courtyard was the deliberate void-a negative mass without a roof-which was prioritized in fortifying the master scheme of the complex's master layout. The importance of this duality 
between voids and solids was so important that the traditional Chinese complex were generally measured in units of Jin 【進】, or Yuan【院】, which are numbers of courts within the groups of architecture enclosed in the complex. In Kostof's depiction:

\begin{abstract}
The house, humble or princely, had as its pivot an inner courtyard. Rooms looked in onto it, their back walls defining the exterior boundary of the household. Or else free-standing pavilions were set within the courtyard and a separate, walled envelope thrown around the compound. The aim always was to screen the intimate world of the house from the bustle of the streets, to observe internal rules of behavior, and to unfold spatial sequences according to what has been called 'graduated privacy.'...The etiquette of the royal palace, with its many courtyards and pavilions, differed only in degree. ${ }^{[62]}$
\end{abstract}

Many who have experienced moving through traditional Chinese compounds may have noticed that the Chinese were extremely attentive to distinct between the plastic and the spatial characteristic of their architecture by manipulating the duality of solids and voids. Plastic quality of a congregation hall within a palace complex, or a pagoda in a temple complex, or even a pavilion within a private garden is emphasized by surround the solids with an excess of voids. Architecture as a three dimensional object with a strong visual essence would be placed at the center of the visual focus.
In contrast, spatial characteristics of any residential complex, or the residential area of any compound, were choreographed by assigning solids to envelop a series of voids. Therefore any of such architectural façades would become a two dimensional surface which work with other components (other facades or walls) to form a negative spatial construct. The voids were a deliberate utilization of uselessness, of the non-existence-negative substantive spaces that were essential inside the container of life. ${ }^{[1] ?]}$

In general, different interactions of the solids and voids were applied in the two categories of Chinese traditional architecture:

...the secular buildings in horizontal sequences and the religious [or ritual] structures in concentric arrangements. ${ }^{[64]}$

As it would be further discussed in a later chapter, the strategies employed in the manipulation of this duality between solids and voids-especially within a traditional JiangNan garden complexmarked the essence of Chinese architecture and the Chinese traditional ways of living.

\section{Conclusion}

In transition from the prehistoric Big House to the ErLiTou palatial complex of the early slave society and finally to the feudalist FengChu noble compound, the initial stage of prototyping what to become of the standard traditional Chinese typology was accomplished with the establishment of the classical rites and rituals. By West Zhou, 
predispositions of Chinese architectural developments have since been strongly bound with the social mechanisms of China's ancient institutions. Persisting from prehistoric societies to the proto-feudalist societies of ancient china, a deep desire to connect with the natural orders and a rooted devotion to honor the elders and the ancestors have contributed to the unique developments of the Chinese social values. During Spring and Autumn Periods of the Eastern Zhou, Confucians as the founder of the school of Literati【儒學】 determined prioritizing patriarchal morals【宗法倫理】as the foundation of a harmonized society. This dogma was continuously reinforced with the utilization of rites and rituals as a political strategy employed by most regimes during the Imperial Era. These particular social values and in Chinese cultural maturation has great impact on traditional architectural developments in steering toward prioritizing its raison $d^{\prime} \hat{e} t r e$ as a social manifestation.

It should be noted that beginning from Eastern Zhou (771 BCE), the decline of Zhou court began to sway the political and military balance amongst the states. As the first social pattern of which Dr. Needham referred to as "bronze age proto-feudalism" [65] began to crumble, radical readjustments in many aspects of the HuaXia culture occurred until 221 BCE would prepare ancient China for the final transition into the second and the major phase of traditional social and economic systems-two millennia of Imperial China which operated on "bureaucratic feudalism" ${ }^{[6]}$. In coming chapters, we would investigate the continuation of architectural developments in relations to a more holistic outlook on the traditional Chinese reality. While the social influence is still the underlying dominant factor, many other cultural aspects would significantly determine the continual advancements in Chinese architecture tradition during the Imperial Eras.

From the proto-feudalist system of Ancient China to the bureaucratic feudalism of Imperial China, the Chinese classical order as a product of a feudalist institution have sustained demands of precise definition of each individual's social position. In the realm of architecture, this translates to a clear designation of spaces in accordance with patriarchal morals within the complex itself as well as within the larger city. All in all, the building and the owner together are bonded to the same identity that must be cohesive with the larger society in operation.

Furthermore, as the contemporary Chinese architect Chang YungHo points out, the chinese world is a concentric world ${ }^{[67]}$. Whereas in Western perspective it is conventional to assume the body approaches the architectural object from the exterior, the Chinese spatial comprehension cultivates on the concept that the body exist as the nucleus inhabiting inside the architectural object. In Chang's explanation, there is no need for the body to approach and enter an enclosed space because the body naturally belongs inside the space. As Wu puts it:

Unlike a temple which as the house of God can only be read by man from the outside in, the city land 
dwelling] of man is to be read both ways: [firstly,] the resident begins from the center, [and secondly,] the stranger from the outside gate...[T]he world of man is a sequence of rectangular courtyards defined by walls and with graduated privacy. ${ }^{[68]}$

Briefly extending beyond the scope of architecture, this is part of a larger concept with which the Chinese culture accepts the reality as it is observed. The ancient Chinese of the classical Zhou have never considered exploring the possibility of an absolute reality in existence outside Plato's cage and they have never question the authenticity of the perceived reality as merely shadows of images. Generally speaking, the official culture does not indulge in the idea of an abstractive and unverifiable metaphysics. The foundation of the Chinese knowledge is based on empirical observations of the rhythm in changes within the perceivable world.

Because each individual and the society at large were all part of the greater perceivable world, the HuaXia culture rationalize to reflect upon the ideals of the natural orders as the idealistic template of the social orders which governs the human realm. The earliest associations between architectural developments and Chinese concepts of the order of the world were most apparently manifested in ritual architecture. Amongst other architectural interpretations that were associated with the Chinese impression of the universe, the duality of voids and solid-an extended articulation of the Yin and Yang-gradually became a founding principle in the spatial composition of most architectural complex. While it would be sufficed to state that the Chinese are generally less concerned about plastic aesthetics in their conventional practice, they are nonetheless very delicate in articulating three dimension qualities of certain privileged architectural types to achieve the purpose to emote grandeur and majesty as the climax of a series of spatial choreography within the complex.

The plastic characteristics and spatial aesthetics of traditional architecture would be further discussed in a later chapter which focus on the regional traditions of JiangNan vernacular compounds, we would first clarify the continual developments of architectural structure in relationship to spiritual aspect and cultural influences of the ancient HuaXia civilization; and to the economical pragmatics which shaped the traditional Chinese construction industry. The next chapter is a humble attempt to explain the next stage of traditional architecture progress as a product of the Chinese reality beyond social aspects-in short, the total reality. 


\section{Reference \& Notes:}

${ }^{[01]}$ STEINHARDT (2002) P $18-19$

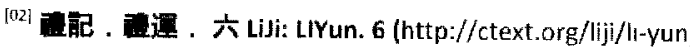

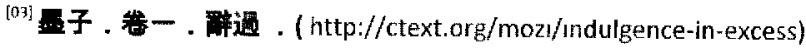

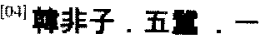

${ }^{[05]}$ http://www hemudusite com/culture 1 asp

[RANG【杨】P45-47

${ }^{[07]}$ [BID. P 1

${ }^{[083]}$ KOSTOF (1995) P 32-35

[(19) L. ZHANG【张】(2004) P 44-45

[119] YANG【桶】(1987) P 29

${ }^{[11]}$ IBID. P 12

${ }^{[12]}$ IBID. P 39

${ }^{[11]}$ |BID. (1987) P 36

${ }^{[14]}$ BOYD (1962) P 6

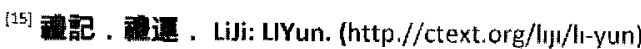

${ }^{[16]}$ \$ULLIVAN (1967) P 31

${ }^{[17]}$ 출

${ }^{[18]}$ BOYD (1962) P 6-7

${ }^{\left[{ }^{\prime 9]}\right]}$ ZHANG L.【张】 UP 59

${ }^{[21]}$ IBID. P 86
[22] WANG【王】(2008) P 3-4

${ }^{[23]}$ IBID. (2008) P 34

${ }^{[34]}$ HOU 【侯】 (1997) P 7

${ }^{[25]}$ IBID. (1997) P 7

${ }^{\left[{ }^{2}\right]}$ [BID. (1997) P 8

${ }^{[P A}$ STEINHAROT (1984) P 60-61

${ }^{[28]}$ HOU【侯】(1997) P ?

${ }^{[24]}$ YANG【杨】(1985) P 76

${ }^{[30]}$ LI 【孪】(1985) P 31

${ }^{[3]]}$ IBID P 140

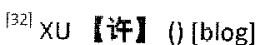

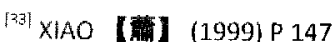

${ }^{[34]}$ SULLIVAN (1967) P 26

[35] U【【枚】 (1985) P 47

[361 ZHANGL.【张】(2004) P 37

${ }^{[37]}$ jiaGuWen Dictionary

${ }^{[381}$ U【【木】(1985) P 48

${ }^{[39}$ HOU【侯】(1997) P 8-9, YANG【糧] (1987) P 81

${ }^{[40]}$ STEINHARDT (1984) P 62-65 
[41]《史記 周本紀》Translation

http $/ /$ www zdic net/cd/cl/4/ZdicE5ZdicA4ZdicA959993 htm

http $/ /$ www zdic net $/ \mathrm{cd} / \mathrm{cl} / 4 /$ dicE5ZdicA4ZdicA9107189 htm,

http //big5 zhengjan org/articles/2007/9/23/48271p htm

prompt thereby submit, http //bug5 zhengulan org/articles/2007/9/23/48271p html

\section{[4 《史記 殷本紀》}

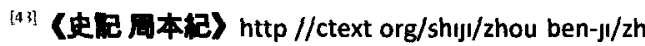

${ }^{[44]}$ BaıHuTong VI Rites and Music - 42 General Remarks (web source Virginia edu) Music takes its image from Heaven rites model themselves on Earth

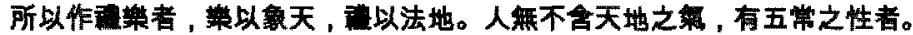

\section{[4r] (周动〉}

${ }^{[17]} \mathrm{XU}(2000) P 34$

${ }^{[48]}$ IBID P 3435,39

${ }^{[49]}$ STEINHARDT (2002) P ?

${ }^{[50]}$ STEINHARDT (2002) P 31

${ }^{[51]}$ STEINHARDT (1984) P 70 Translation of the term MingTang and BIYong

${ }^{[52]}$ STEINHARDT (1984) P 74

BiYong is another type of ancient ritual space

It is generally taken to refer to a moat (yong) which encloses a space in the shape of the flat jade ceremonial disk (bi) [T]he term BiYong came to be used symbolically to represent "by its circular form the circumambient sky and by its flow the universal, fertilizing spread of learning "By the time this reference occurs, BiYong actually refers to the college where candidates were educated for imperial service Although still standing alongside the MingTang, its purpose was no longer ritual [T]he functions of MingTang and $B_{1}$ Yong were contained in the one structure, and the latter bulding, in the form of a ringed moat, was used as an educational institution

\section{${ }^{[53]}$ LI【孛】(2008) P 40}

${ }^{[54]}$ RAPSON () P 11

[ "] U 【李】 (2008) P 40 - 41

${ }^{[56]}$ STEINHARDT (1984) 77

${ }^{[57]}$ KOSTOF (1995) P213
${ }^{[58]}$ IBID P213

I 'STEINHARDT (2002) P26 27

${ }^{[60]}$ U【李】(2008) P 141

${ }^{[61]}$ LI【㐋】(2008) P 141

${ }^{[62]}$ KOSTOF (1995) P213

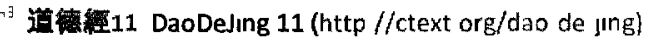

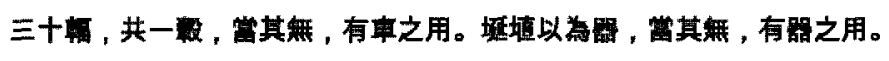

以為室，学其每，有室之用。敬有之以算利，無之以為用。

(The use of what has no substantive existence)

The thirty spokes unite in the one nave, but it is on the empty space (for the axle), that the use of the wheel depends Clay is fashioned into vessels; but it is on their empty hollowness, that their use depends The door and windows are cut out (from the walls) to form an apartment, but it is on the empty space (withın), that its use depends Therefore, what has a (positive) existence serves for profitable adaptation, and what has not that for (actual) usefulness

\footnotetext{
[r WU (1963) P 42

${ }^{\left[{ }^{[5]} \text { BOYD (1962) P } 7\right.}$

${ }^{[n 6]}$ IBID P 12

${ }^{\left[b^{\prime \prime}\right]}$ CHANG【张】(2006) P 45

${ }^{[68]}$ WU (1963) P 42
} 


\section{List of Illustrations:}

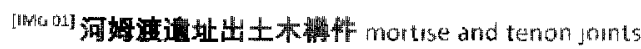

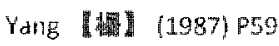

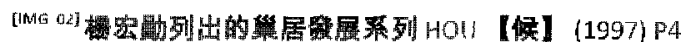

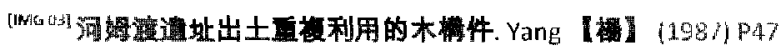

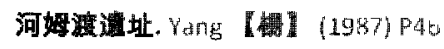

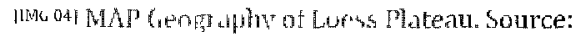

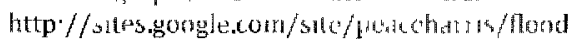

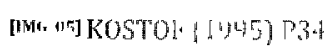

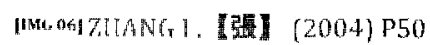

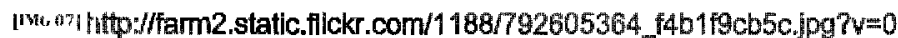
http://darkwing.uoregon.edu/inaasim/Foundations/Keynotes\%202.htm

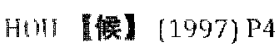

INLA

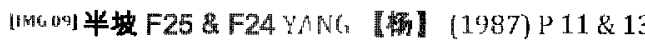

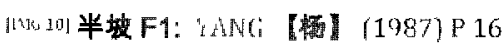

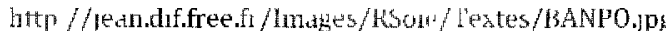

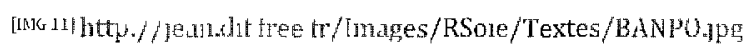

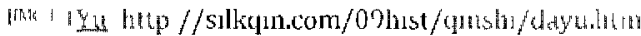

Yu tamung the tlood.

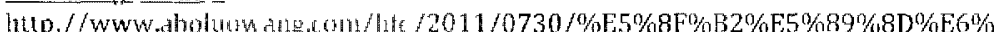

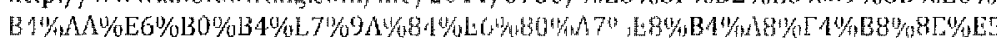
6A4\% 7\% E6\% $30 \%$ BOW

HuangHe Basin

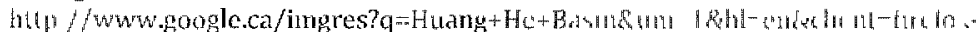
a\&rls=ulg.thorilla en-

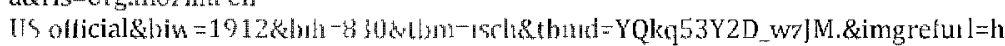

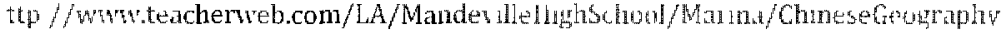

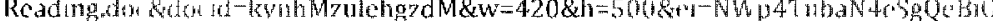

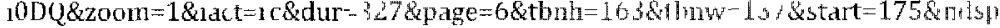

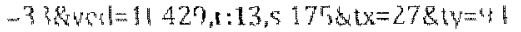

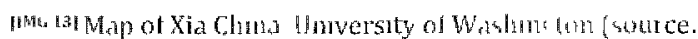

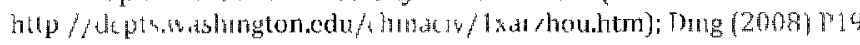

UMG M ZIAO 【榅1 (2007) P 29

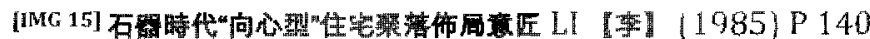

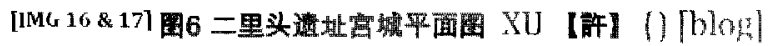

[IMG 18] XU【許】 0 [blog]

[IMG

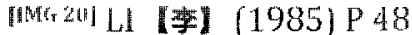

[MG 21] Plate 2.3 PanLongChenge Shang site. STEINHARDT (1984) Po4

[MH.: IXU (2000) P $34-35$

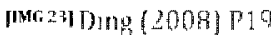

|initi. $2+\mid$

Plate 3.5 English names corresponding to ronms of MingTang and imperial posidions of the twolve moons:

INSER"I" IROM. S"IEINHARDT (1984) P 75

Plate 3.6: a. Plan of MingTang; five roum system; \& L. Plan of Ming Tang, nine ruonis system

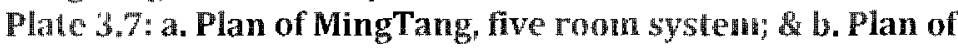
Ming Tang, four side halls surrounding five rooms.

INSERT FROMU. STEIHIIARDT (1984) P 76

[IHG 25] STEINHARDT $(1084) 177$

[Muth 241 LI (1985) P 48 
upon economical changes which would further transform the political landscape of the fragile Zhou regime:

Bronze had had its most striking effect in the improvement of weapons; that of iron may have been in the improvement of agricultural implements. From the fifth century B.C. a great and comparatively rapid expansion of cultivated lands took place with the clearing of grasslands and forests, leading eventually to a complete change in social relations. Gradually the communal strip cultivation of land in rotation was superseded by private ownership by the peasants, who were enabled to open up land for themselves. The same process on a larger scale went on among the nobles, leading to a weakening of the system of fiefs and obligations and the rise of many small independent states, contending among themselves in rivalries and alliances. ${ }^{[01]}$

Although the initial establishments of rites and ritual classics during early Zhou holds great significance to the later developments of the Chinese culture, these novel achievements designed with the purpose to instate a formal social framework, which stabilized the feudalist state alliance. These measures were rendered obsolete as the Zhou court lost its military influence and political authority as the leading state of the alliance in $771 \mathrm{BCE}$. For the next five centuries, the historical period that is generally known as Eastern Zhou, the Zhou authority was reduced to a small and impotent state, merely maintaining the title as the royal house and served as a figurehead when states of growing powers would only request consultations condescendingly on matters of legitimacy and inheritance. Following the demise of the Zhou court, ancient China quickly enters the Iron Age. Boyd points out such technological advancements has brought

Combined with the invention of the harnessed plough, new technology have led to advance tools and also the use of permanent irrigation. All of these changes have resulted in new economic circuits, in which the stimulated growth of population and new pioneer of lands radiating outwards from China proper would promote an expansion of the HuaXia cultural area, and exchanges between the different states within HuaXia world. What is more important, as Pirazzoli-T'serstevens points out in his book Living Architecture: Chinese, is that:

The emancipation of the artisan class fostered a mercantile spirit that gradually replaced the old aristocratic mentality. ${ }^{[02]}$ 
Radical changes in agricultural productions and the gradual but steady societal changes nourished the most exciting period in Chinese history called Spring and Autumn. During this first half the Eastern Zhou from $771 \mathrm{BCE}$ to $475 \mathrm{BCE}$, the flux of society cultivated an optimal environment for the exchange of thoughts and ideas. As old orders of the stratified slave society began its slow disintegration, the accelerating competition to acuminate power and influence amongst regional noble lords encouraged a relatively open platform for the free expression of ideas and thoughts. Several important schools of thought that would later be constituted as the backbones of the Chinese culture and contribute to the maturity of architectural traditions-namely Confucianism, Daoism, Legalism, and etc-was fostered during this period of the 'hundred flowers blooming' or 'hundred opinions contending' I百家暗】. Also, much of the folk poetries, historical events and ceremonial records from the prehistoric and ancient past were edited and compiled into collections during this important period of enlightenment. Though much would be lost later with the tragic elimination of ancient knowledge enforced by the tyrant Qin Shi Huang【秦 始量】， many survived literature would permeate the Chinese culture as classical references.

At the end of Spring and Autumn, the proliferations of iron advancements have resulted in a surge of production; the economical improvements have fermented much momentum not only in societal changes but also in the cultivation of arts, and of course, architectural crafts. As with the enlightenment of literature and philosophy, as old restrictions of the feudalist slave society obsolesced, aggravated uncertainties brought upon exploration of new possibilities in the field of architecture. From previously discussed architecture developments of the classical Zhou, we have learned that formalities of Zhou's institutional tectonics were established as the prototype of all official and institutional, or GuānFāng【官方】, architecture which persisted until the end of the Imperial Eras. Hou argued that ritualistic formalities as promoted by the Zhou court was highly received and accepted by many authorities of other states at this time as the ideal interpretations of formal institution not only because of its significance as the legitimate systemized standards ${ }^{[0\lrcorner]}$; but it was also because of the advantages of timber frame construction-its great potentials in adaptation and flexibility in different physical and cultural environments, and in its ability to amalgamate with technical advancements from other architectural systems. ${ }^{[04]}$ But before timber construction became the proper standard in official architectural practice as a social mechanism utilized by the Imperial regimes, the Zhou archetype was not the only architectural approach pursued by the noble courts of the many Eastern Zhou states. We would like to return to the pragmatic advantages of timber construction later in this chapter; but first, it would be vital to elaborate on the exciting architectural explorations taken during Eastern Zhou eras until the end of early Imperial Era in order to understand the Chinese approach towards structural developments. 


\section{Cutlural}

Period of Adolescence: Architectural Explorations

Toward the latter half of Eastern Zhou-a period commonly referenced as the Warring States (475 BCE to 221BCE)-the competing kings and noble lords who benefited from the iron-induced economical advancements have began to break away from the collapsing Zhou regulations and started to explore new potentials in the tectonics of pounded-earth platforms. As they grew stronger in military fortitude and political strength during the quick passing of Zhou's feeble leadership, they were anxious to soar from the ground and to take their ambitions to the skies. Though they were reaching for heights, their intentions greatly differed from the tradition practice of tall buildings in the West. Li pointed out that,

People of the West have pursued the "objective presence" of eminence and immensity through the physical forms of architecture itself. Their intentions were to create a visual impact and through the presence of such architectural forms; and by doing so, they would be able to impose faith and to display the extent of their power. In contrast, the Chinese motivation in developing high-rise architecture was simply to bring normal human activities and human living to a higher plane...Foundation platform as a main component of ancient building developments was the beginning of advancing towards higher altitude. As the foundation platforms augmented and elevated progressively in height, they transformed into Tai 【台】 ${ }^{[05]{ }^{[06]}}$
As mentioned in the previous chapter, though it was first conceived during the prehistoric times, the profusion of pounded-earth technology was a cultivated product of the ancient slave society ${ }^{[L I N K]}$. As one of the two components which constitute traditional Chinese Earth and Timber Integrated Structure, large scale pounded-earth structures required mobilization of a significant number of labors in its construction process. Since the prehistoric societies, specific heights of pounded-earth platforms have always been utilized as one of the systemized rites that indicated the social standing of its occupant ${ }^{[07]}$. With their accumulated wealth from iron advancements, the noble lords began to detach themselves from the constraints of Zhou standards. The motivations of elevating pounded-earth platforms have encouraged the initiation of an unique Chinese architectural typology-Tai.

We know that the earliest Tai were relatively small in scale; the timber structures on top were usually open structure built as posts for observatory, venues for banquet, and/or stations for archery. ${ }^{[08]}$ In later developments, the term Tai evolved to have different meanings when used in different context:

...it could be referred to as the foundation platform of any architecture ${ }^{[\mathrm{IMG}}{ }^{01]} ;$ a construction and structural technique to acuminate mass in achieving a multistory high building ${ }^{[\mathrm{M} / \mathrm{G} 02]}$; a general name of a group of building complex that was built on top of or

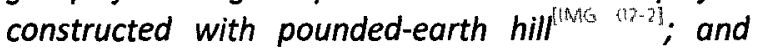
lastly, any individual rammed-earth construction

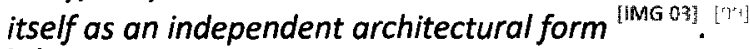
[10] 

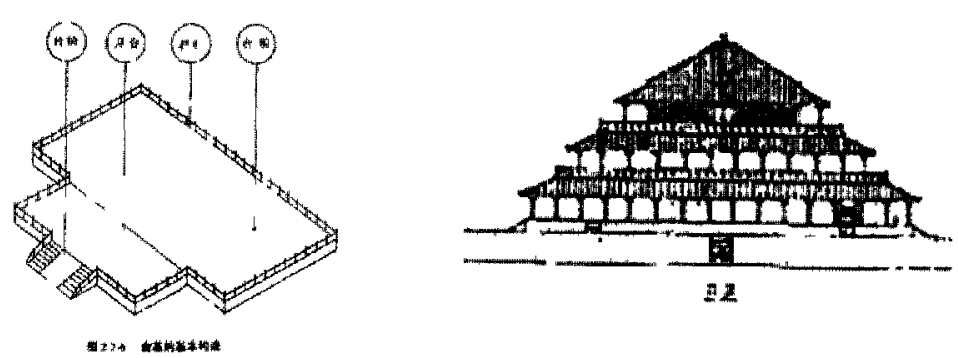

[IMG 01]

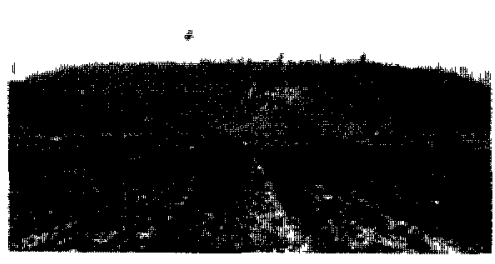

[IMG 0.4$]$ Kemains of foundation of building

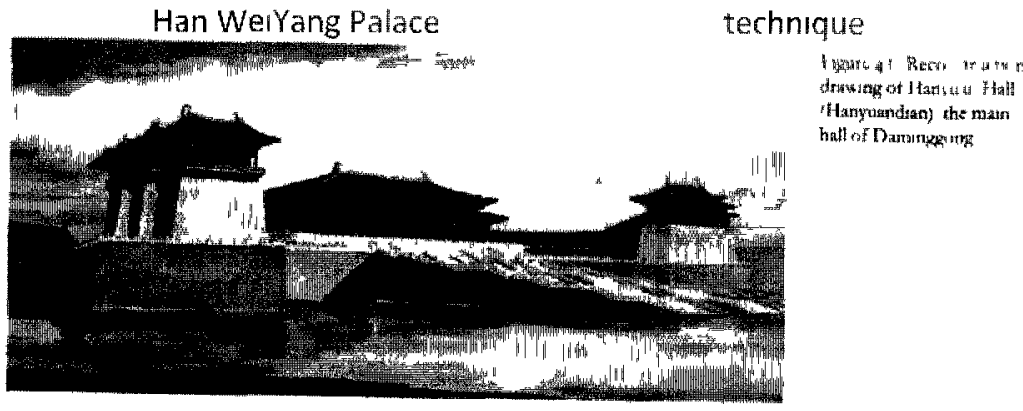

[IMG 02-2] Tang Pddce HanYuandian (entrance hall)

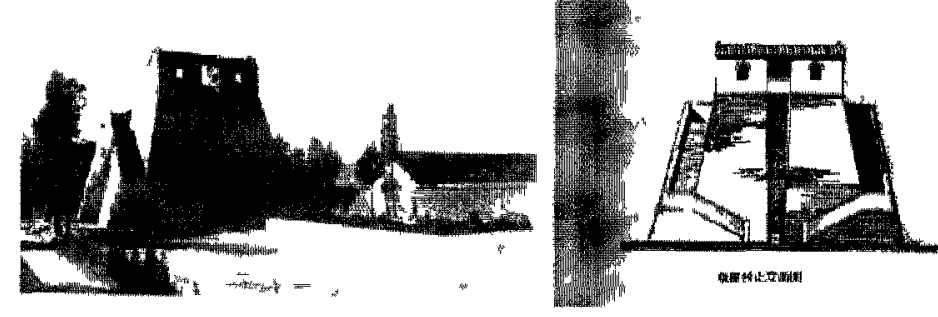

[IMG US] Observatory from Yuan Dyndsty
All and all, the flourish of Tai developments during Eastern Zhou and the early Imperia Eras was an unprecedented period of achievement on vertical constructions in Chinese architectural history. As each Independent authority of the various states contended to showcase their potency, Tai construction started to reach its climax during the Spring and Autumn. Over the next few centuries, numerous Tai was raised in forms of or on top of artificial rammed-hills or modified high grounds. To name a few of the most distınguished Tai there were the earlıest example of LıngTai 【R台】 commissioned by King Wen of Western Zhou【周文王】; the ZhangHuaTai 【章華台】 built by the state of Chu【楚】, the CongTai【䛾台】 of Zhao【蚰】; followed by Imperial construction of LangXieTai【琅邪台】 by Qin ShiHuang【秦 始量】， BoLiangTai【柏梁台】 raised by Han WuDi【谟 武帝】; and the list goes on. Unfortunately, with no survivıng artifact, remınisce of these great architectural novelties could only be found at the ruins of the remained pounded-earth foundations ${ }^{[I M G}$ 04] and in the descriptive literatures as recorded in classical references ${ }^{[11]}$. With its momentum sustaıned well until the end of Han Dynasty $(220 \mathrm{CE})$, elevated platform-GaoTai 【需台】 - construction maıntained as a millennıum long mainstream practice for at least a third of the recorded Chinese architectural history. ${ }^{[12]}$

In terms of architectural progressions, late Eastern Zhou, or the preQin-otherwise known as the XianQin【先菜】—epoch, was arguably the most exhilarating perıod of developments in Chinese architectural 
chronicle. Though the ritual systems of Western Zhou was significantly substantial in exemplifying legitimacy, rivalry amongst the many powers for dominance of the Central Plain provided a relatively free stage for the exchange for innovations and encouraged refinements of new concepts. It was, in retrospect, the age of adolescence during which many aspects of the Chinese culture was shaped and transformed into maturity.

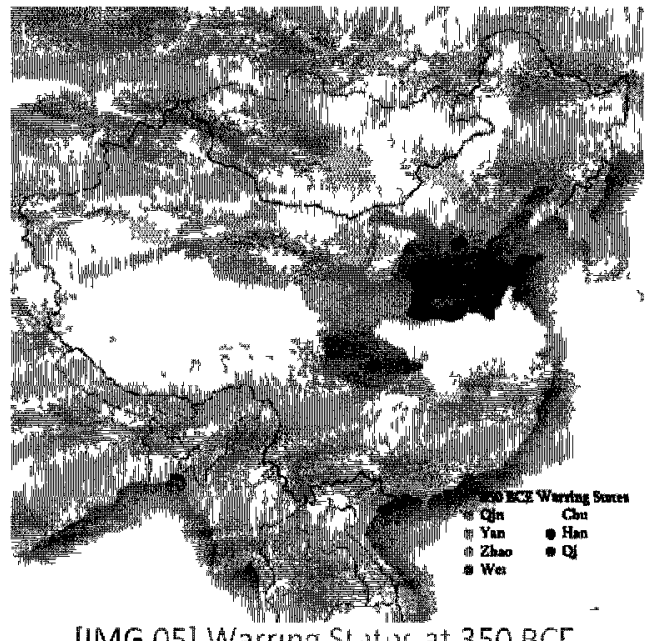

[IMG 05] Warring States at $350 \mathrm{BCC}$

Progressing towards the beginning of the Warring States where only seven powers would be remained to battle against each other for the complete dominion of the entire HuaXia civilization, the ancient

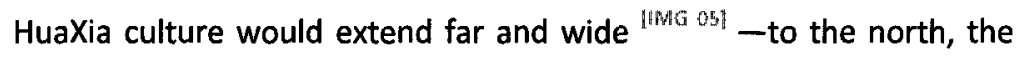
Yan【燕】state envelops around the modern day BoHai Sea【湖海】 into the Northeastern Plains approximate to the lower reaches of the Liao River; to the east, the Qi 【 I State broadened its border towards the eastern sea coast to include the ShanDong
【山慗】 peninsula; to the south, the burgeoned state of Chu

【枯】 consumed the alluvial plains around the lower reaches of the YangTze River; and finally, to the west, the aggressive state of Qin 【萧】 advanced its terrains along the Wei River【溈河】 and southwards to monopolize control over the SiChuan Basin [四川盆地】. Radiated outwards from Central Plain, the HuaXia civilization grew in complexity as the rivaling states absorbed and interacted with new regional resources, distinct environmental conditions, and native customs of the assimilated "barbarians".

Archeological evidences of this period have indicated extensive experimentations with alternative materials and structural constructions during this period of architectural development. Professor Yang argued that, based on the abundance of relics excavated from archeological sites of various locations, bronze structural pieces-usually by the name of JinGang 【金妅】 [IMG 06] in ancient China-were widely applied in architectural constructions for the purpose of reinforcing timber joints to support a heavier load when roof tiles were first invented and were selectively incorporated in the roof structure during Eastern Zhou ${ }^{[13]}$. Yang suspected that, inspired by metal bracings used in carriage designs ${ }^{[\text {[Mc } 07]}$, these metal components were improvements to the primitive rope binding technique to secure structural connection and they were originally invented sometime during the Western Zhou. The astonishing discoveries of a group of delicate JinGang【金红】 at YongCheng 
【䔨城】 (a former Qın [櫘] capıtal durıng Spring and Autumn in ShangX province) stood as specimens of such metal architectural components at its height of practical utilization before a slow

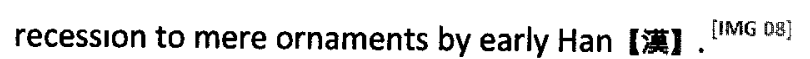
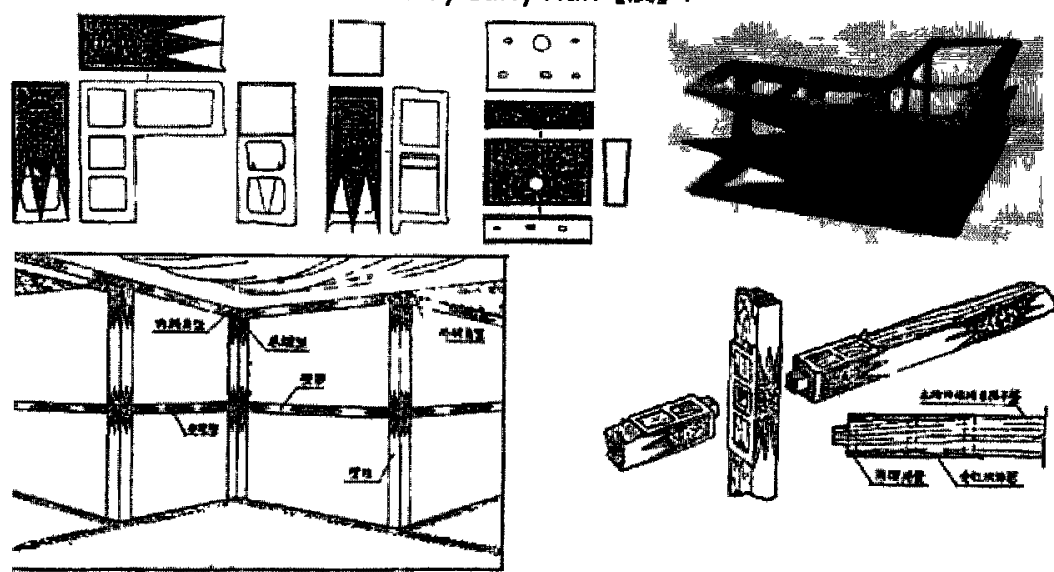

Top [IMG 06] JinGang

Right [IMG 07] Carrage metal bracings

Bottom [IMG 08] Decorative Motifs

Imitatung JunGang during later eras

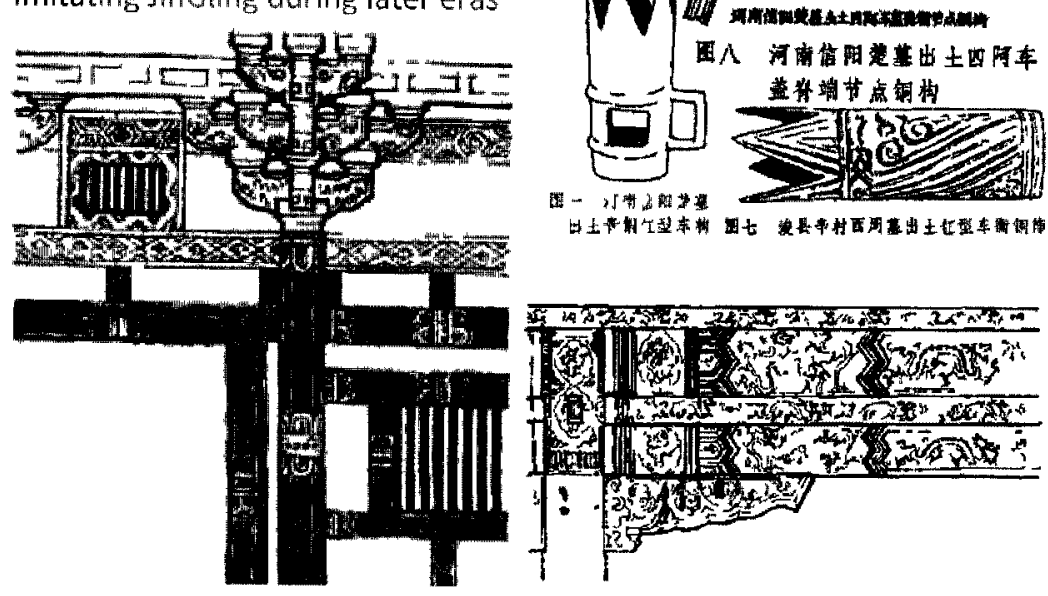

Furthermore, the ancient Chınese were also experienced builders with a long tradition of constructing in brick and masonry. From the begınnıng of tıme, there were the prehıstoric giant stone monuments

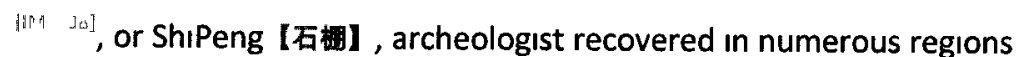
spannıng across Chına from the Southwestern mountaıns to the Northeastern plains.

[IMG 08] LoLations of ShiPeng discovered in China

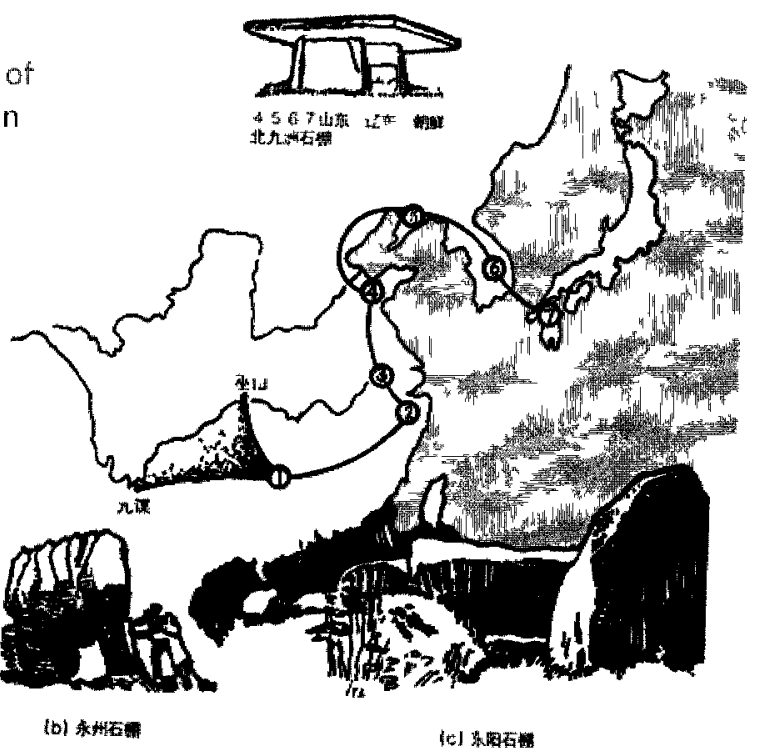

Zhang $L$ belıeves that these monuments were essential components of a common religıous or ritual practice of the ancient BaıYue culture. ${ }^{[14]}$ Durıng Late Warring States, we could find the first appearance of hollow brick construction used in excavated tomb chambers. ${ }^{[15]}$ By late Han, the abundance of masonry mausoleums, solid or hollow brick burıal chambers, and combınatıon brıck and stone tombs were Indıcations that early Imperıal Chınese builders were quite famılıar 
with applying these materials to architectural construction in a sophisticated manner $\left.\left|\mathrm{M}^{n}\right| \mathrm{t} \mid \mathrm{y}\right]$.
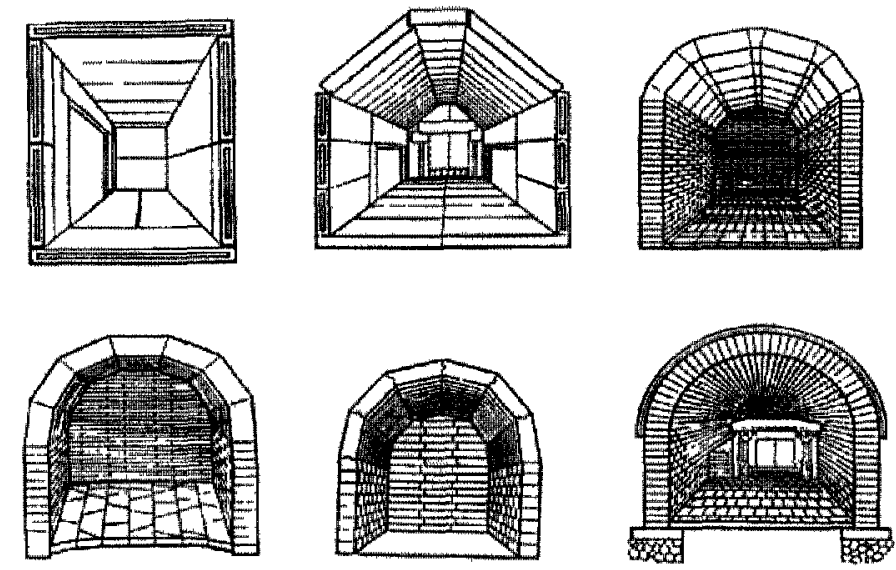

[MG OD] For ms of Vaulting used in Han tombs

As Steinhardt points out:

...Qin-Han China advanced the technique of vaulting, and vaults were used in such places as tomb interiors. Arches were made of flat and curved segments, of even and uneven sizes. Sometimes beams were lodged between the layers of arches, and other times mortar was used. In early Han China, trabeation, a column-and-tie beam system supporting an arch on top, was the most common kind of construction. But during the Han period, arcuate construction appeared-that is, buildings came to be supported by the arch itself, with true curved lines that added a new contour to architecture of the Eastern Han. ${ }^{[16]}$

Masonry and brick building technology continued to advance well into the Sui Tang Eras. Many of the surviving multistory monastery and funerary pagodas were erected using stone blocks and/or layered bricks constructions. Moreover, the phenomenal developments in bridge technology as shown in the unprecedented example of the AnJi

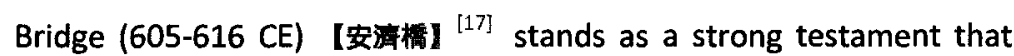
traditional Chinese builders were exceptionally capable of refining construction technology using alternative materials outside the mainstream practice of timber and earth structure ${ }^{[M G 10]}$.
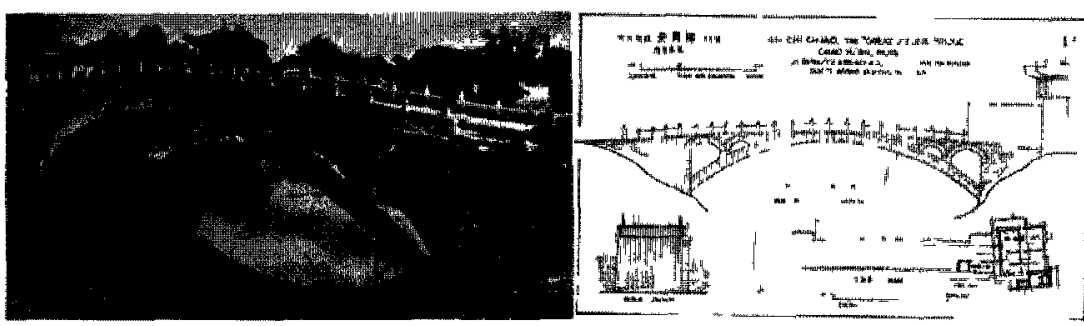

\section{[IMu 10] Anı Bridge【安洋灀]}

It becomes interesting then-especially as we follow the further developments of Tai by the nobility and the new rich, as well as other large scale constructions throughout late Ancient China and towards the end of early Imperial China-the Chinese architectural tradition remained persistent on the use of timber and earth given the options of many other building materials. Considering the more malleable advantages of metals such as bronze and iron, as well as the durable qualities of brick and masonry; the Chinese affinity for timber and earth as the prevailing material for architecture was sustained by many unique aspects of the Chinese culture. 


\section{Materiahty}

The first topic Zhang $\mathrm{Q}$. discusses in his book Chinese Ancient Architects was the issue of materiality of tradition Chinese constructions-on the opposition between timber and stone. Zhang points out that the Doric order ${ }^{[\text {[MG }}{ }^{11]}$ of classical Greek architecture was initially composed in wood and gradually transitioned into masonry constructions. The same transformation from timber to stonework also occurred in Indian architecture at an early stage. ${ }^{[13]}$ Obviously the purpose of these conversions is to perpetuate an immortal quality in their building, especially in all of the important religious architecture.

[IMG 11] Greek Dork order. transition from timber to stone
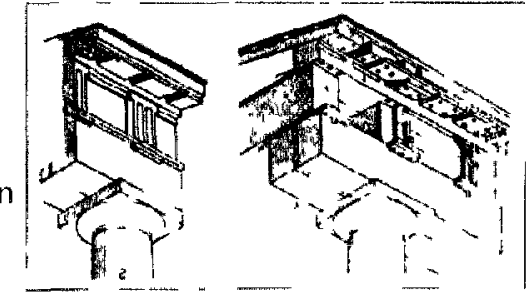

As we could see in the famous Great Wild Goose Pagoda ${ }^{[1 \overline{11}}{ }^{12]}$

[大㕍塔】 first built in Sui [䨛】 times and restored during Tang

Dynasty IFI in 648 CE, there have been similar appraoches in

Chinese architecture. Of the two categories in multistoried brick pagodas ${ }^{[\mathrm{N} O T E]}$, the Great Wild Goose Pagoda belongs to a group called

LouGe【接缃】 form that some academics believe to be an imitation of Chinese wooden pagoda forms ${ }^{[19]}$ (the original timber constructed LouGe was an evolved form of $\left.\mathrm{Tai}^{[20]}\right)$. In fact, according to Liang, [c]ontrary to the general assumption, the design of the Chinese pagoda was not imported from India; rather, it is a cross between the architectural ideas of the two civilizations. The body is entirely Chinese, the Indian element finding expression only in the spire, which is derived, often in much modified form, from the stupa. Many of the pagodas are brick and stone translations of wooden prototypes embodying the traditional Chinese architectural conceptions. ${ }^{[21]}$
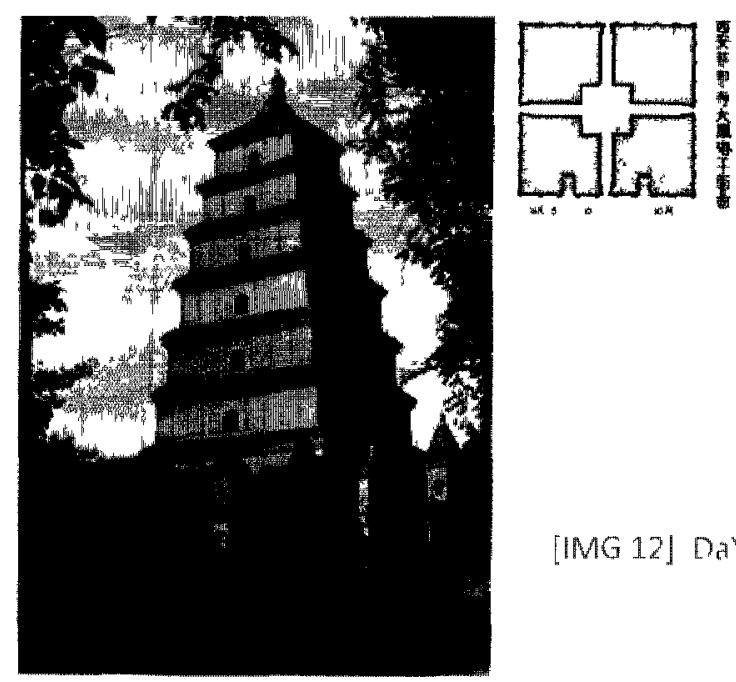

[MG 12】 DaYanTa, Great Wilt Guose Pagoda

However, the practice of stone or brickwork imitating timber structure remained atypical to the general conventions of Chinese architectural traditions. Even when faced with the fatal vulnerability to the common destructive force of fire, the most important Chinese official and religious architecture were pertinaciously built and restored with timber constructions. To explain this exclusive preference in Chinese traditional architecture, both Zhang $\mathrm{L}$. and Li believe that the key is in the spiritual dispositions of the Chinese culture. In fact, Li suspects 
that the fundamental difference between Chinese architectural traditions and the architectural developments of many other cultures is essentially induced by the distinctive religious values and spiritual perceptions of the Chinese culture. In the previous chapter, we have established that,

...the Chinese had little sympathy for the mystical or the infinite. Theirs was basically a secular, intellectual order; unmoved by any need to search for some ultimate truth, they plotted their own precise, clear-cut place on Earth. ${ }^{\text {[22] }}$

Few would argue against the fact that, since the establishment of classical Zhou, there has never been a time in Chinese history where thearchy is placed above everything else. In Li's words,

The contrasting cultural concepts [between the East and the West] on spirituality-one collected around mortal humanity, whereas the other was grounded on physical matters and focused on honoring the immortal realm-were the pivots that have set apart the divergent demands in the quintessential notions of architecture in the East and in the West. While the immortal and the finite object are immutable, the mortal soul is transient. Such dissimilar conditions of cultural values consequentially have encouraged different approaches and means in the undertakings towards architecture. It is quite possible that the Chinese dedications towards timber structure as the underlying architectural principle throughout its entire extensive historical developments were closely $\underset{[23]}{\text { associated with such unique cultural characteristics. }}$
Zhang is in accord with Li's argument and he further suggests that the critical determinant is the discrepant concepts of "eternity" 【永唒】.

Since "eternity" as interpreted by the Western and Indian culture was “constant" 【不现】, the best architectural manifestation of "eternity" must be forged with stone or concrete. Therefore they were bound to build their most important religious and institutional architecture in forms of masonry construction. On the other hand, the Chinese

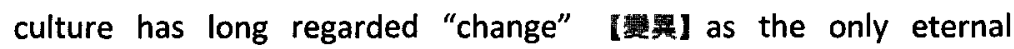
constant of the universe. The principles of this philosophy fundamental to the Chinese culture are thoroughly elaborated in the

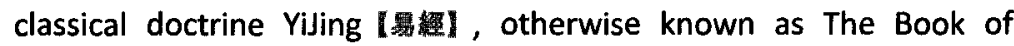
Change. From “The Eight Trigrams of King Wen”【文王八卦】，we could find that both the element of wood 【木】 and the season of spring 【春】 are closely associated with each other in representing life; whereas the elements of metal【金】 and stone【石】 are related to autumn【秋】 and winter【类】 in symbolizing death. In short, Zhang concluded that,

... [the perishable] wood is the representation of life while the enduring stone symbolizes death. Based on this [cultural] concept, the Chinese utilize timber in building dwellings [for the living], and bestow masonry on tomb constructions [to serve the dead].

The greatly esteemed architect and architectural historian Professor Liang SiCheng【漂愚成】， who was amongst the first who revealed the 


\section{association between such determinant cultural characteristics with the} general considerations in Chinese traditional architecture throughout its continuous developments, has made an interesting comparison in his authoritative publication Chinese Architectural History:

... [The Chinese] were not really concerned with the concept of preserving original accomplishments. Therefore, from the beginning of times, the Chinese have never attempted to achieve architectural feat in the same manner as the ancient Egyptians in striving for endurance and immutability. Rather than obliging artificial accomplishments to compete with the longevity of natural matters, the Chinese reconciled with the logics of metabolism and complied with the natural laws in the perpetual cycle of creation and destruction. Architecture was regarded as linens and garments, and as carriages and horses, all of which requires [maintenance and] replacements from time to time. The Chinese does not agonize themselves over the durability of their establishments, nor do they have the ambitions to preserve their endeavors indefinitely. They would accept inadvertent destructions of fire as peculiar adversity or as punishment of fate, instead of faulting on the building material and construction. Such accustomed perception resulted in the following outcomes: first, [the Chinese have sustained] satisfaction in the continual utilization of timber over thousands of years. The sequential refinements of timber constructions, and the inadvertence to potentials in the substitution and the application of masonry and brick works. Secondly, the custom of restoration was not nearly as popular as the tendency to complete reconstruction. Over the centuries, remodeling and improvement projects would conventionally neglect conservation of the incipient physical conditions, only the original site and date of construction were held in high esteem ${ }^{[1 \mathrm{~m} n \mathrm{~s} \text { 13] [25] }}$

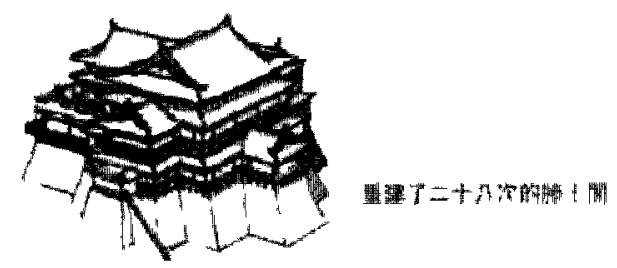

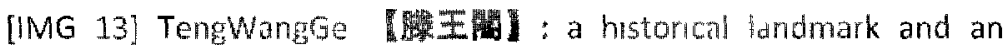
object of inspiration for many poet, "whd literati, is located in that cty of Nanchang 1 in the province of Janry erected in 653, and has been subsequenty reconstructed 29 timc, at the sallleste (Source CHU 【趙】(2007) P 40)

With such considerations determined in the practice of architecture, it is understandable that the Chinese have cultivated on their affection with timber construction. As Zhang points out, using timber-a representation of life in Chinese culture-in construction is not only a symbolic gesture; within the timber structure itself there is also an inherent characteristic of life. Timber configuration is versatile and flexible; in other words, it is organic in its nature. The most appealing characteristics and the greatest advantages of timber architecture are its adaptability, expandability, flexibility for replacements, and efficiency to dismantle. ${ }^{[26]}$ Zhang believes that these pragmatic nature of timber fabrication is the determinant factor of its prevalent implementation in China over thousands of years.

[The] deliberate ephemeral architecture, whose products were not destined to defy time, is explained 
by the fact that china has never linked its destiny with the transient fate of its material realizations. It views history as a predestined, inevitable sequence of events, in which the various moments count less than a certain coherent continuity...it was not in their monuments that the Chinese expressed their passion for eternity but in the ideas that presided over their design and the spiritual tradition they exemplified. ${ }^{[27]}$

Lastly, we would have to clarify on what is perhaps the most misjudged fallacy of timber construction. As a matter of fact, there is sufficient archeological evidence to suggest that, given the proper maintenance regularly, timber and earth structure could be sustained tenaciously. The Wooden Pagoda from Ying County [磨馬木塔] [IMG 14] is one of over thirty surviving edifices built before the thirteenth century. Standing at a staggering height of 183 feet, this extraordinary wooden pagoda was built in 1056 during the "Period of Vigor". ${ }^{28]}$
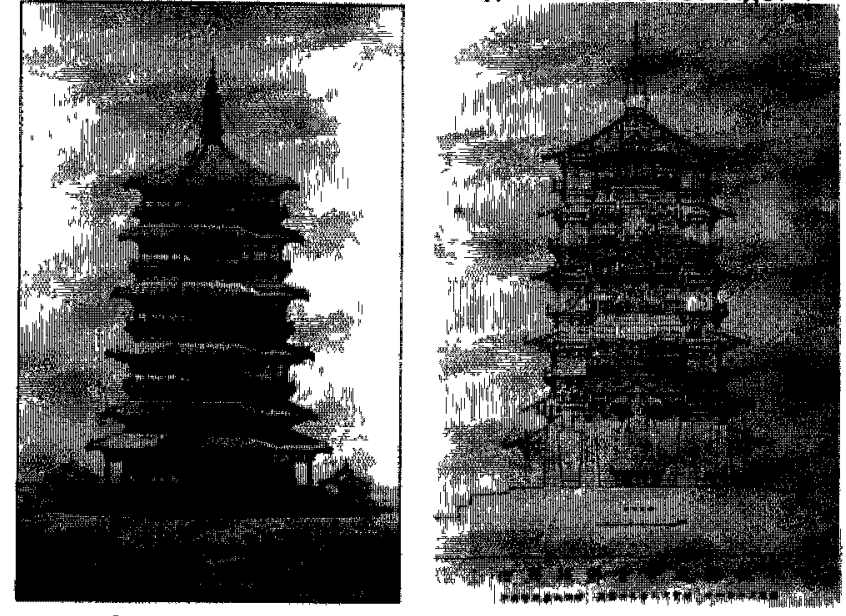

[IMG 14] Wooden Pagoda from Ying County
Earth constructions by nature are more enduring than timber structure. As we have seen in the previous chapter, fragments of pounded earth vestige excavated at numerous archeological sites have offered us much insight to the prehistoric reminisces. In addition to these fragments, it is not difficult to find strong testaments that would stand proud when compared with Egyptian pyramids bequeathed from a much distant antiquity. Beginning in Easter Zhou, the practice of sealing tombs with an artificial mount has become a popular trend amongst kings and aristocrats, and its momentum would peak during the early Imperial Eras. The first Imperial earthen pyramid was constructed on top of Qin ShiHuangDi's

始量帝】tomb at the foot of Mount Li [E山】 in the province of ShanXi [陕西】 . Covering a base four times the area of the Great Pyramid, this remarkable feat was cloaked with vegetation over the many centuries. Like many more earthen pyramids ${ }^{\left[\text {MG }^{15]} \text { constructed }\right.}$ later during the successive dynasties of early Imperial eras, this artificial hill was truly a synthesis of manmade wonder with the natural environment.

Among the disadvantages of timber construction compared with masonry must certainly be counted its lower degree of permanence. But societies do not all put a high value on permanence. Modern Americans do not, and the ancient Chinese, for most purposes, did not. What they wanted was rather 'renewability'; and complete rebuilding, being relatively cheap, was frequent. The permanent 
features were the planning principles, the decorative principles, the plan forms and the building types. ${ }^{[29]}$
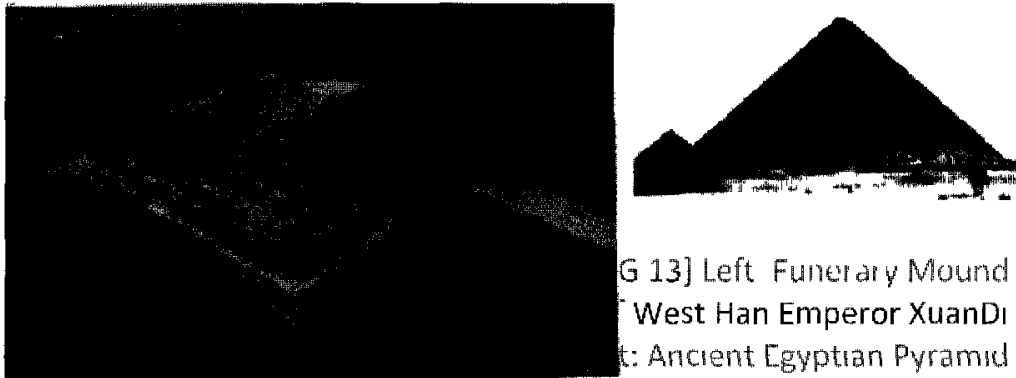

G 13) Left Funtel ar y Mound West Han Emperor XuanDI : Ancient Egyptian Pyramid

It would be fair to conclude that the Chinese have long adopted a realistic, almost prudent, postulation towards the role of architecture. The famous landscape architect Ji Cheng【計成】 have analyzed this mental disposition in his master piece Yuanzhi 【魚冶】, otherwise known as The Craft of Gardens ${ }^{[30]}$ in the West. Published during the $17^{\text {th }}$ century, the manuscript was the most completed work on Chinese traditional garden design. Ji reasoned a disparity between human beings and object matters is the duration of their existence. Whereas physical objects could possibly last for thousands of years, human life seldom exceeds a century. Therefore it would be sufficient to plan most artificial environments according to the duration of the average human life expectancy. In terms of dwelling conditions, it seems that the Chinese does not insist on imposing their absolute aspirations upon their descendants. ${ }^{[31]}$ The fact of the matter is, no one could be certain if the successor of their estates would be completely satisfied with their original schemes, there is little point to exhaust efforts and expenses in abiding arrangements under such circumstances. Li commented on this topic,

This is largely a realistic attitude. Whether it is urban or rural, the progress of construction is never complete; in any given time [the schemes] constantly renew themselves in a perpetual metabolic state. Generations of people have come to pass; their dwellings and architecture have always refurbished periodically. Considering the accelerated developments of modern societies, this substantiated approach is entirely practical. ${ }^{[02]}$

This pragmatic approach continued to dominate Chinese architectural tradition throughout the Imperial eras. In the next section beginning with the evolution of Tai, we would first investigate the structural origin of timber construction, the bracket sets [斗拱] in particular, in association with the larger cultural context.

\section{Regional Exchanges}

Little is know about the details on the evolution of Tai. Other than some ruins of earth mounts that were once the foundations of grandeur and opulence, we could only rely on clues left on tomb drawings and engraved on bronze vessels ${ }^{[\mathrm{MMG} 14]}$ to apprehend what were perhaps the most important developments during the adolescent stage in Chinese architectural practice. Through these abstractive representations, it is apparent that these multi-story buildings, structurally speaking, by leaps and bounds were much advanced from the Western Zhou noble complex discovered at 


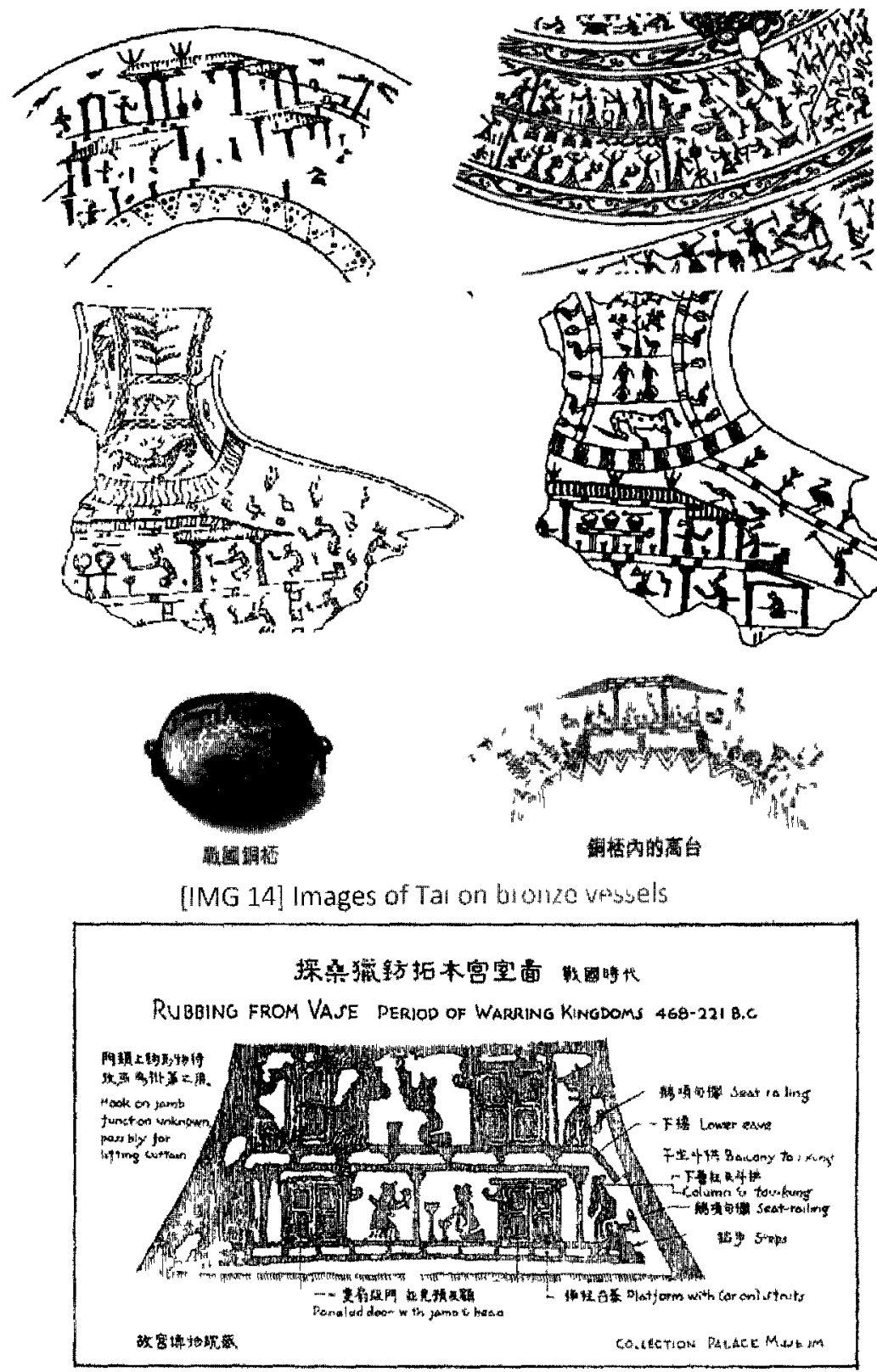

[IMG 14] Images of lai on bronve vessuts
FengChu village. Upon closer inspection, these earliest sectional details have all illustrated a structural component that connects the vertical element with the horizontal surface. With these indirect evidences, we are certain that the prototypes of bracket setotherwise known as PuZuo [鋪作】 in earlier developments and DouGong 【斗拱】 or Douke【斗科】 in late Imperial terms, all of which describe this fundamental structural element unique to the Chinese culture-have been widely adapted in many important constructions across the Central Plain of China by the beginning of the Warring States ${ }^{[2,3]}$.

The bracket sets, as suggested in its name, is not a column capital liikG ${ }^{15 !}$; it is a structural system, which in its definitive form, shares similar structural logics with modern space frames. The earliest concrete evidence of the bracket set structures were found at ZhongShan kingdom [中山团】 .
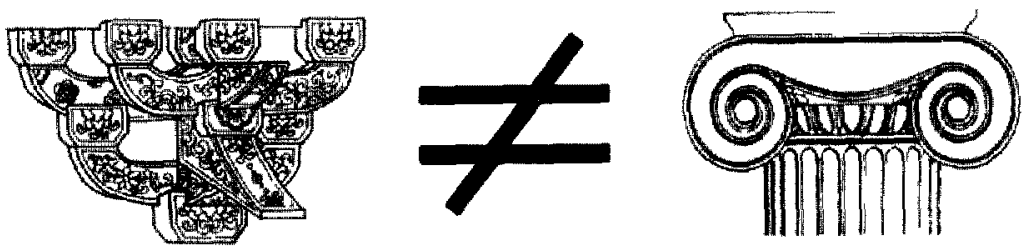

[IMG 15]

Though short lived, it was a significant state during the early Warring States period. As discussed by Steinhardt, the ZhongShan royal necropolis was, 
... an important mausoleum from Eastern Zhou times [, which] belonged to a ruler of the [ZhongShan] kingdom who was buried at the end of the fourth century B.C.E. in [PingShan] [平山] county of [HeBei] 【河北】 province. The ruler planned to be buried in a line together with his wife and concubines. Although only his tomb and that of one female exist, we are certain of his intent because beneath his tomb an extraordinary artifact was unearthed: a bronze plate known as [ZhaoYu Tu]

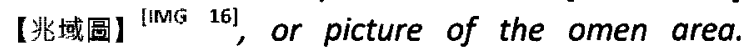
Engraved on the ninety-six by forty-eight centimeter plate is a bird's-eye view of his planned necropolis, with south shown at the top as is customary in early Chinese maps. The names of the intended occupants of the five halls are given, as are dimensions of (and distances between) each hall, the two enclosing walls, the front gates, and the small back halls. Equally impressive, an inscription decrees that a copy of this plate was to be kept in the palace so that future generations would know how to replicate their ancestral plan. Although other maps are known from the Eastern Zhou period, the bronze plate from the [ZhongShan] necropolis is the earliest Chinese site plan drawn to scale [at 1:500]. Furthermore, excavation has confirmed that the funerary temples plotted on the face of the bronze plate were indeed constructed above the graves "thith: 17]. [34]

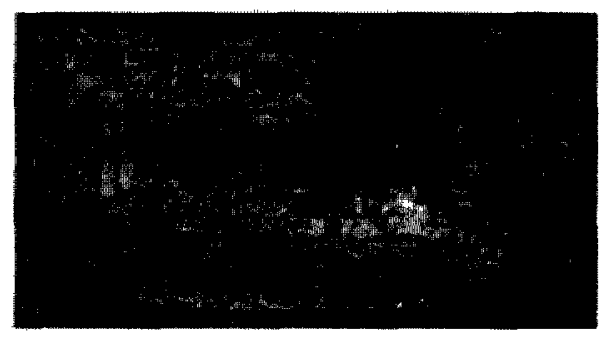

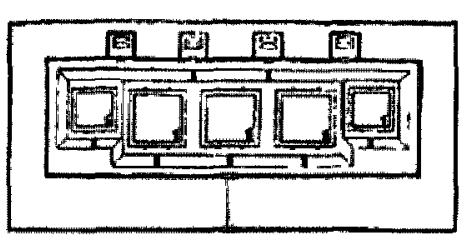

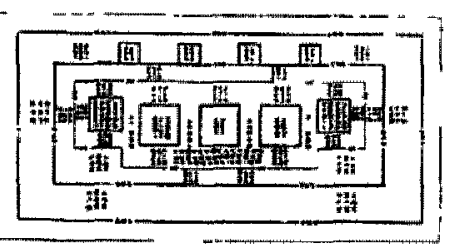

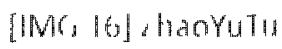

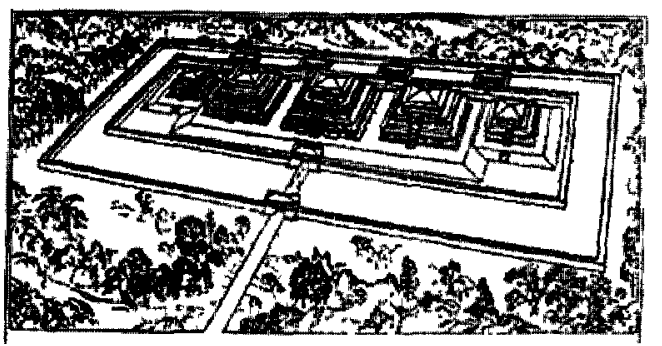

[IMG 1/] Ruconstiucted Image of Zhongshan royal necropols Indeed an ambitious project that employed tai construction technology at a grand scale, the royal necropolis as depicted in the ZhaoYu Tu along with several other relic excavated from the ZhongShan royal tombs and LingShou [䠤專】 city (the capital of ZhongShan kingdom) have offered much insights to the architectural tectonics and structural details of the early Warring States. Architecturally speaking, perhaps the most intriguing artifact next to

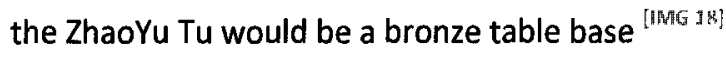

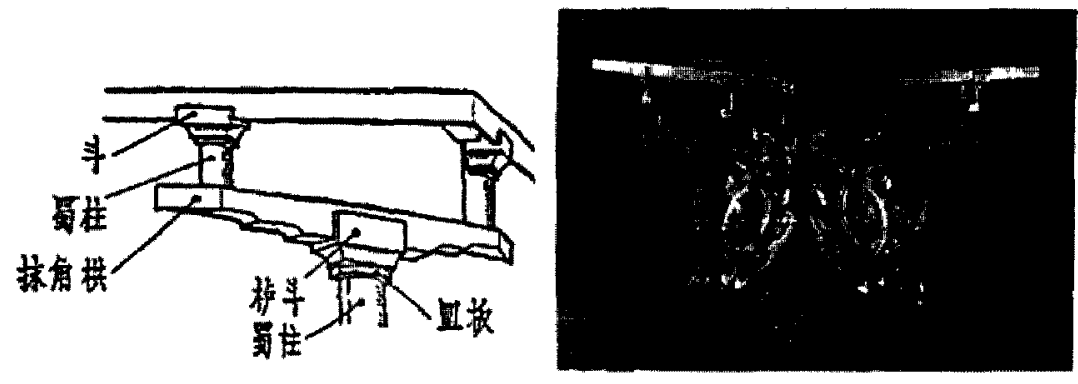

[1MS 18] Bronze Tablathate 
uncovered from the royal tomb, where a three dimensional archetype of bracket set was clearly depicted as a part of its structure. Diagonally supporting the four corners of the top frame as part of the table base, this earliest depiction of such configuration demonstrated the first formal composition of the two basic components: the squared block Dou【斗】 and the horizontal bracket arm Gong【撗】. While Gong is generally believed to be an evolved form of $\mathrm{Ji}$ 【枅】, a rectangular brace placed on the top of a column to help support a beam or overhang eaves; Dou, on the other hand, first made its appearance on a Western Zhou bronze vessel ${ }^{[I M G}{ }^{19]}$ as a squared connector between vertical column and the perpendicular beams. ${ }^{[35]}$

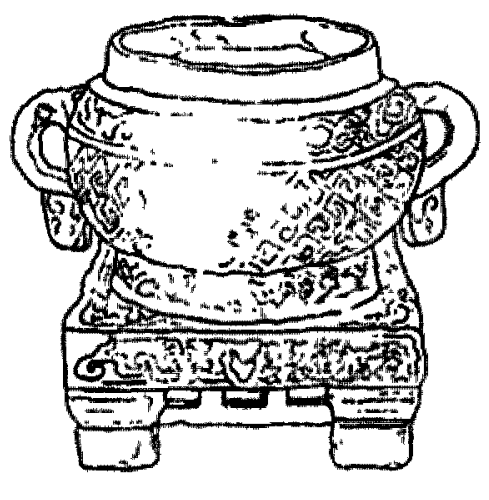

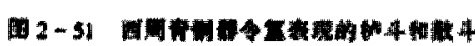

\section{[IMG 19] Bonze vessel \& Dou}

A collection of ceramic Dou [IMG 20] discovered at LingShou city exemplified a continual development of these structural blocks as complex load bearing joints.

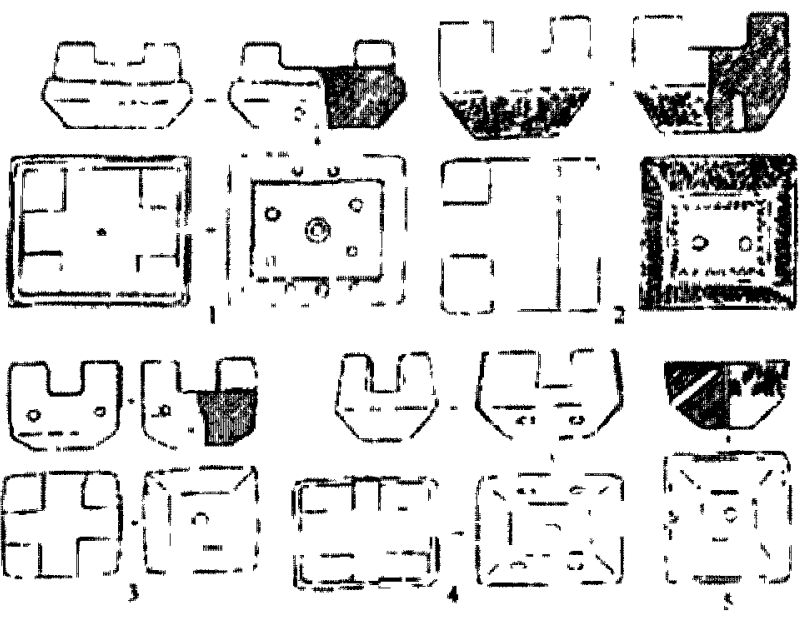

\section{[MG 20] Ceramic Dou}

Of course these remnants of antiquity could only justify an elementary development of bracket sets. Many academics have long been searching and debating over the inception of the original bracket sets, and several developed arguments have outlined convincing theories from a structural genesis point of view.

Professor Yang argues that the development of the bracket sets system is one of the most important topics in the discussions of tradition Chinese architectural structure. The Chinese conventional practice of Earth and Timber Integrated Structure demands maximum eaves extensions to protect its timber columns and earth wall from precipitation. As such, the first bracket set originated as an essential component that served to connect the roof structure with its load bearing gridded columns; and also to provide structural support for the extended eaves. Based on the remnants found at ErLiTou, 
PanLongCheng and other Shang ruins where single or double shallow post bases were found in close proximity to each submerged plinth of the exterior columns ${ }^{[\text {ING } 21]}$; Yang believes it is possible that DouGong might have been initially derived from the assimilation of two originally separate structural components: the main columns that bore the weight of the roof and the subsidiary eaves supporting posts, or in Chinese terms QingYan Zhu 【㢣䱦柱】 [IMGG 22].

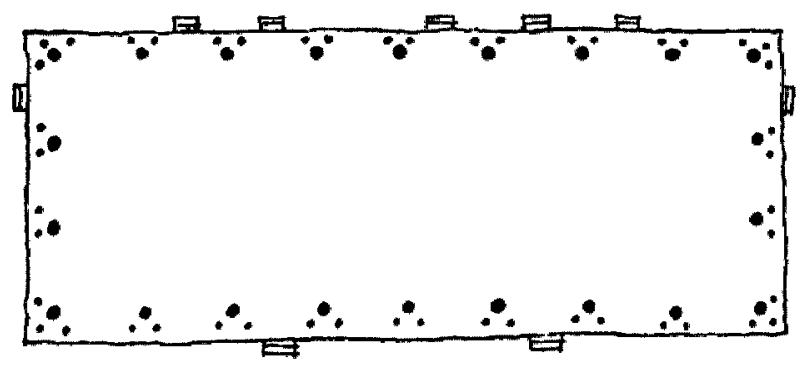

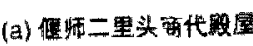

[IMG 21] Excavated plan of trliTou palace ruin

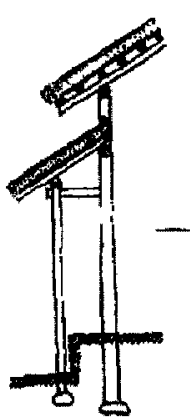

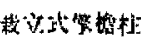
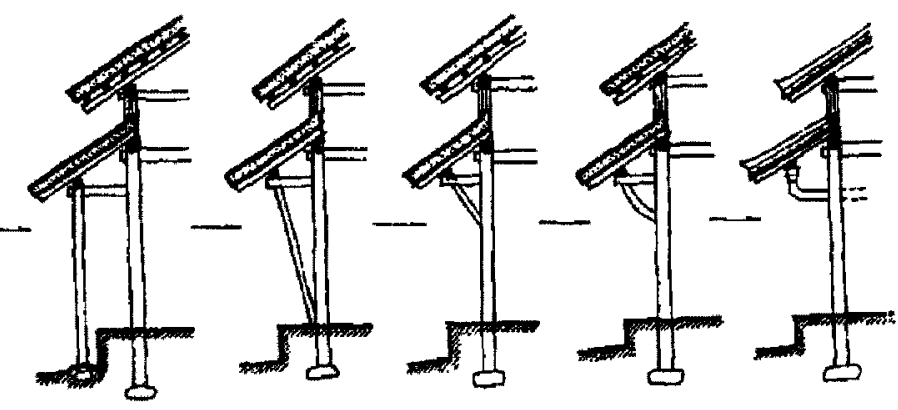

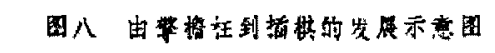

[IMG 22] Transitions from Qung Yan Zhu to bracket sets
However, Zhang L. points out an interesting interpretation and disagrees with Yang's argument. Using a main hall of a palatial complex from ErLiTou as an example, base on the distance between the smaller post bases from the main columns, which is about 60 to 70 $\mathrm{cm}^{[36]}$, and the diameters of the eaves supporting posts, about 18 to $20 \mathrm{~cm}^{[36]}$, and also considering the height of these posts; Zhang L. believes that, base on the ratio of their diameters and heights, these subsidiary vertical elements could barely support their own weight. It should be considered that the density of these small posts would have clustered all around the perimeters limiting visual and physical access to the building with small gaps in between. Furthermore, he points out that, since the initial timber frames are mostly inspired by the organic model of tree forms, it is an oversight to assume the ancient Chinese failed to grasp the simple physics of cantilevers ${ }^{[37]}$. He believes that the 9 by 4 grid with columns each measuring $40 \mathrm{~cm}$ in diameter could easily support cantilever beams providing structure for overhang eaves extending beyond the perimeters of the exterior columns.

Zhang L. suggests that, considering GanLan【干欄】—stilt dwelling一 tectonics and XiJu【席居】 - the ancient mats and sheets life style ${ }^{[R \&]}$ were widely practiced across ancient China until the end of the early Imperial era, it would be more logical to reference a Japanese traditional structural detail [IMG 23 ] to rationalize the use of these smaller posts. Detached from the main columns which primary task was to support the thatched roof, these subsidiary vertical elements were more likely placed to provide an independent structure for a low 
stilt-flooring framework. By isolating the flooring structure from the roof support, this typical GanLan tectonic could minimize the need to drill into the main columns, and in doing so, it would prevent comprising structural integrities of these main columns while also providing a stronger framework for the floor planks at the same time [IMG 24].

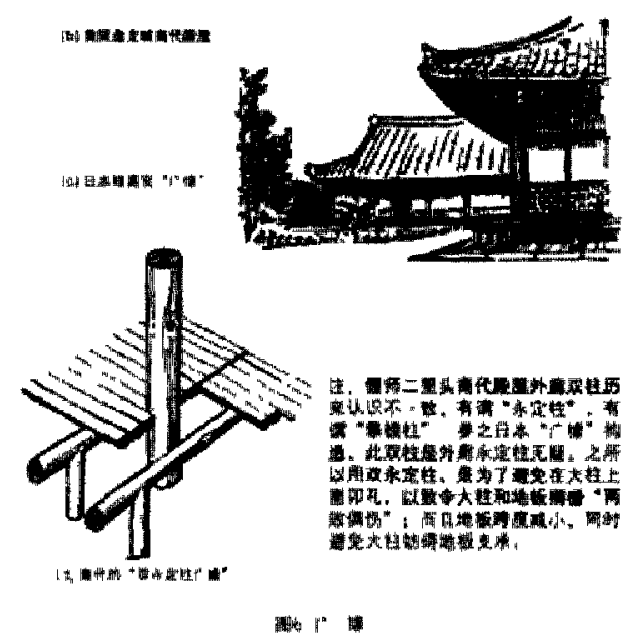

Top: [MG 23] GuangYuan: Japanese structural tectonic Bottom: [IMG 24] Structural Detall for elevated floor planks

Chen DaMing 【陳 達明 1 - an expert on Structural Carpentry ${ }^{[39]}$ ( or

Chinese term DaMuZuo【大作】) -inspired by his intensive analysı of the YingXian Wooden Pagoda, was the first to suggest bracket sets tectonic was derived from JingGanGou【井幹構】， literally translated as Well Core Structure-a heavy timber construction which first appeared at the prehistoric HeMuDu settlement as the retaining core of the communal well ${ }^{\left[1 m b i{ }^{25]}\right.}$. The assemblage of the tiered tie beams essentially shared the same structural logic of intersecting logs; in fact, the entire bracketing system could be seen as layers of cantilevered junctions flaring beyond the corners of the Well Core Structure ${ }^{[40]}$.

\section{Liu Jie【劉杰】 in his book Timber Construction of JiangNan Region}

【江南木構】 so far has presented the most convincing argument. He believes that the typical bracket set as a structural component should not be separated from the rest of the tectonic framework. A profound analysis of its origin and developments should also investigate its role within the larger structural scheme. From a macro-structural perspective, Liu takes into account the fine deviations of the two predominant Chinese tectonic frameworks. Distinguished by regional differences and social regulating standards, both structural systems were matured by the mid-Imperial eras.
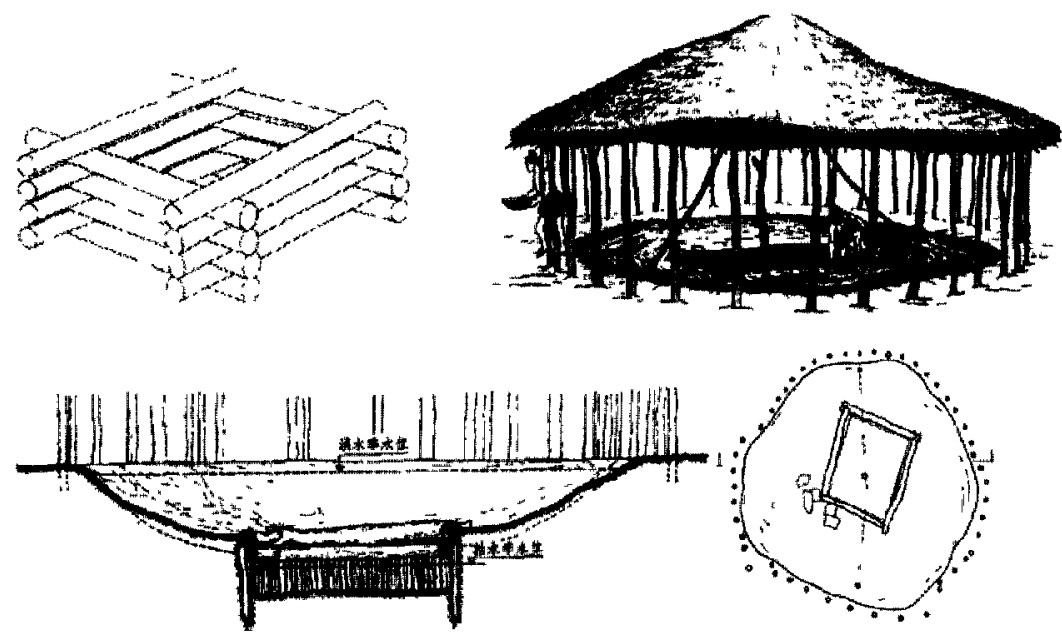

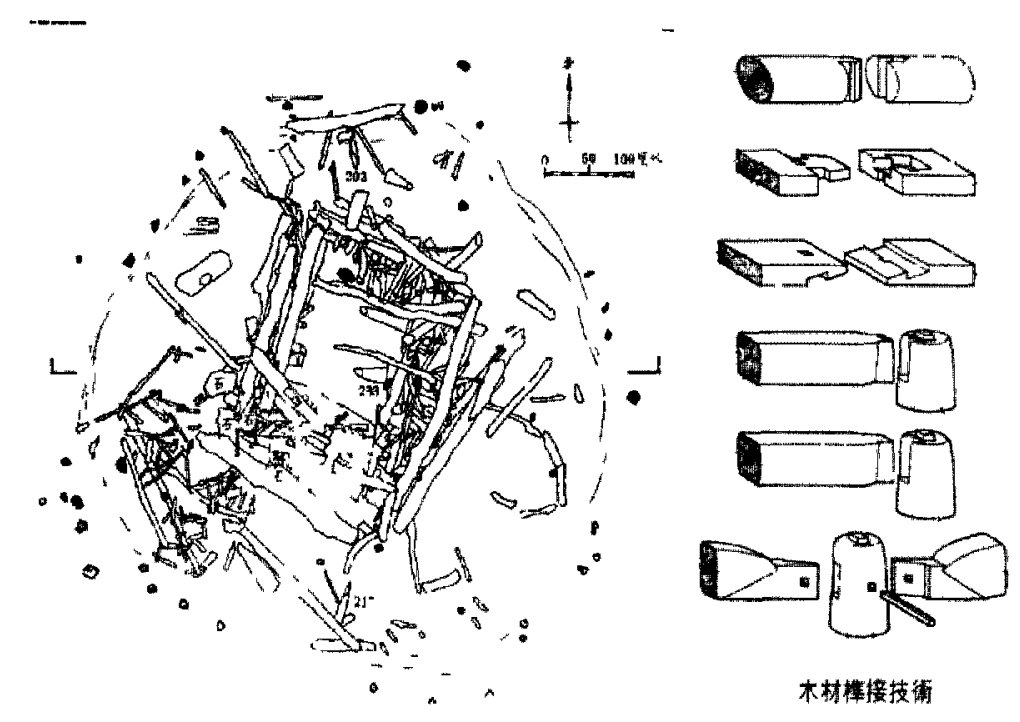

[IMG 25] HeMuDu Well structure

In Northern China where TaiLıang Technique in Structural Frameworks 【抬梁式構架】 $\left[1 \mathrm{ML}^{2}\right.$ 26] -a column-beam-and strut system-were conventionally used; girders spanning across the depth of the structure were stacked, one on top of another with lengths reduced consecutively on short vertical struts (which were usually king or queen posts (respectively in Chinese terms: ShuZhu【虫柱】 and TongZhu【童柱】), in order to provide supports for the roof loads. Therefore, the invention of the squared Lu [攎] (a former name for Dou【斗】) and the horizontal Ji【枅】, the primitive form of Gong 【拱】，were necessary to reinforce stability in connecting the vertical and horizontal structural elements ${ }^{[41]}$.

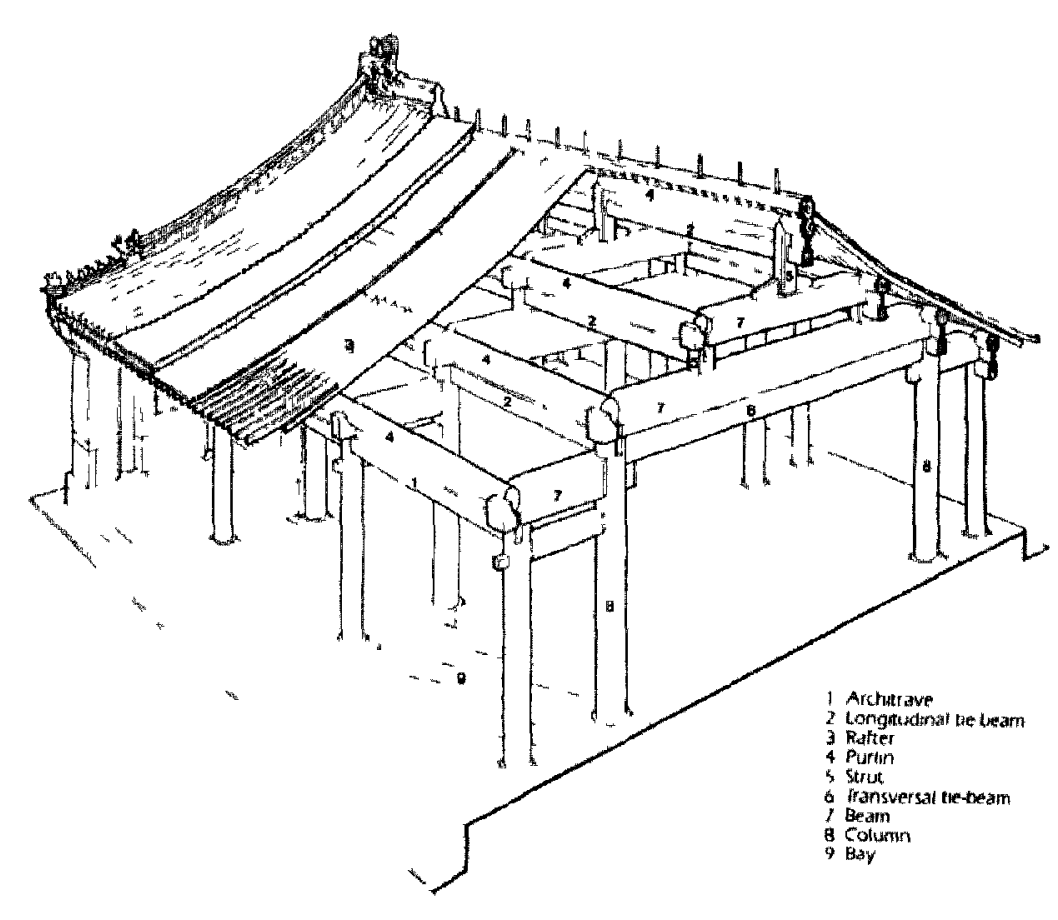

[IMG 2t:] Tdh lang lechnque Structural Frameworks 【抬梁式構架]

In contrast, the ChuanDou Technıque Structural Frameworks 【穿斗式椿架】 [1以3 27] - otherwise known as the column-and-tie system-which prevalled in most southern Chinese constructions, were composed using complex tenon-and-mortise joineries between vertical columns【柱】， axial tie beams【橙】，and longitudınal architraves【枋】 


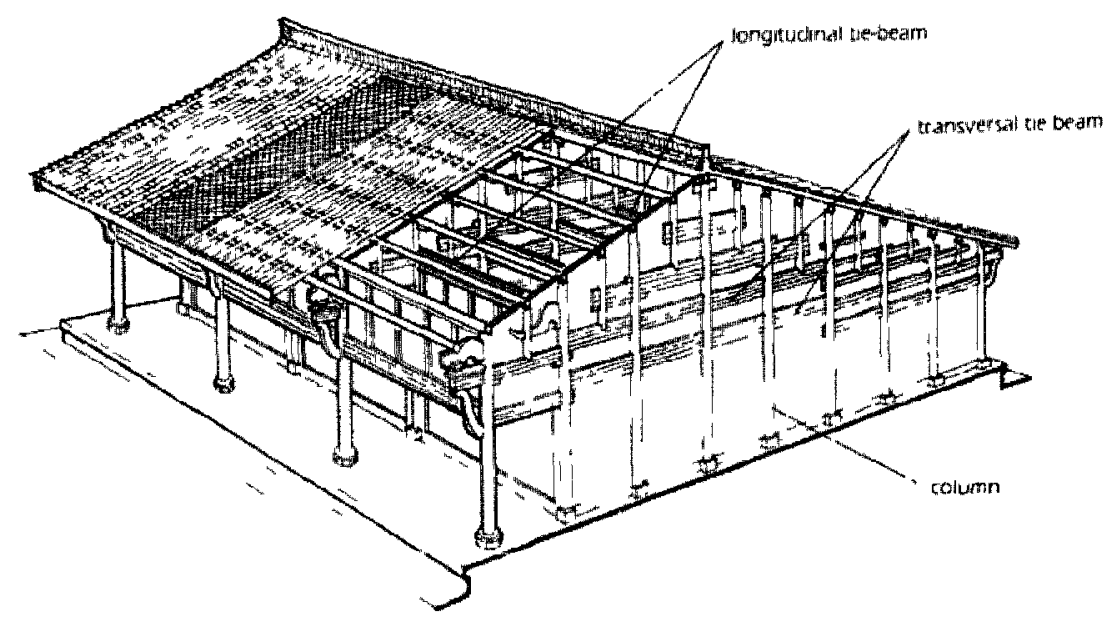

[IMC 27] ChuanDou Technique structural Frameworks [穿斗式構架]

Because this type of structural frames spanned shorter in distance and the column grid formations were generally denser, it would be less complicated to use a cantilevering beam (in Chinese term, a TiaoLiang (挑墚I) to support eaves overhang by simply extending the interior tie beam through the exterior columns ${ }^{\left[4 k_{1}\right] 2 !}$. $^{[42]}$ In other words, the bracket system of Dou and Gong is completely unnecessary, or as coined by Professor Han BaoDe [漢 珼德] inorganic, in ChuanDou Style Structural Frameworks. In fact, the simple solution of cantilever beam under overhanging eaves is commonly found in the many traditional secular buildings in extant.

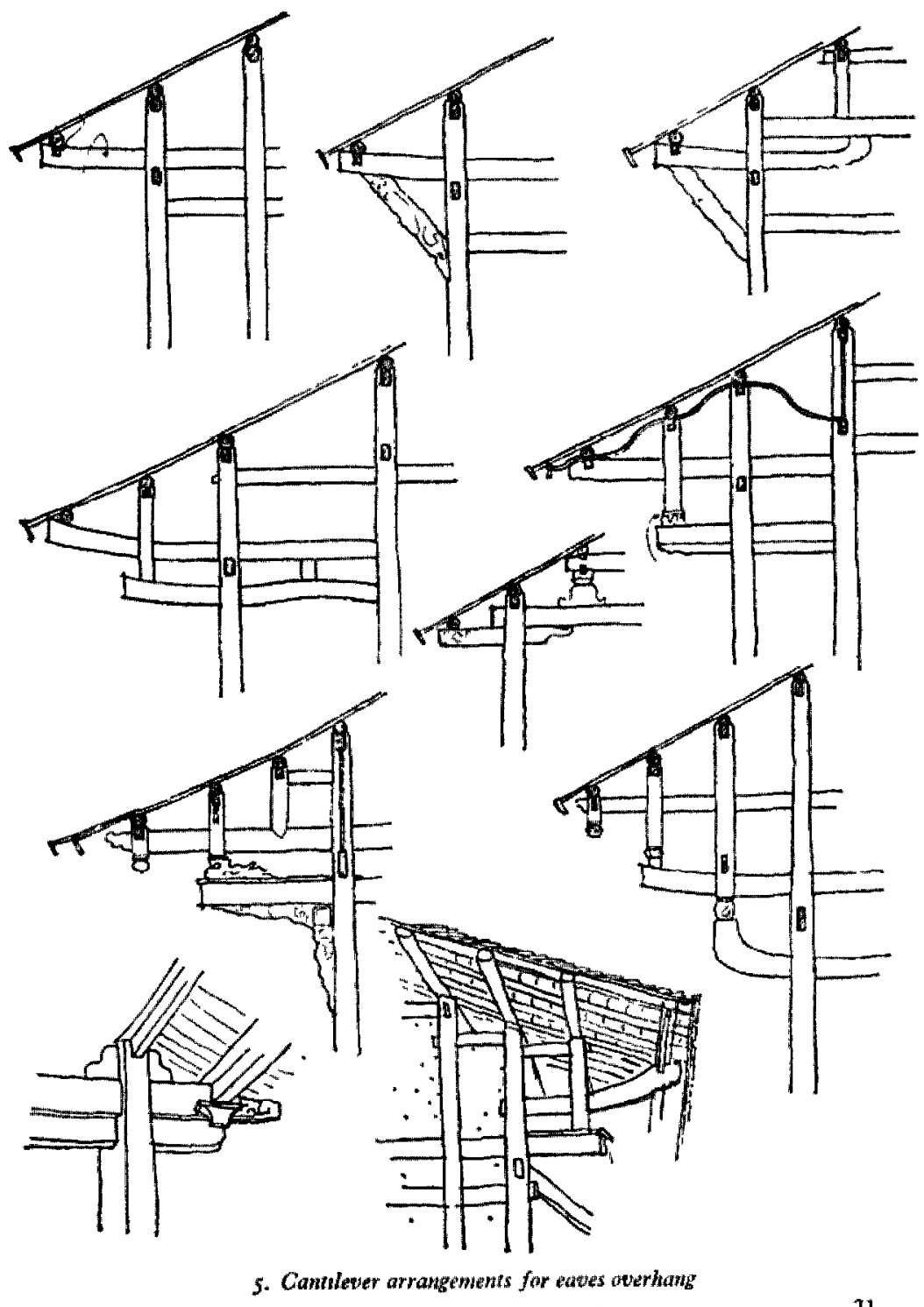

[IMG 28] Cantilever ar rangerrients for eaves overhang in southern domestic constructions 
Here we must provide some clarity pertaining to structural principle of the Chinese timber framework. Whether it would be in the TaiLiang technique or the ChuanDou technique, Chinese timber structure is basically composed by a series of (relatively) two-dimensional axial frames $\left.{ }^{[\mathrm{A}) \mathrm{ig}} 29\right]$
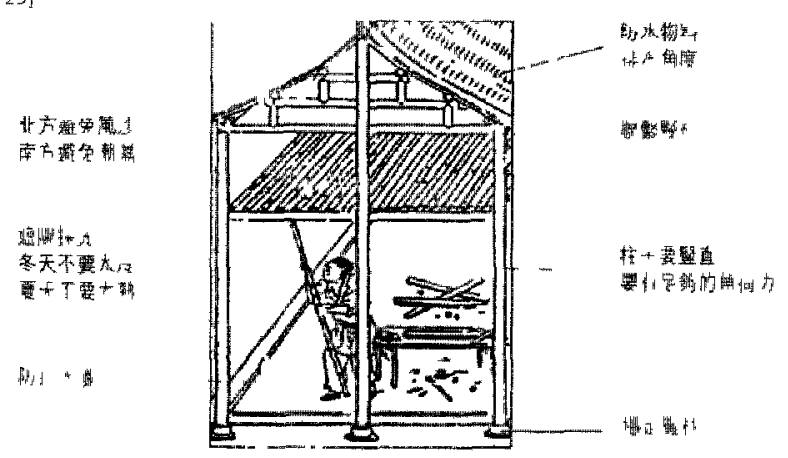

[IMG 29] Two dimensional dxal trarle

Placed at regular intervals along the length of the building, each axial frame was connected with another by a number of longitudinal tie beams and purlins ${ }^{\mid \| M t}$. Focusing on these frames, we could roughly characterize the structural parts into three vertical sections: columns II, systems of bracket sets【鋪作】, and the roof canopy【屋蓋】 11111$]$.

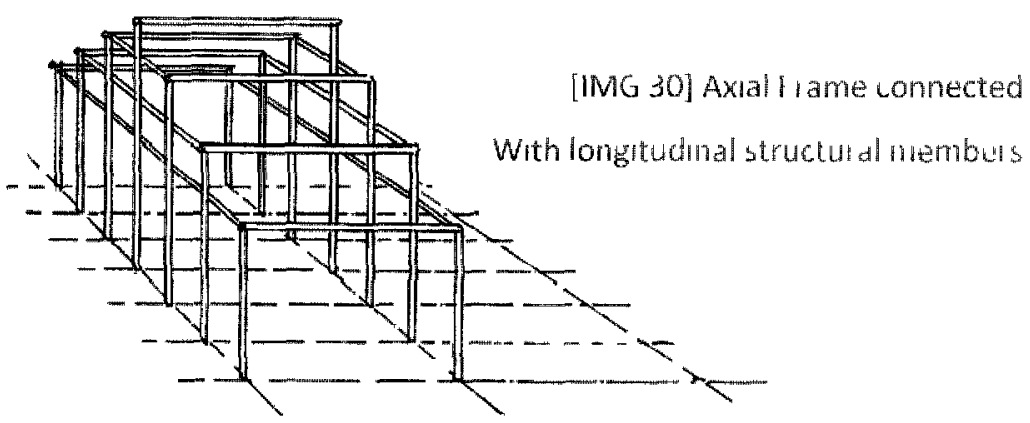

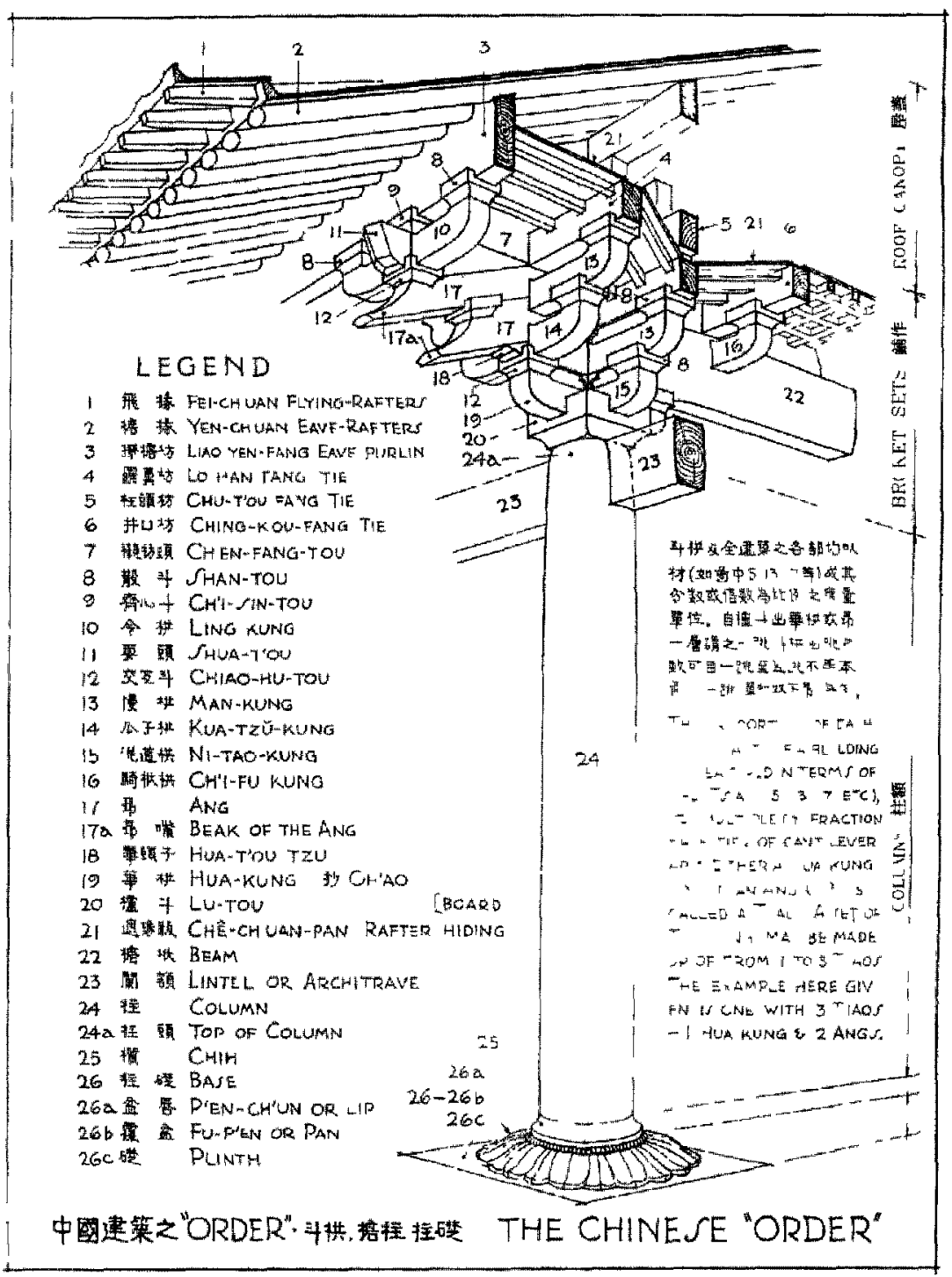

IIMG 31] Thu che we rtical sections of axial timber frame 
Here we see how the structural configurations of Chinese frames have set themselves apart from the Western constructions. Using Banpo models ${ }^{[i \mathrm{~m}]}, "$, Chu compared the rudimentary structural intentions of the Chinese traditions to the Western approach in structural compositions. He interpreted building of the West are typical

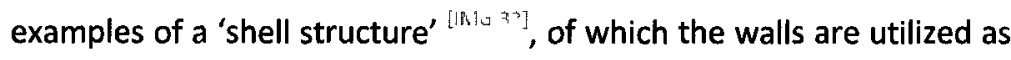
structural support and spatial enclosure. As manifested in classical Greek temples, in terms of the entire structural composition, timber roofs were dependent on load bearing stonewalls and columns for support; but in essence, the two components were fabricated independently from one other with different materials and different structural logics. Although solid masses were excellent material for achieve heights, the disadvantage of the complete structural dependency on load bearing walls would prompt comprises in the interior spatial schemes as intensification of load bearing masses would be inevitable in correlation to the increase in height ${ }^{[43]}$.
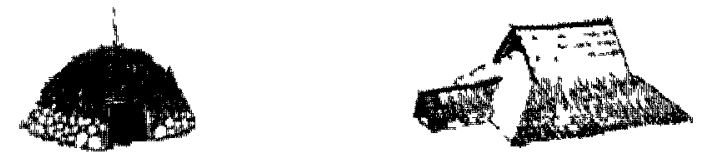

[IMG 32$]$

Left: Western prinutive hut Right: BanPo semisubterranean dwelling
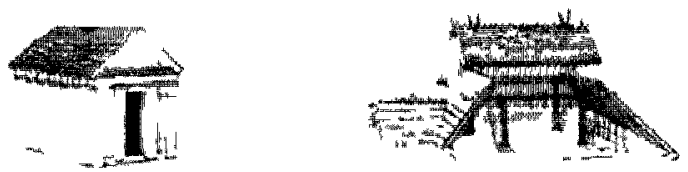

IIMG 33]

Left Western Iudmentary house. Right BanPo fudimentary house
On the other hand, Chu uses the metaphor of a 'skeleton structure' to describe the Chinese timber frame configurations. Walls as spatial enclosures were free from load bearing obligations and were often completely removed from the roof and the building entirely. On its own, it is used to envelope groups of building at the perimeter of the complex. Propping up the overhanging canopies, gridded columns performed as extensions of the roof frames. As depicted in ShiZhenTu

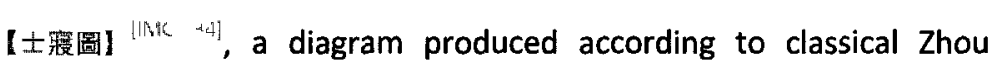
regulations which standardized dwelling for Shi $\llbracket \pm$ (the lowest rank of the ancient nobility), each of the columns was given a specific name in correspondence with the name of the architrave it supportedclearly, the columns existed solely to upheld these horizontal elements which carried the roof loads ${ }^{[44]}$. In other words, the roof configurations determined the orthogonal layout of the column grids.

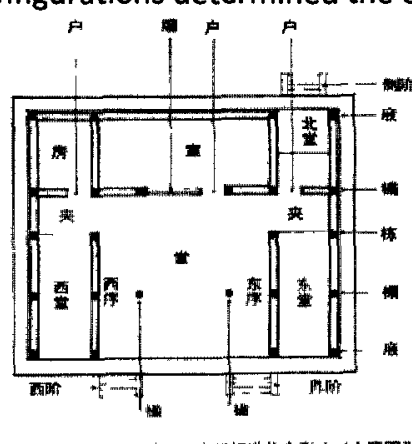

[IMG 34] ShizhenTu【士眐圆】 Columwis named after architraves of the roof fiame The essence of the Chinese structural intention, as illustrated on a Qin ceramic roof tile ${ }^{\operatorname{lIMG}{ }^{2 r}}$, was to conserve an intact canopy and have it lifted with continual developments on structural support technology. Therefore, even though the Chinese axial frame could be generally 
categorized into groups of components-the columns, the bracket sets, and the roof frame; the intricacy of their articulations with one another would make it difficult, if not impossible, to grasp the complete structural intentions if each group were to be analyzed independently. In particular, the bracketing system as a structural intermediary between the roof canopy and its extended vertical supports should not be regarded as simply a capital on top of a column. The bracketing system in essence is a versatile "solution", a flexible composition responding to specific needs in different structural conditions, before they were conformed to the Chinese social regulations and became formalized standards. ${ }^{[45]}$

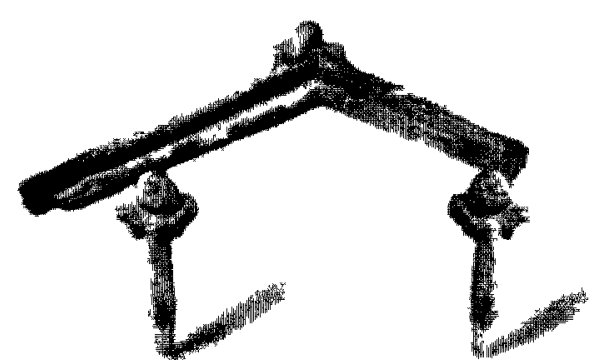

[IMG 35 ] Columns, bracket sets and roof canopy tectonic as depicted on a Qun ceramu the

The benefit of such skeleton structure was that it was effective in conveying a sense of spatial distinction between the interior and the exterior without the need of a physical obstruction. With such structural approach the Chinese avoided the absolute separation of the interior space from the exterior and offered a wide spectrum of infusions between the two as desired by the planner in different schemes.

Instead of extending vertically in height, the typical Imperial buildings expanded horizontally in size. As the coverage of the building amplified, the fluidity of the interior space would be hindered by the matching increments of vertical supports. Li suggests that the ChuanDou technique was an earlier development, while the Tailiang technique was an evolved form, which significantly reduced the number of columns required by simply substituting the reinforcement of axial tie beams with load bearing girders ${ }^{[\mathrm{k}(\mathrm{i}) 36]}$.

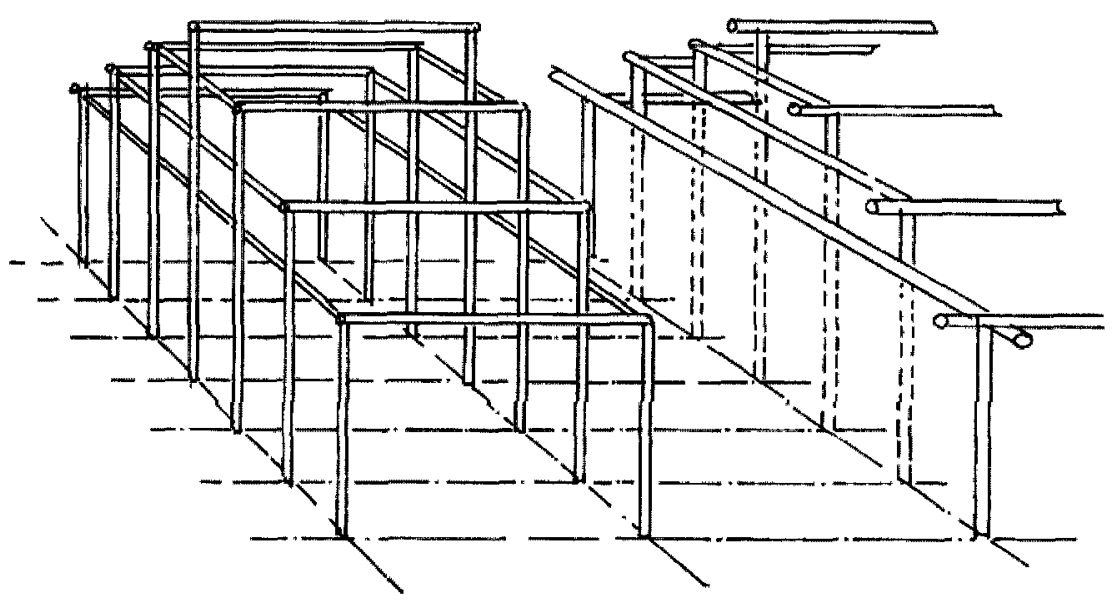

[MG 36] llansthung from ChuanDou to lablang

But by altering the structural composition, the Tailiang structural frame no longer has the capacity to reinforce cantilevering beams as a support for the overhanging eaves. Liu is convinced that, in order to 
attain maximum depth from eaves coverage while achieving a gentle and pleasing roof curvature with an open interior space, the development of the bracketing sets system was absolutely essential in TaiLiang structural frames. ${ }^{[46]}$

Exploiting both ChuanDou and the Tailiang technique, the concept of a load bearing envelope structure remained neglected in Chinese building practice. Here we must stress that the ChuanDou and Tailiang framework were not so much as two distinctive styles as they were two different construction methodologies. The Chinese were aware of the strengths and weaknesses of both techniques. While the ChuanDou technique limited the fluidity of interior spaces, it responded better to wind resistance. Most importantly, there were less structural demand on individual timber components. Therefore it is economically and technologically more efficient in its construction. For such reasons, the ChuanDou technique was immensely popular in Southern domestic dwellings ${ }^{[47]}$. On the other, the Tailiang framework was composed of both vertical and horizontal load bearing elements. Even though the quantities of structural elements were significantly reduced, it demanded timber with larger cross sections and a greater material expenditure in general ${ }^{[48]}$. For such reasons, the Tailiang framework was mostly reserved for religious and official constructions. So long as the construction codes as defined by the Imperial social standards have not been breached, these two techniques were often interchangeable and 'integratable' depending on the project's budget and it's programmatic character.
In his detail analysis of the origins and evolutions of the bracket sets with its associations to the complete timber frameworks, Liu points out that a common misconception must be corrected:

[T]he "Tailiang Frame" that would be
implemented nationally during later imperial eras
was not an independent developments of the North.
Instead, it was a comprehensive cultivation
perfected with the gradual amalgamation of
architectural technology from different regions...the
origin and evolution of the bracket set as a matured
system during the Tang and Song eras was in fact
the product of assimilated timber construction
technology between the North and the South. To be
more precise, the bracket set system was shaped
during the gradual maturation of architectural
conventions as a part of Yellow River Basin culture in
the North as this progress coincided with a
continuous influence and absorption of advanced
architectural culture from the southern regions. ${ }^{[49]}$

Even though there is an absence of architectural artifact to validate Liu's argument; considering the socio-cultural transitions took place as the Ancient HuaXia cultures metamorphosed into a unified Imperial China, it would be imprudent to overlook how

the major regional and cultural exchanges have contributed to later architectural developments. Within one and a half century, the Chinese civilization have set apart itself from the feudalist past and consolidated its character as an Imperial society.

The Qin regimentation and its many acts of unification in all social and cultural aspects have effectively forged a permanent bond between 
the different ancient cultures. Followed by the consummation of the Imperial system constituted by the Han regime, the social cultural aspects of many Chinese traditions took on character during this final stage of adolescence. We would further discuss in detail the changes in architectural developments as resulted from these socio-cultural transformations.

It is clear that, the adolescent developments of the Chinese structure did not evolve based on one single regional or cultural source. Let us be reminded that during times of the Eastern Zhou, China proper covers a vast area with different geographical and climatic conditions, and also with various natural resources. Though to a certain degree nobilities of the vassal states were sharing the same regulated standards established by Zhou's royal court, each of the pre-Qin states have cultivated distinctive cultural characteristics and technology accustomed to the diversified regional difference. Without any doubt, the heated competition of Tai constructions has contributed to significant improvements in architectural technology within each of the states. During this period of ferment and change, the deterioration of the stratified slave society has prompted a gradual emancipation of artisans from under the control of noble families. Needless to say, this new socio-political conditions have further encouraged the exchange of crafts and building technologies.

The chaos and the excitements of Eastern Zhou came to an end when the second most significant societal and economical revolution took its stage in the year $221 \mathrm{BCE}$. Transforming and unifying the entire HuaXia civilization, this second and major phase, called by Dr. Needham as "bureaucratic feudalism", was initially established by the short lived Qin regime; and for the next two millennia, China proper would be governed by a system of centralized Imperial administrations.

Qin ShiHuang, as the first Imperial emperor, issued two important

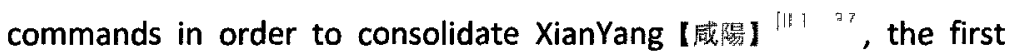
Imperial capital located closely to the northeast of our contemporary city XiAn【西安】. According to SiMa Qian, after each victory over the other six vassal state, Qin ShiHuang would order to reconstruct a replica of the royal palace of the defeated state at XianYang. Also after he has conquered all, he uprooted and transferred a hundred twenty thousand families of the wealthiest and of the most powerful within his new empire to his Imperial capital. ${ }^{[50]}$ Only a precursor to the many acts of unification, the fortification of XianYang was perhaps the first and the greatest assimilation, in both official and secular practice, of architectural technologies in Chinese history.

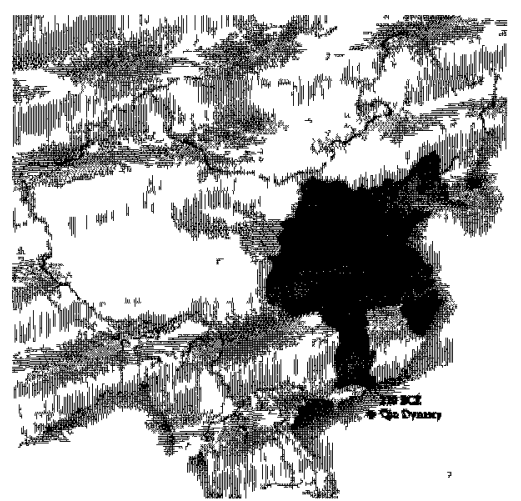

[IMG 37] Om China. $221 \mathrm{BCE}-207 \mathrm{BCE}$ 
Within a short 15 years period, the autocracy of the Qin regime with its many extensive construction projects, all require mobilization of a tremendous labor force at the national scale, has exhausted the newly established unity. The Han dynasty as its replacement has learned from Qin's mistakes. The early Han reigns adopted Daoist ideologies in its governance and strived to encourage economic prosperity and political stability. Internally, the central authority would refrain from interfering with the people's affairs; and externally, the sovereign maintained several decades of pacifist approach in its foreign policies. For a very long time since centuries of chaotic changes of the Eastern Zhou and since the ferocious tyranny of Qin, these were the golden decades during which the entire HuaXia civilization was able to rest and rejuvenate socially, culturally and economically.

It should be noted that the new monarchy Liu Bang【㖶邦】 and his court were mostly survived subjects from the defeated state of

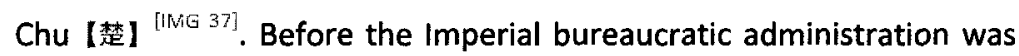
enacted, descendents of Chu origin dominated the politics of the early Han reign. Naturally, the ruling class would have imported the Chu culture from the southern YangTze river region and incorporate their native culture with the northern customs in the establishment of the new empire. Aside from the cross-regional cultural transformation, fundamental changes in the social orders have also determined the formalization of architectural developments.
At the end of this golden era, commonly known as the Rulings of the Emperors Wen and Jing 【文量之治】，the centralization of the imperial power was actualized during Emperor Wu's reign (141 BCE to $87 \mathrm{BCE}$ ) [HMG 39]. Politically, Emperor Wu strategized to put an end to the transitioning feudalist system by diminishing the powers of the last of the Han vassals (members of royalty) and recanted their fiefs. Economically, he monopolized iron and salt production under the control of the central government. Lastly, he established the most important instrument of the Imperial system which endured until the end of the Imperial eras:

...[T]he most characteristic feature of the whole system was a large, educated state bureaucracy or civil service, appointed and controlled from the center, cutting across local interests and controlling all parts of the administration, revenue and justice, including the army. This huge 'class' or rather section, from which most of the great men of letters, scientists, painters and statesmen in Chinese history were drawn, was recruited in theory by means of open competition from all classes, in practice mainly from those who had the means and leisure to be educated and to compete-the landowners and merchants. ${ }^{[51]}$ 


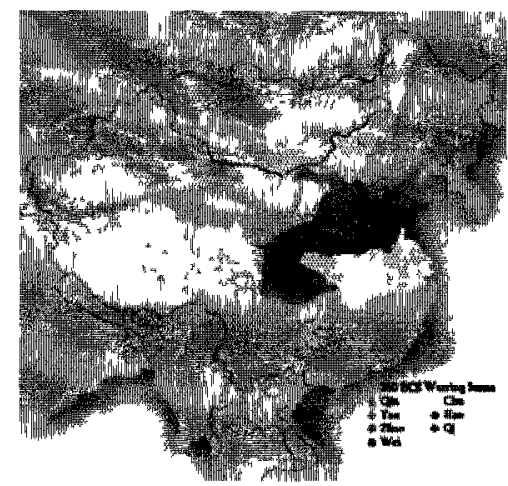

[1/VG 38] Warring States. Chu 4 1 BCE- $221 \mathrm{BCF}$

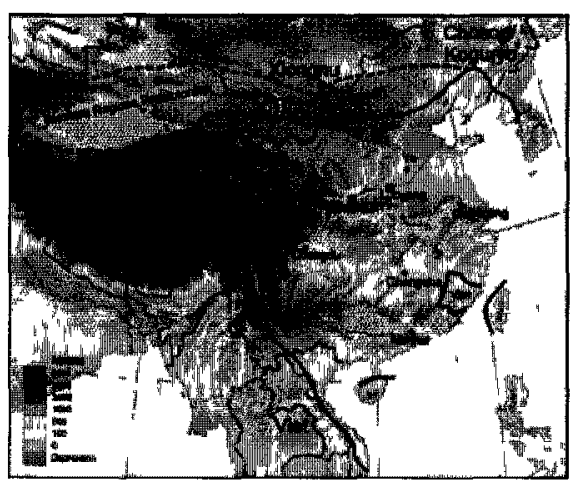

[IMG 39] Han China $206 \mathrm{BCC}-220 \mathrm{CE}$

From this point onwards, politics was no longer a privilege privatized by royalty and nobility. The imperial bureaucrats have replaced feudal aristocrats in running the state machine under the guidance and instruction from the Imperial emperors. The stratified society of the feudal past was replaced by four classes of occupation: bureaucrats, farmers, artisans, and merchants. It should be noted that,

[The] Chinese society was neither a caste society nor even one where status was rigidly fixed by birth. It was more fluid, and status was based more directly on wealth and official position. A man was not necessarily born a 'gentleman'; he could become one overnight by passing an [official] examination. Great families could sink to poverty, and poor ones could rise, however rarely, through office to power and riches. ${ }^{[5,]}$

The new fluidity of social orders and modes of production brought about great transformations in architectural practice. There is little

evidence to offer us insight to the commoner's dwelling before Imperial times. The Zhou standards only applied to official and ritualistic buildings and the regulations they imposed concerns only the estates of vassal lords and nobilities. In such stratified society, it would be unlikely the free and slave peasants and artisans have much liberty to develop an autonomous approach in domestic residences, or for that matter, any luxury beyond the minimal survival necessities. The instability of political chaos during later parts of Eastern Zhou and Qin dynasty would not have provided much room to sustain the civilian building industry.

But during the golden half-century of early Han, the broken orders and the new social conditions have nourished architectural improvements in the private sector. Profited by older traditions and innovations, the building boom of the time resulted in a definitive crystallization of the traditional features of domestic dwellings, which in many ways were ensued from the idealized spatial and structural principles of official constructions. That being said, in contrast to the ancient pre-Qin settlements, which were private domains of the vassal lords; it was deemed necessary for the Imperial cities as official administrative centers to adopt a formalized layout compatible with the social regulations.

The rectangular Han dynasty tile...is a rigid, finite, and unnatural design. Wherever circumstances permit, this image is readily translated into the equally unnatural classical city plan of China, sometimes using the same animal symbols to name 
the gates at corresponding cardinal points. It manifests an intellectual order superimposed upon a natural terrain. The [Tang] dynasty capital of [ChangAn] and its Japanese copies, Nara and Kyoto, are such expressions... This rationalized basic design is not only frequently seen in city plans but is also sensed in the layout of houses, palaces, and tombs. Always keep man in its center, it is an image of man's society, organizing its enclosed space around him. The Chinese designer is continually challenged and inspired by the specific requirements of each social program and by the human relationships in the society which his building serves and portrays. ${ }^{\left[{ }^{60}\right]}$

The implementation of rigid planning known as LiFang Zhi【里坊制】， which was a pre-Qin city regulation with enclosed wards, has imposed a significant restrictions to the formal developments of domestic dwelling. As manifested in the Han capital ChangAn【長安】 《ivis which was originally located at the immediate northwest of the modern city XiAn [西安】， early Imperial urban layout was divided into standard blocks by intersections of north-south and east-west public roads within the city enclosures.
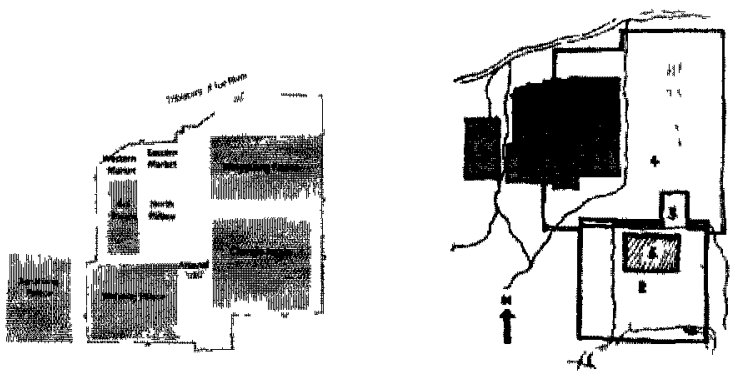

[IMU 40] Western Han Capital ChangAn 【長安】
These roads, lined by uniform walls, were no more than passageways for internal traffic. As mentioned in previous chapters, the early Imperial urban layout had no room for undefined open public space within the city walls. The walled urban wards, otherwise known as fang 【坊】, mostly housed residential dwellings and two larger ones in particular were designated as the East and West Markets "[Mth $" 11]$. These urban progressions are extremely significant to the architectural developments, as Wu emphasizes,

The dual quality of the house, as a setting for ceremony and as a home, is a most important characteristic of the house as an image of human relationship... Theoretically, the number of courtyards one could have, and the accompanying sense of depth in privacy, was determined by one's status. The situation of a house in a Fang (a square of houses with its own network of streets), as indicated in Han dynasty sources, was again determined by the status of the owner. However, instead of the seclusion in depth, it was the prominence of the location that denoted prestige within a Fang. ${ }^{[56]}$

... The lasting values in the tradition beginning with the formative period of Han (at the latest) perhaps should be sought in the enduring design that has shaped the humble family house as well as the Chinese city of man. The house is the basic cell in the organism of Chinese architecture, just as the family it houses is the microcosm of the monolithic Chinese society. ${ }^{[53]}$ 

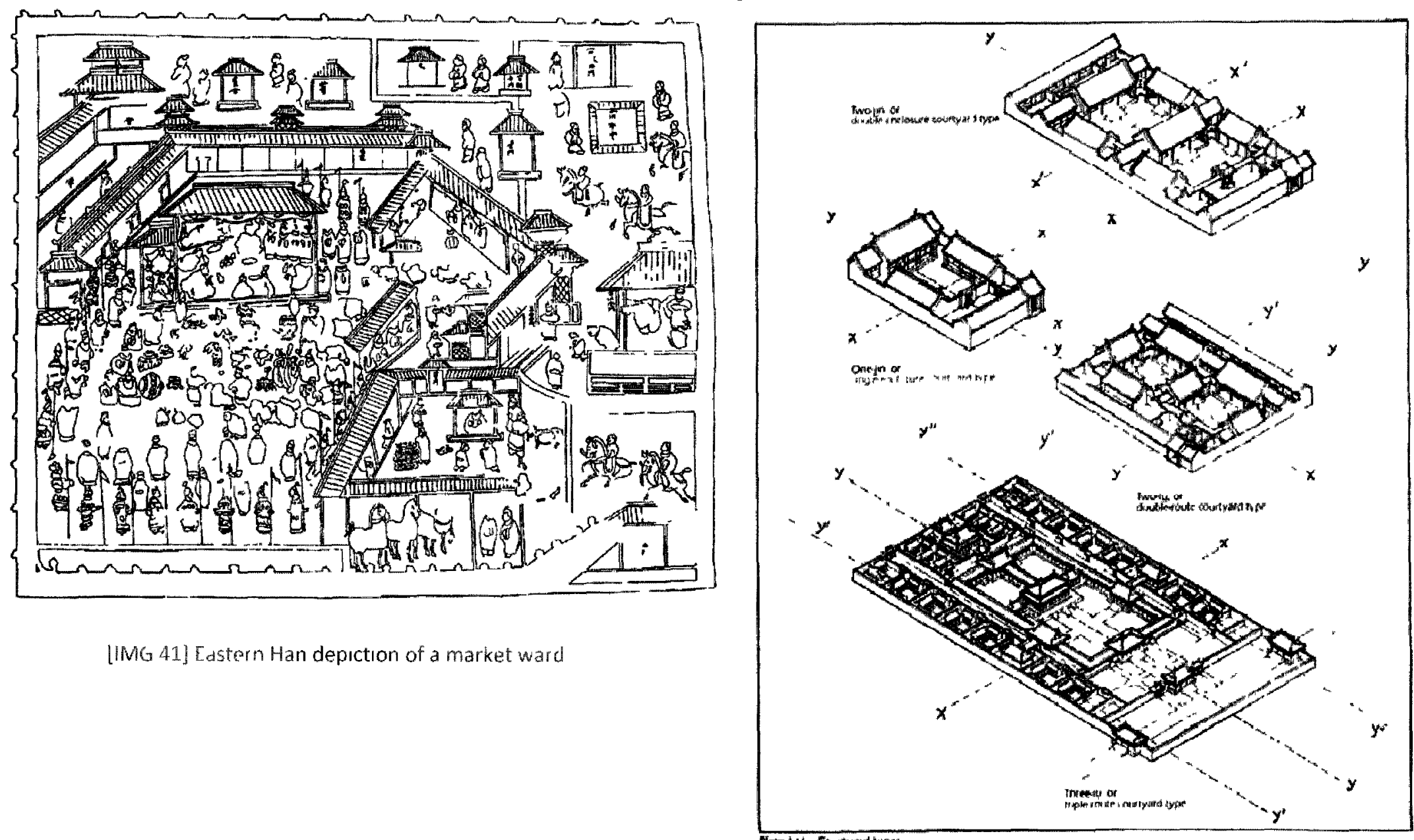

[IMG 41] Edstern Han depiction of a market ward

II countyed types

[IMG 42] Similarities between offiud and Conventional $S p$ itiul

Schemes 
In short, domestic residences and their dwellers of different social standings must abide by Imperial standards which dictated the name of their dwellings, the spatial and structural components in each of their buildings, the number of courts and the overall configurations of the courtyard complexes, and the position of their dwellings within the enclosed wards ${ }^{[57]}$. The main entrance of each ward that was shared amongst all occupants would be guarded and peasants would be prohibited from exiting and entering at will during the nights. However, this daily curfew would not be applied to higher-level government officials who were permitted to position their entrances on the exterior walls of the wards and had direct access to the main roads.

Under these circumstances, it should come as no surprise that the Imperial developments of private constructions would affiliate their spatial and structural principles in reference to the standardized official schemes $\left[{ }^{[M i s}+2\right]$. As depicted in many tomb murals, the courtyard complex as the conventional domestic typology was consummated during the Han dynasty ${ }^{[M G G 4]}$.

[IMG 43] Ceramic nodel depicting a typical domestic complex

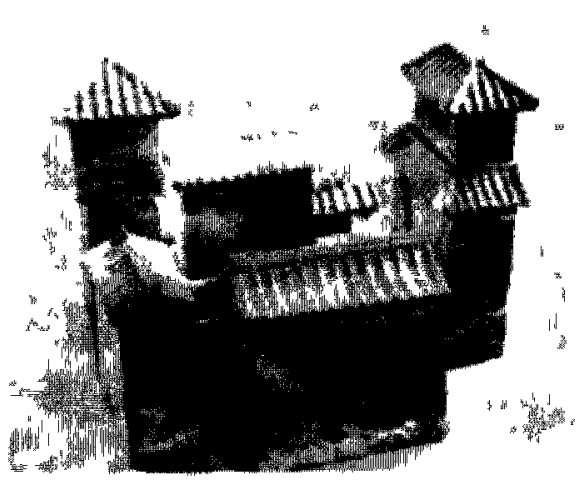

Within these few centuries, MinJian 【民間】 architectural developments have significantly ameliorated and emerged compatibly as a counterpart of GuangFang [官方】, or official constructions. Indeed from some of the artifacts dating back to later eras of Eastern Han, we could see that it was conventional for wealthy merchants and landlords to exhibit their fortunes through the expansion of their estates. While it was common for courtyard complex of the rich to grow in complexity on the horizontal plane from a number of funerary

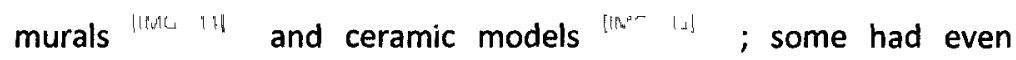
incorporated LouGe【樓閭】， or multistoried towers, as a defensive mechanism to secure their properties ${ }^{[58]}$.

The extraordinary details of these potteries have provided crucial clues to the continuous structural developments during the Han dynasty. By Eastern Han, societal changes have finalized and new orders have conditioned; therefore the old methods of obtaining height through pounded earth technology, which required a large labor force, was no longer a sustainable practice especially in the private sector. Given the surge in timber technology, the vertical Tai were transformed into multistoried towers assembled utilizing timber tectonics.

On these intricate models, the experimental configurations of the basic elements in all bracket sets-Dou【斗】 and Gong 【拱】-were positioned at a forty-five degree angle extending from the wall corners primarily to support the overhanging eaves. It seems like the Han 

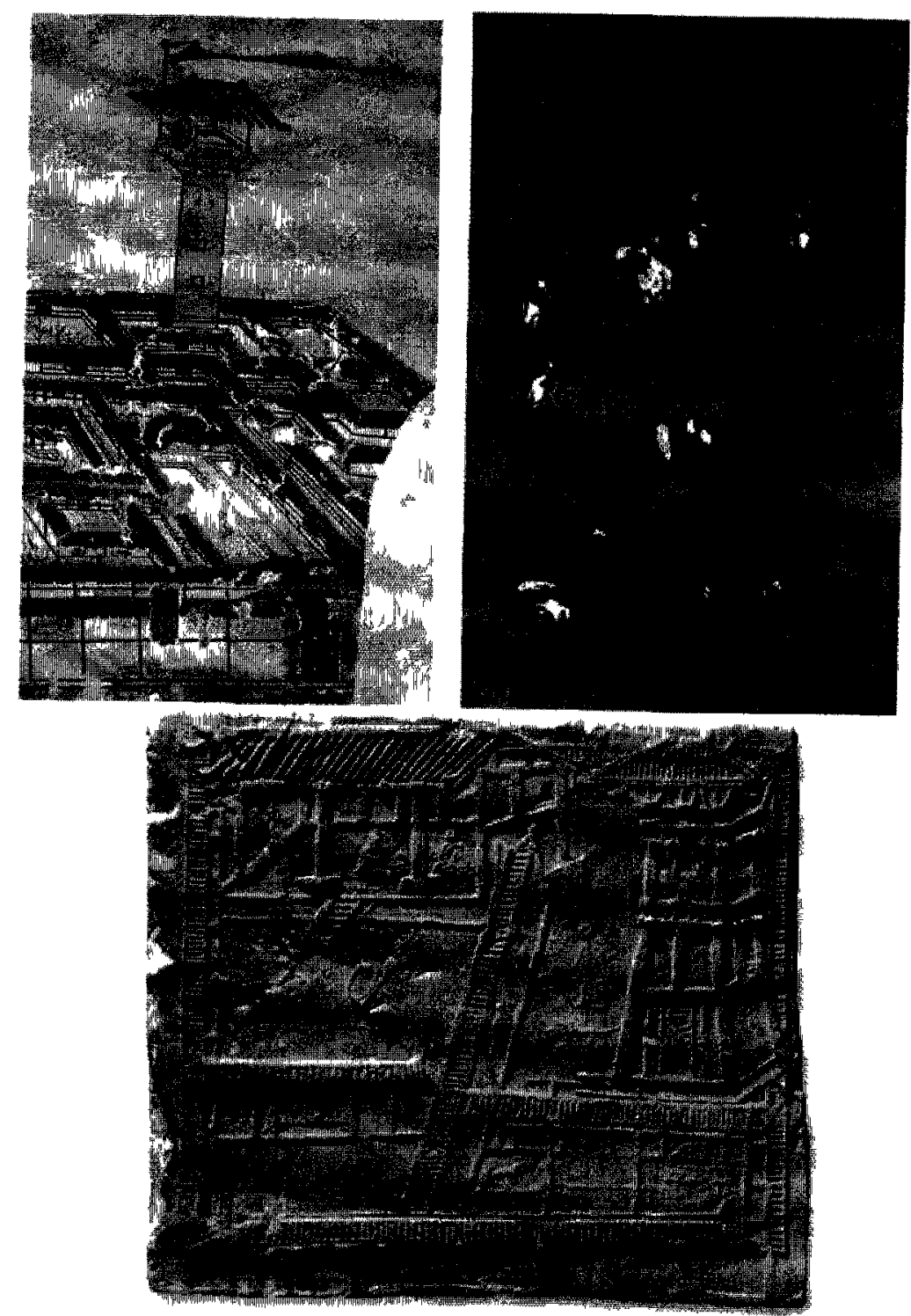

[IMG 14] Han murals depicting domestic cornplex and multistoned towers
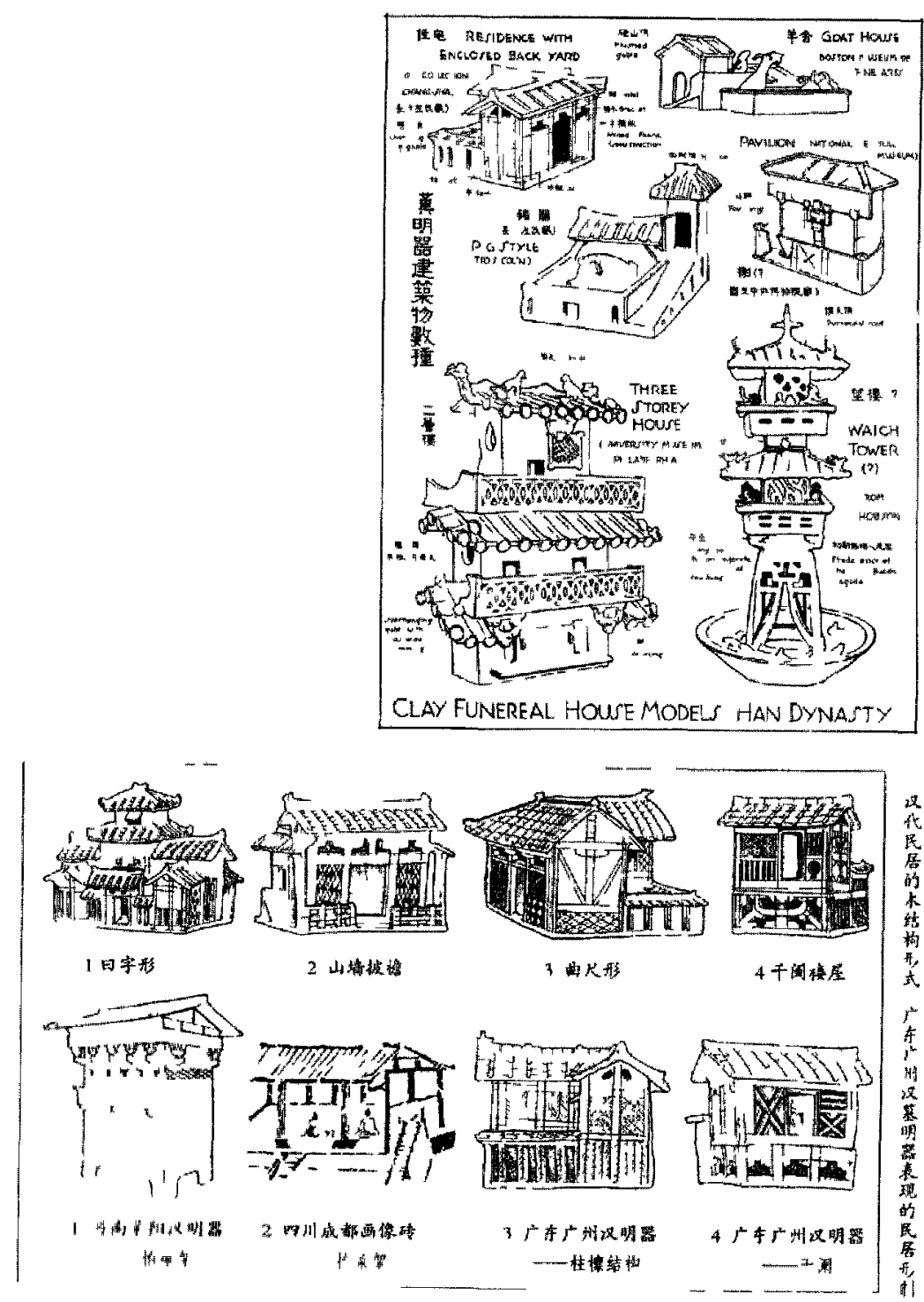

[IMG 45] Han ceramic models uf domestic houses and tuwers 
builders were quite experienced with the load bearing nature of the basic bracket sets, especially the Dou component, and its important role in increasing the pressure-bearing surface between the straightgrained column and the cross-grained girder or axial tie beam ${ }^{\prime \prime M G} 46$ [59]

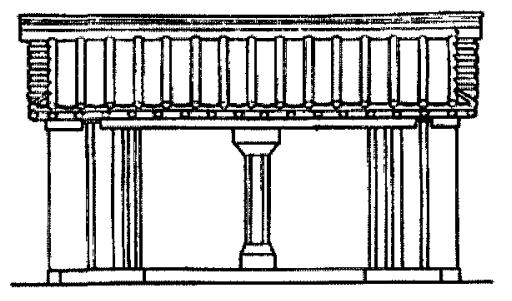

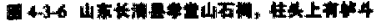

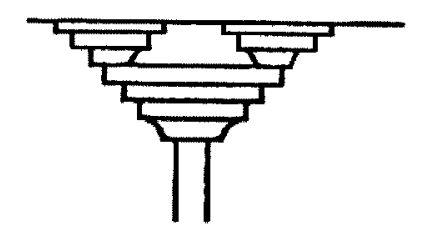

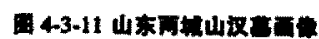

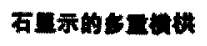

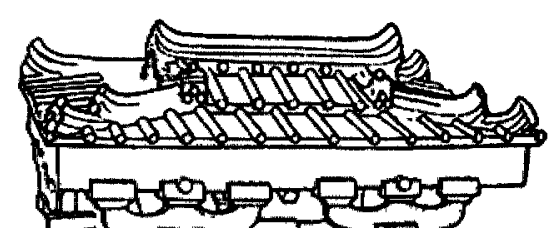

\section{圆 4-3-9 纡代的 “一斗三乐"

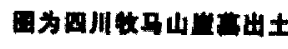 本 汉用至}

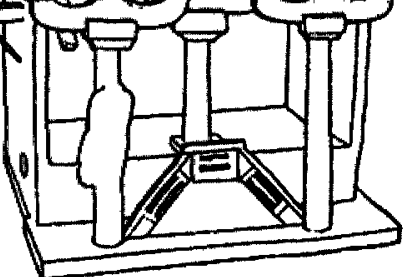

[IMG 46]

Top Left. Rudimentary Dou Bottom Left: stacked Gong

Rutht. Rumimentary Composition of Dou and cong

The cantilevering capacity of Gong was not fully utilized during this early stage of structural exploration. The Easter Han builders have not discovered the use of outstretching Gong, and similar to the bronze

table base from the ZhongShan royal tombs, a bracket set would require an angle support to bring it outwards in order to brace the extended eaves. At this stage, each bracket set functioned independently with relatively little correlation to one another.
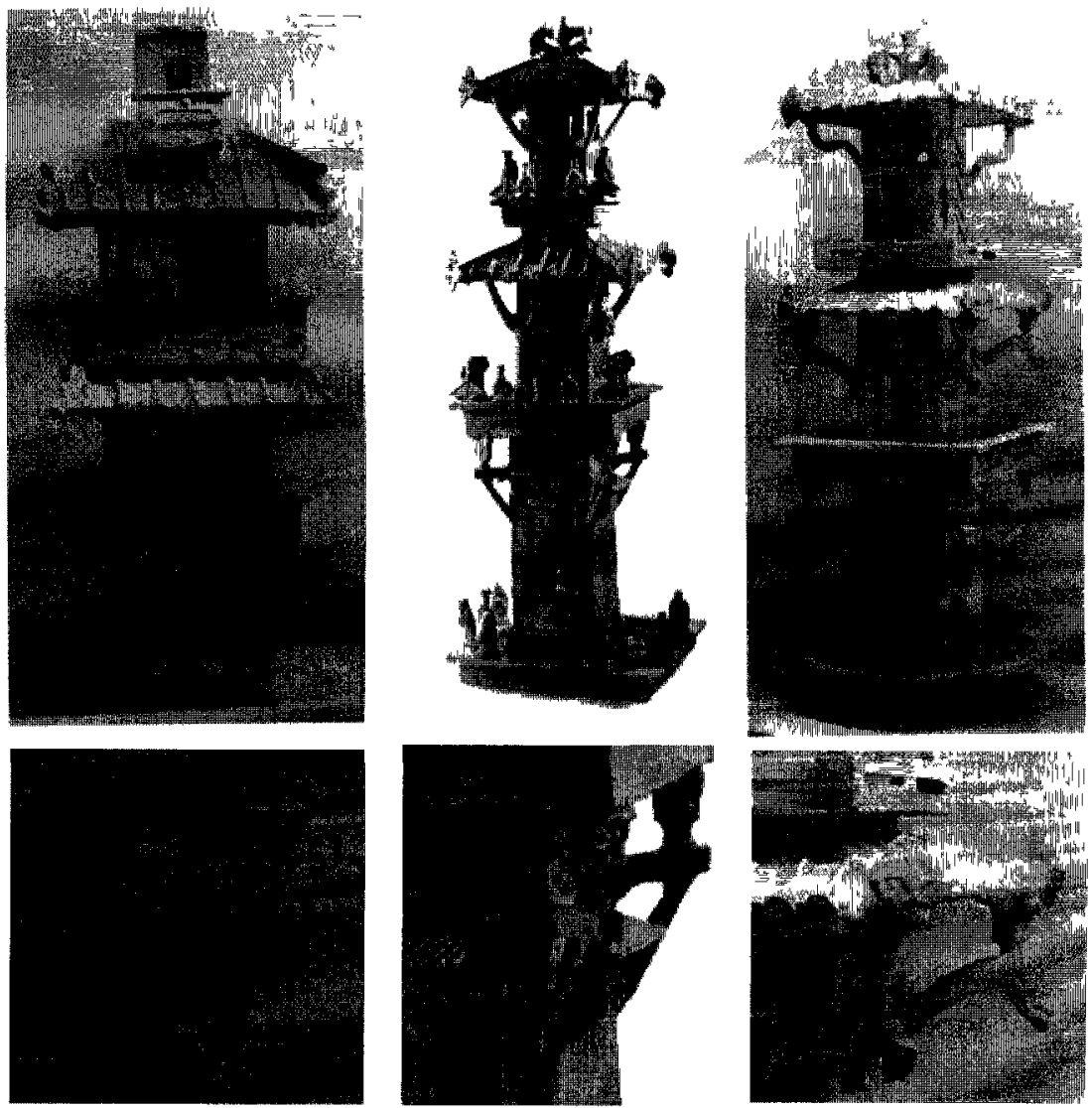

[IMO 47] Angle: support for bracket sets

In later improvements, we could find tiers of Dou and Gong compositions resting on a short beamed extended from the corner 
columns. These two-dimensional bracket set configurations remaıned quite crude, but it is interesting to note that most of them were no longer resting on angle supports. ${ }^{[1 / 1 / 6}$ ts]
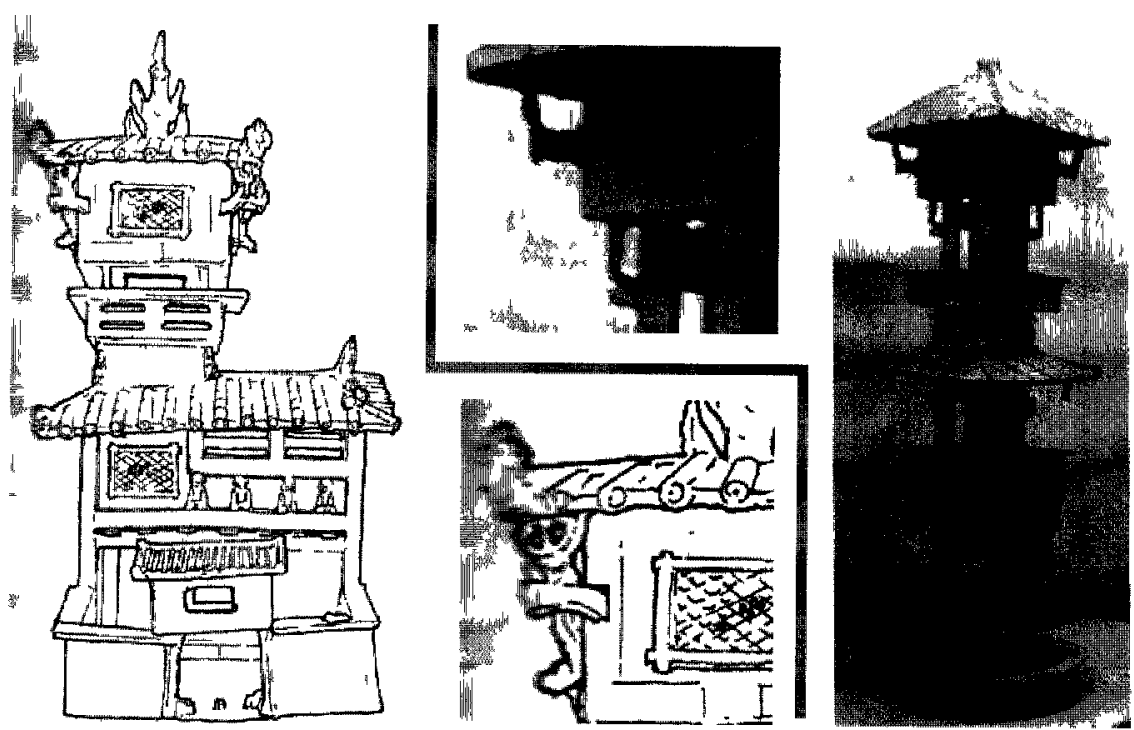

[IMG 48] Bracket sets restung on cantulevered beams

In the next stage, they were positioned parallel to the vertical surface around the corners and solely relied on the short-cantilevered beam for support. In these examples, each tiered bracket sets must remain leveled with one another other in order to support a horizontal stratum for the eaves overhang. In other words, the brackets sets consorted with each other, and collectively, they would continue to develop into a networked structural mechanism as a whole. ${ }^{\left[\mathrm{int} t \mathrm{t}^{\mathrm{t}}\right]}$
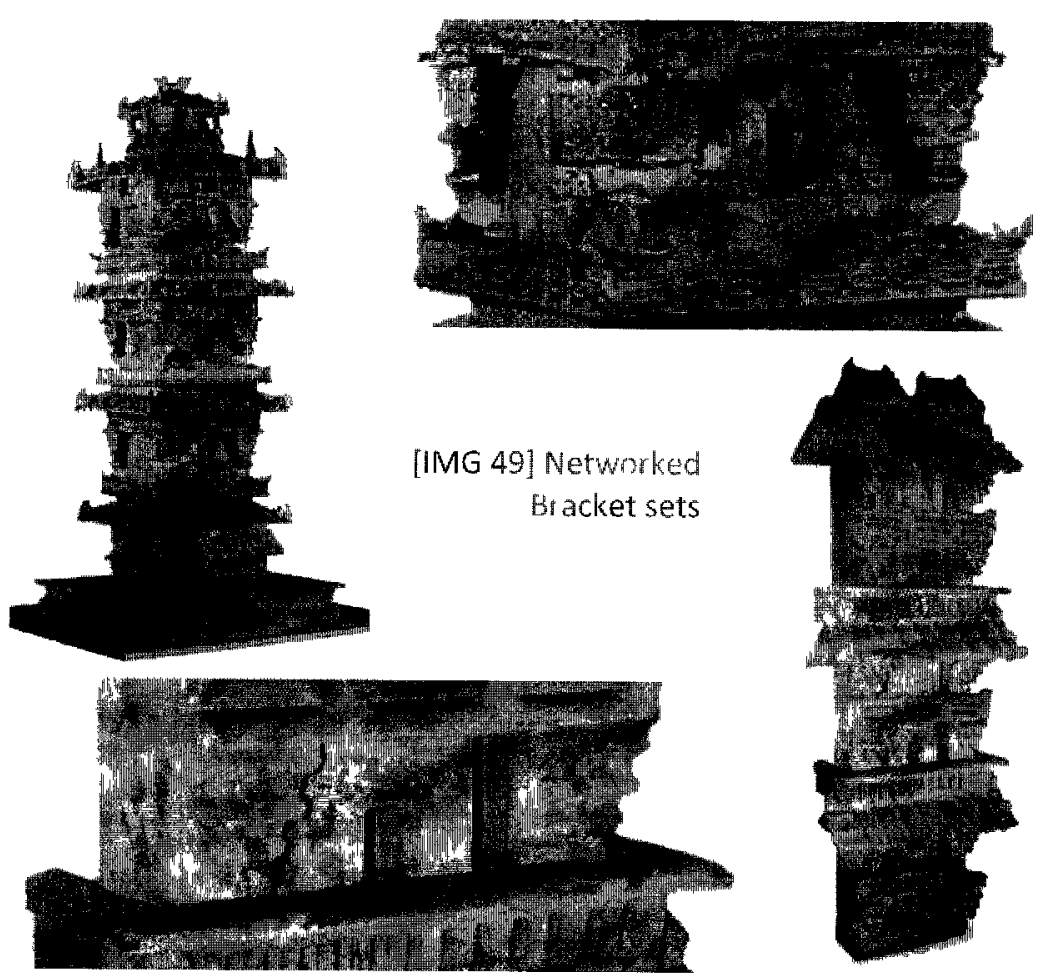

Lastly, it seems that the Chinese builders have discovered that, by placing the bracket sets between columns and beams, they were able to shorten spanning interval between fixed points; and also to effectively minimize both shear and bending stress on the structural components. In other words, they could increase the load bearing capacity of beams and girders while maintaining the same spanning distance ${ }^{[60]}$. It is evident that such comprehension of physics as related to timber tectonic has inspired a further structural 
development during $5^{\text {th }}$ to $6^{\text {th }}$ century the intermediate bracket sets Commonly depicted on Southern and Northern Dynasty (420 - 580) engravings and cave sculptures, several variations of which-usually by the name RenZı Gong [人字拱】—were found at mid-span between lintels in order to further reduce shear and bending stress [it $c$ sol
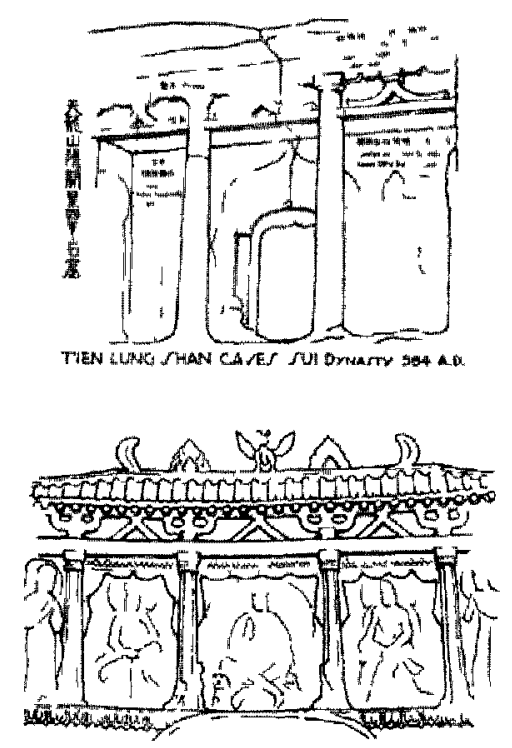

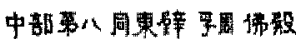
THREE BAYED TEMPLE HALL.

[IMG 50] The Ust of Ren7 Gong【人字拱】 as intermedele bracket set.

The cultural identity of China as a unified entity was completed by Han. No later than Emperor Wu's reign, the Han sovereign and subjects have established a formal collective consciousness of their existence in relations to the surrounding barbarians. The Chinese civilization, now exitıng the ancient phase of HuaXıa, has now positioned itself at the center in reference to the four cardinals and elements

At this tıme, we should note that the XuanXue concepts have been merged by the Confucian academics, and with the strong endorsement of Confucian school of thoughts as ordered by Emperor Wu; Liu argued that final orthogonal tectonic of the bracket set is a manifestation of this ideology as it approaches its matured

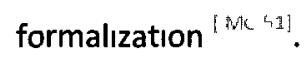
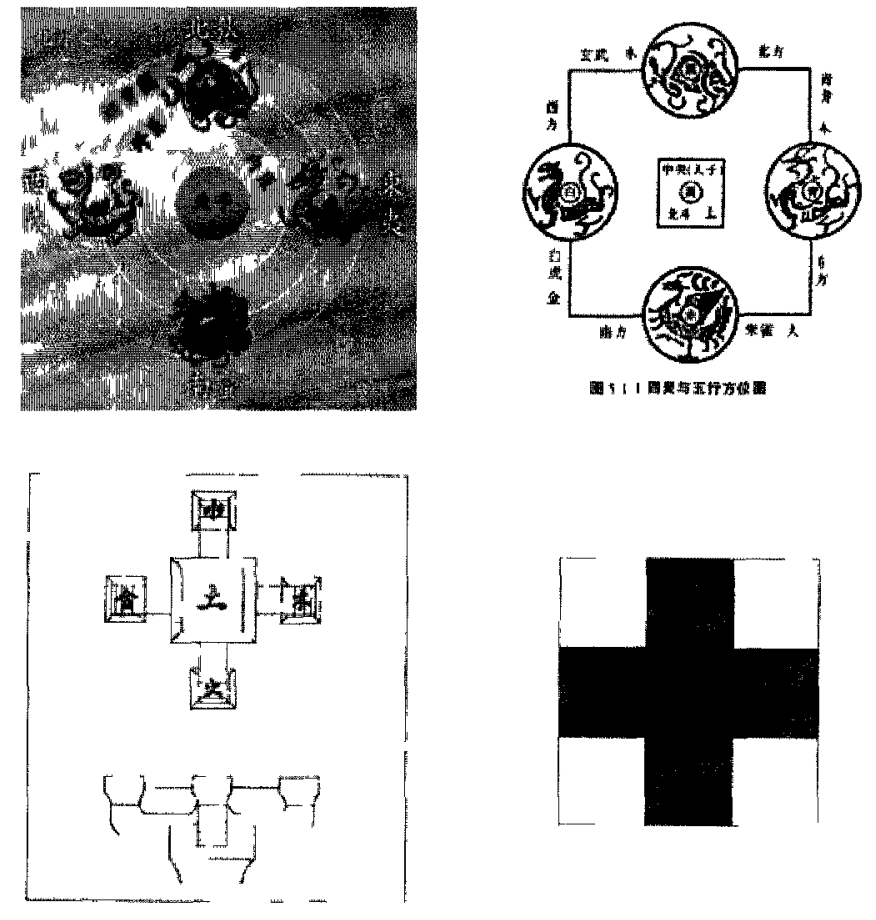

IIMG 51] Politıcal \& cultural colitext influence in bracket set's defintive formalization 
When Han regime was replaced by four centuries of armed conflicts and rival regimes attempting to once again reunite the whole of China, the architectural developments would slowly come to an end of its adolescence. As the regional cultures continued to amalgamate internally, the Chinese began to interact with foreign civilization through the southern aboriginals and nomadic tribes in the north. According to Boyd,

[b]y 200 B.C. when the trade routes to the rest of Asia and the west were opened up and intercourse increased, the Chinese architectural system, like her script and so much else of her culture, was both advanced and set, not to say stereotyped. And during the centuries that followed China transmitted to the rest of the world more than she absorbs from it. $^{[62]}$

That being said, it should also be noted that during this process of sinofication, an important cultural exchange progress-the introduction of Buddhism as imported from India - in particular has definitively refined many cultural aspects of Chinese civilization. It is the least to say that these external interactions have contributed to mutual exchanges in crafts and technology. Internally, famine and invasions from various northern nomads during early $4^{\text {th }}$ century have forced the Jin 【殎】 exodus of monarchy and official administration from the Central Plains, and drove the Chinese demographic center towards the Yangtze River regions. This significant historical event has stimulated developments of the JiangNan regions and further propelled the regional exchanges in arts and technology between the north and the south.

During the turn of the $7^{\text {th }}$ century when China was once again unified

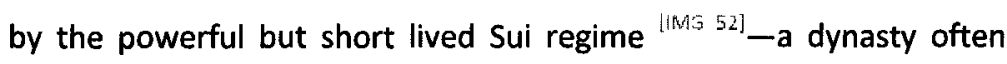
compared to the Qin establishment for its accomplishment of uniting China and also for its overachieving ambitions-the emperors were eager to establish a stable and efficient connection between the political center at the north in the Yellow River Valley, and the core economic and agricultural region at the south cultivated around the Yangtze River Basins. In the ensuing centuries, this monumental engineering feat would be critical in fostering an indigenous economy and the nourishments of new urban centers along its routes. Culturally speaking, it would also fortify a permanent bond between the north and the south.

After the great turmoil of the so-called Six Dynastites (220-589), when India's Buddhism, sponsored by many foreign rulers, developed roots in Chinese soil, and when China was united once again in the Sui dynasty toward the end of the sixth century, the new ruler (of mixed ancestry) picked a site southeast of the Han city and laid a bold new plan for its capital city, [DaXing]. This plan combined Chinese classical ideals with Central Asian experiences. ${ }^{[63]}$

The age of adolescence, which concluded before the heyday of Tang dynasty $\left[\begin{array}{ll}{[m a} & \end{array}\right.$ formalization of the bracket sets as a unique structural mechanism. 
Occurred over the span of sixteen hundred years, this gradual development was carried out simultaneously with the maturation of timber frame constructions techniques. In the next session, we would focus on the flexible and adaptive nature of the matured timber frame system; and also, elaborate on how formalization of architectural standards and structural modulations was shaped based on the economic and pragmatic nature of construction industry.

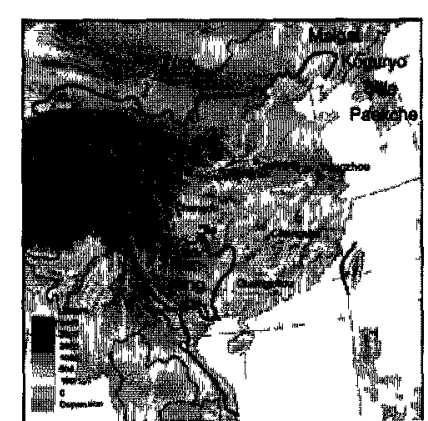

[IMG 52] Suichina

$$
581-618
$$

Economics

Period of Vigor

It is impossible to draw a line of demarcation to separate the imperceptible steps in the process of revolution. ${ }^{[64]}$

Even thought division of periods pertaining to the matured architectural developments is arbitrary; according to Liang, the prime of Chinese architectural traditions could be interpreted in three general intervals. The first interval was the Period of Vigor【现時期】， which began sometime during the $7^{\text {th }}$ century and ended in 1050 . In Liang's words,
The Period of Vigor-only a few specimens of its final phase remained-must have had a brilliant past stretching considerably before the middle of the ninth century, perhaps as far back as the beginning of the [Tang] dynasty, or early seventh century. As to the wooden buildings of this hypothetical first half of the period, we can only resort to contemporary graphic art for information. ${ }^{[65]}$...This period is characterized by a robustness of proportion and construction which must have been that of the glorious [Tang] dynasty and of which this is but its magnificent conclusion. ${ }^{[66]}$

The basic characteristic of the refined structural composition at its peak during this period consisted of three parts: a raised platform, a timber structural frame composed of post-and-lintel skeleton and bracket sets, and a pitched roof canopy with overhanging eaves ${ }^{[M, G, 4,4]}$.

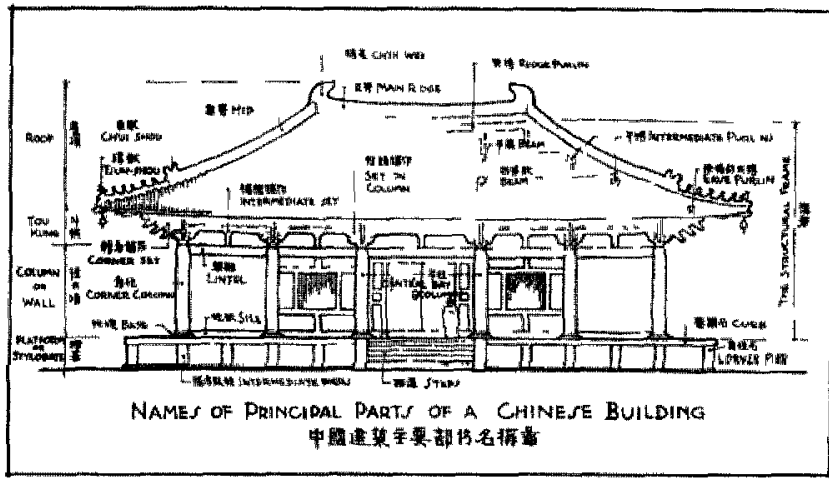

[IMG 54] Principal part's of a typical Chınese tectonc compostizion. 
Bearing the weight of the roof and standing on top of the platform, the timber structural frame would arguably be the most extraordinary achievement in the whole of Chinese architectural traditions. The coherent structural articulation not only permits the complete freedom in partitioning with or without solid walls and translucent screens, thereby renders the unlimited possible configurations practical and comfortable to be utilized within a large spectrum of climatic and geographical conditions; but more importantly, its structural modulation as the generator of spatial layouts allows for the greatest flexibility in satisfying various demands of most, if not all, design schemes. Last but not least, the use of bracket sets and its role in the standardized parametric system, which guaranteed cost and time efficiency as well as optimal building speed, is truly the strongest-and the most unique-advantage of the traditional Chinese timber frame construction.

\section{Structural Articulation: Spatial Anatomy}

Whereas formal style buildings were defined by rectangular plans, layouts in all other forms were categorized as miscellaneous style building ${ }^{\lfloor\mid h t s 55\rfloor}$.

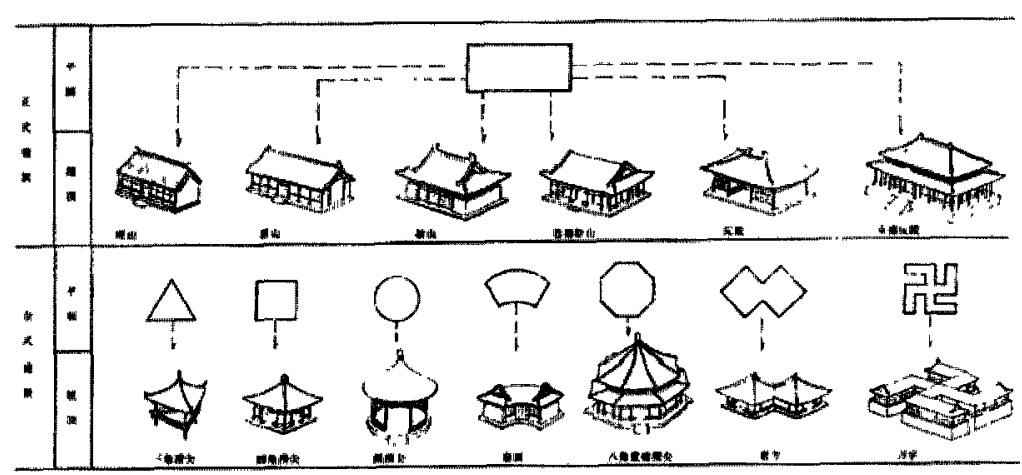

[MG 55/Top: Formal style buildings. Bottont. Miscellaneous style buildings.

In tradition Chinese construction, the spatial layout of each formal style building often measures in units of Jian 【間】, Jia 【架】, and

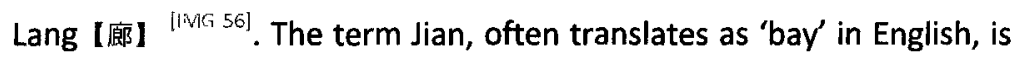

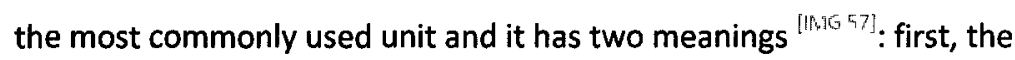
orthogonal area formed by four columns at each corner is called a Jian; secondly, Jian was also the number of bays between pairs of axial

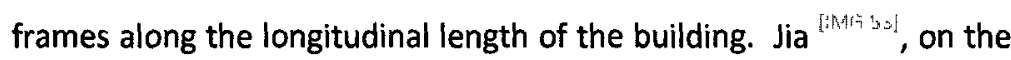
other hand, measures the depth of the axial frame of the building by the number of purlins used to support the pitched roof. Finally, Lang $[k x+3,4]$ is the optional gallery extension located at front, back, and permitted only in official projects, around the perimeter of the building. 


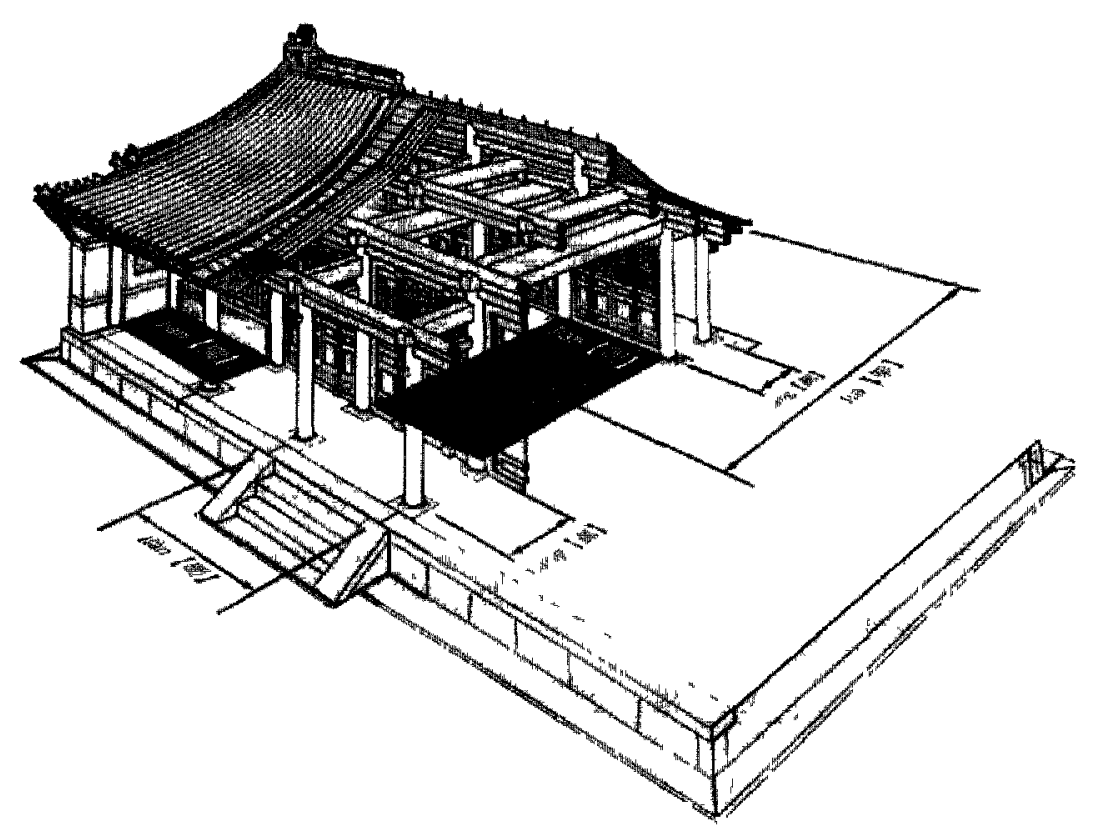

[IMG 56] Thee units of spatial layout. Jan [間], Ja [架], and Lang【廊】
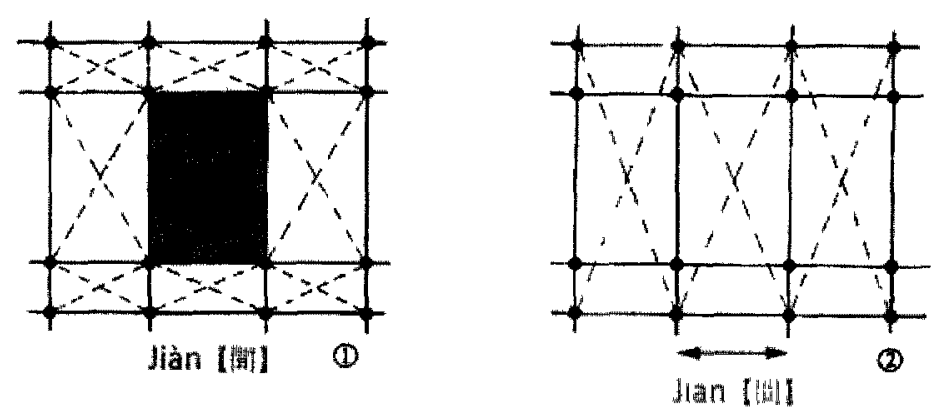

[IMG 57] Two medning of Jaan [間】
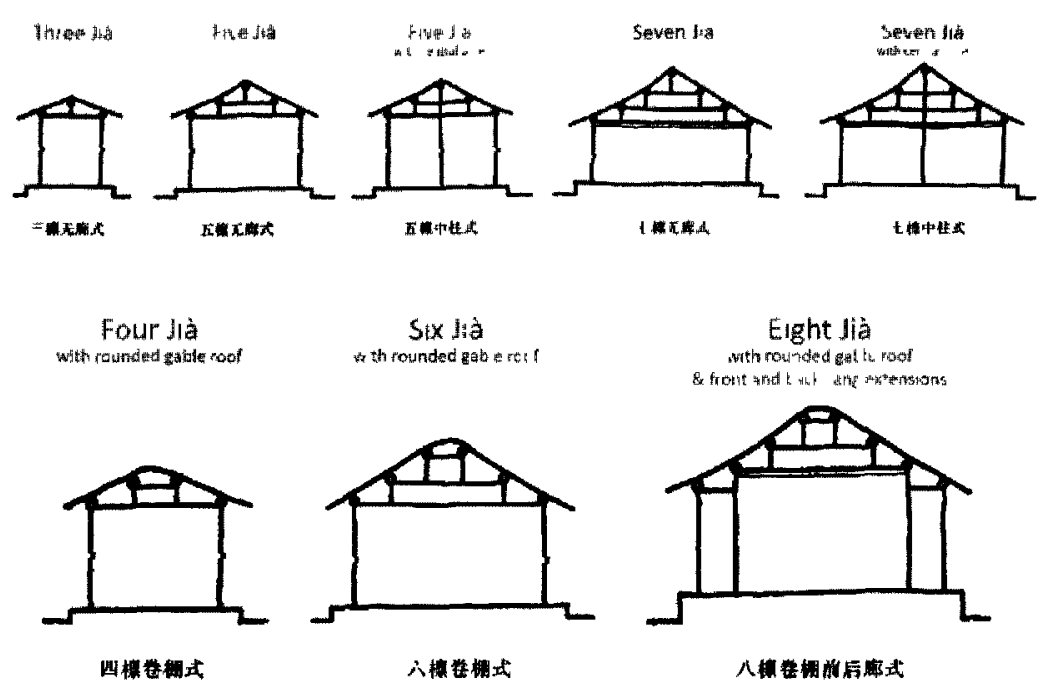

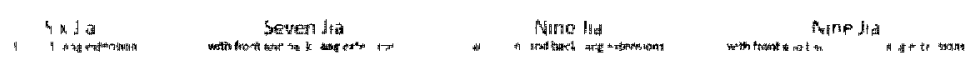

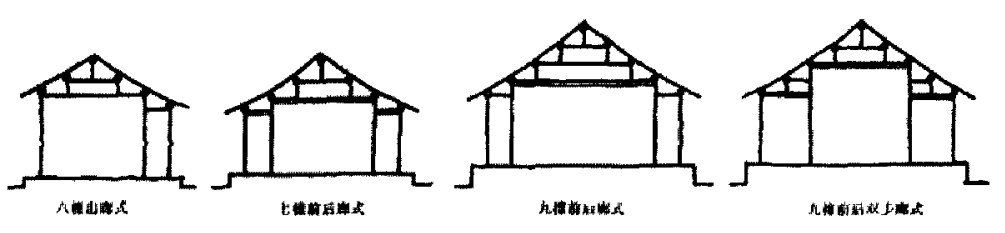

[IMG 58 ] Vdriou, contigurations of Jla [架] 
As depicted by Boyd,

Style with

No Lăng extension

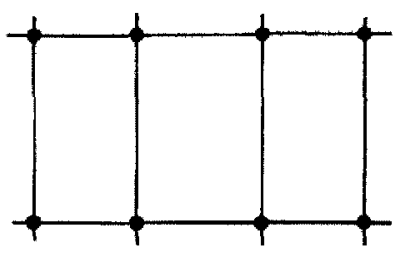

(1) 无能式

Style with

Front and Back Láng extensions:

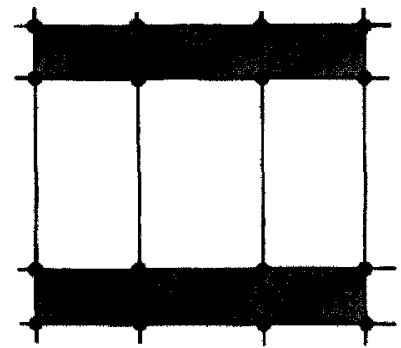

(3) 前后廊式
Style with

Front Lang extension

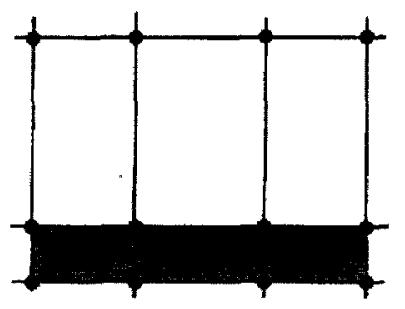

(2) 前出麻式

Style with

Enveloped Lâng extensions

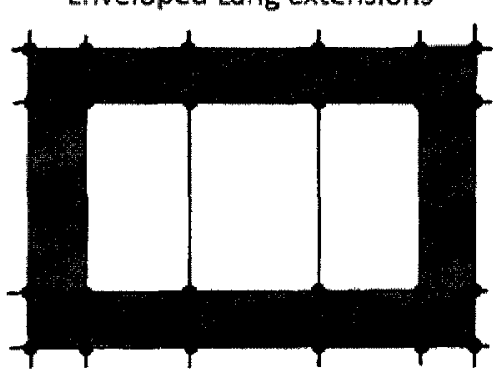

(4) 周同府式

\section{国 2-1-2 出的几种形式}

[IMG 59] Four spatial configurations with or without Lang【廊】

[The] basic bay was capable of expansion in all directions across the plan in the direction of the span by widening the bay and increasing the number of beams, by adding columns, forming verandah bys or inner spaces of varying widths, and always of course lengthways by mere repetition. ${ }^{[6]]}$

Because there are structural limitations to the span of a bay or the length of a girder, these units generally would give an adequate approximation to the overall size of a formal style building. According to the official regulation, the number of Jian (bays) that could be used in a spatial configuration increases in odd numbers. According to the Tang regulations ${ }^{[68]}$, while most peasants and lower level officials were allowed three Jian layouts ${ }^{[69]}$, a maximum of nine Jian could be used in the most important official constructions (i.e. Main hall of the palatial complex, or a royal commissioned religious building). With the exceptions of rounded-gable roofs and uneven gable roofs, usually formed when one side of the eaves overhang extends in response to an addition of a Lang, the number of Jia also increases in odd numbers beginning with three ${ }^{[70]}$. The building depth is also limited to four Jia for the general population outside of the official administration. Working with these three basic units, an infinite number of configurations could be fabricated following the parametric rules as

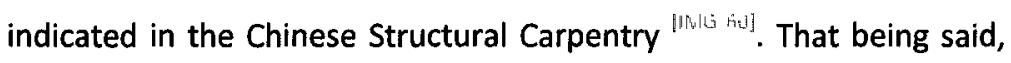
since the official regulations of building sizes remained relatively constant until the end of the Imperia eras, the majority of individual 
building dimensions permitted for the general population generally measures about 9 to 10

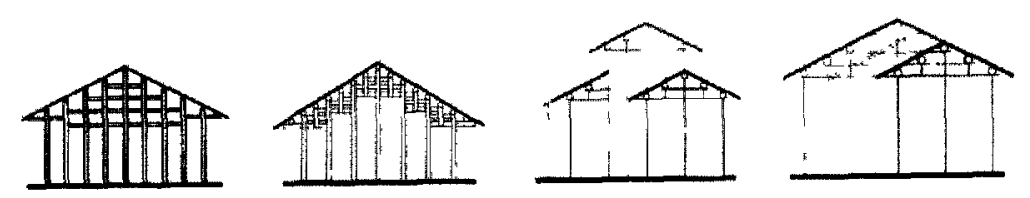

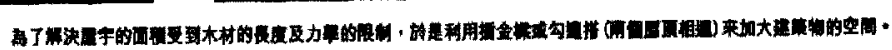

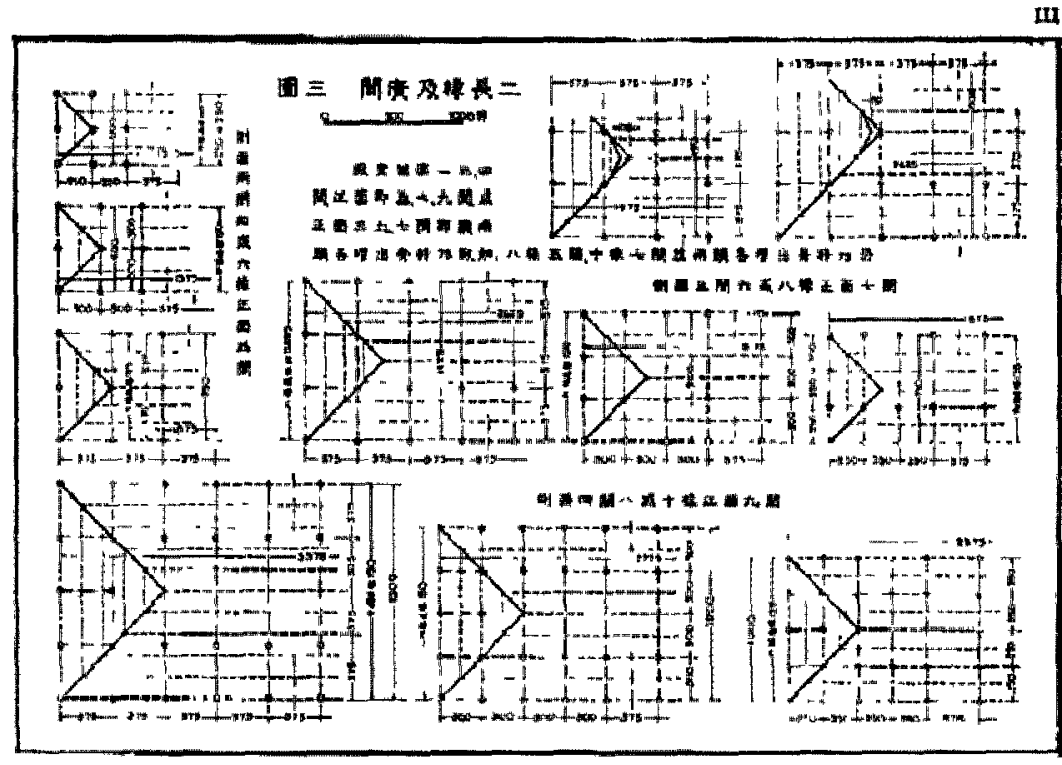

[IMG 60] Parametric composition as outlined in chapters of Structural Canpuntry in Song construction manual Yug/ao Fash

meters in length and 4 to 6.4 meters in depth. This proportion is optimal for the traditional spatial scheme of a central common room flanked with two private rooms at its sides ${ }^{[\mid M G ~ 61]}$. Also, with the average area ranging from 40 to 60 meters squared, such building sizes are ideal individually as a single dwelling, or as a spatial component of a larger complex layout. ${ }^{[71]}$

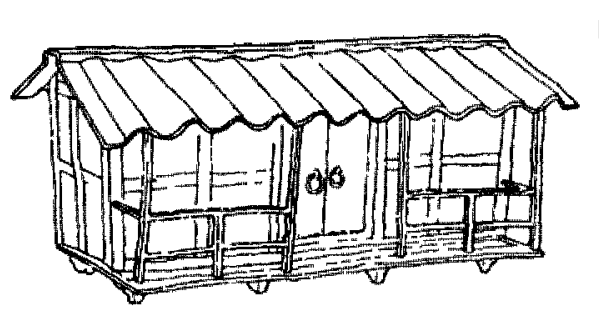

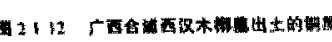

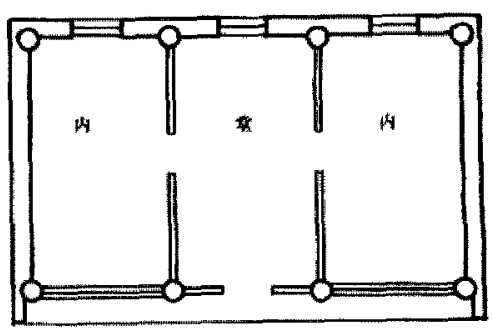

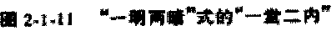

[IMG 61$]$ Conventional domestic three-Jian spatial ly wout

As mentioned earlier in this chapter, the traditional Chinese structural articulation of any standard rectangular plan is composed of an alignment of axial frames along the longitudinal length of the building. Like all dimensions of the other structural components, the longitudinal distance between each bay and also the length of axial girders, which span the depth of the frame, were all part of a standardized parametric system that would be further elaborated in an upcoming session.

Structural Articulation: Structural Anatomy

The Chinese timber frame was essentially different from other traditions of timber construction in its use of roof framing technique called JuZhe【堅折】-a system of vertically stacked beams of 
diminishing lengths-instead of an arch or a truss to support the weight of the roof ${ }^{\left[\mathrm{WW} \mathrm{w}_{0}\right]}$.
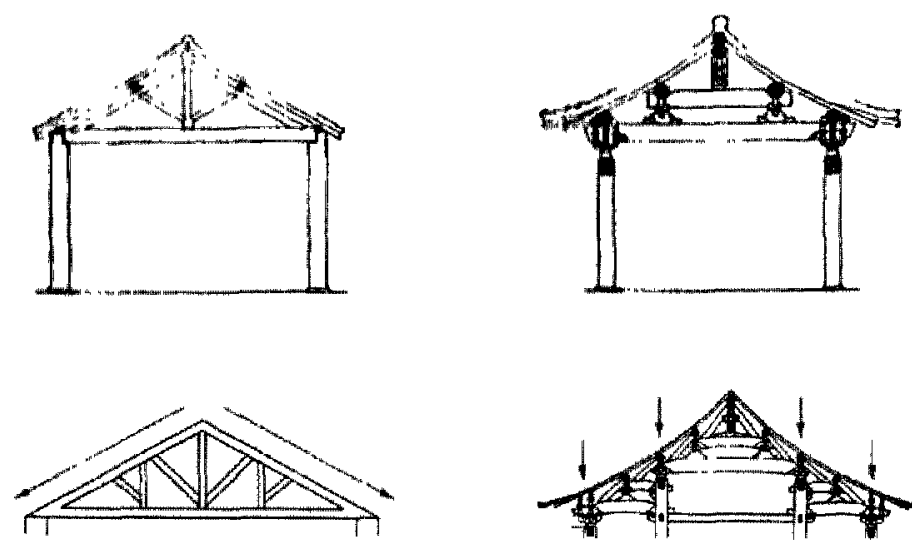

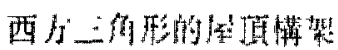

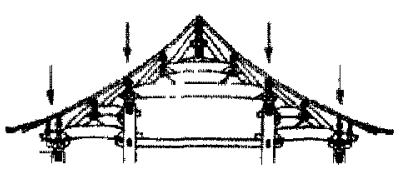

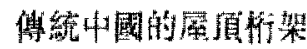

[IMG 62] Westen truss vs. Chinese post \& beam roof framing.

We should not make haste to assume the Chinese builder lacked the experience with triangulated support or arch configuration. In fact, in the earliest experiments of the rudimentary bracket sets as well as the example of AnJi bridge mentioned earlier, it is evident that the Chinese were well aware of the physics of these basic structural geometries.

Chu points out that while a triangulated roof truss could rest comfortably on stable load bearing walls in a typical 'shell structure', its angled outward-thrust would be quite overwhelming for the gridded columns in a 'skeleton sculpture'. Furthermore, because the

natural dimensions of timber would impose limitations on the lengths of truss rafters and ceiling joist, the depth of a traditional Western pitched roof would encounter more restrictions in its overall dimensions. Not to mention, the greater amount of material expenditure as required with the use of building triangulated truss would be economically inefficient. ${ }^{[72]}$

Rather than insisting on geometries of a straight pitched roof and accepting the material limitations of timber, the JuZhe technique is a logical solution to assemble large span roof frames by dispersing the loads vertically at intervals through purlins placed on top of girders' ends. Such roof configuration requires segments of shorter material; therefore the selections of adequate dimensions would be more readily available. As explained by Boyd,

[The roof frame] could also be extended upwards by varying the heights of different parts of the crosssection, forming lower verandahs with a higher internal room, clerestoreys, galleries surrounding a higher internal space and so on. Finally, the crosssection could be extended upwards by the addition of one or more upper stories...It is an obvious and striking feature of the Chinese cross-section that, not being based on a triangle above column level, it encouraged considerable freedom in the design of the roof line because the relative positions of the purlins, which controlled this, could be varied so as to be in a straight line or in any required curve. ${ }^{[73}$

Also by using the JuZhe technique, it is effortless to achieve various roof heights with minimal calculations. In general, the gradual sloped 
could range anywhere between 1:2 for a small house and 2:3 for a grand hall. According to Liang, the pitch is determined by the total rise, or JuGao【舉高】. The height of JuGao varies from one-quarter to one-third of the total distance between front and rear purlins-and of course, such dimension is determined by the type and size of the building as stated in the official regulations.

The curve of the rafter line is obtained by ["depression"-in Chinese term, Zhe [折]-] or lowering the position of the first purlin below the ridge, by one-tenth of the height of the [JuGao], off a straight line from the ridge to the eave purlin, and the next purlin below is "depressed" by onetwentieth of the JuGao. The process is repeated, and each time the "depression" is reduced by half. The points thus obtained are joined by a series of straight lines and the roof line is plotted. ${ }^{[\mathrm{IM}}$
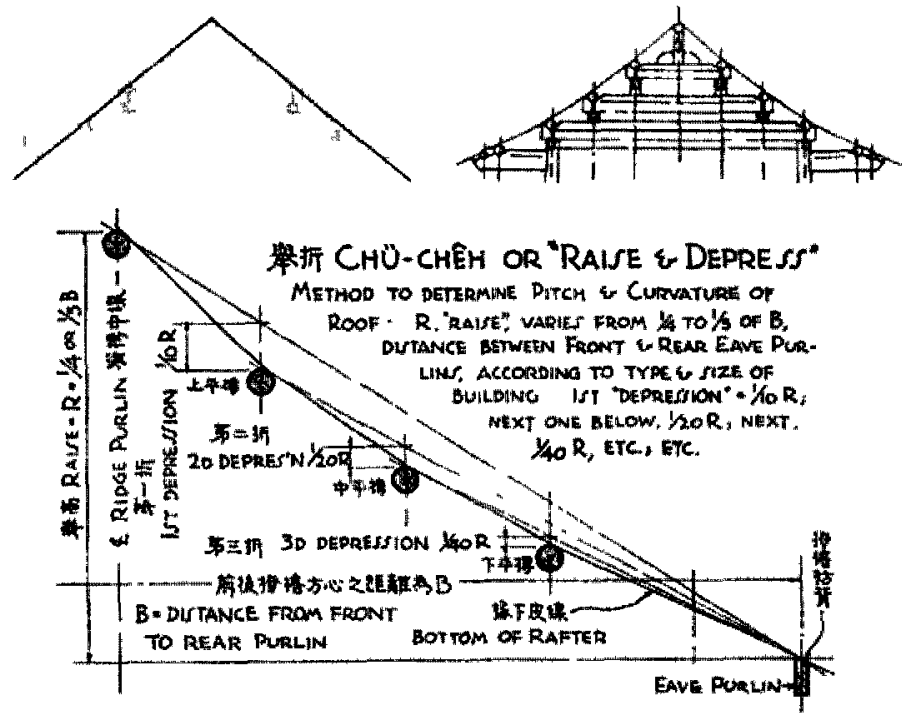

[IMG 63] JuZhe roof framing technique and its parametic calculations
Because of the simplicity in the JuZhe geometry, the structural components could easily be prefabricated before assemblage. Another roof structural technique called TuiShan [推山】 [NMG 64] is used to intensifying the curvatures of the hips by elongating the main ridge.
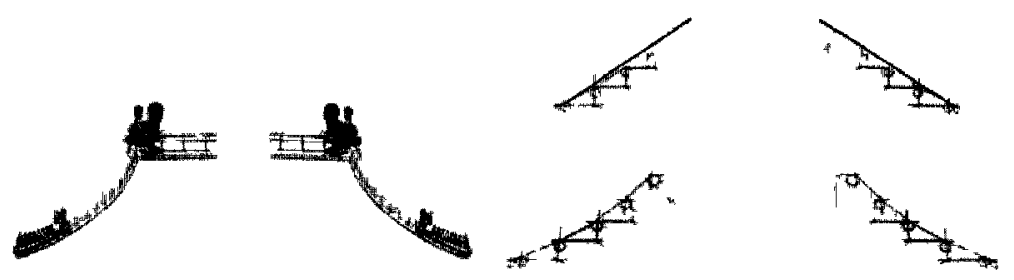

[IMG 63] Tuishan roof framms Letinique and its pal ametric calculatıons.

Note that during the Imperial eras, this technique could only be applied in official constructions because the use of hip roof, gable-hiproof, and other variations of these two types were limited to official and institutional constructions. None of the roof constructions allowable for domestic or commercial buildings were composed with

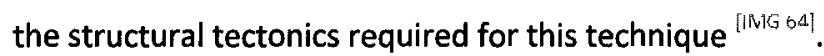<smiles>CC(C)(C)C12CC3CC(CC(C3)C1)C2</smiles>
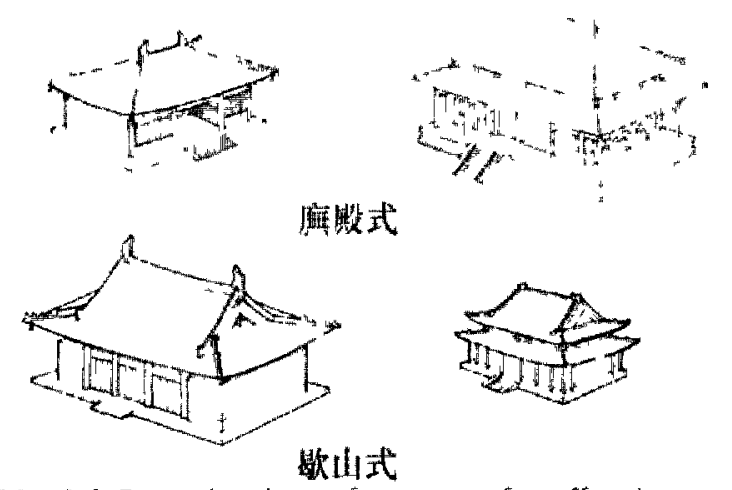

[IMG 64] Formal style roof tectonks for official use 


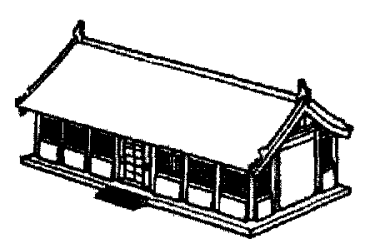

懸山式

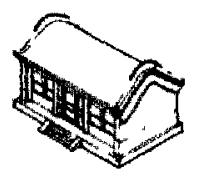

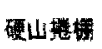

硬山式
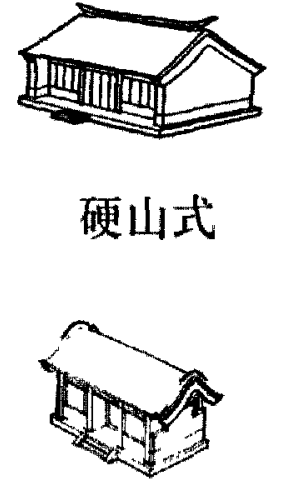

㭧山楼糊

Forral style roof tectonics for domestic and commer tial use.

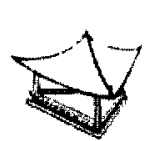

三角强尖

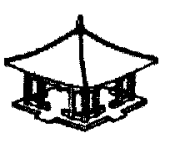

四角均尖

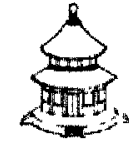

回㩲采

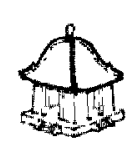

盃原

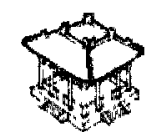

挍尖碩切去一青 便成為盘頂

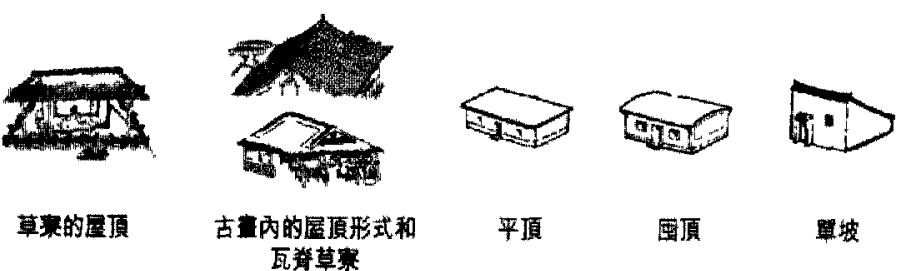

Miscellaneous style roof tectoric for domestir and conmercial une

Contrary to the belief that the Chinese curved roof is an aesthetics expression, the excessive effort to ensure an elegant curvature is in fact intended for pragmatic functions. Not only would a steep fluid curve sheds rain water more efficiently and prevents the acumination of snow; as argued by Chu ${ }^{\left[\mathrm{M}^{5} \text { 65] }\right.}$, it also improves air circulations, and most importantly, it allows more nature light to penetrate into the interior space despite the wide overhang, especially important mechanism during winter times. It is safe to conclude that not only is the Chinese roof system more frugal in its use of material and technologically more efficient and more flexible to construct, it is also a pragmatic solution to enhance the operational conditions of the interior space.
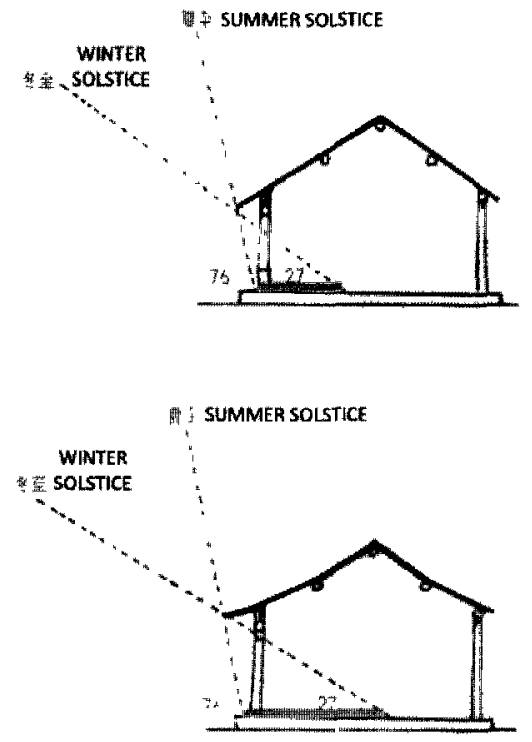

[MG 65 . Study of light penetration with straight and curve roofs. 


\section{Structural Articulation: Joint Anatomy}

Arguably the most exclusive structural feature worthy to represent the essence of traditional Chinese architecture, bracket set system is often misconceived to be an abstruse structural composition. The fact is, the only esoteric attribute one could find in approaching the bracket set is the naming of their parts.

While the notion of structural simplicity may at first be difficult to appreciate, the bracket cluster in any Chinese building, from any time period, in fact can be broken down into fewer than five fundamental parts [MGG[u] [75]

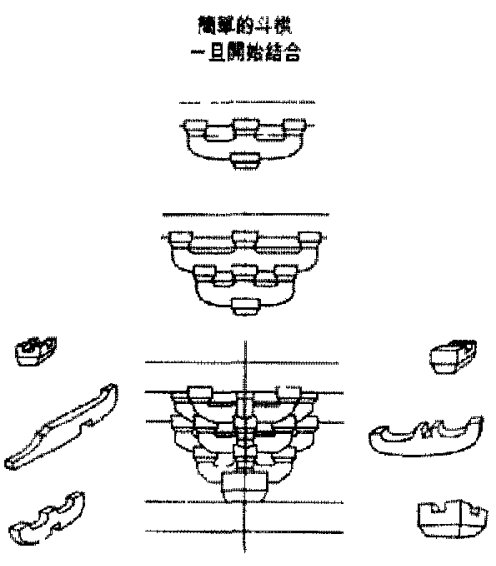

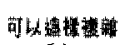

[IMG 66$] 5$ fundamental parts of bracket sets base on 2 slements:

\section{它閒只是}

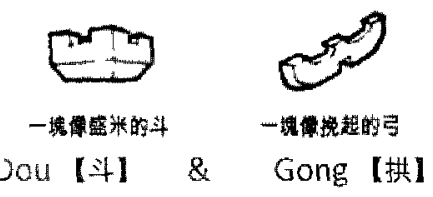

To add on to Steinhardt's statement, the five fundamental parts are in fact variations of two basic elements: Dou and Gong. We are fairly familiar with the basic compositions of the bracket set in the previous discussion of its origin and formal evolution. Basically, a bracket set is an assemblage of a number of Dou (blocks) and Gong (arms) ${ }^{[76]}$. Before jumping further ahead, what we would like to discuss here is the role of the bracket set within the matured structural framework.

Because the earliest timber frame building maintained at its original state was from the last era of Tang during the mid ninth century, once again we would have to rely on indirect evidence to provide us with details of earlier bracket set configurations before the emergence of the final formalization. The original engraving on the tympanum ${ }^{[1 M G}$ 67] over the west gate of DaYanTa from early eighth century (701-704) is one of the few earliest graphics found to depict bracket sets with outstretching Gongs, or cantilevering arms, to support the great eaves overhang. Not quite arrived at their advanced forms, these brackets sets-like all others in any building constructed from this point forward-could be categorized into three groups: first, the "columns set"【柱頚科】, which is a set place on a column; secondly, the “intermediate set”【平身料】，which is a set placed on the architrave between two columns; and lastly, the “corner set"【角科】 which is a set placed on a corner column. 

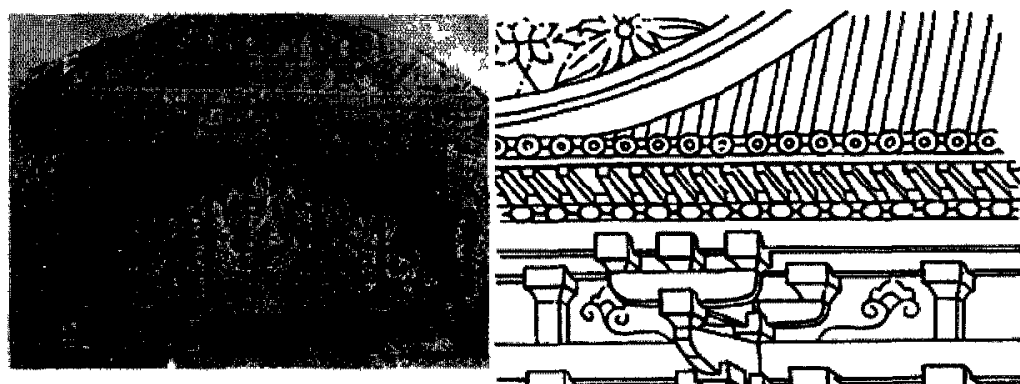

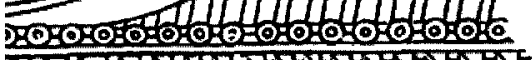
12
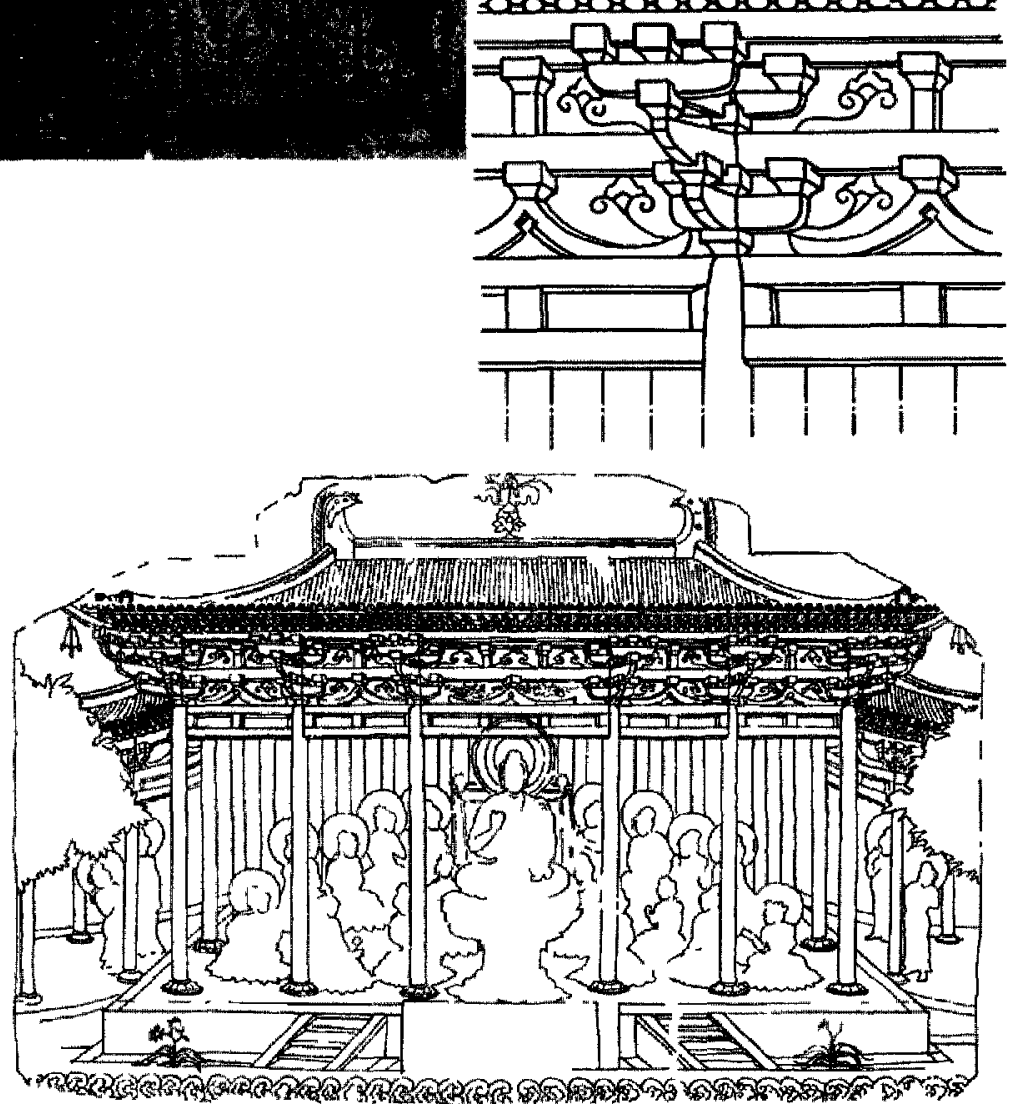

A TEMPLE HALL OF THE TANG DYNASTY

AFTER A RUBBing OF THE ENGRAVING ON THE TYMPANIIUM OVER THE WEST

GATEWAY OF TA-YEN T'A, TZ'U-EN JrŬ, ЛT-AN, NHENI

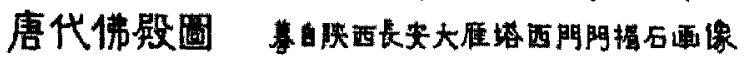

[IMG 67] Depiction of bracket sets in engraving on DaYanTan

tympanum
While the intermediate set remained in its primordial form as RenZi Gong-a curved triangulated reinforcement; in both the column set and the corner set we find significant improvements from late Han articulations. These brackets set as depicted on the engravings were composed with repetitions of single tier brackets. Instead of the twodimensional tiered arrangement supported by a short cantilever from the wall, the eave architrave now rests on outstretching Gongs, which perpendicularly intersect the stacked transverse single tier brackets along the wall line and also the architrave on top of the column. The corner set is a similar composition, with the additional sets of bracket arms extending at 45 degree to support the corner of the overhanging eaves.

Another detail portrayal of bracket sets from the ninth century could be found on the famous Paradise of AmitaBha ${ }^{\text {ati a }}+$ il $-a$ DunHuang mural inside cave number 172 of the MoGao Grottoes. The intermediate set has evolved into a combination of Renzi Gong and the repeated perpendicular intersections of single tiered brackets. Advancing to a very close stage just steps away from its definitive formalization, the improvements of the corner set on this mural were quite extraordinary. We could find the first attempts of double tiered brackets; and most importantly, the incorporation of Ang [昂] -a segmented roof rafter which is vital structural component that supports the roof overhang. 
In both illustrations, it appears that each bracket set was no longer individual entities with independent structural intention; instead, every bracket affiliated with others to form an integral network of segmented and leveled frame. Such structural organization could be clearly explained with the main Hall of FoGuang Si【佛光寺】 in Mount WuTai 【五台山】 -the oldest surviving timber structure from $857^{\text {[IMG }}$ 69].

IMG 68 Depiction of bracket sets on Paradise of AmıtaBhaa DunHuang inurill from MoGao Grotto \# 172

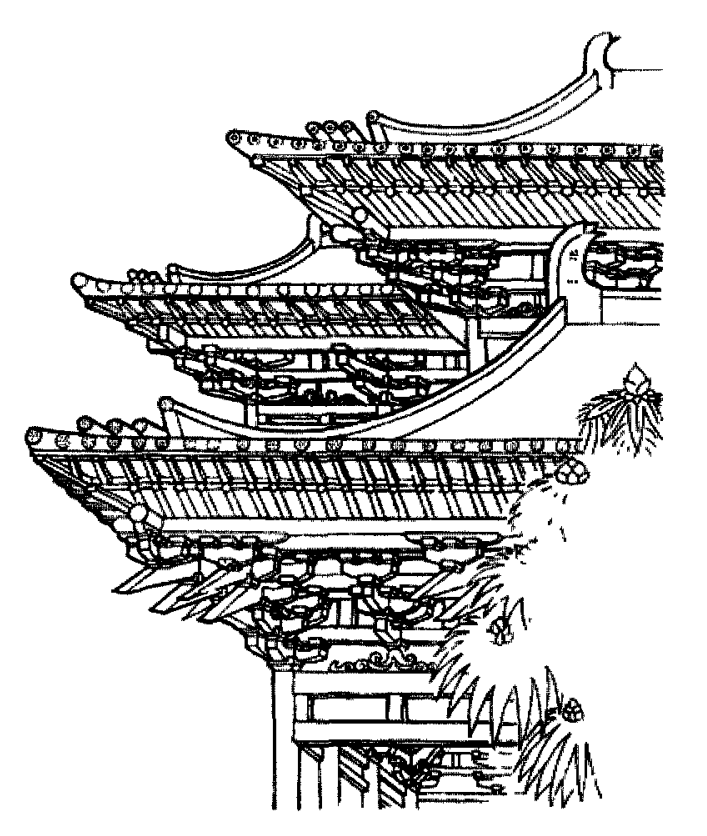

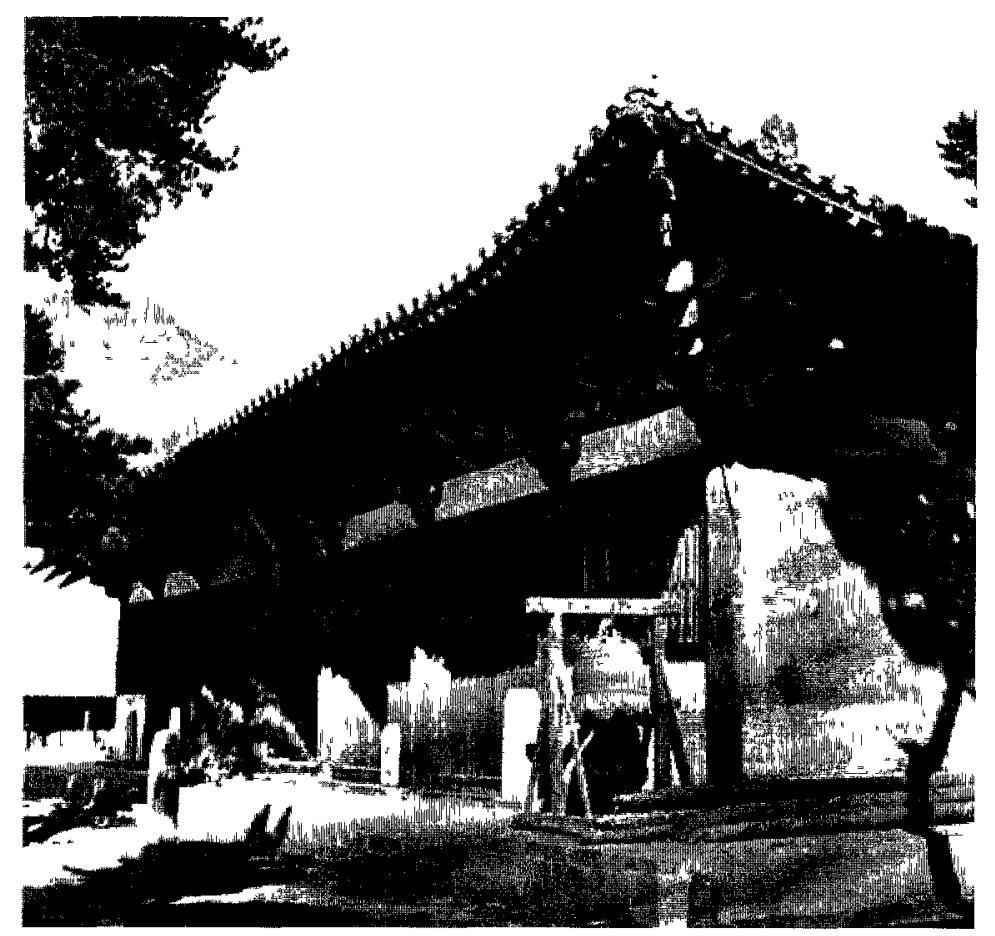

[MG 69] Mall Hall of FoGuang \$1 【佛光寺, orymal construction In 857 .

In its structure, the use of RenZi Gong as the intermediate set was discontinued; in its place, tiers of transverse bracket sets provides 
support for a secondary roof architrave outside the exterior wall line. The column set used in FoGuang $\mathrm{Si}$ is similar with the definitive form as standardized in a Song Manual, YingZhao FaShi【篦造法式】，a canonical manuscript that would be recapitulated shortly. Liang sums up the basic form in the following paragraph:

The members that make up a set may be divided into three main categories: [Dou], [Gongl, and [Ang]. There are four kinds of [Dou] and five kinds of [Gong], determined by their functions and positions. But structurally the most important members of a set are the [LuDou [楅斗1] , or major bearing block, and the [HuaGong【華拱]], or arms extending out from it to form cantilevers to both front and rear, at right angles to the façade of the building. Sometimes a slanting member, at approximately a 30-degree angle to the ground, is placed above the [HuaGong]; it is called the [Ang]. The "tail" or upper end of the [Agn] is often held down by the weight of the beam or the purlin, making it a lever arm for the support of the large overhang of the eave. ${ }^{[|\mathrm{M}| \mathrm{G}, 70][77]}$
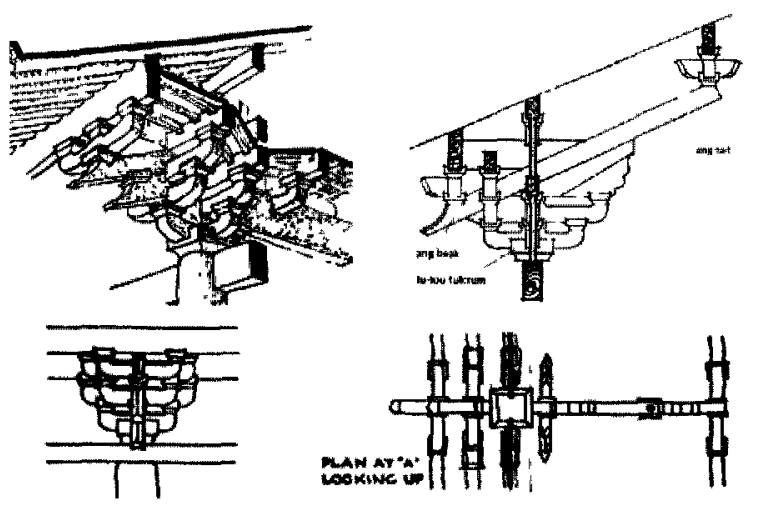

anminow

[IMG 70] A typical bracket set in basic form.
The column sets at FoGuang Si, however, are in fact closer to what

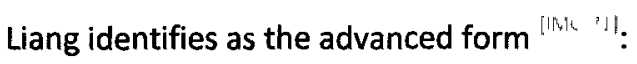

The [HuaGong] may be used in successive tiers, each extending front and rear a certain distance beyond the tier below. Such a tier and extension is called a [Tiao 【跳】], or "jump," and the number of [Tiao] in a set may vary from one to five. Transverse [Gong] intersect the [HuaGong] in the [LuDou]. One or two tiers of transverse [Gong] may be used in a [Tiao]. Such an arrangement is known as [JiXin [龍心] ], or "accounted heart," while a [Tiao] without transverse [Gong] is known as [TouXin【偷心】], or "stolen heart." One tier of transverse [Gong] is called [DanGong [累拱]], or single [Gong]; a double tier is called [ZhongGong [䡒拱】], or double [Gong]. By varying the number of "jumps," by "accounting" or "stealing" the "hearts," by cantilevering with [HuaGong] or with [Ang], and by using single or double transverse [Gong], different combinations of the [DouGong] can be assembled. ${ }^{[78]}$
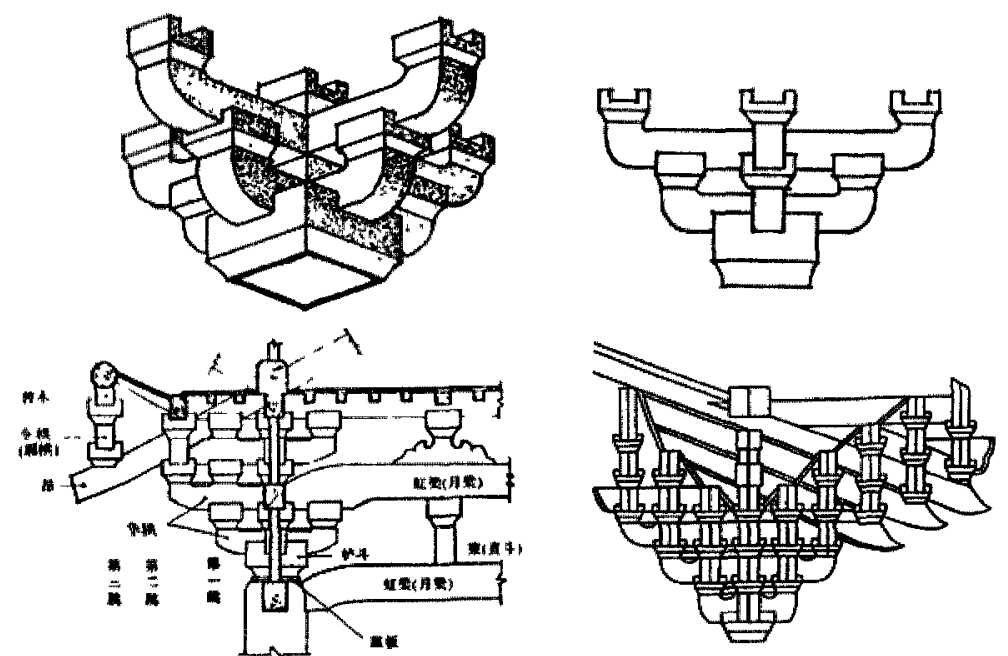


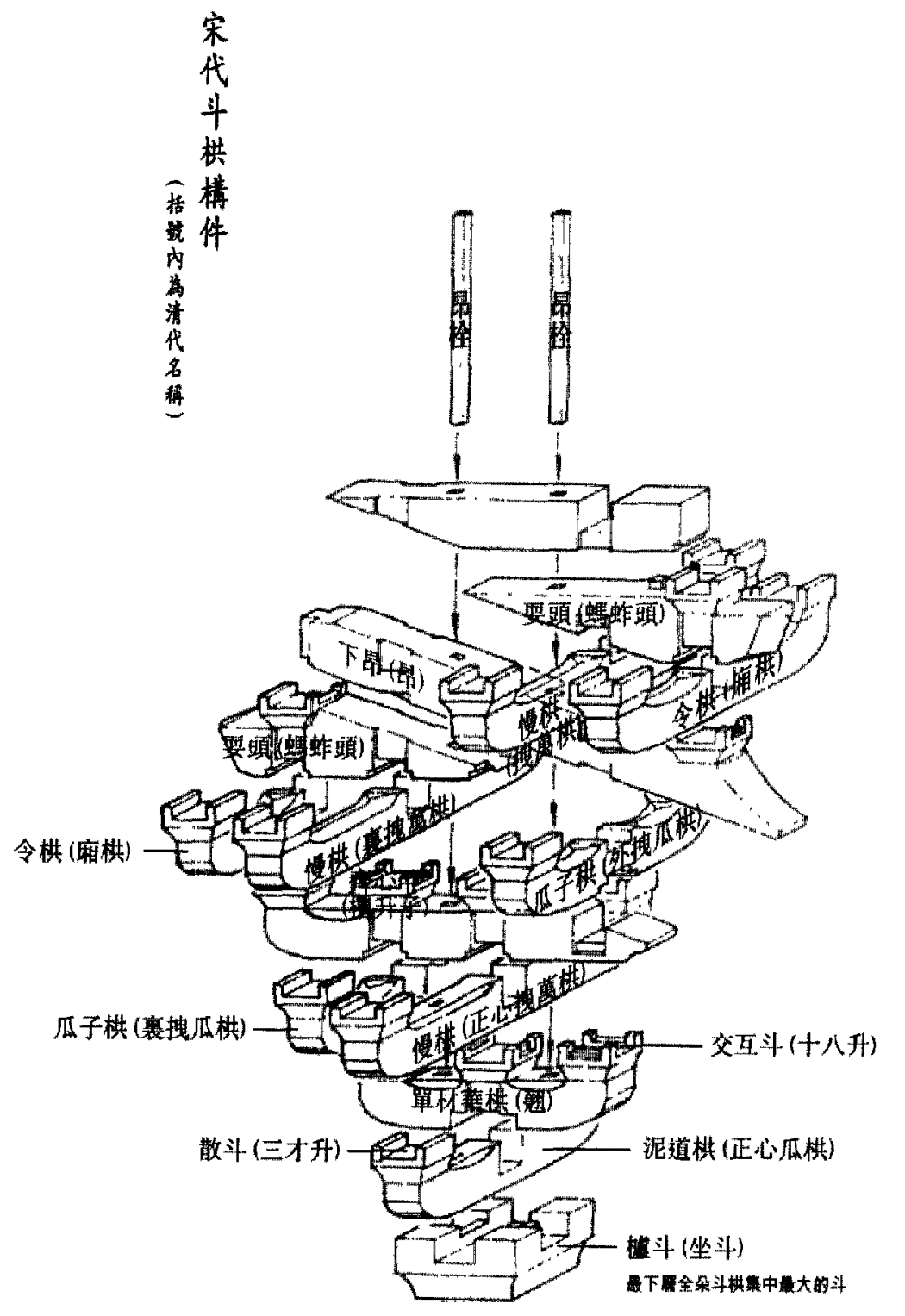

[IMG 71] Typical bracket sets in adwanced form.
As highlighted in Steinhardt's exploded axonometric analysis ${ }^{\text {[MAc } 724}$ of the collective bracket sets tectonics within the typical frameworks of a Tang hall, she has provided us with some clarity as to how the bracket set collectively associates with the gridded columns and the roof framework.

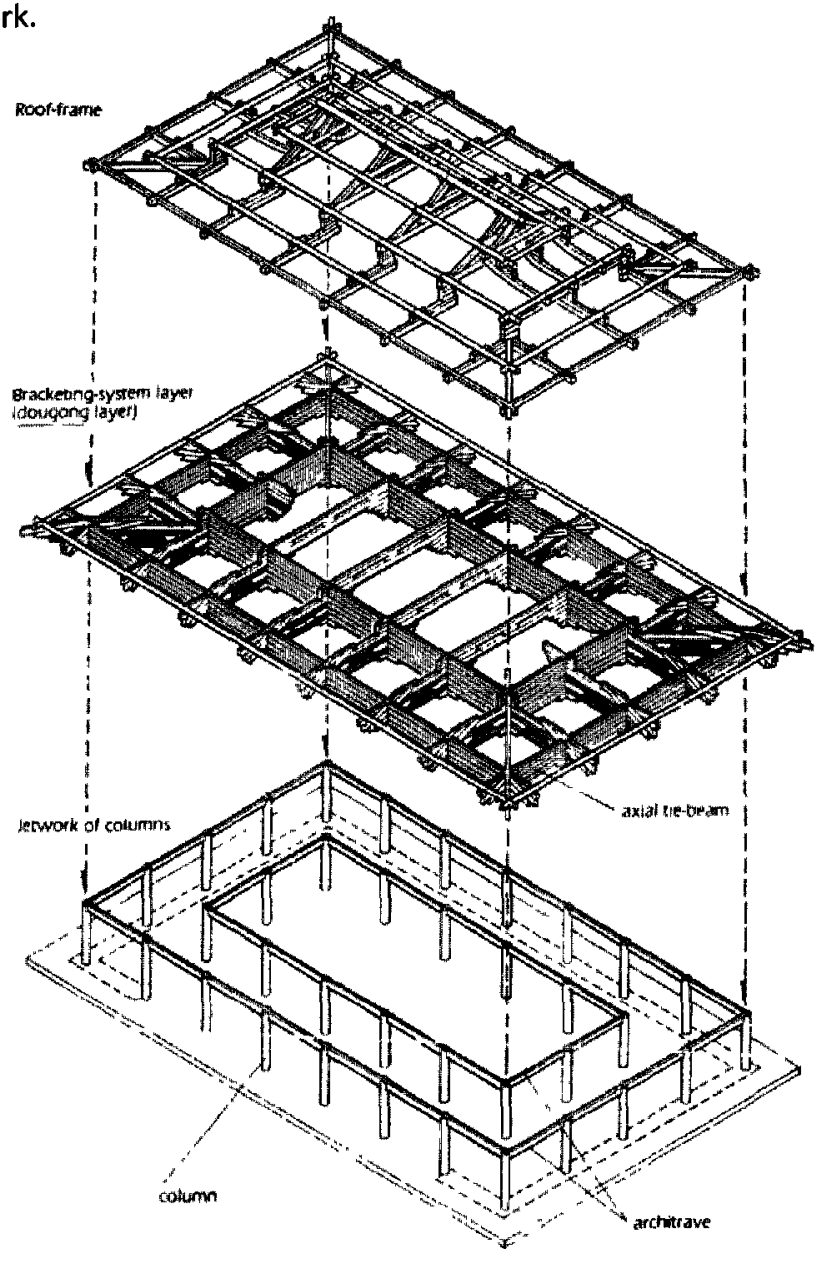

[IMG 72] Analysis of the collective bracket sels tectonic 
The tectonic of this structural analysis is almost identical to the structural articulation of FoGuang Si. As indicated in a cross section of the Main Hall ${ }^{[1 \times 1}$, some of the outstretching bracket arms, or HuaGong, are in fact extensions of axial tie beams place between the exterior and the interior columns.

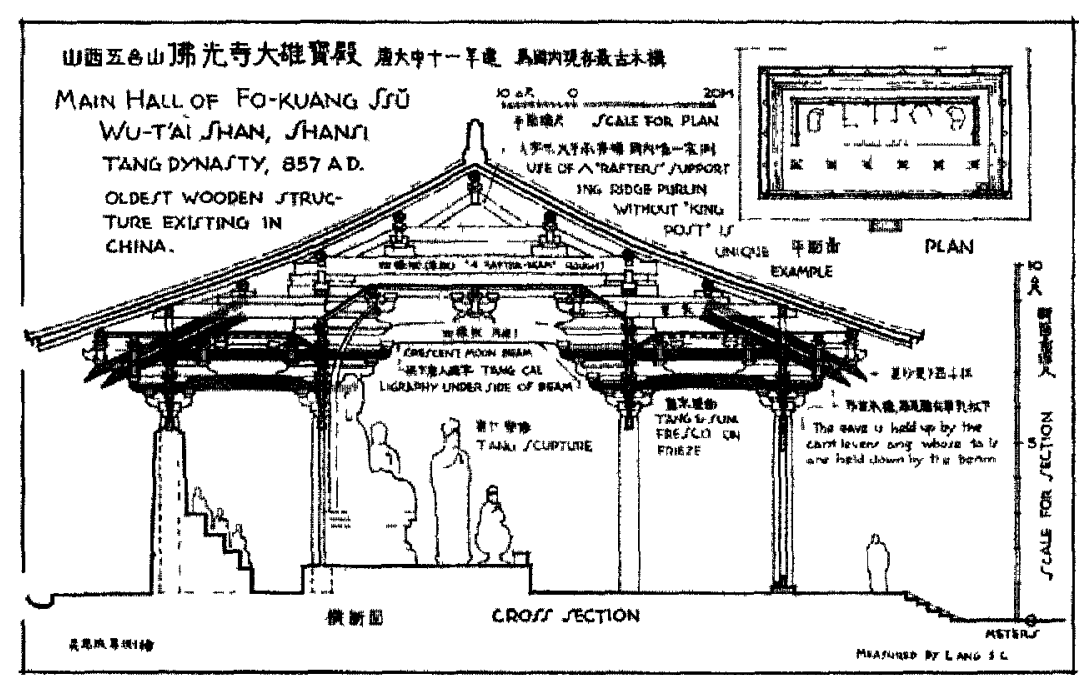

[IMG 73] CIOss stuction of the Main Hall of FoGuang St

The lever juncture between the Ang with the bracket set and also with the purlin, as depicted by Liang, was also used in this Hall. Overall, the entire layer of bracket set framework as depicted in the axonometric analysis is crucial for maintaining the structural integrity of the entire construction; therefore it is inseparable from the roof frame above and the column grid below.
Hou concludes that,

... [T] hese bracket sets not only have manifested a strong correlation to the rational physics and a clear structural logic with the construction techniques involved and the overall assemblage ${ }^{[1, i, 7,4]}$; formally they were sculpted in a sensible and regulated manner, thereby projects a sensation of robust vigor and exhibits an effortless embellishment with their prodigious sculptural profiles.

Such configurations have achieved a high degree of harmony and unity between structural mechanism and aesthetic presence. We should say that this is the peak condition of bracket sets at the height of its maturation-this is an important embodiment of rationalism within the system of timber frame construction. ${ }^{[79]}$ 


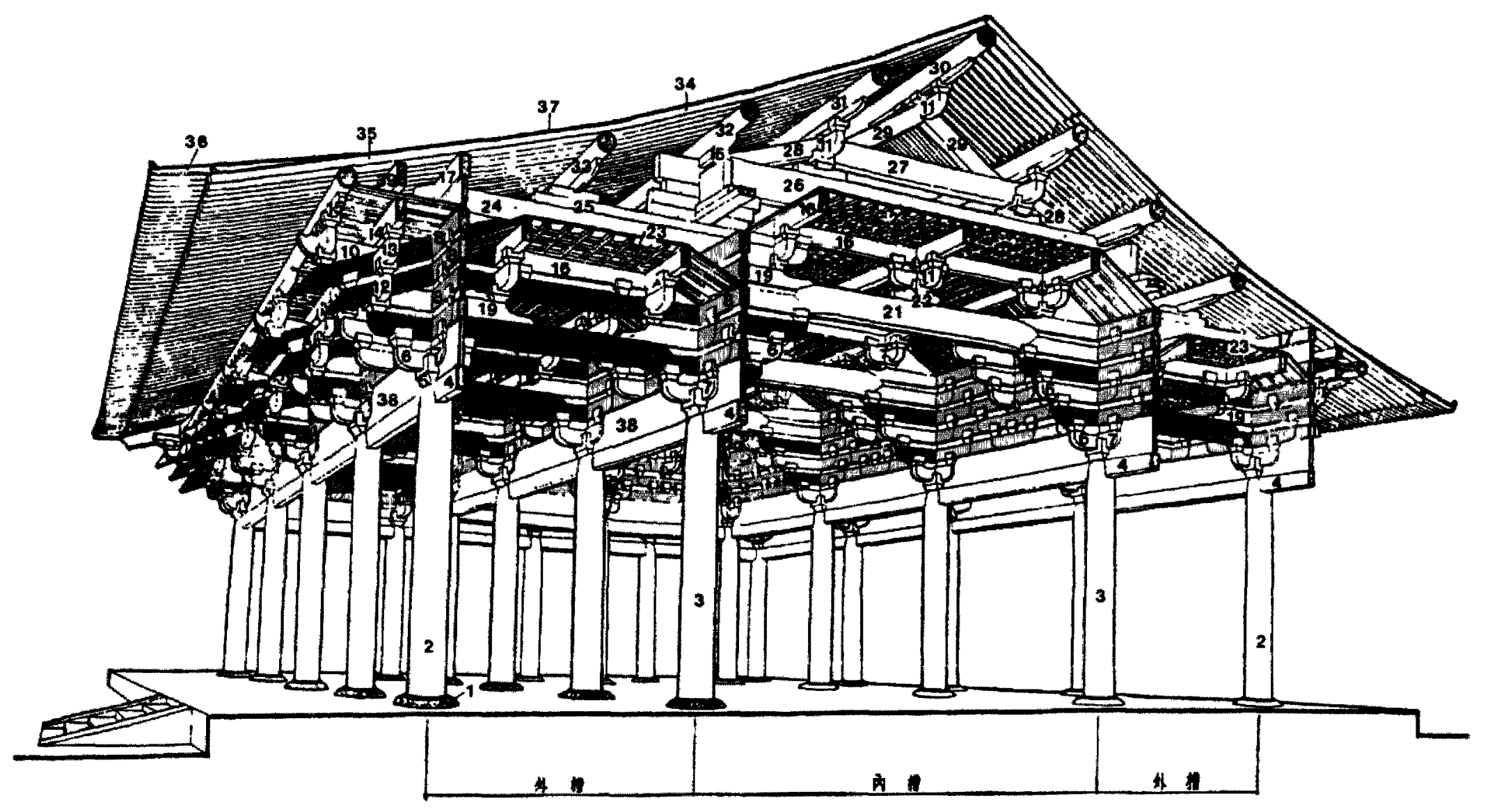

[IMG 74] Analysis of the collective bracket sets tectonic 


\section{Standardization \& Parametric Modularization}

If you think a bracket set is just a structure, think again.

[The DouGong] (bracket set) plays the leading role, a role so important that no study of Chinese architecture is feasible without a thorough understanding of this element, the governing feature of the Chinese 'order'. ${ }^{[80]}$

Structurally speaking, it may be the smallest component of any given timber frame; but technically, it is the most crucial element in traditional Chinese Structural Carpentry. Because it is the smallest and the most repeated entity in architectural construction, therefore it has been designated as the modular unit for the standardized parametric design system used in official and conventional practice since an early age.

According to Zhou regulations, all commonly used measurements are standardized based on human anatomy. The most commonly used units amongst architectural builders were Zhi 【用】, and Xun

【一】. While Zhi refers to the distance from the tip of the thumb to the tip of the middle finger or the little finger on a stretched hand; Xun is the measurement from the two tips of middle fingers when both arms are stretched to the sides horizontally. The ratio between Zhi and Xun was later finalized as 1:8. This is the first recorded system of measurement in Chinese traditions.
As recorded in KaoGongJi, different architectural spaces-chambers, halls, palaces, fields, and roads-were measured in units of different names. However, with the exception of the unit used in measuring chambers, all others equal to the same distance of eight Zhi. The dimensions of architectural halls were measure in Yan 【综】 - the length of bamboo mats used in all building interior as a custom of the stilt-dwelling lifestyle-which were the equivalent of Xun. Yan has soon become a module unit for regulated official constructions, as stated in KaoKongJi ${ }^{[21]}$.

When stilt construction and mats dwelling style disappeared from conventional architectural practice sometime before the Tang eras, the Chinese builders have turned to structural component this time to find a replacement as the basic unit of architectural modulation. Bracket sets as the smallest parts and the most repeated element would make an ideal candidate for this task.

Period of Elegance

The Period of Elegance extended from the middle of eleventh century to the end of the fourteenth century or from the reign of Emperor [YingZong] of the [Song] dynasty, through the Yuan dynasty, to the death of Emperor T'ai-tsu, founder of the Ming dynasty. It is marked by a gracefulness in proportion and refinement in detail. ${ }^{[82]}$

During the Period of Elegance, a very important official building manual was compiled by LiJie, the superintendent of construction at the court of Emperor HuiZong (ruled 1101-1125) of Song dynasty. 
Published in 1103, the YıngZao FaShi ${ }^{4{ }^{4 h}}{ }^{75}$ is arguably the most important Chınese architectural manual. Inside,

[of] the thirty-four chapters thirteen are devoted to rules governing the design of foundations, fortifications, stone masonry and ornamental carving, "major carpentry" (structural framing, columns, beams, lintels, ties, brackets, purlins, rafters, etc.), "minor carpentry" (doors, windows, partitions, screens, ceilings, shrines, etc.), brick and tile masonry lofficial rank and use of tiles and ornaments), painted decoration (official rank and design of ornamental painting). The rest of the text contains definitions of terms and data for estimation of materials and labor. The last four chapters contain drawings illustrating various kinds of designs in carpentry, stonework, and ornamental painting... Because timber is the principal material used in Chinese architecture, the chapters on "major carpentry" are the most important part of the book for understanding the structural system. ${ }^{[83]}$
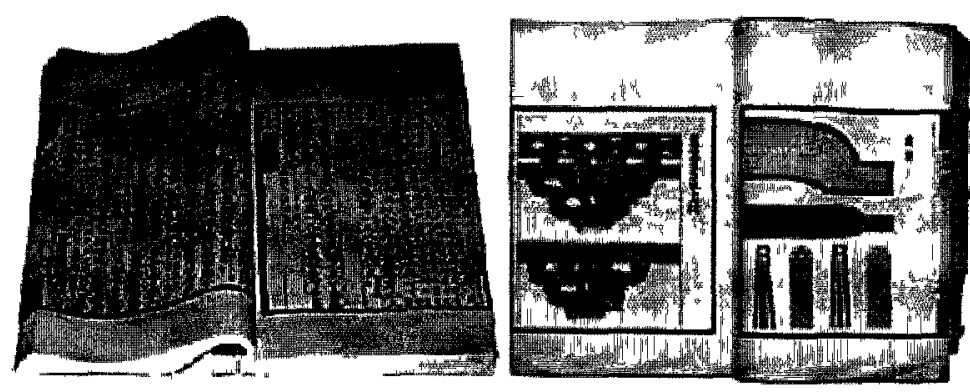

[IMt 75$]$ YingZao FaSh
According to the Manual,

Regarding rules of building constructions, [Cal] is the key of prime importance. [Cai] is divided into eight grades, to be used according to the size of the building. ${ }^{[84]}$

Liang gives a clear definition of Cai [材】 [ini $\lrcorner$ 7E],

The term [Cai] has a two-fold meaning:

(a) A standard-sized timber used for the Kung, or "arms" of a set of brackets ([DouGong]); and all timbers of the same depth ad width. There are eight sizes, or grades, of [Cai], which are determined by the type and official rank of the building to be erected.

(b) A module for measurement. ${ }^{[85]}$

Cai, the section of Gong, is used as the basic measurements for the Chinese traditional parametric design with the division of Fen, or sections:

For each grade of [Cai], the height is divided into 15 [Fen [分】], with 10 [Fen] as the breadth. The height and depth of a building, the length of each member, straight or curved [lforms of all structural elements)]], raise and depress [(contour of the roof structure)], appropriate application of the regulations in an actual job, all are governed by the number of [Fen] of the lumber used. ${ }^{[86]}$ 


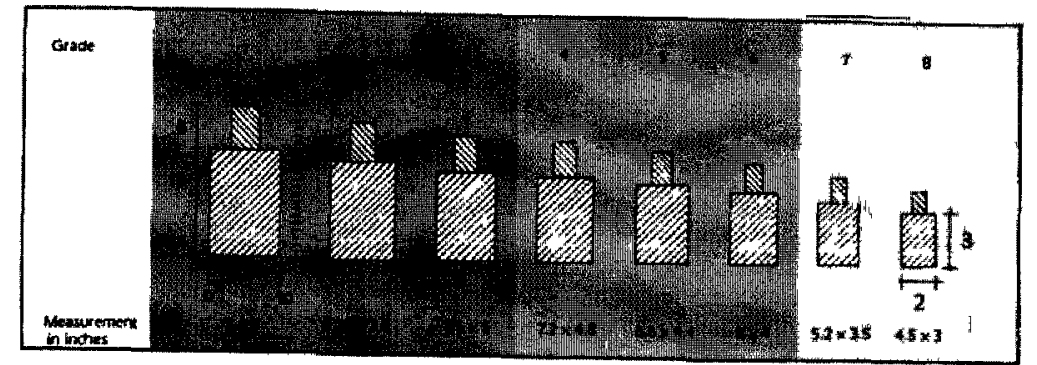

[IMC 76 ] 8 Grades of $\mathrm{Cal}$ and their dimensions according to Ying $\angle \mathrm{Ao}$ FaSh

When two [Cai] are used one above another, it is customary to cushion them by filling the gap with a block six Fen in height, called a [Qi [契] ]. A member measuring one [Cai] and one [Chi] in depth is called a [ZhuCai], or "full [Cai 【足材] ]." The measurements of, and the proportions between the different parts of a building of the [Song] dynasty are always expressed in terms of the [Cai], [Qi], and Fen of the grade of [Cai]

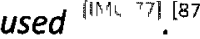

Structurally, all members in any given Chinese typical timber frame construction were generated by parametric rules as written in the manuscript. There are clear indications to the dimension of various sections allowable for the load bearing beams and columns based on the Cai grade determined at the beginning of the project.

In the 80 s, by comparing all dimensions of the 27 measured building from the period of Elegance, Chen DaMing was able to prove that the lengths of beams, the height of columns, and the depth of eaves were also fitted into the system of modular units. Meaning, the spatial dimensions are also governed by the basic unit of Cai.

It is astonishing the Chinese have cultivated a long tradition of parametric construction. It is in fact the longest endured system of standardized prefabrication and assembly that promised efficiencies in time and cost of construction. Such pragmatic approach, which coincides with so many modern ideals, is worthy of experimentation and reinvention. With the project of this thesis, we would critically extract from the structural and spatial knowledge of the traditional Chinese architecture. 


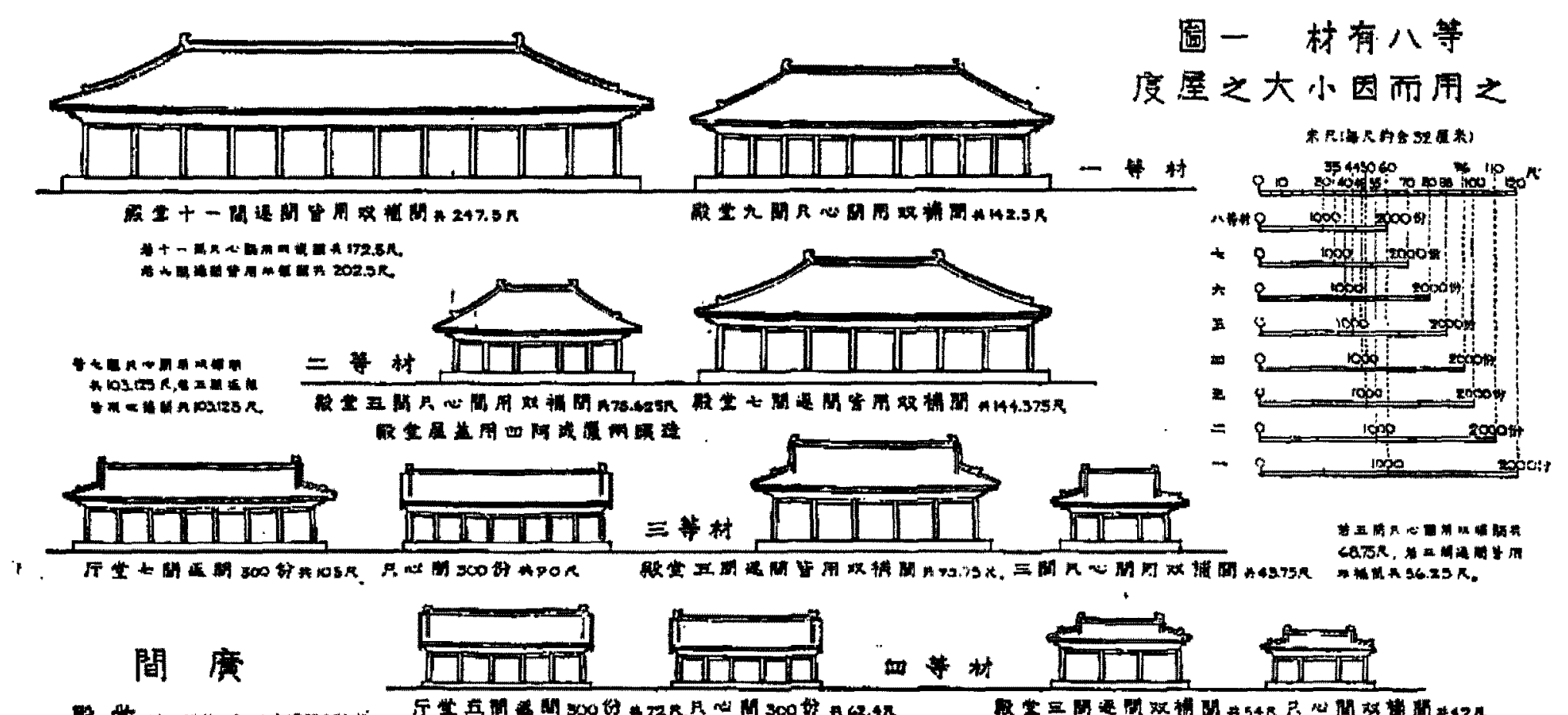

間 廣

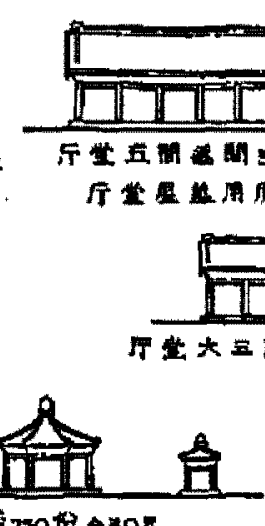

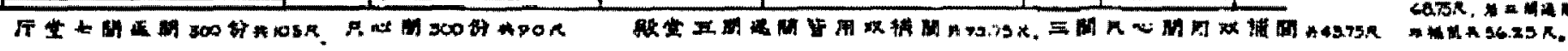

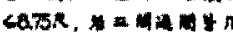
度屋之大小因而用之

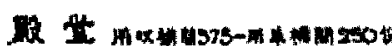
F 堂 $300-230$ 构为

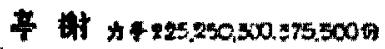
M 4 11575,500,750

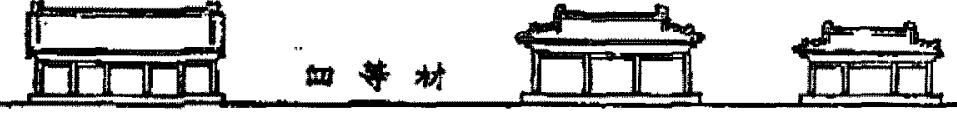

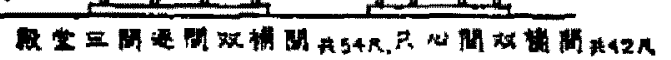

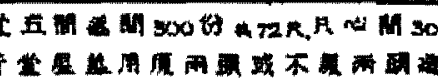

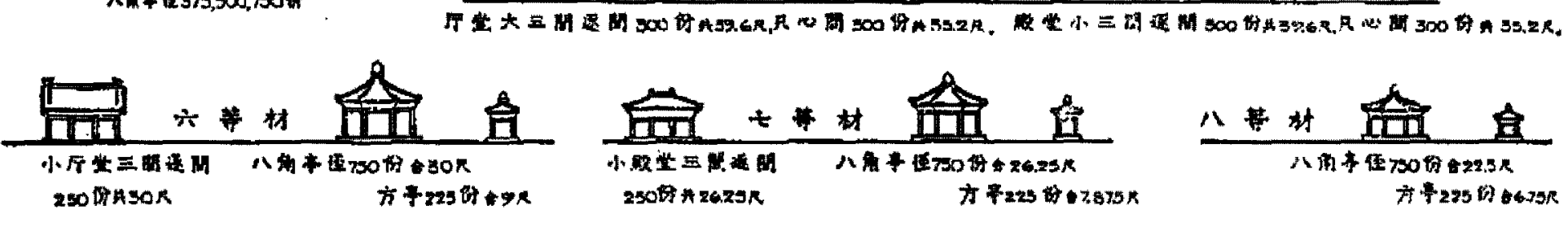

[IMG 77] Use of different timber grade in projects of vat lous soule. 


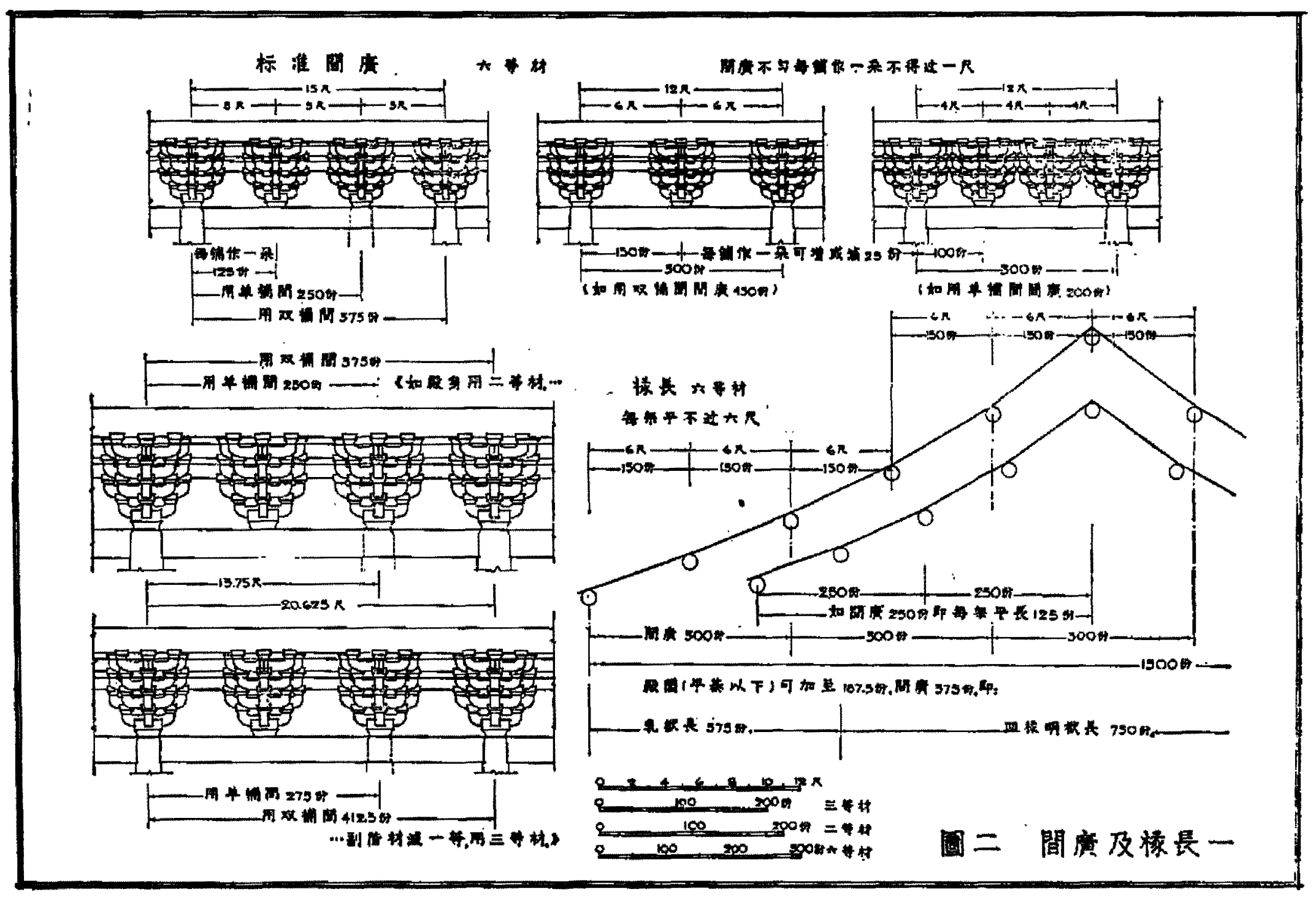




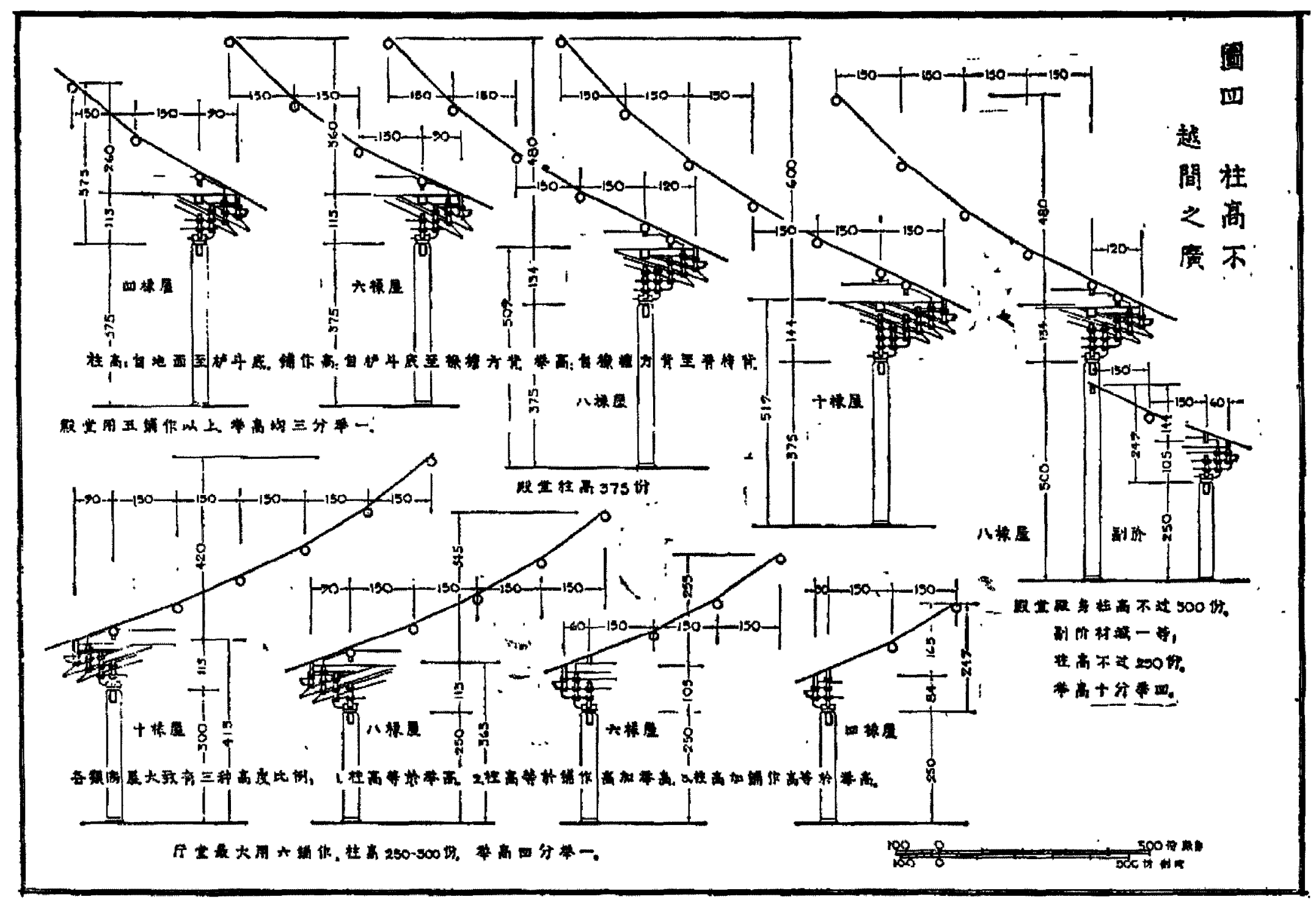




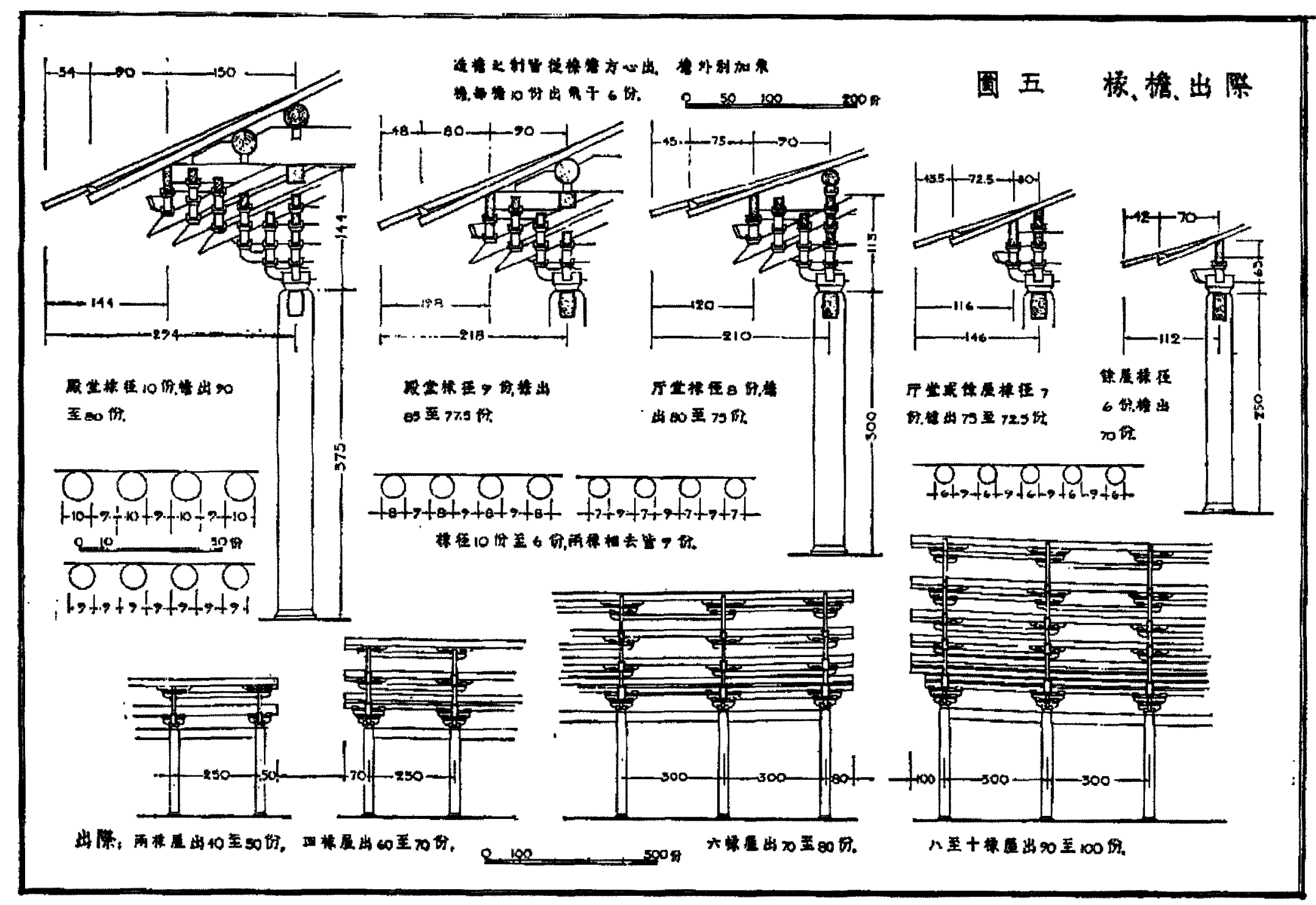




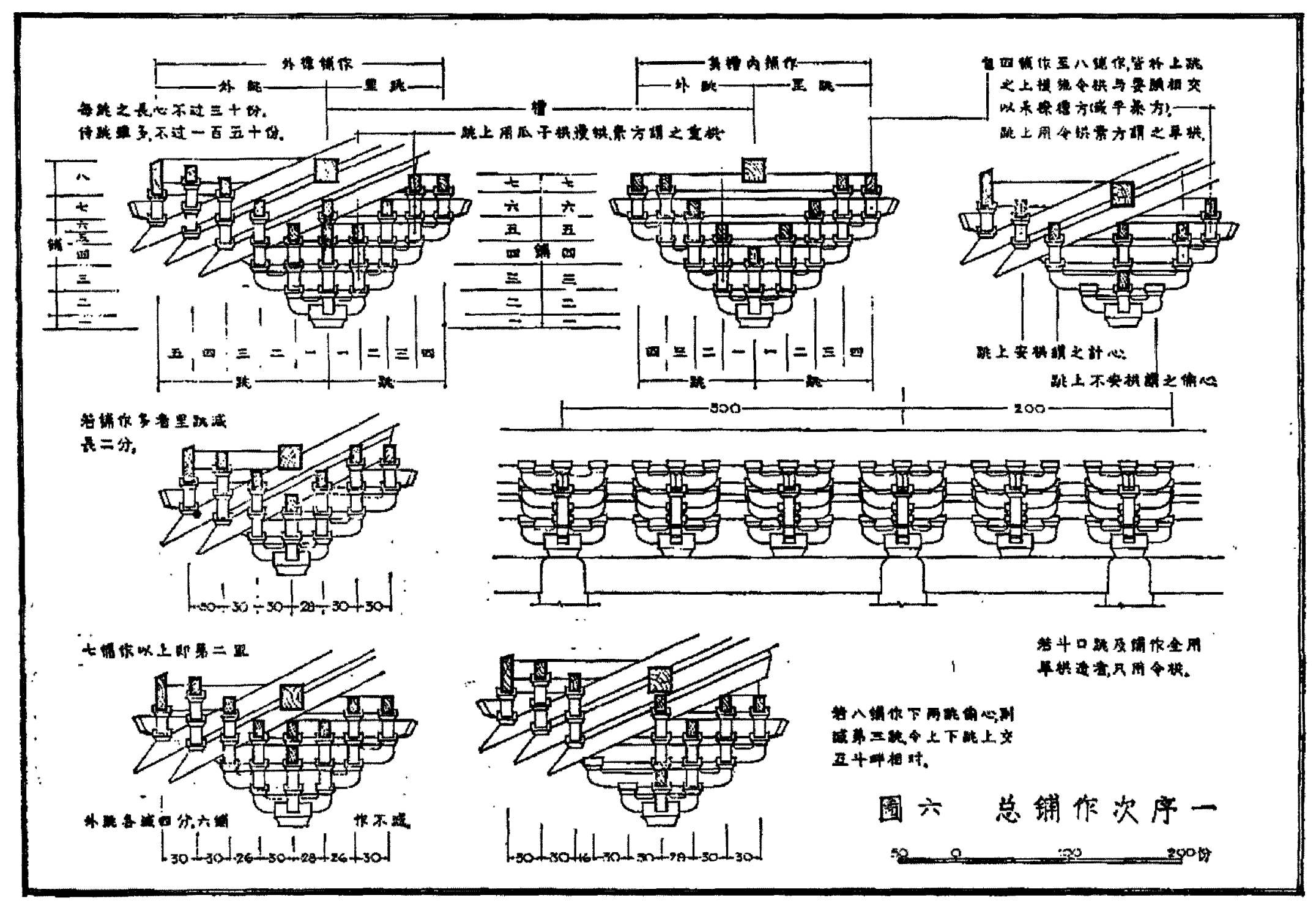




\section{Reference \& Notes.}

${ }^{[01]}$ BOYD (1962) P 6

${ }^{[02]}$ PIRAZZOLI-T'SERSTEVENS (1971) P 6

[Li? "琶王之制”

${ }^{[04]}$ HOU [㑨】 (1997) P 9

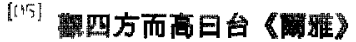

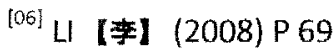

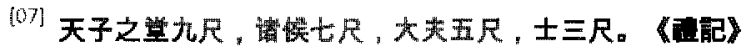

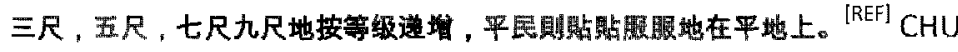

【䚂】(2007) P 28

${ }^{[08]} \mathrm{CHU}$ 【坥】(2007) P 29 quoting (中國大百科全嗇，建筑卷)

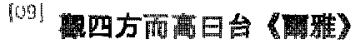

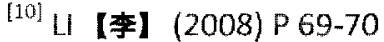

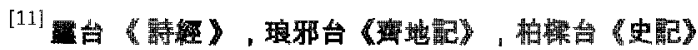

${ }^{[12] ~ C H U 【 t a n] ~(2007) ~ P ~} 27$

${ }^{[13]}$ YANG【杨】(1985) P 117

${ }^{[14]}$ ZHANG L.【张息】(2004) P 244-245

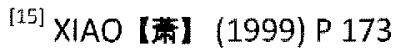

${ }^{[16]}$ STEINHARDT (2002) P 59

${ }^{[17]}$ The most extraordinary bridge of the day was Anji Bridge, which spanned the NanJiao River in Zhao county, HeBei. [Sui engineer LiChun] came up with the segmented-arch, open-spandrel bridge design that in China was first implemented at Anji Bridge. The bridge's twenty-two stone segments, each 1.03 meters wide, were laid together to form a continuous arch, pierced by two small and two large spandrels on either side. The span of the structure is 37.2 meters and its rise is 7.23 meters. The spandrels on either side helped both to reduce the load borne by the stone arch and to allow water to pass through at times of potential flood. Anli Bridge predates open-spandrel bridges in Europe by an astonishing twelve hundred years. ${ }^{[R E F]}$ STEINHARDT (2002) P 125, correction of the designer from LI【斈】(2008) P 352

${ }^{[18]}$ ZHANG【张】(2008) P 14-15

${ }^{\text {[19] }}$ STEINHARDT (2002) P 125
${ }^{[201}$ [... Whereas the MiYan varnety derived from on otininal indian form whose shute-shaped exteror lines offered un unt and beautifut

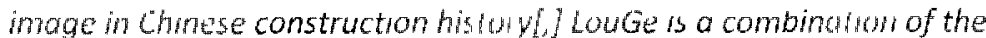
Chinese characters for mults tory structure (Lou) and powilion

(Gol.. Louge structure consist of clearly differchuted stories. wh the lowest story the tollest and the abinding stories successively shorter. [21] LIANG (2008) P 063

[22] KOSTOF (1995) P 231

[23] U【【李】(2008) P 33

${ }^{[24]}$ ZHANG 【聯】(2008) P 15-16

[25] LIANG【柇】(2001) P 9-10

${ }^{[26]}$ ZHANG【张】(2008) P 16-17

[27] PIRAZZOLI0 P 12

${ }^{[28] ~ L I A N G ~(2005) ~ P ~} 68$

${ }^{[29]}$ PIRA77OLI (1971) P 3

${ }^{[31]}$ 園冶・管一第五節

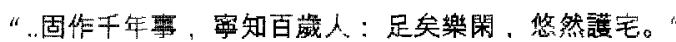

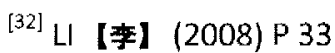

[33] Stemhardt suggest that future excavations may be able to push the ongrins of DouGong, or the brathet set, into the second rrillennium BCE.

${ }^{[34]}$ STEINHARDT (1984) P 48

${ }^{[35]}$ XIAO【萧】(1999) P 181

${ }^{[36]}$ Dimensions taken from Yang's reports. YANG【肠】 (1987) P 76

${ }^{[37]}$ ZHANG L. [聯】 (2004) P 52

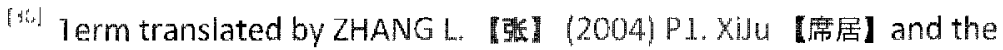
YanXi【筐席】system weln ancient custom similar to the uso of taterin in Japanese architectural traditions.

[30] Term translated by LIANG (2005) 116

${ }^{[40]}$ ZHANG L.【张】(2004) P 51

${ }^{[41]}$ LIU【체】 (2009) P 138

${ }^{[42]}|\mathrm{B}| \mathrm{D}$.

${ }^{[43]} \mathrm{CHU【1}$ 【2007) P 40

[44] 【【【孪】(2008) P 33

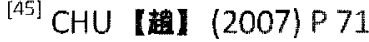


[46] LIU【刘】(2009) P 138

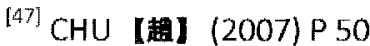

${ }^{[48]} \mathrm{CHU【t}$ 】(2007) P 51

[49] LIU【刘】(2009) P 140

${ }^{[50]}$ http //ctext,org/shıl/qun-shi-huang-ben-j!

史記 · 秦始皇本紀第十七

徙天下豪富於减陽十二萬户。諸筋及章言、上林皆在渭南。秦

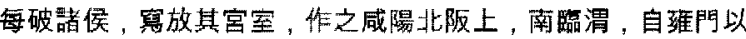

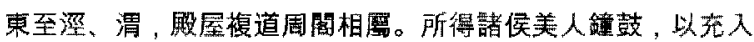
之。

${ }^{[5.1]}$ BOYD (1962) P 12

[52] BOYD (1962) P 14

${ }^{[53]}$ WU (1963) P 13

${ }^{[57]} \mathrm{HOU}$ 【侯】 (1999) P 164

${ }^{[58]}$ LI【杽】(2008) P 86

[59] HOU【侯】 (1999) P 174

${ }^{[60]} \mathrm{HOU}$ 【侯】 (1999) P 175

direct quote from: LIANG 梁思成文暻（二），北京：中国建筑工业出版社， 1984. Pg 302, 334

${ }^{[61]}$ LIU【刘】(2009) P 140

${ }^{[62]}$ BOYD (1962) P25

${ }^{[63]}$ WU (1963) P $37-38$

[64] LIANG (2005) P 37

${ }^{[65]}$ LIANG (2005) P 40

[66] LIANG (2005) P 37

${ }^{[67]}$ BOYD (1962) P 27

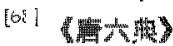

${ }^{[69]}$ HOU 【渎】 (1999) P 19

${ }^{[70]}$ HOU 【侯】 (1999) P 15

${ }^{[71]}$ HOU 【保】 (1999) P 19

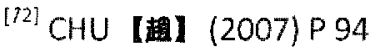

${ }^{[73]}$ BOYD (1962) P 28-29

[74] LIANG (2005) P 17

${ }^{\text {[75] }}$ STEINHARDT (1984) P 122

${ }^{[76]}$ LIANG (2005) P 15
[77] |BID.

${ }^{[78]}$ IBID

${ }^{[79]}$ HOU【侯】 (1999) P 19

${ }^{[80]}$ LIANG (2008) P 059

${ }^{[811}$ 周鉏考工嘌第 72 沂人

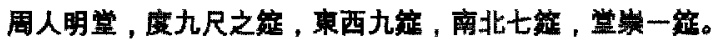

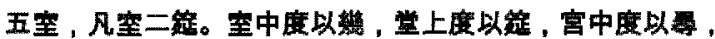
野度以步，嵞度以勏。

[82] LIANG (2005) P 37

${ }^{[83]}$ LIANG (2005) P 14

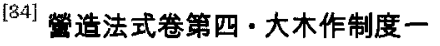

凡楼屋之制皆以材為祖。材有八等，度屋之大小，

因而用之。

Translation: CHEN【陈】 (1981) P 237

[85] LIANG (2005) P 15

${ }^{[86]}$ 營造法式卷第四・大木作制度一

各以其材之后分為十五分, 以十分為其厚。凡屋字之高深,

名物之短長，曲直舉折之勢，規矩臓墨之宜，

皆以所用材之分，以為制度焉。

Translation: CHEN【烸】(1981) P 233

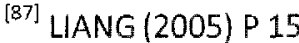


List of Illustrations:

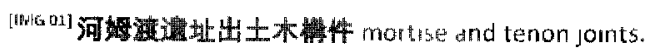

Yang【樈】(1987) P59

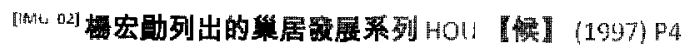




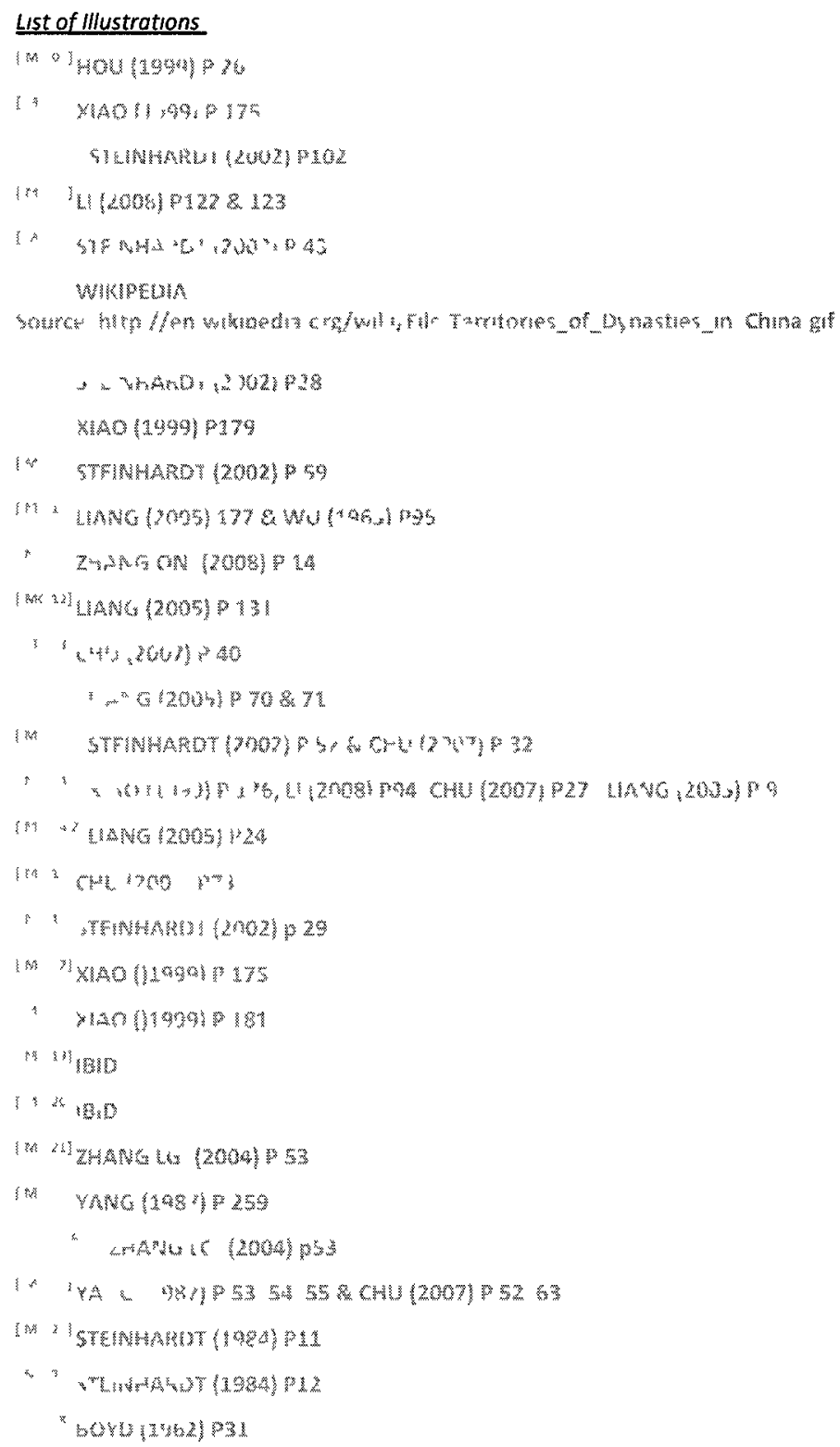

\section{If 21 chu (2007) as

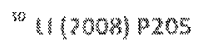

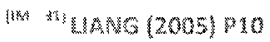

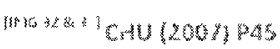 \\ in s.

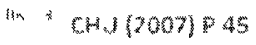 \\ [m) *1 (2008) p 205

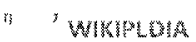

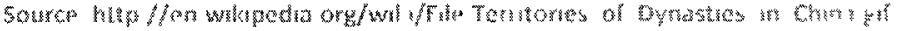

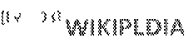

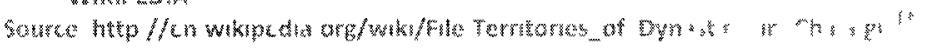

"Ba: UNVERSTY OF WASHMOTON

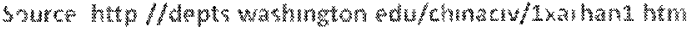

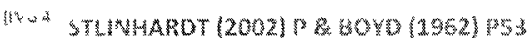

H:

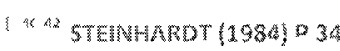

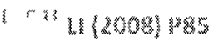

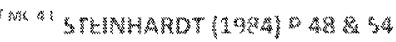

(2 " LANG (2005) P 29 \& LW 2009 ) 130

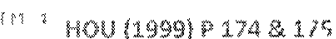

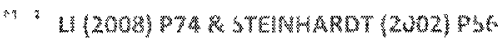

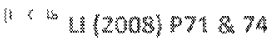

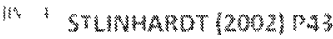

(1) "LANG (2005) 32

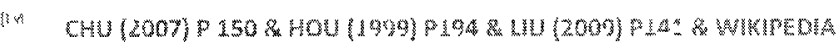

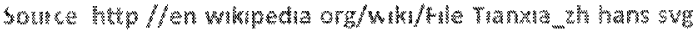

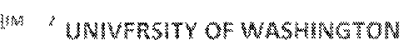

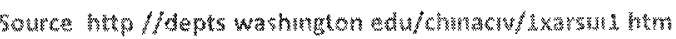

\section{* UNVERSTI Y OFASGHWTON}

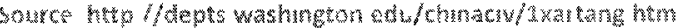

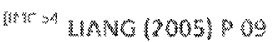

(m) Hou $119991 \mathrm{P} 22$ 


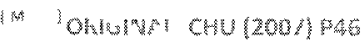

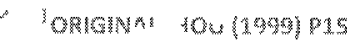

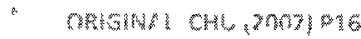

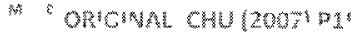

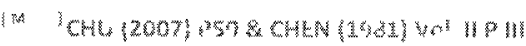

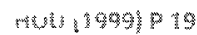

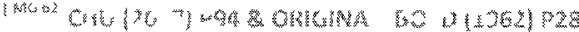

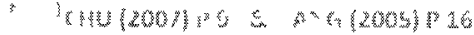

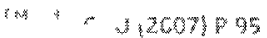

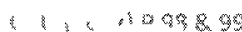

stuplons:

a

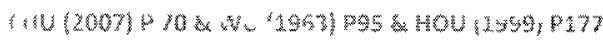

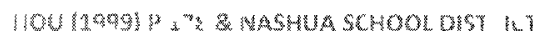

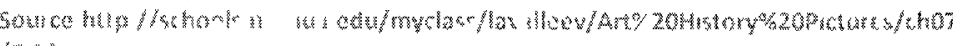
1\% 1318

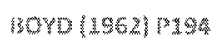

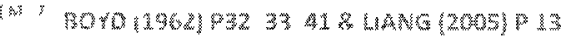

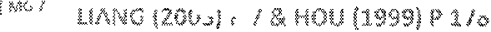

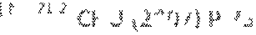

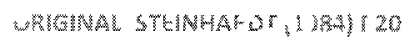

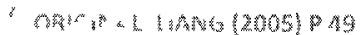

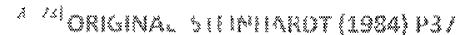

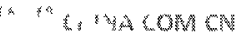

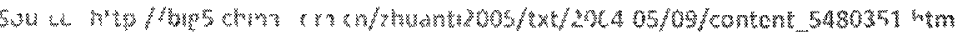

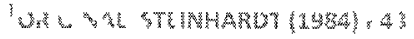

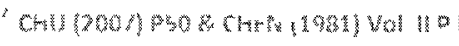

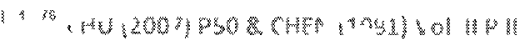

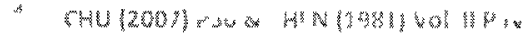

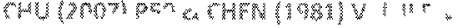

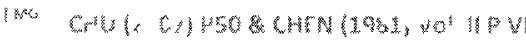


characters $\left.{ }^{(I M G} 01\right]$. In fact, the typologies were nuanced variations of a universal paradigm-the axial symmetric courtyard hierarchical configurations established no later by classical Zhou as elaborated in earlier chapters.

The planning problem of the Chinese architect is not that of partitioning a single building, since the framing system makes the interior partition mere screens, but of placing the various building of which a Chinese house is composed. These are usually grouped around courtyards, and a house may consist of an indefinite number of such courtyards. The principal buildings are usually oriented toward the south, so that a marimum amount of sunlight can be admitted in winter, while the summer sun is cut off by the overhanging eaves. Adapt from the variations required by special topographical conditions, the same general principles apply to all domestic, official, and religious architecture.

\section{traditions that sanctioned personal cultivations and spiritual}

Which emphasized efficacy and pragmatism, and from the Chinese aspirations; it is possible to strategize a pragmatic approach that promotes an open platform on which, building upon a common architectural language, the practicing professional and the laity-the daily occupants- of architecture could engage in a more sufficient dialogue by embracing collaborations of every participating individual in the perpetual reinventions of their physical reality.

\section{Typology}

As depicted by Ito Chuta, a renowned Japanese architecture historian, the Chinese traditional building typologies shared many common attributes despite each of them committed to different programmatic

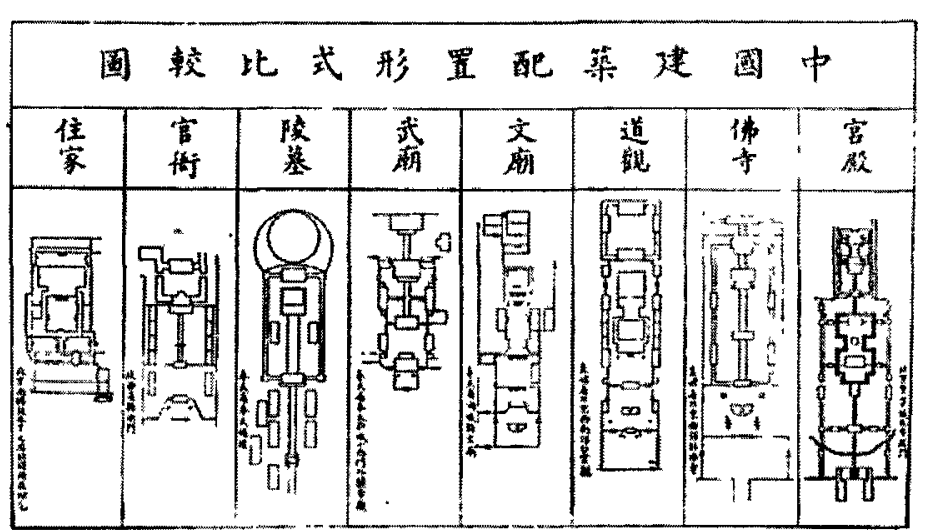

[IMG 01] Chinese Building Typology by ITO Chuta 
Li suggests that the persistent attempts to emulate according to the official ordinance, along with the reluctance to explore beyond the existing architectural paradigm, could be explained by the traditional approach to design in general. He argues that in the general design approach within all aspects of their traditional culture, the Chinese were accustomed to an all-purpose design strategy-ready mades, so to speak-in contrast to the made-to-order conventions of the West ${ }^{[I M G 02]}$. Li concludes that,

[i]n regards to the Chinese intentions towards all artificial articles their design, and towards their utilizations; there remained a constant effort to demand a high degree of flexibility in preparation of adapting to possible changes within various settings of their applications...Historically speaking, Western architectural conventions catered to individual specificity, while Chinese building practice accommodated universal configurations. According to the design principles of the traditional Chinese dwelling, a building should be instrumental as a building-ideally it should be fitted for most programs. ${ }^{\text {wis }}$

In short, various building typologies would establish their programmatic character-not through formal articulation or spatial configuration-but rather, through ornamental decorations, interior displays and artistic installations. Here we must note that all but one of building typologies shown in Ito's diagram were official buildings subjected to official standards. Indeed, the universal paradigm as regulated by official standards and ritualıstic ordinance was far from being the exclusive rendition which dictates all architectural configuration in the Chinese practice. As pointed out by $\mathrm{Li}$, a more extensive outlook on the many historical and indigenous examples in extant from various regions of China would indicate that traditional architectural developments, though by large would reference the official architectural principles, were capable to transform and adapt themselves to variations of external conditions accordingly.
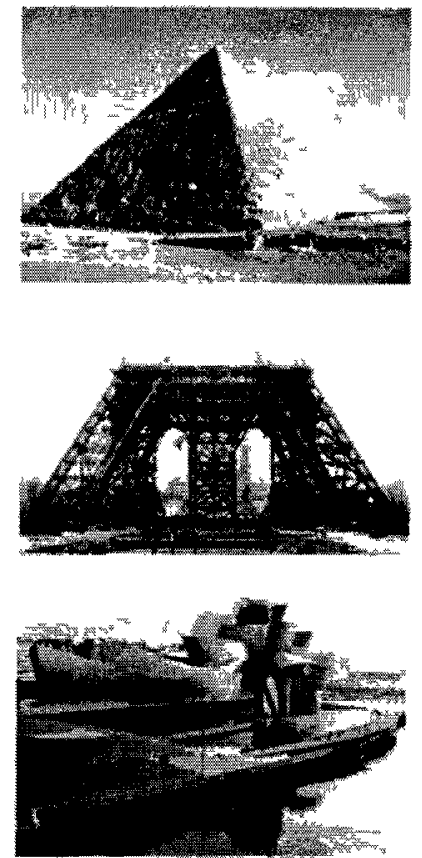

PART-BY-PART CONSTRUCTION

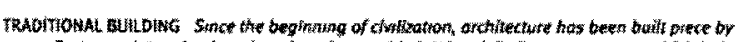

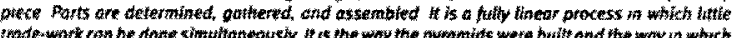

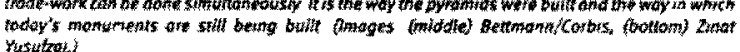

[IMG 02] Made to Order Conventions of the West. 


\section{Regional Reinterpretation}

Two of the most interesting regional articulations worth mentioning are a semi-institutional monastery located in the North near the southern border of Inner Mongolia, and a rural domestic vernacular typology found in Southern China.

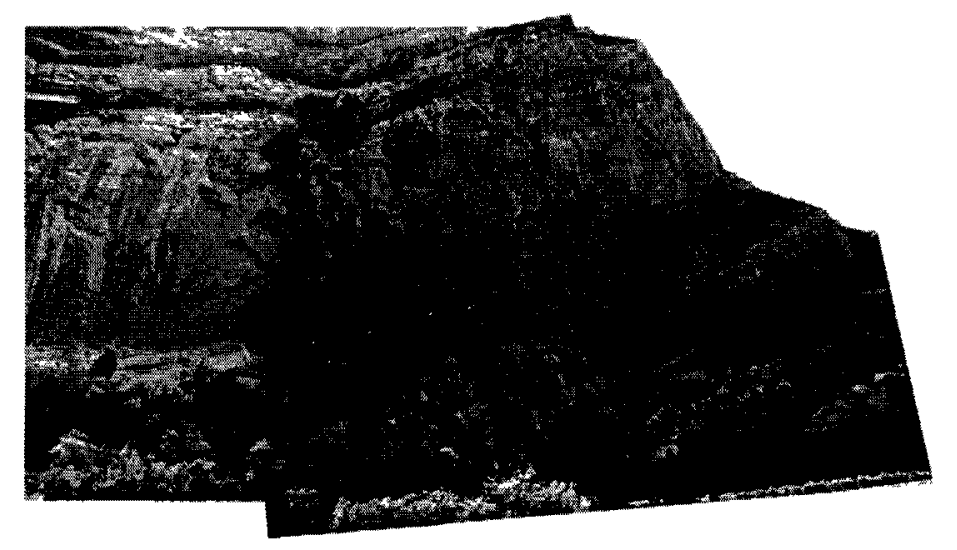

[IMG 03] Hanging Monastery, ShanXi China

The Hanging Monastery [IMG 03], or XuanKong Si, is by far the most intriguing reinterpretation of the traditional Chinese architectural paradigm. Building on top of an existing ancient passage, the monastery was constructed on the side of Mount Heng along the contours of a cliff. Mainly supported by a framework of inserted crossbeams cantilevered from the side of the cliff, the spatial configuration of the monastery resembles a sectioned courtyard complex with corresponding hierarchical spatial movements through a series of halls and pavilions ${ }^{[I M G}{ }^{04]}$. Structural details of individual buildings suggest that the similar parametric tectonic construction was employed from the initial construction some 1400 years ago-the standardized components were first prepared on the ground, and then the component were transported to midair to be assembled. The monastery, an unusual institution which houses all three prominent Chinese religions-Confucianism, Daoism, and Buddhism-remained an architectural and engineering feat through the continuous rebuilding and restoring process throughout the centuries.
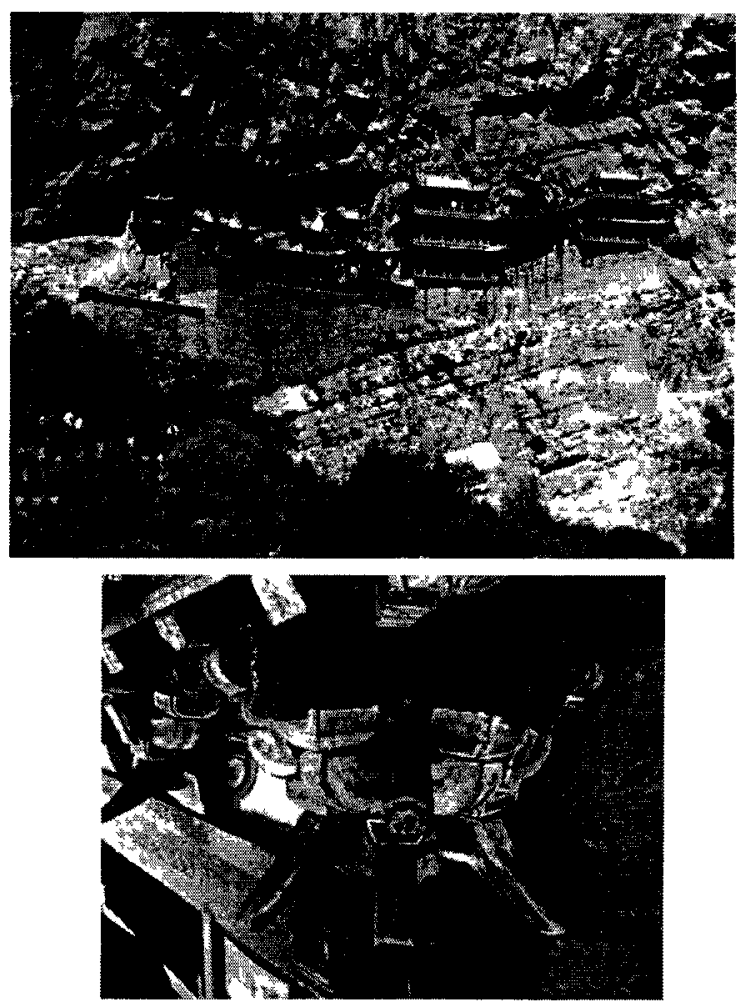

[IMG 04] Hanging Monastery and Tectonic Details 
The second example was an abundant domestic type native to Southwestern FuJian province known as the Hakka Clay Bulldings, or TuLou [IMG 05]. This vernacular type is one distinctive form of Hakka dwelling evolved from self-defensive exigencies in responds to the local ethnic disputes. Historically, the Hakka people were a branch of the Han ethnicity that gradually migrated southwards during chaotic periods of wars and turmoll. Over tıme, the intensified tension between the natives and the Hakka settlers have prompted a new approach to the vernacular type.

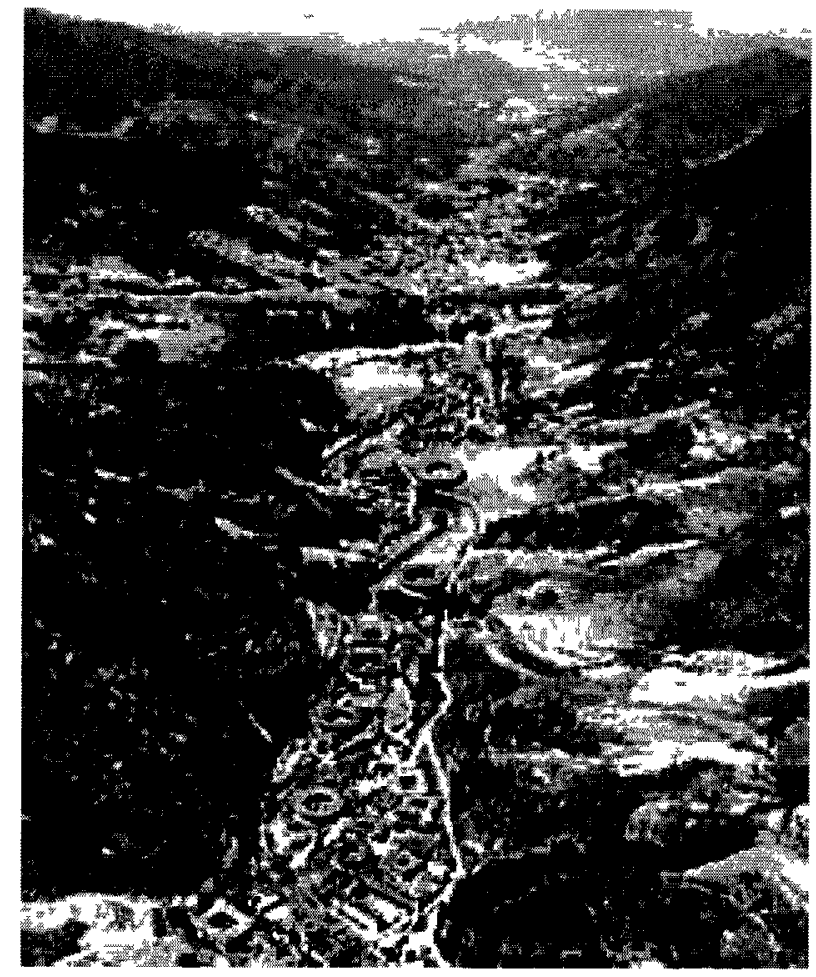

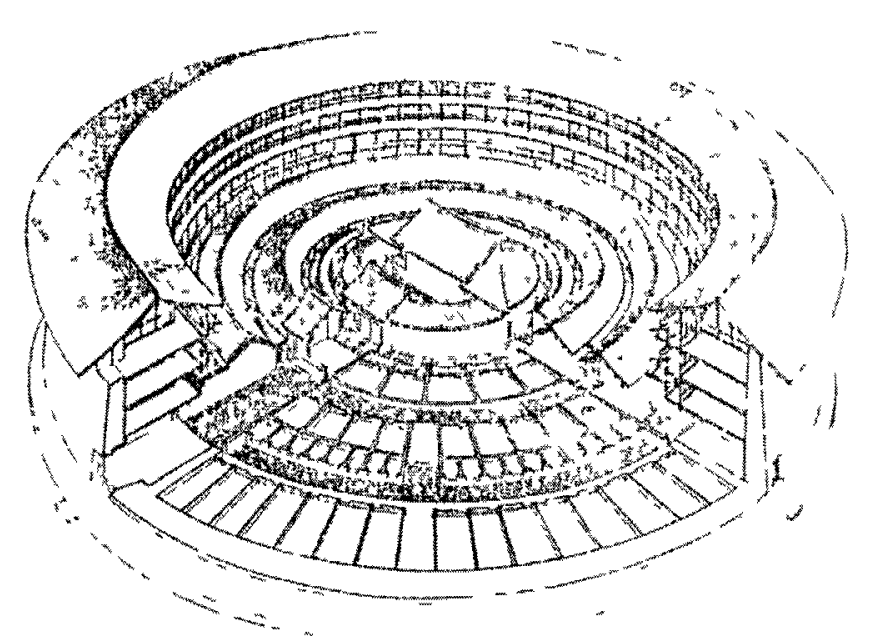

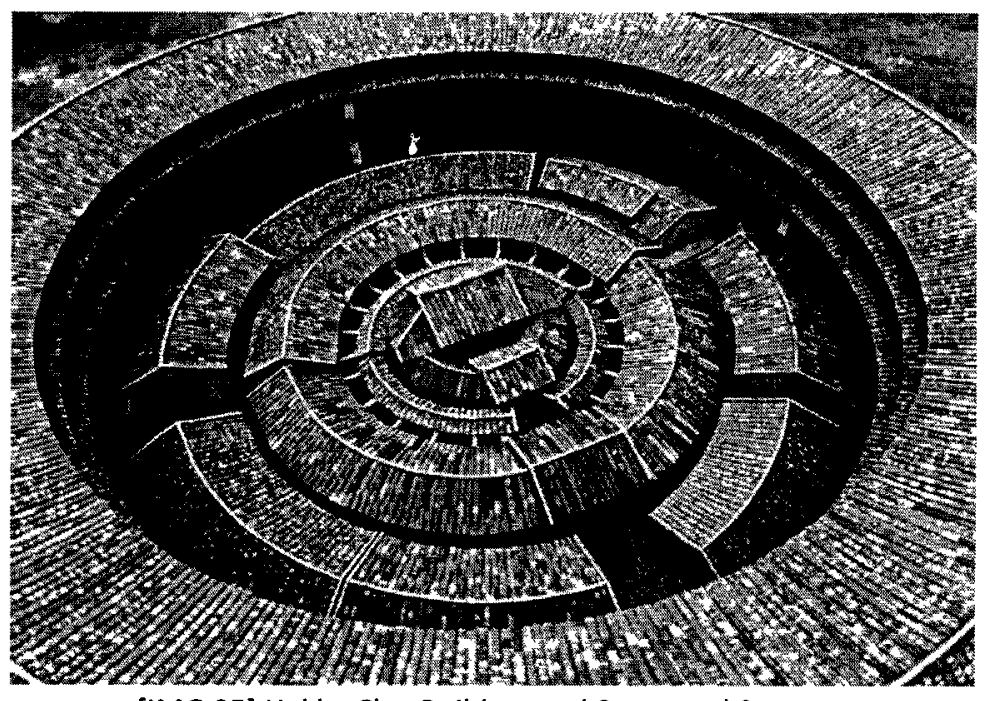

[IMG 05] Hakka Clay Buildıng and Structural Section 
The flat surface of the clay building is characterized by symmetry with explicit building centre while having reflected strong hierarchal ideas. Such a kind of arrangement embodied the patriarchal clan ideology while being in line with the management and control of the conglomerated clan. In terms of technology, though a great deal of ramming technologies were applied, the construction of the clay building was not divorced from the timberframe building system popular in the Central Plains..." "I

The concentric configurations of the clay buildings planned around centralized courtyards in an abundance of shapes and sizes are clear indications of a flexible reinterpretation of the architectural paradigm as a branched regional development. The Hakka people may have incorporated building technologies from natives of ZhangZhou regions

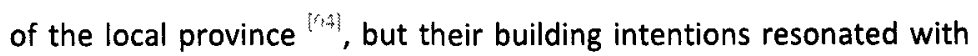
Han cultural values in terms of spatial configuration and utilized the pragmatic nature of timber frame tectonics [IMG ${ }^{06]}$. It should also be noted that the clay buildings were self-directed inventions of the occupants-every farmer as a member of the clan would participate in construction during winter times. Occasionally, craftsmen would be hired by a clan with means to build the ancestral hall, which locates in the center of the clay building. But in general, the method of production of the traditional construction technology developed in the agrarian based Chinese society relied on collaborative efforts of a relatively small number of individuals. As such, we believe that the Chinese paradigm merits further contemplation in the exploration of post-critical possibilities.
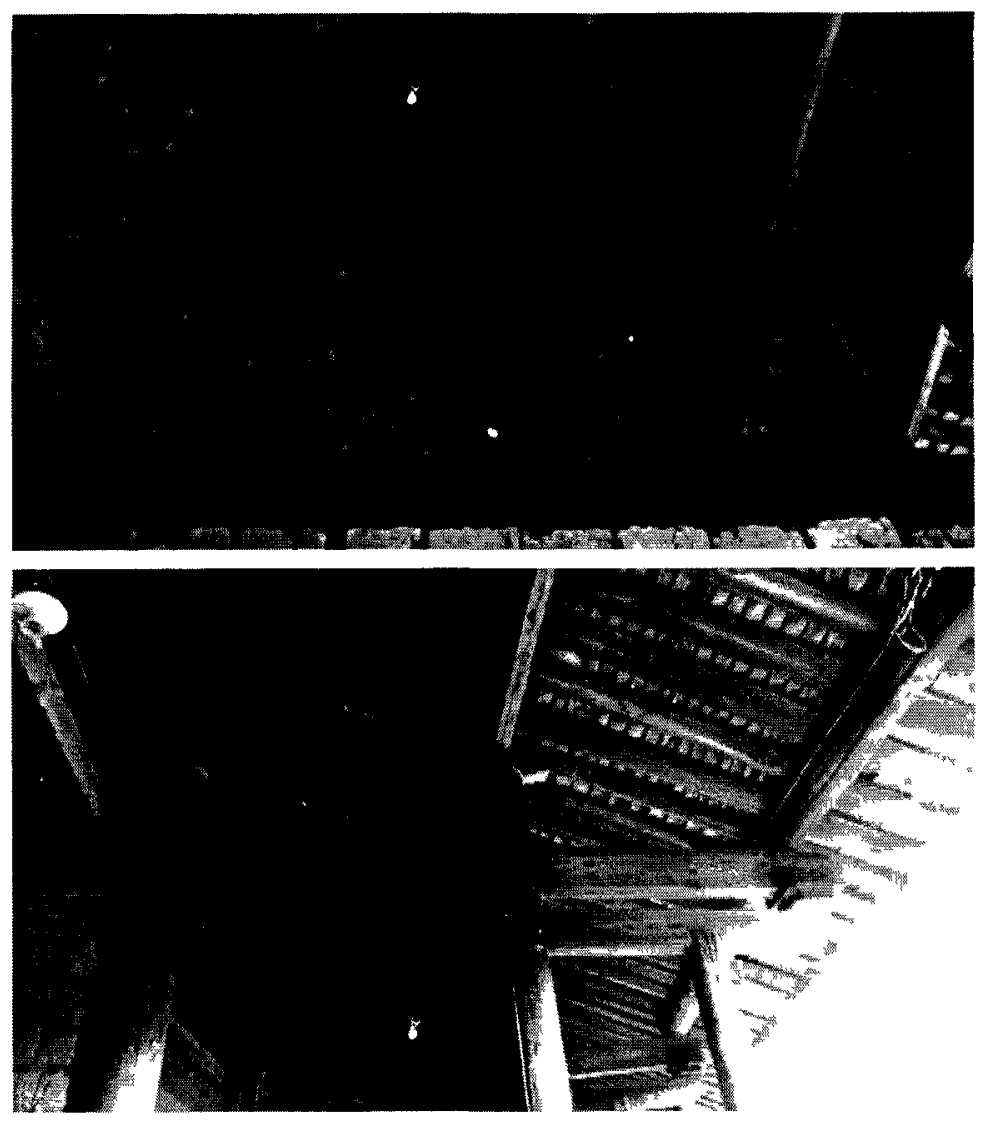

and Structural Section

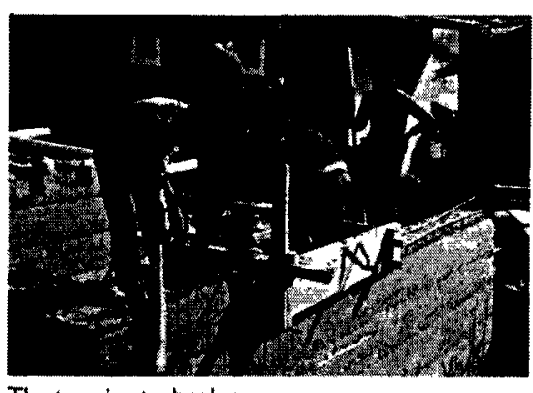

The tamping technology 
The Chinese architectural paradigm and its intended course of developments were largely focused on enhancing the instrumental capacity of buildings. Architectural formalities were conceived based on parametric articulations of standardized assemblage established upon technical objectivity. Even though the rigorous practice of ritualistic conventions and the centralized official regulations have imposed much restrictions on the spatial configurations of most building typologies in urban setting; many historical and regional precedents, such as the Hanging Monastery and the Fulian Clay Buildings, have revealed alternative articulations which capitalize on the structural and economical proficiencies of the paradigm and further transcended such established framework in achieving architectural manifestations on an alternate dimension.

The many clay buildings of the Fulian province and the Hanging Monastery are two of the many Chinese examples that would prompt architects to rethink the nature of our architectural professionalism. For decades, architects have indulged in utilizing architecture as a weapon of criticality. To some degree, architecture of the West inherently possesses the tendencies to criticize the established status quo and the prevailing discourse. Kengo Kuma, an acclaimed practicing architect, in his book Defeated Architecture precisely dissects the nature of criticality and its developments in the modern era. He questions the relevance of architects and architecture in our contemporary opened societies, and he alleges that the notion of criticality is merely pretence-a position in which the architects took by turning sideways to protect the relevance of their professionalism $\left[c^{\infty}\right]$.

Kengo's fascinating interpretations on modern conditions and contemporary architectural discourses and his in depth analysis on the nature of criticality call into question the necessity of architecture as representations of aesthetics and as representations of ideologies. In the preindustrial worlds, architects have made themselves relevant by providing service to the elite class by articulating architecture as a manifestation of arts. In the recent modern eras, architects have made alliances with the emerging middle class by investing in architecture as a weapon of struggle and as a critical tool endorsing new ideologies. In our contemporary geopolitical reality, when the emerged middle class is just as archaic as the aristocrats, have architects lost insight of a new position the profession must take in order to once again transform itself and to maintain its relevance?

\section{INTEGRATION}

More than ever, self-reflectivity has now become an important obstacle the profession must overcome. The post critical explorations as initiated by Koolhaas and others are indeed a calling for prospects beyond the resistance and the negation that so many professionals have found meaning in and have manipulated to forge an identity of self with. As argued by Kengo, both a resilient attribute and also a fatal weakness of the critical discourse lies in its self-defensive mechanism-its inability to criticize itself. If architects would 
objectively evaluate the pressing contemporary conditions of our globalizing reality-the geo-political conditions, the diminishing physical resources, the environmental crisis-and also the communicational technology we have developed-the digital networks of communication, the burgeoning collaborative market ran and fueled not by corporate but by individuals-would they realize that criticality needs to be criticized?

We question the established discourse in architecture and we query the practicality and the relevance of criticality-its embodiment of transgressions and its failed attempts to communicate with the general public-in a world where the middle-class have emerged and in a world where the focus should be broaden to evaluate the changed and changing geo-political status quo between the developed and the emerging worlds. In realizing that the architectural manifestations of the critical discourse as transgressions towards political status quo would have little significance in the post-cold war-and even the post911 world-the critical approach must be reconsidered. We would also ponder, on other more prominent issues-such as a multiplying complexity between the capital forces and their conflicts with the greater society-how would architecture perform critically against its endorsers? In such cases, even if architecture were effectual as a media, it would most probably be a bias critique when its context is in conflict of the capital.
The limits of representation must be acknowledged if architecture were destined to service the society as a media. How others from outside the profession receive criticality is often a lesser concern of the architects. Architecture as an implicit media that engages the body and the mind would only be able to operate at an intuitive level. Too often an ideological manifestation would require analytical communication on the context and the concept of the design. Many of such attempts may have pushed the envelope too far beyond the comprehensions of laity short of six years in professional education, let alone actually becoming a physical manifestation. No matter how well it is scripted, a monologue or an exclusive dialogue without any attentive audience is a failed attempt of communication. Incarcerated in the architects' own prison, the preservation of architectural interventions as manifestations of the critical discourse is, unfortunately, an autistic idiosyncrasy of the profession.

Perhaps the autonomy of the profession needs to depart itself from the autonomy of architectural practice. A repositioning of professional relativity would benefit from replacing the oppositional autonomyversus-instrumental mentality with an autonomy-with-collaboration strategy. It is in the nature of the architectural profession to use and be used by the capital. But just like the modern architects who have liberated themselves from the confines of aesthetic manifestation by realigning themselves with the interests of their contemporary new forces of capital-the emerging middle classes; our contemporary practitioners could conceivably harness the transpiring forces of 
collaborated consumption ${ }^{150}$-a thriving new form of networked marketing based on the collaborations of individuals rather than monopolies of corporations and commercial organizations. There are certain potentials that architecture could once again be liberated from the constraints and the brutality of the conventional capital force, providing room for autonomy not only for the professionals, but autonomy for every proactive individual who wishes to participate in architectural interventions.

...there is a basic similarity between the ancient Chinese and the ultramodern. But can they be combined? Can the traditional Chinese structural system find $a$ new expression in these new materials? Possibly. But it must not be the blind imitation of "periods." Something new must come out of it, or Chinese architecture will become extinct.

Drawing from debates on criticality and post-critical possibilities and the alternative approach to architecture from the Chinese traditions, we proceed to consider the potentials in restructuring the architectural professionalism. Contrary to architectural practice of the West, the Chinese traditional building industry has little demand for the profession of architects.

The Chinese traditional culture did not prioritize architecture as a media of representation; instead, the utilitarian nature of building was cultivated with an emphasis on economical and technological efficiency. Furthermore, with the consistent developments on timber skeletal framework as the prominent tectonic articulation, the Chinese have been accustomed to interpret architecture spatially rather than formally. In short, traditional Chinese architecture is not so much about representation as it is about instrumentalitybuildings are first and foremost regarded as apparatus, tools with which the Chinese organize their social structure methodically in precision. Their distinctive standardized and parametric tectonic ingenuity has provided an open platform on which a common architectural language was accessible to all within the society. Most importantly, the economic and technological efficacy of the Chinese paradigm encompasses the potentials to liberate architectural innovation on the individual level.

\section{What we have gathered from the Chinese experience is that it is} possible to openly engage architecture with every proactive individual of our globalizing society. Instead of confining building practice to professionals and other related disciplines, a truly liberated art of building could emerge by devouring collaborative efforts from all participating individuals - an architecture practice which invites and embraces all.

The elaborations on the professional, social, and the holistic aspects of Chinese architectural traditions are precursory attempts aiming to provide a template on which we could begin to investigate an alternative architectural approach which prioritize architectural efficacies beyond iconic and symbolic representations. A prominent 
result from such investigations is that it offers insights from a

millennium-long practice of a somewhat universalized architectural platform that was, to a large degree, opened to interpretations from craftsmen, academic literati, official bureaucrats, and most importantly, to the general occupants of the common practice. The potential contributions of the Chinese culture are particularly crucial in exploring post-critical strategies in respond to issues of globalization focusing on contemporary socio-economical conditions.

\section{REINTERPRETATION}

[The Chinese] focuses his eyes on the ground instead of heaven; he is the originator of knowledge and not the seeker of enlightenment who makes the eternal pilgrimage from the periphery toward the center. The Chinese organizes his basic cell in order to organize the world around it. His immediate world, measurable, controllable, is forever encroaching on the Unknown. His kingdom is the Central Kingdom.
In adverse times his sphere can be reduced to a hibernating spore, inactive and defensive but still organic. Inside his walls he regulates human relationships to achieve internal harmony, to him the highest goal on earth. As the society became complex and the relationships between men more refined, new architecture was created which further clarified human positions and their movements in space.

To begin constructing an open architectural platform, we borrowed from the traditional Chinese paradigm - specifically their approach to standardization, parametric modularization, and efficacies in method of production. As a point of departure, we begin with the reinterpretation of the basic tectonic unit-DouGong, or the bracket sets. In reviewing the Chinese timber frame construction, we have recognized a few similarities between the Chinese structural system and the heavy timber frame construction from the European traditions.

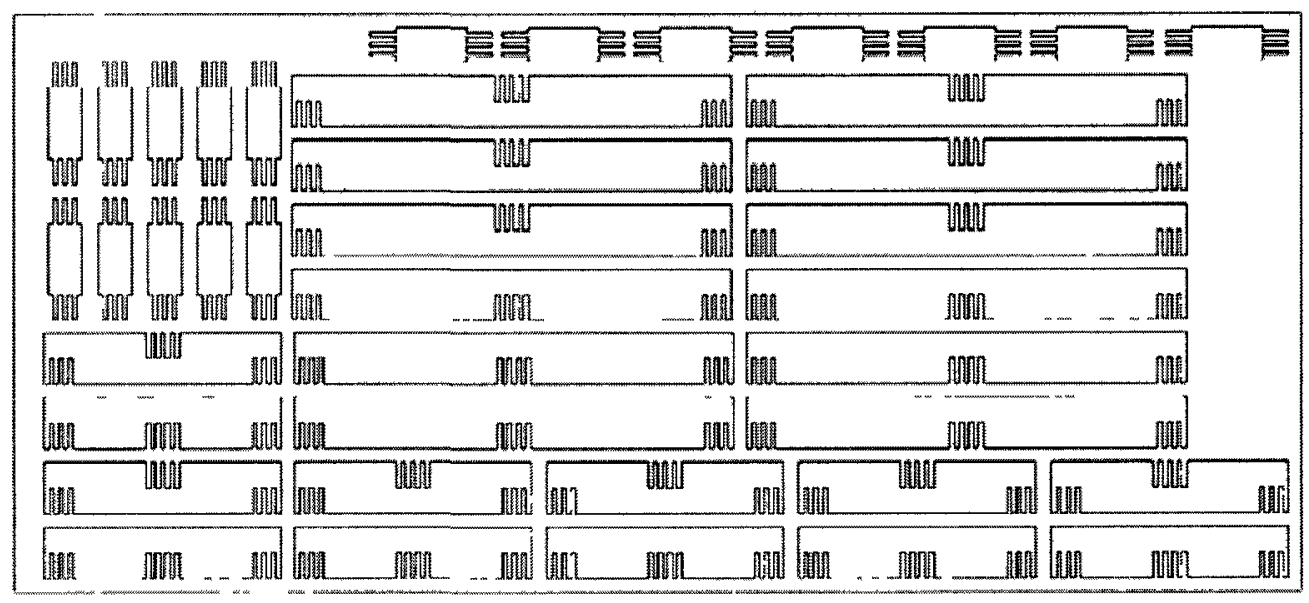

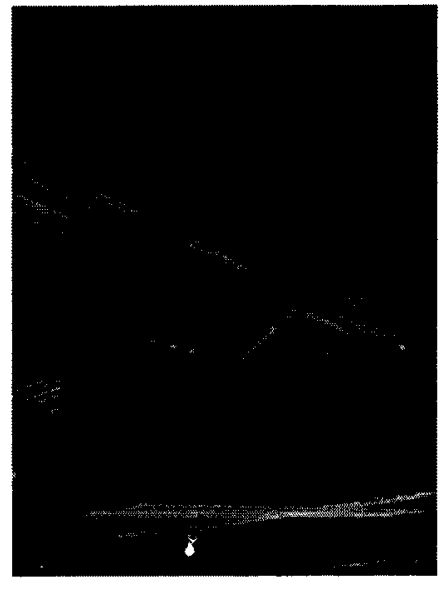

[IMG 07] Tectonic Prototyping 


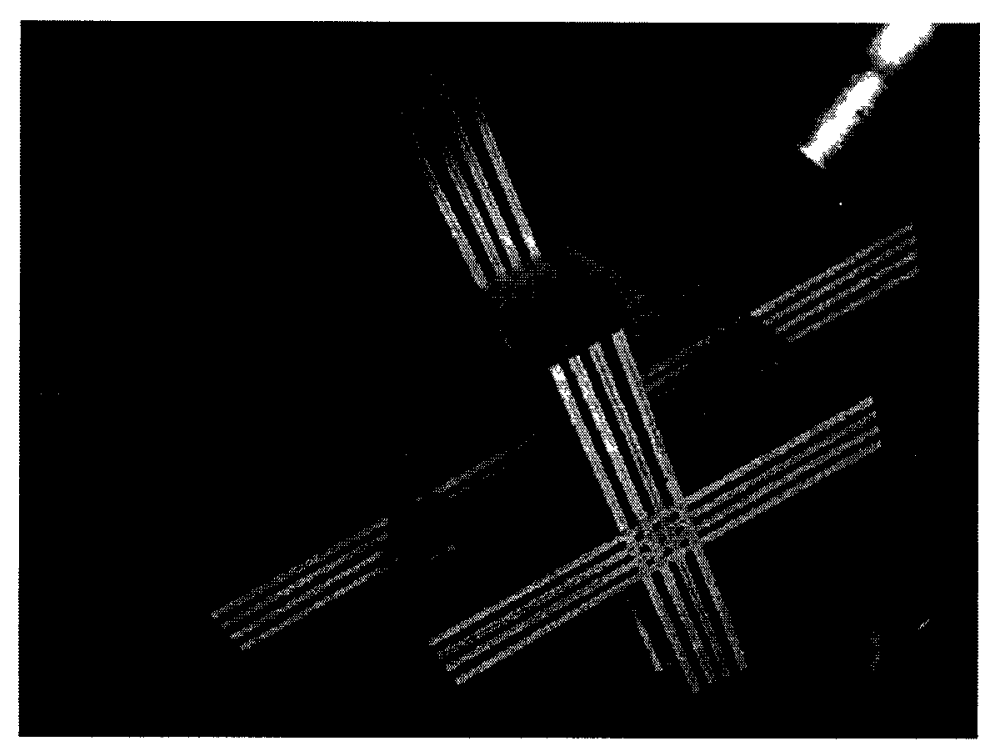

[IMG 08]

Reinterpretation of DouGong with Dimensioned Lumber at 1:5

The Chinese system is distinctive in its standardized and modularized attributes, but essential, both systems from the East and from the West intended to create a skeletal framework as a spatial enclosure. Both examples have achieved a high level of elegance in structural logıc; however, the demand on material consumption would outweigh such merits if tested in mass production. We propose an experiment utilizing dimensioned lumbers as standardized in the North American industry to reinterpret the tectonics of the traditional Chinese paradigm. [IMG 07 \& 08]
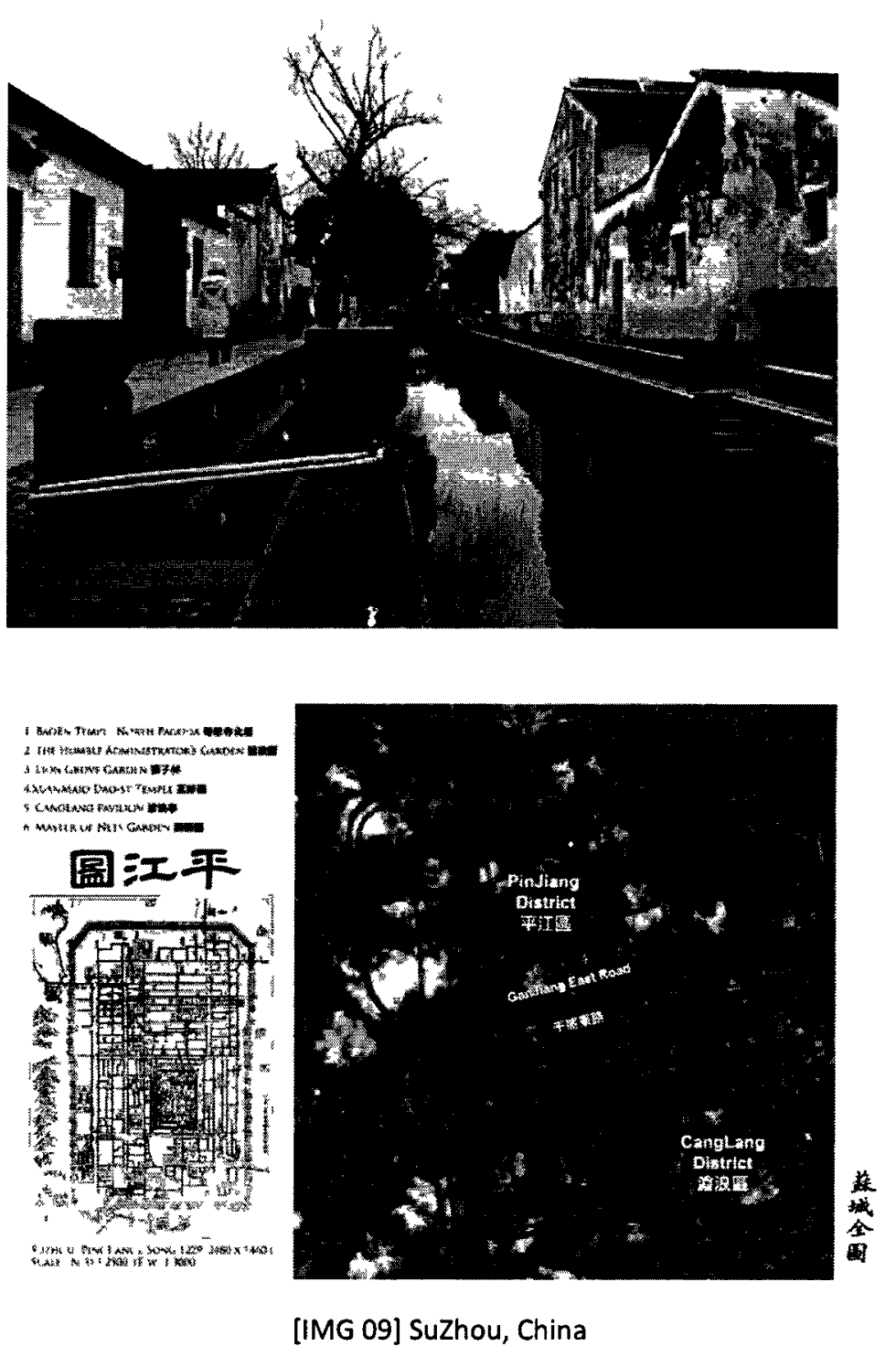


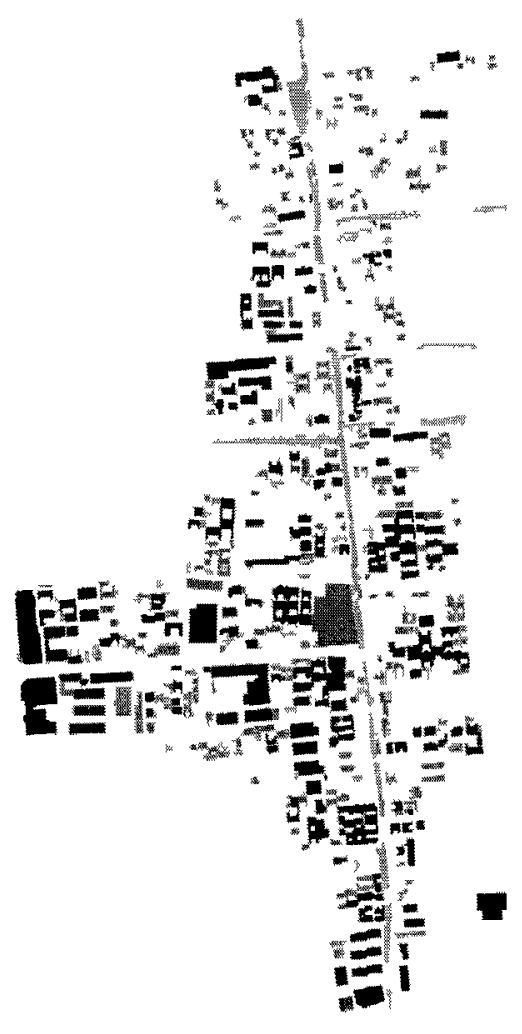

[IMG 10] Site Location \& Images
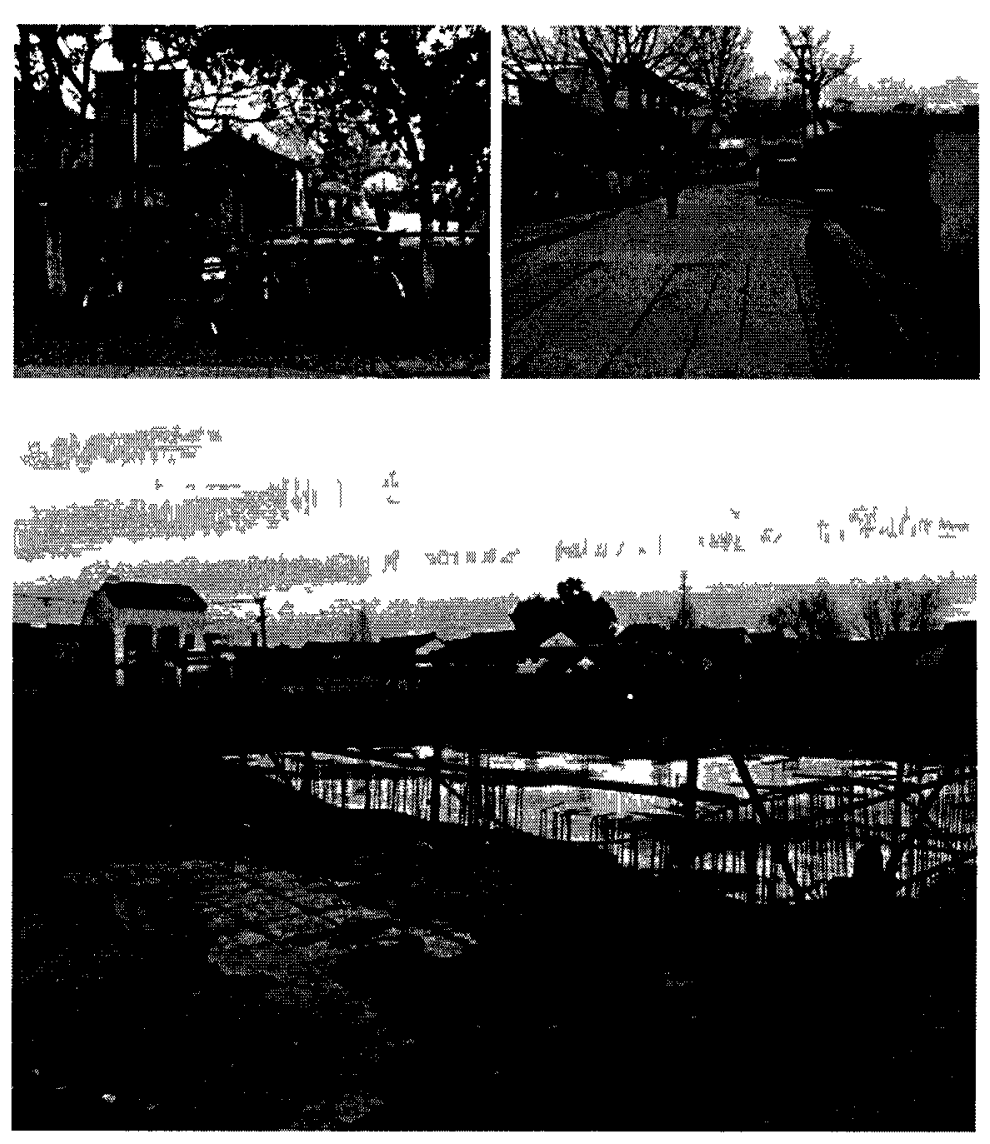

[IMG 10] Site Location \& Images 
The project then would move on to a site in SuZhou, China ${ }^{[I M G}{ }^{09]}$. The site was under construction with the intention to provide a parking facility for the local historical preservation-the PingJiang Road. We intend to approach this site in a non-imposing manner by keeping the original intention of the site. ${ }^{[\mathrm{IMG} 10]}$ An additional programmatic character would be introduced to enhance the historical context of the immediate proximity. The project would consist of a professional institution, the Chinese Architectural Culture Centre (space in red); small emporium spaces for local business (space in green); small gallery spaces for information (space in purple); hostel to

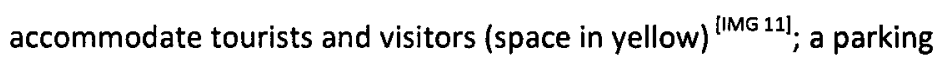
garage for vehicles and also storage amenities for bicycles (as shown in interior perspectives) ${ }^{\text {[IMG 13]. }}$

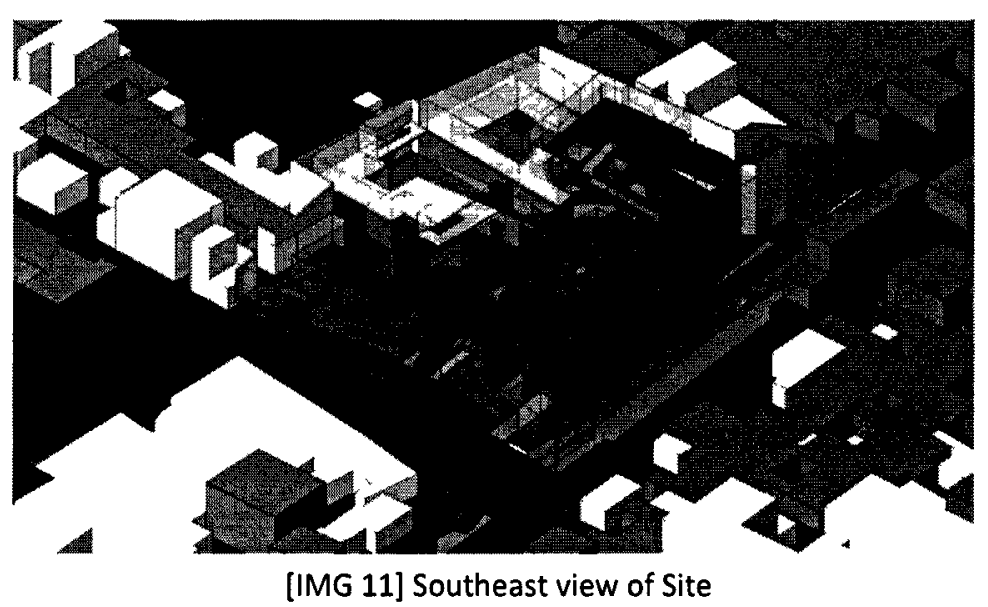

With the exceptions of the paiking facilities as the foundation of the site and the elevated floor planes of Architectural Cultural Centre, the tectonic articulation of all programs would be in accordance with the proposed standardized and parametrically modularized timber frame structural system. The ephemeral characteristic of this system as derived from the Chinese traditional paradigm would potentially become the building blocks of an architectural laboratory where the local occupants would be encouraged to experiment with in collaboration with local or foreign professionals.
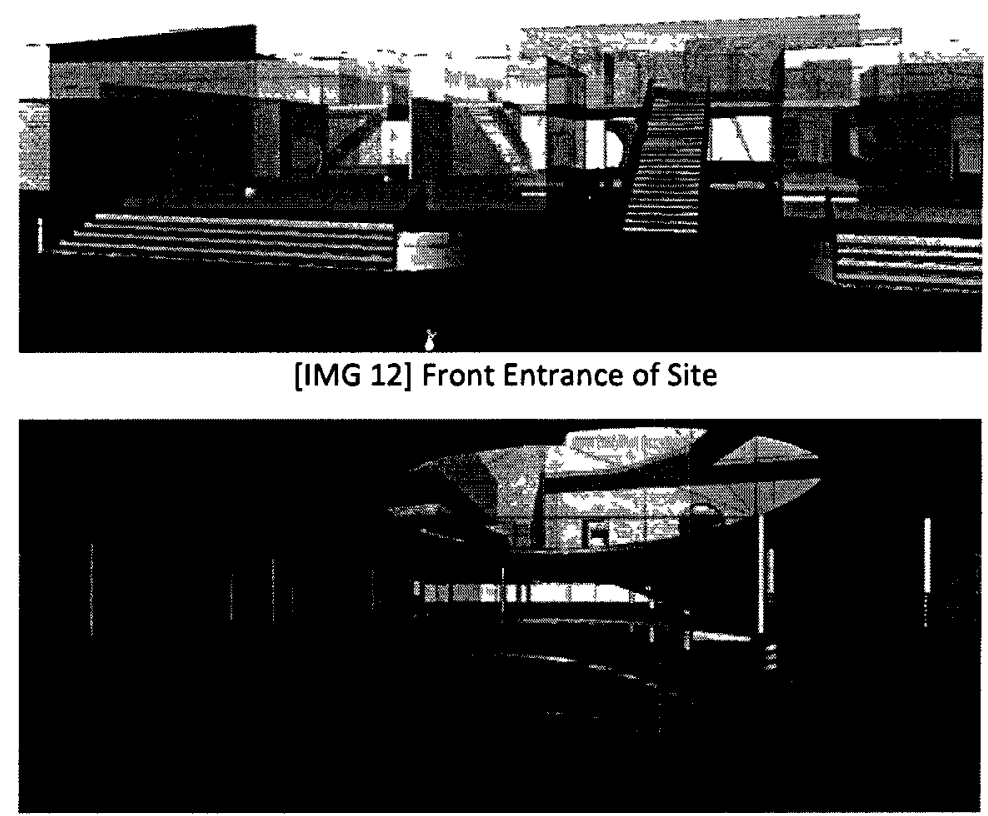

[IMG 13] Parking Garage and Bicycle Storage 


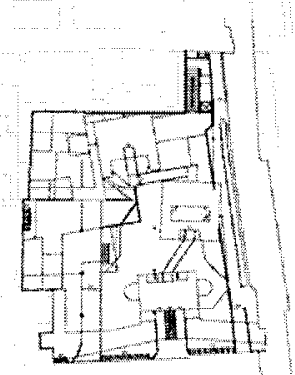

Top: [IMG 14] Site Plan; Bottom: [IMG 15] Plan B2 to B1
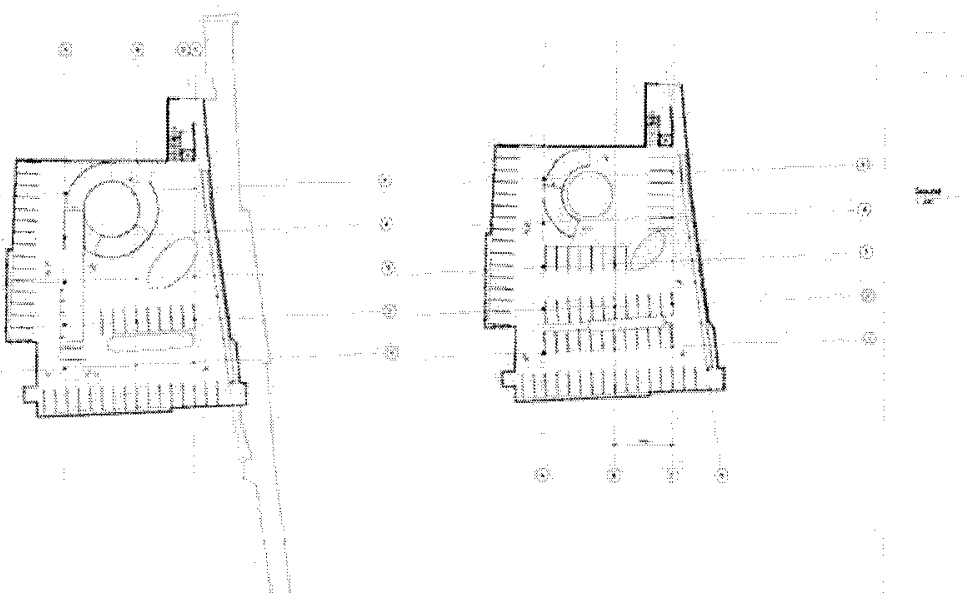

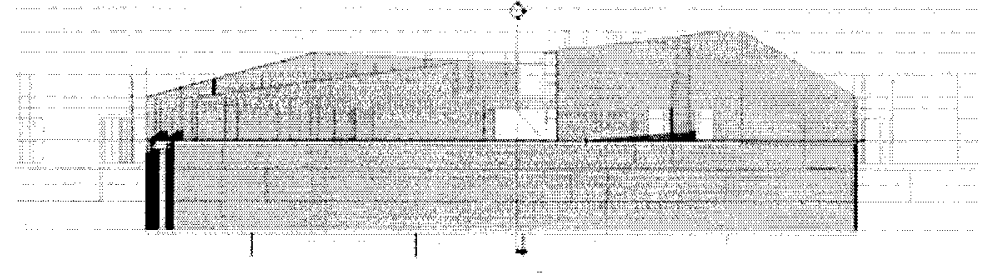

Top: [IMG 16] East Elevation, view from canal Middle: [IMG 17] Ground Plan (Left) \& [IMG 18]1/F Plan (Right) Bottom: [IMG 19] Roof Plan (Left) \& [IMG 20]2/F Plan (Right)

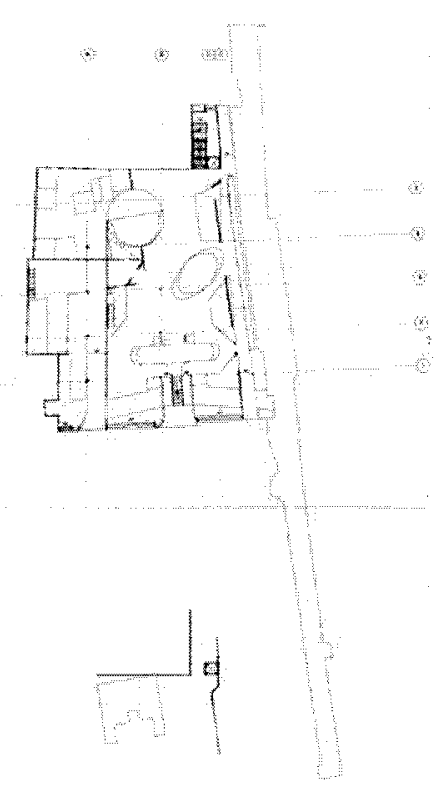




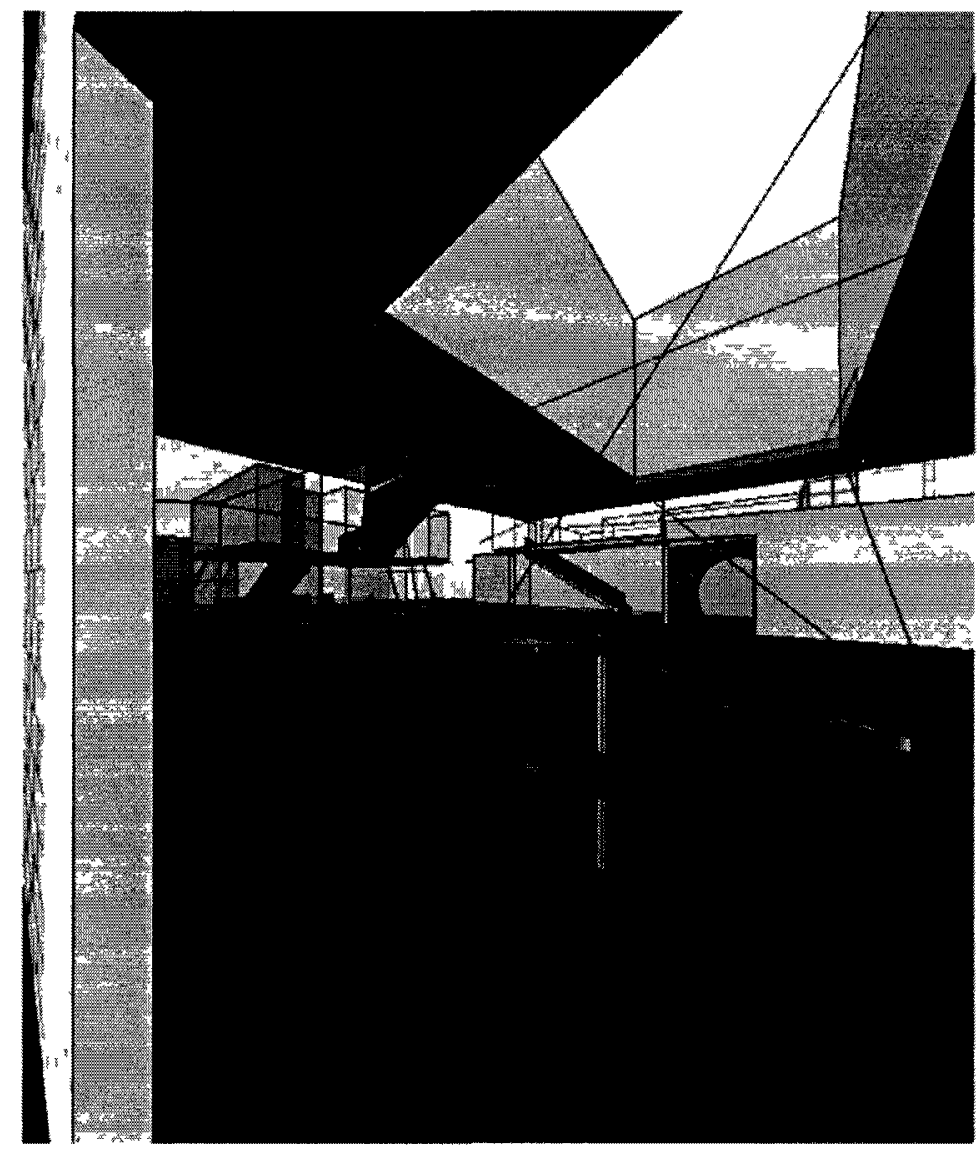

[IMG 21] Interior view from underneath

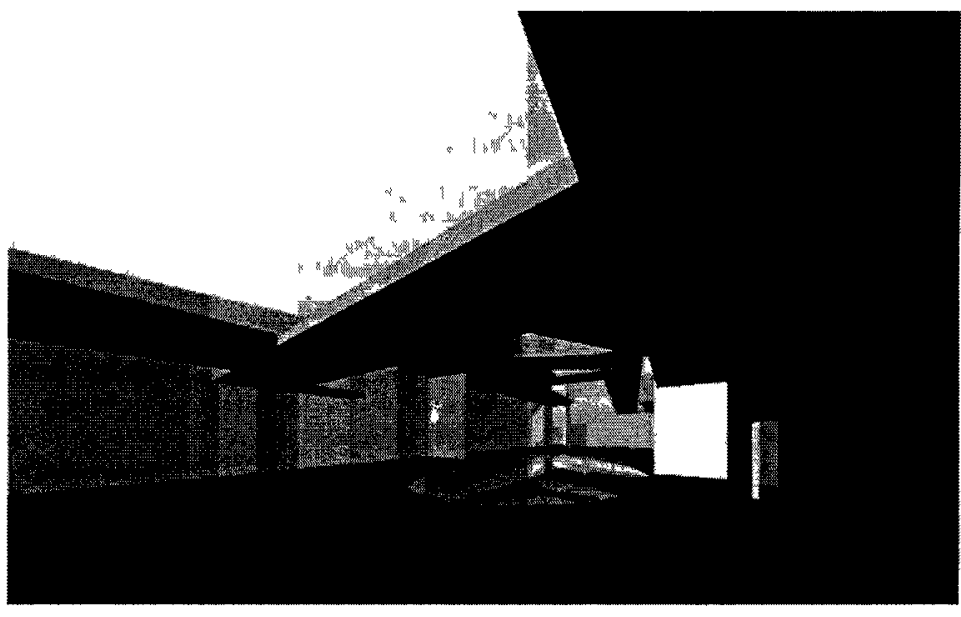

[IMG 22] Interior view from Courtyard of Hostel Architectural Cultural Center 


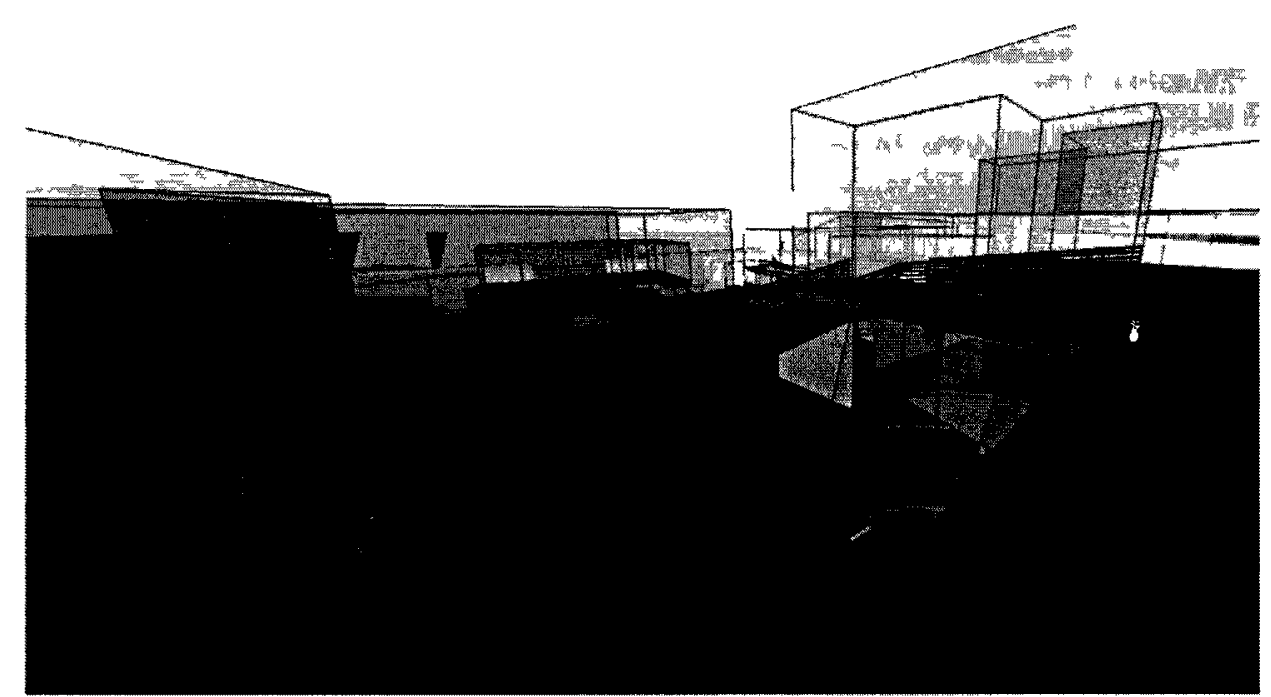

[IMG 23] Top Interior View from back entrance (2/F)

[IMG 24] Bottom Interior View from back entrance (G/F)

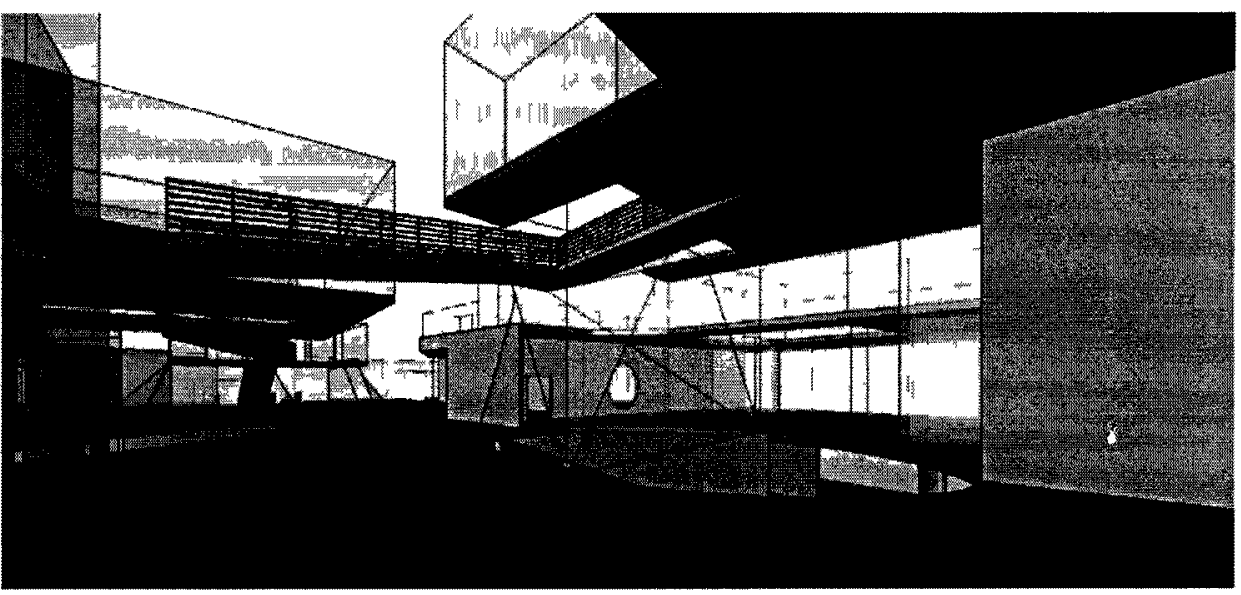




\section{Reference \& Notes:}

"LIANG (2008) P 059

'L1(2008) P 079

(3) $U(2008)$ P 078

1) SHAN (2004) P 120

WHAN SHAO4) P 121

KENGO(2004) P 072

'LIANG (2005) P 3

(9) WU(1963) P 35

\section{List of Illustrations:}

Chinese Building Typology by ITO Chuta

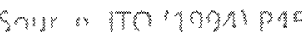

Made to Order Conventions of the West

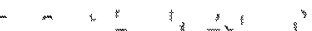

Hanging Monastery, ShanXi China

Hanging Monastery and Tectonic Details Sources:

Hakka Clay Building and Structural Section

Left: http://www.travelvideo.tv/news/wp-

content/uploads/2011/02/0china.bmp

Top of Right: SHAN (2004) P116

Bottom of Right: http://www.chinafacttours.com/index.php?image-

745-imageid-5.html

Hakka Clay Building and Structural Section

Source: Bottom: SHAN (2004) P110
Tectonic Prototyping

"Reinterpretation of DouGong with Dimensioned Lumber at 1:5 SuZhou, China

"Site Location \& Images

Southeast view of Site

Front Entrance of Site

$4 \quad$ Parking Garage and Bicycle Storage

I3 ${ }^{2+3}$ ste plan

( : Plan B2 to B1

$\| \alpha+$ East Elevation, view from canal

" Ground Plan

(2) 1 /F Plan

" : Roof Plan

2/F Plan

? Interior view from underneath Architectural Cultural Center

I Interior view from Courtyard of Hostel

: Interior View from back entrance (2/F)

. Interior View from back entrance (G/F) 


\section{BIBLIOGRAPHY}

\section{ENGLISH TEXT: BOOKS}

BOYD, Andrew. "Chinese Architecture and Town Planning: 1500 B.C. - A.D. 1911." Chicago: The University of Chicago Press, 1962.

CAMPANELLA, Thomas. "The Concrete Dragon: China's Urban Revolution and What It Means for The World." New York: Princeton Architectural Press, 2008.

CARROLL, Peter J. "Between Heaven and Modernity: Reconstructing Suzhou, 1895 - 1937." Stanford: Stanford University Press, 2006.

CHANG, Chao-Kang; \& Werner BLASER. "CHINA: Tao in der Architektur (Tao in Architecture)." Basel: Birkhäuser Verlag, 1987.

DECKER, P. "Chinese Architecture, Civil and Ornamental." England: Gregg Press Limited, 1968 Republished.

EDELMANN, Frederic. "In the Chinese City: Perspectives on the Transmutations of an Empire." New York: Actar Publications, 2008.

FLETCHER, Banister "A History of Architecture on the Comparative Method"

FRIEDMAN, Thomas. "Hot, Flat, and Crowded: Why We Need a Green Revolution - And How It Can Renew America" New York: Farra, Straus and Giroux, 2008.

GUTIERREZ, Laurent; Valerie PORTEFAIX; et al. "Being Chinese in Architecture - Recent Works in China by Rocco Design" Hong Kong: MCCM Creations, 2004 
KIERAN, Stephen; \& James TIMBERLAKE. "refabricating ARCHITECTURE: How Manufacturing Methodologies Are Poised to Transform Building Construction." New York: McGraw-Hill Companies, 2004.

KOOLHAAS, REM Editor; CHUNG, Judy ChuiHua Judy; et al. "Great Leap Forward." Cambridge, USA: The President and Fellows of Harvard College, Harvard Design School, 2001.

KOSTOF, Spiro. “A History of Architecture: Settings and Rituals.” New York: Oxford University Press, $19952^{\text {nd }}$ Edtion.

LIANG, Ssu-Ch'eng (a k a LIANG SiCheng). “Chinese Architecture: A Pictorial History.” Mineola, New York: Dover Publications, Inc., 2005.

MA, Laurence J.C. Editor; Fulong, WU Editor; \& et al. “Restructuring the Chinese City.” New York: Routledge, 2005.

MARMÉ, Michael. "Suzhou: Where The Goods of All The Provinces Converge." Stanford: Stanford University Press, 2005.

MARS, Neville; \& Adrian HORNSBY. "The Chinese Dream: A Society under Construction" Rotterdam: The MIT Press, 2008.

MUMFORD, Eric. "The CIAM Discourse on Urbanism, 1928-1960." Cambridge, Massachusetts: The MIT Press, 2000.

PIRAZZOLI-T'SERSTEVENS, Michèle. “Living Architecture: Chinese” New York: Grosset \& Dunlap, 1971.

RAPSON, Ralph. "Walls: Inside China and Its Architecture." Minnesota: The University of Minnesota, School of Architecture and Landscape Architecture, 1981

SHAN, DeQi Author; \& DeHua, Wang Translator. “Cultural China Series: Chinese Vernacular Dwelling.” BeiJing: China Intercontinental Press, $20041^{\text {st }}$ Print.

STEINHARDT, Nancy S.; et al. “Chinese Traditional Architecture.” New York: China Institute in America, 1984.

STEINHARDT, Nancy S. Editor; Xinian, FU; \& et al. “Chinese Architecture.” New Haven, Connecticut: Yale University Press, 2002.

TRACHTENBERG, Marvin; \& Isabelle HYMAN. "Architecture: From Prehistory to Postmodernity." New York: Harry N. Abrams, $20022^{\text {nd }}$ Edition

TZONIS, Alexander; \& Liane LEFRAIVRE. “Critical Regionalism: Architecture and Identity in a Globalized World.” Munich: Prestel Verlag, 2003.

WU, Nelson I. "Chinese and Indian Architecture: The City of Man, the Mountain of God, and the Realm of the Immortals." New York: George Braziller, $19672^{\text {nd }}$ Printing.

XU, Yinong. "The Chinese City in Space and Time: The Development of Urban Form in Suzhou." Honolulu: University of Hawai'i Press, 2000. 
XUE, Charlie QL. “Building Practice in China.” ChaiWan, Hong Kong: PACE Publishing Ltd., 1998.

YAO, Jacqueline. "The Chinese City in Space and Time: The Development of Urban Form in Suzhou." Honolulu: George Braziller, $19672^{\text {nd }}$ Print.

ZHAO, Sui Sheng. “A Nation-State by Construction: Dynamics of Modern Chinese Nationalism.” Stanford, California: Stanford University Press, 2004.

\section{ENGLISH TEXT: ANTHOLOGY}

ETTLINGER, Leopold D. (2000) "The Emergence of the Italian Architect during the Fifteenth Century." The Architect: Chapters in the History of the Profession. KOSTOF, Spiro. Berkeley and Los Angeles: University of California Press, 2000. Pg. 96-123.

EISENMAN, Peter. (1995) “Critical Architecture in a Geopolitical Worold." Architecture Bevond Architecture. DAVIDSON, Cynthia C. \& Ismail Serageldin. London: Academy Editions, 1995. Pg. 78-81.

CUFF, Dana. (2000) "Foreword." The Architect: Chapters in the History of the Profession. KOSTOF, Spiro. Berkeley and Los Angeles: University of California Press, 2000. Pg. vii-xvi.

HICKEY, Dave. (2007) “On Not Being Governed.” A Harvard Design Magazine Reader: The New Architectural Pragmatism. SAUNDERS, William. Minnesota: University of Minnesota Press, 2007. P94 - 100.

KOSTOF, Spiro. (2000) "The Practice of Architecture in the Ancient World: Egypt and Greece." The Architect: Chapters in the History of the Profession. KOSTOF, Spiro. Berkeley and Los Angeles: University of California Press, 2000. Pg. 3-27.

MACDONALD, William L. (2000) "Roman Architects." The Architect: Chapters in the Historv of the Profession. KOSTOF, Spiro. Berkeley and Los Angeles: University of California Press, 2000. Pg. 28-58.

MALLGRAVE, Harry Francis. "Foreword." Studies in Tectonic Culture: The Poetics of Construction in Nineteenth and Twentieth Century Architecture. By FRAMPTON, Kenneth. USA: The MIT Press, 1995. Pg. ix - xi.

VAN TOORN, Roemer. (2007) “No More Dreams? The Passion for Reality in Recent Dutch Architecture ... and Its Limitations.” A Harvard Design Magazine Reader: The New Architectural Pragmatism. SAUNDERS, William. Minnesota: University of Minnesota Press, 2007. Pg. 54 - 74.

WILKINSON, Catherine. (2000) "The New Professionalism in the Renaissance." The Architect: Chapters in the History of the Profession. KOSTOF, Spiro. Berkeley and Los Angeles: University of California Press, 2000. Pg. 124-160. 


\section{ENGLISH TEXT: ARTICLE}

ALLEN, Stan. "Stocktaking 2004: Nine Questions about the Present and Future of Design" Harvard Design Magazine. Volume 20:4 (2004): Page 4-52.

BAIRD, George. "Criticality' and Its Discontents" Harvard Design Magazine. Volume 21 (Fall/Winter 2004): Page 16-21.

BAIRD, George. "Thoughts on the Current State of Criticism in Architecture" Journal of Architectural Education. Volume 62:3 (February 2009): Page 5.

DODDS, George. “Editorial: On Criticism in Architecture: An Invitation to Practice” Journal of Architectural Education. Volume 62:3 (February 2009): Page 3.

FUNG, Stanislaus. “Orientation: Notes on Architectural Criticism and Contemporary China” Journal of Architectural Education. Volume 62:3 (February 2009): Page 17, 96.

HAYS, Michael. "Critical Architecture: Between Culture and Form” Perspecta. Volume 21 (1984): Page 15-29.

HICKEY, Dave. "Dialectical Utopias: On Santa Fe and Las Vegas" Harvard Design Magazine. Volume 4 (1998): Page 1-5.

SOMOL, Robert; \& Sarah WHITING. “Notes around the Doppler Effect and other Moods of Modernism” Perspecta. Volume 33 (2002): Page $72-77$.

SPEAKS, Michael. “Design Intelligence and the New Economy” Architectural Record. Volume 190:1 (January 2002): Page 72-79.

VALE, Brenda \& Robert VALE (2010). "Domestic Energy Use, Lifestyles and POE: Past Lessons for Current Problems." Building Research \& Information.38: 5, Page 578-588.

WISCOMBE, Tom. "Emergent Models of Architectural Practice” Perspecta. Volume 38 (2006): Page 58-69.

ZHU, Jian-Fei. "Criticality in between China and the West" The Journal of Architecture. Volume 10:5 (2005): Page 479-498.

ZHU, Jian-Fei; Peter EISENMAN; George BAIRD; et al. "Dialogue: Debate on 'Criticality in between China and the West" Time + Architecture. Volume 5:91 (September 2006): Page 56-83.

ZHU, Tao; \& ZHU, Jian-Fei. “Critical Dialogue: China and the West” The Journal of Architecture. Volume 12:2 (April 2007): Page 199-207. 


\section{TRADITIONAL CHINESE TEXT: BOOKS}

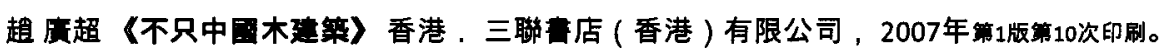

CHIU KwongChiu. "Bù Zhĩ ZhōngGuó Mù JiànZhù" (IIt. "Not Merely A Chinese Wooden Architecture") Hong Kong: Joint Publishing (H.K.), $20071^{\text {st }} e d, 10^{\text {th }}$ print.

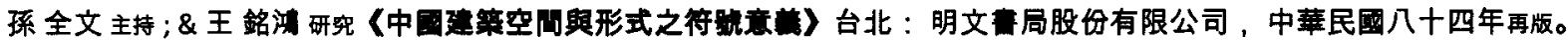

SUN Chuan-Wen supervisor; \& MingHong, WANG Researcher. "A Semiotic Analysis of Space and Form in Chinese Architecture" Taipei: Ming Wen Book Co., Ltd. , $19953^{\text {rd }}$ ed.

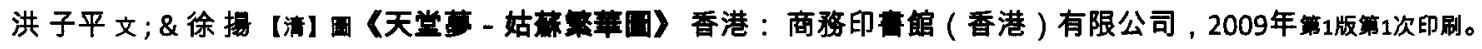

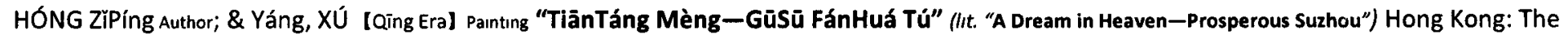
Commercial Press (K.K.) Ltd., $20091^{\text {st }}$ ed, $1^{\text {st }}$ print.

梁思成〈中國建策史〉香港：三聯寒店（香港）有限公司，2001年第1版第3次印煀。

LIANG SICHENG. "ZhōngGuó JiànZhù Shi”" (IIt "Chinese Architectural History") Hong Kong: Joint Publishing (H.K.), $20011^{\text {st }}$ ed, $3^{\text {rd }}$ print.

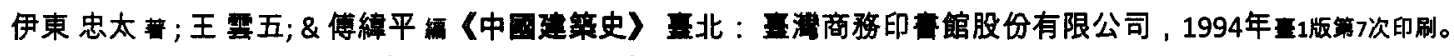

ITO Chuta Author; YúnWǔ, WÁNG ; \& WěiPíng FÙ Editor. "ZhōngGuó JiànZhù Shr̉” (IIt "Chinese Architectural History") Taipei: Taiwan Commercial Press, 1994

Taiwan $1^{\text {st }}$ ed, $7^{\text {h }}$ print.

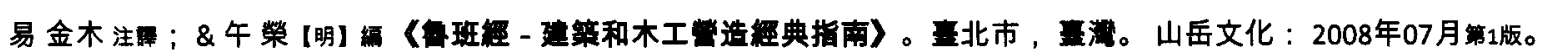

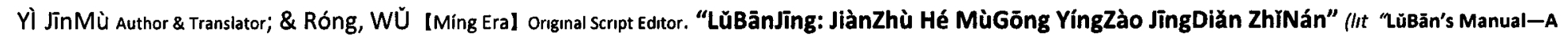

Classical Guide for Architectural and Carpentry Management and Production"). TaiPei: Neptune Culture Publisher, $20081^{\text {th }} \mathrm{ed}$

\section{TRADITIONAL CHINESE TEXT: WEBSITE}

Liji: Li Yun. Donald Sturgeon Edtor. Chinese Text Project. Mar $7^{\text {th }}, 2011$

$\langle$ http://ctext.org/liji/li-yun/zh>.

Mozi . Indulgence in Excess. Donald Sturgeon Editor. Chinese Text Project. Mar $7^{\text {th }}, 2011$

$<$ http://ctext.org/mozi/indulgence-in-excess>.

輅非子．五鳁. Donald Sturgeon Editor. Chinese Text Project. Mar $7^{\text {th }}, 2011$

$<$ http://ctext.org/hanfeizi/wu-du>. 
HanFeizi WuCan. Donald Sturgeon Edtor Chinese Text Project Mar $7^{\text {th }}, 2011$

$<$ http //ctext org/hanfelz1/wu-du>

\section{SIMPLIFIED CHINESE TEXT: BOOKS}

陈明达《营造法式大柞制度研究〉北京 文物出版社，1993年第2版。

CHEN MingDa "YingZao FaShi DaMuZuo ZhiDu YanJiu” (IIt "A Research on Yingzao FaShı Structural Carpentry Regulations") Beijıng, Chına Cultural Relıcs Publishıng House, $19932^{\text {nd }}$ ed

丁 俊清〈江南民居〉上海 上海交通大学出版社，2008年第1版策1次印㓮。

DING JunQıng "JiangNan MinJu" (lit "JiangNan Vernacular Dwelling") ShangHal: Shanghal Jiao Tong University Publishing House, $20081^{\text {st }}$ ed $1^{\text {st }}$ Prnt

胡 适《中国的文艺每兴》北京 外语教学与研究出版社，2007年第一版第四次印剧。

HÚ Shi “The Chinese Renaissance” Beııng. Foreıgn Language Teachıng and Research Press, $20071^{\text {st }}$ ed $4^{\text {th }}$ print

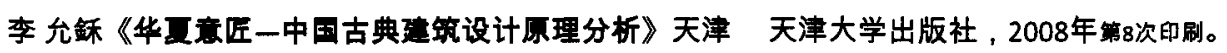

LI YŭnHé "Cathay's Idea-Design Theory of Chinese Classical Architecture" Tıanjın, Chına Tianın Unıversıty Press $20088^{\text {th }} e d$

刘 杰〈江南木构〉上海上海交通大学出版社，2009年第1版第1次印剧。

LIU Jie "JiangNan MuGou" (IIt "JlangNan Timber Tectonic") ShangHal Shanghal Jiao Tong University Publishing House, $20091^{\text {st }}$ ed $1^{\text {st }}$ Print

波姆《贝聿铭谈贝聿铭》林兵译。上海文汇出版社，2004年第版策1次印剧。

VON BOEHM, Gero Author, \& Bīng, LI'N Translator "Conversations with I. M. Pei" Shanghai. WénHuì Publicatıons, $20041^{\text {st }}$ ed $1^{\text {st }}$ print

倪晓英，\&徐宁《贝事坮与苏州楼物馆》苏州 古吴轩出版社，2009年第1版第2次印剧。

Ní XıăoYing, \& Níng, XÚ “I. M. Pei and Suzhou Museum” Suzhou Guwuxuan Publıshıng House, $20091^{\text {st }}$ ed $2^{\text {nd }}$ print

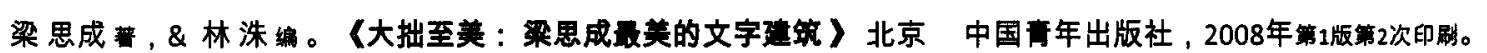

LIÁNG SiChéng Author, \& Zhū, LIN Editor. "Dà Zhuó Zhì Měi: Liáng SīChéng Zuì Mèi De WénZì JiànZhù" "lit "Jeauty in Simplest Modesty: Liáng Sīchéng's Most Elegant Words in Architecture") Beljing China Youth Press, $20081^{\text {st }}$ ed $2^{\text {nd }}$ print

强 钦榑〈中国古代建筑师〉北京，中国。生活素書 新知三联书店 2008年第1版次。

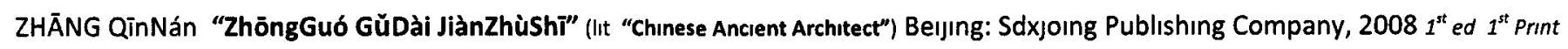

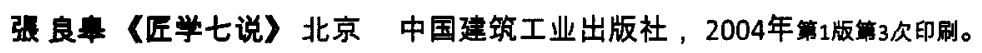


ZHĀNG LiángGāo. "Seven Comments on Traditional Chinese Architecture" Beijing: China Architecture \& Building Press, 2004 1st ed $3^{\text {rd }}$ Print.

侯纤林〈中国建筑美学》哈尔滨：黑龙江科学技术出版社，1997年第1版第1次印刷。

HÓU YòuBīn. "Aesthetics of Chinese Architecture" Harbin: Heilongjiang Science and Technology Press, $19971^{\text {st }}$ ed. $1^{\text {st }}$ Print.

王其钧摧蓄《中国民居三十讲》北京：中国建筑工业出版社，2008年第1版策3次印刷。

WÁNG Qíjūn Editor \& Author "ZhōngGuó Mijū SānShí Jiăng" (IIt. "30 Topics on Chinese Vernacular Dwellings") Beijing. China Architecture \& Building Press: 20081 st ed $3^{\text {rd }}$ Print.

萧默主编《中国建筑艺术史 (上)》北京：文物出版社，1999年算1版次。 XIĀO Mò Chief Editor "Chinese Architectural Art History (Volume 1)" Beijing, China. Cultural Relics Publishing House: 1999. $1^{\text {st } e d ~}$

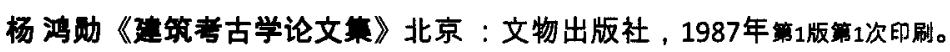

YÁNG HóngXūn “Essays on Archaeology of Architecture in China” Beijing, China. Cultural Relics Press: 1987 1sted. $1^{\text {st }}$ Print.

易 中天《帝国的终结：中国古代政治制度批判》北京：中国建筑工业出版杜，2008年第1版第3次印刷。

yì ZhōngTıān "DiGuó de ZhōngJié: ZhōngGuó Gǔdài ZhèngZhì ZhỉDù PīPàn" (IIt "An Empire's End: A Critique on China's Ancient Political System") Shanghai, China. Fudan University Press: 2007 1st ed. $1^{\text {st }}$ Print.

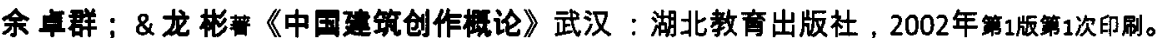

YÚ ZhuóQún ; \& Bīn, Lóng "Research Library of Chinese Architectural Culture: The Generality of Creation of Architecture in China" Wuhan, China. Hubei Education Press: 2002 1st ed $1^{\text {st }}$ Print.

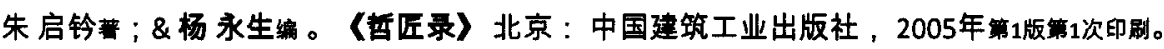

ZHŪ QĩQián Author; \& YǒngShēng, Yáng Editor. "Zhé Jiàng Lù" (lit "A Record of The Profound Craftsmen") Beijing: China Architecture \& Building Press, 2005 $1^{\text {st }}$ ed $1^{\text {st }}$ Print. 